The copyright of this thesis vests in the author. No quotation from it or information derived from it is to be published without full acknowledgement of the source. The thesis is to be used for private study or noncommercial research purposes only.

Published by the University of Cape Town (UCT) in terms of the non-exclusive license granted to UCT by the author. 


\title{
Flows and Fates of Nickel-Cadmium Batteries in the City of Cape Town
}

\author{
Kyle Mason-Jones
}

\author{
Thesis presented for the degree of \\ Master of Science \\ Department of Chemical Engineering \\ University of Cape Town
}

December 2009 
I know the meaning of plagiarism and declare that all of the work in the document, save for that which is properly acknowledged, is my own. 


\section{ABSTRACT}

Current patterns of economic activity entail high rates of material extraction from the natural environment and the generation of large amounts of waste. Alternative strategies must be found if we are to avoid the exhaustion of resources and the environment's capacity to safely absorb our wastes. Examining current resource use is an important step towards achieving a more sustainable society, and the toxic substances widely applied in our technologies form a crucial part of this examination. The heavy metal cadmium is one such substance.

The use and disposal of nickel-cadmium secondary cells (the basic components of NiCd batteries) in Cape Town, South Africa, has been investigated with the objective of quantifying the associated flows of cadmium. This was achieved by applying substance flow analysis methodology to the year 2005 with a steady-state approach to quantify the disposal commitment arising from inflows in that year. Uncertainty in the calculated results was quantified by means of Monte Carlo simulation.

Small sealed cells were found to make the dominant contribution to overall cadmium flows, with cordless power tools and separately imported cells accounting for most of these. Essentially all of these cells either have or will enter the municipal solid waste streams of the city. Large industrial cells made a smaller but significant contribution to overall inflows $(3.4-14 \%)$, but none were known to have entered municipal waste. These went primarily to hazardous waste disposal outside the city or recycling abroad, with some going into storage.

In order to assess the environmental significance of the cadmium sent to landfill, hypothetical "best worst-case" scenarios were developed which involved the worst case of total cadmium release from landfill, and best-case calculations of the potential contamination of agricultural land that could result from such release. A total release to agriculture was found to contaminate the city's croplands in under twenty years. Although these scenarios considered contamination potential but not the likelihood of contamination, and hence were not predictive, it could nevertheless be concluded that the amounts of cadmium destined for landfill disposal justified concern and caution.

The disposal of environmentally significant amounts of cadmium in Cape Town and the very limited understanding of landfill behaviour necessitate the elimination of $\mathrm{NiCd}$ batteries from municipal solid waste streams. Some approaches are briefly discussed by which this might be achieved, with regard to both environmental protection and resource conservation in general and the changing landscape of waste management in South Africa.

Significant challenges were encountered from limited data availability during the application of substance flow analysis within a developing-world urban setting. This necessitated primary data collection and adaptation of data from other geographical and temporal scales. Adjusting national data to the city scale required the development of scaling factors which were more plausible than the use of population share or regional GDP. 
Some similarities were noted between the cadmium metabolism of Cape Town and that of previously studied regions in the developed world. This supported the suggestion that some insights from substance flow analysis studies can be transferred to other regions when resources are not available for thorough local study. Important differences were also present, however, and further research is required to develop this possibility. 


\section{ACKNOWLEDGEMENTS}

This research would have been impossible were it not for the many people in industry, government and elsewhere who gave freely of their time, knowledge and insight. In particular, thanks to

Peter King, City of Cape Town

Peter Schneider, SAPTA

Brian Rothman, Cape Aero Services

Fred Dohne, DeWalt SA

Staff of City of Cape Town Electricity Services

My sincerest thanks go to my supervisor, Assoc. Prof. Harro von Blottnitz, for his steady guidance, critical suggestions and eye-opening discussions.

Thank you also to Craig Mason-Jones, my sounding board for all statistical thoughts and wrangles.

I would also like to acknowledge the support provided by the University of Cape Town, African Centre for Cities, Council for the Built Environment, Ernst and Ethel Eriksen Trust and National Research Foundation. 


\section{ABBREVIATIONS USED IN THE TEXT}

$\begin{array}{lll}\text { AMPS } & : & \text { All Media and Products Survey } \\ \text { ADF } & : & \text { advanced disposal fee } \\ \text { ARF } & : & \text { advanced recycling fee } \\ \text { CAA } & : & \text { Civil Aviation Authority } \\ \text { COCT } & : & \text { City of Cape Town (local authority) } \\ \text { CV } & : & \text { coefficient of variation } \\ \text { EPR } & : & \text { extended producer responsibility } \\ \text { GDP } & : & \text { gross domestic product } \\ \text { LCA } & : & \text { life cycle analysis } \\ \text { MSW } & : & \text { municipal solid waste } \\ \text { NiCd } & : & \text { nickel-cadmium } \\ \text { RSD } & : & \text { relative standard deviation } \\ \text { SFA } & : & \text { substance flow analysis } \\ \text { USITC } & : & \text { United States International Trade Commission } \\ \text { WWTW } & : & \text { wastewater treatment works }\end{array}$




\section{TABLE OF CONTENTS}

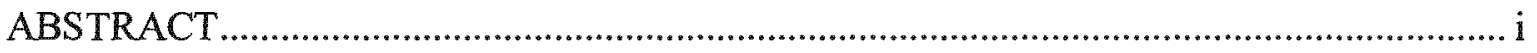

ACKNOWLEDGEMENTS ..........................................................................................ii

ABBREVIATIONS USED IN THE TEXT ........................................................................ iv

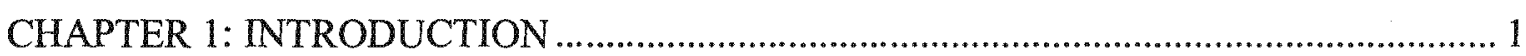

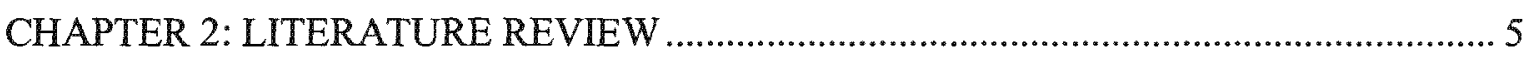

2.1 Industrial ecology ....................................................................................... 5

2.2 Substance flow analysis .................................................................................... 6

2.2.1 Material flow analysis............................................................................ 6

2.2.2 Substance flow analysis ........................................................................ 6

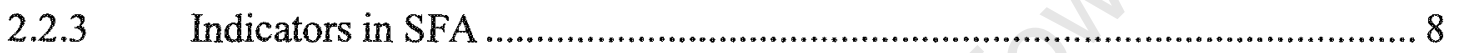

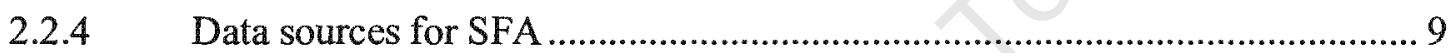

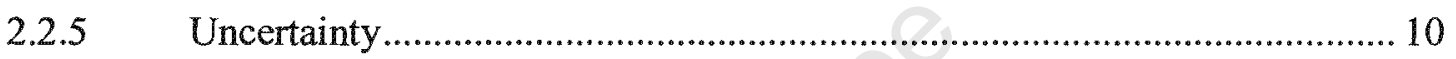

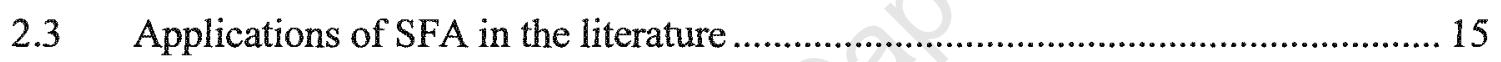

2.3.1 SFA of cadmium in other regions......................................................... 15

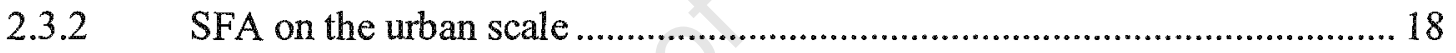

2.3.3 Previous studies in Cape Town ............................................................ 18

2.4 Cadmium in the economy ......................................................................... 19

2.5 Cadmium in health, waste and environment ....................................................... 20

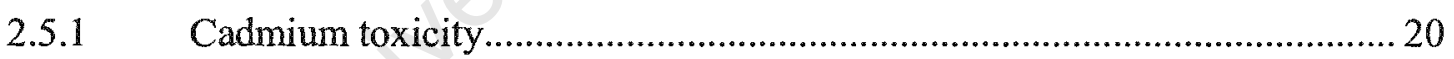

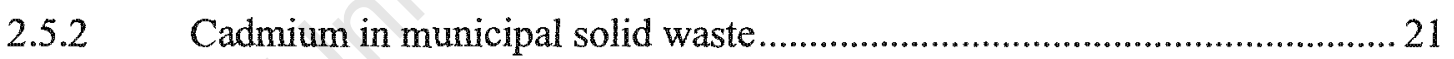

2.5.3 Cadmium in agricultural soil .............................................................. 24

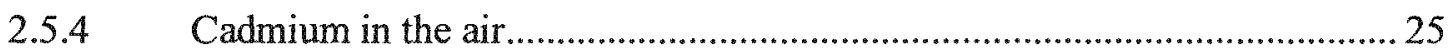

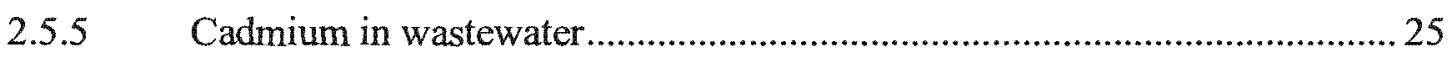

2.6 Waste management in Cape Town and South Africa ............................................ 26

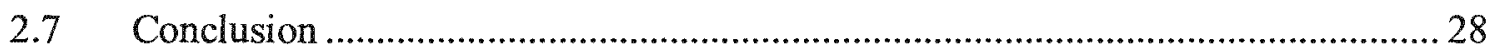

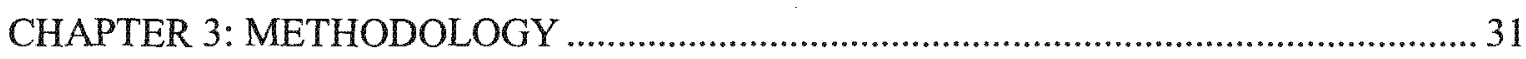

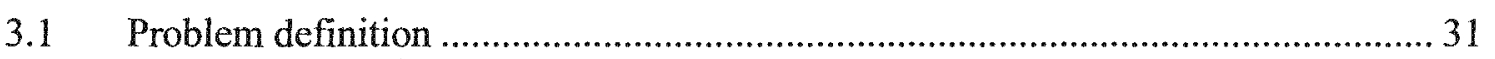

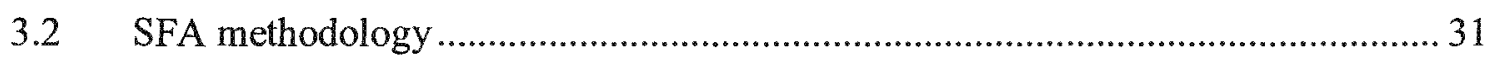

3.2.1 Methodological framework..................................................................... 31 


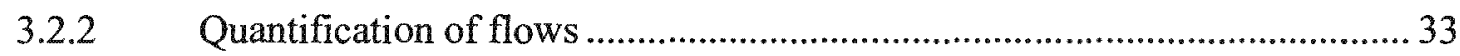

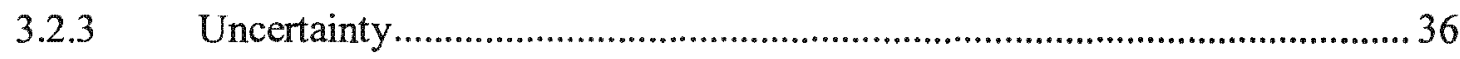

3.2.4 Illustration and interpretation.......................................................... 40

3.3 Environmental significance of cadmium disposal ............................................. 41

3.3.1 Assessment framework .................................................................. 41

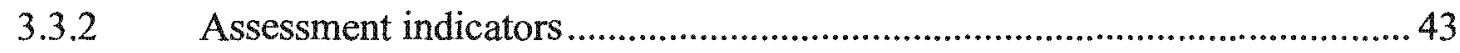

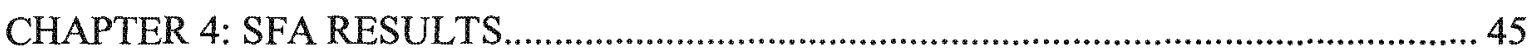

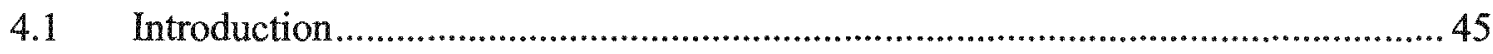

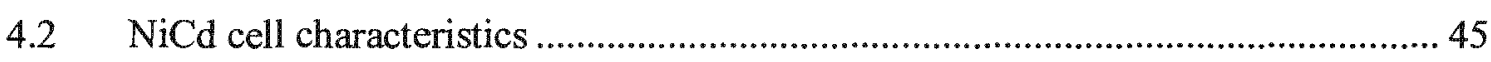

4.2.1 Mean NiCd cell mass .................................................................. 45

4.2.2 Mean cadmium content .......................................................................... 47

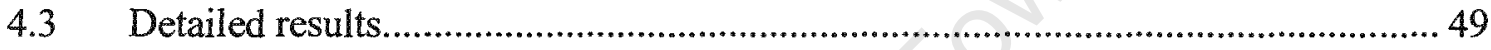

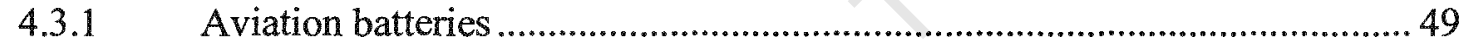

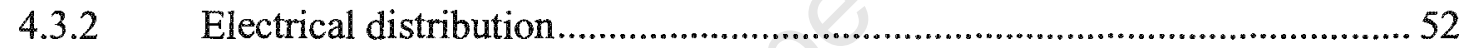

4.3.3 Miscellaneous large cell applications ................................................ 53

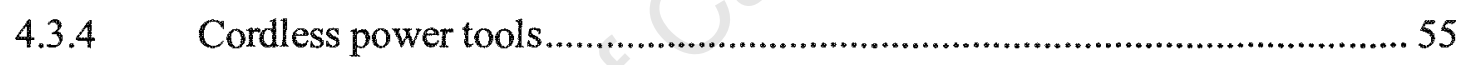

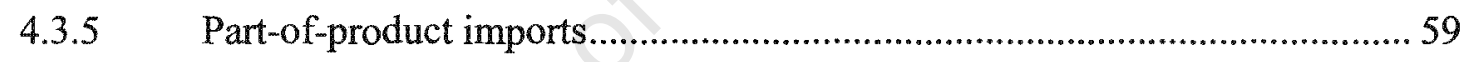

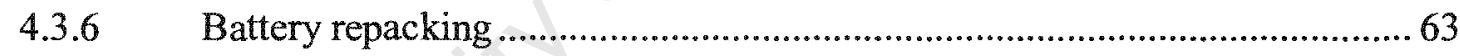

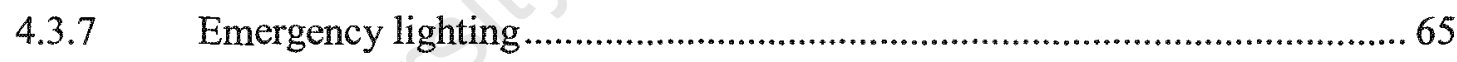

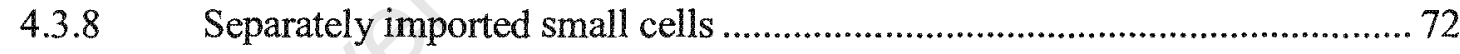

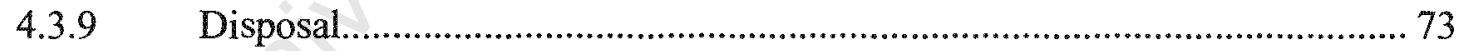

4.3.10 Negligible NiCd applications................................................................. 75

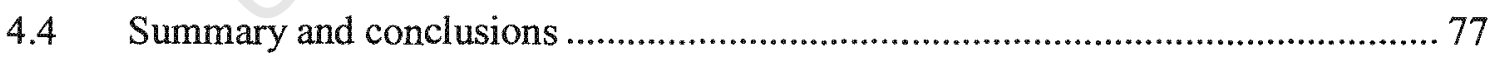

CHAPTER 5: ENVIRONMENTAL SIGNIFICANCE OF CADMIUM DISPOSAL .......... 81

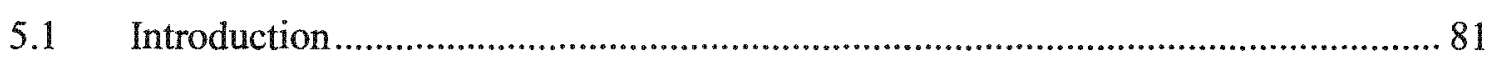

5.2 Agricultural area and background cadmium in soils ....................................... 82

5.3 Cadmium flows in phosphate fertilizer ........................................................ 85

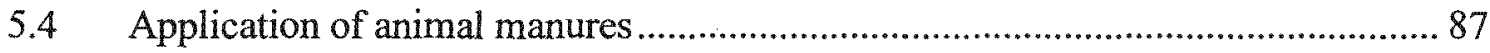

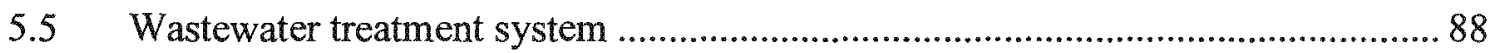

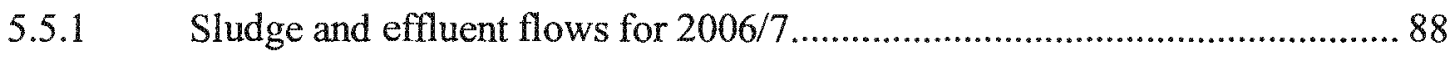

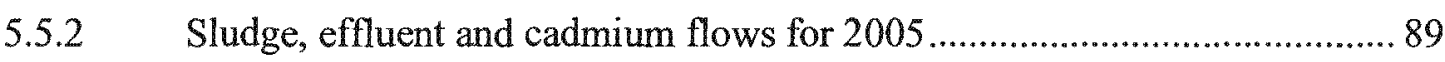


5.6 Rate of soil contamination under conditions of zero landfill retention .91

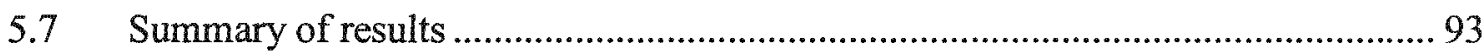

CHAPTER 6: DISCUSSION AND CONCLUSIONS ............................................. 95

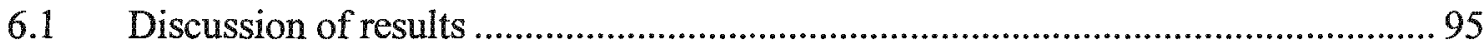

6.1.1 NiCd battery flows of cadmium in Cape Town ...................................... 95

6.1.2 Environmental significance of landfilled cadmium ................................. 96

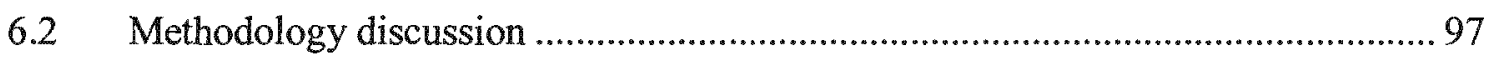

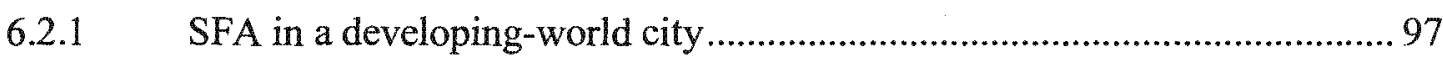

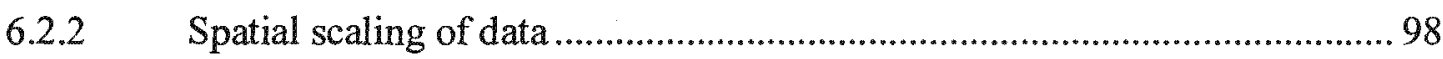

6.2.3 Method for assessment of environmental significance ............................ 100

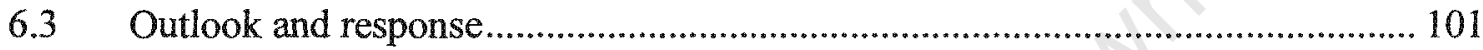

6.4 Conclusions and recommendations.................................................................. 104

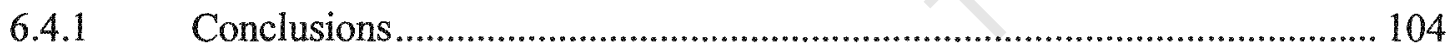

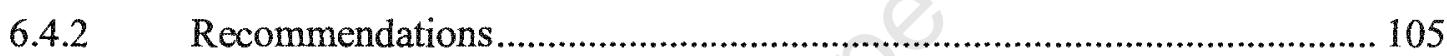

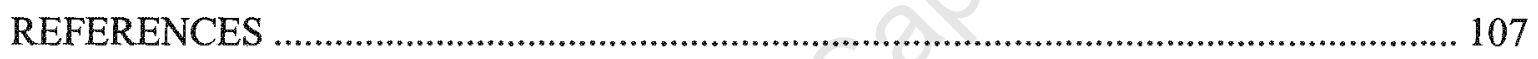

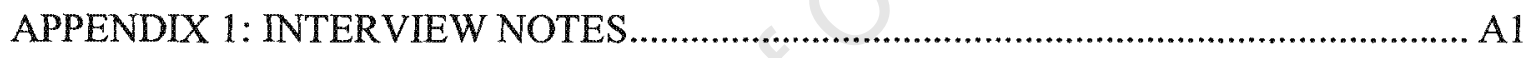

APPENDIX 2: SURVEY OF ELECTRICAL CONTRACTORS - RESPONDENTS AND

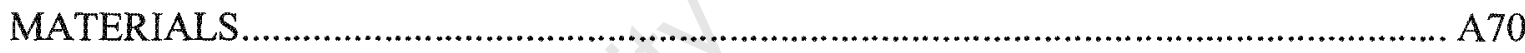

APPENDIX 3: HISTOGRAMS OF MONTE CARLO OUTPUT DISTRIBUTIONS...... A78

APPENDIX 4: PYTHON CODE FOR MONTE CARLO SIMULATION ....................... A85

APPENDIX 5: BATTERY SAMPLING DATA ...................................................... A98

APPENDIX 6: PART-OF-PRODUCT TRADE CATEGORIES AND STATISTICS ..... A100

APPENDIX 7: PART-OF-PRODUCT CELL COUNTS ........................................... A101

APPENDIX 8: MAP OF SOIL SAMPLING SITES ................................................... A104 


\section{CHAPTER 1: INTRODUCTION}

It has become clear that the current patterns of economic activity and growth, with associated high levels of resource use and waste production, cannot be sustained indefinitely. Widely extending this pattern in an attempt to uplift the lives of people in developing nations is not merely unwise, but physically impossible. 'If social and economic development is to be achieved without risking a collapse of the supporting environment so essential to our survival, it is necessary to re-think our use of natural resources and the natural sinks that receive our wastes. Examining our use and disposal of toxic substances forms an important part of this task.

The year 2008 saw the first point in human history at which half of the world's population was living in urban areas. ${ }^{2}$ With so many people and such concentrations of infrastructure and economic activity, cities play particularly important roles in material flow through the overall economy. Production and consumption in cities influence material flows from the ecosphere at scales ranging from local to global, and their emissions and wastes have similarly wide-reaching effects. Understanding the patterns of material use and disposal in urban areas is therefore important for realising transitions toward more sustainable modes of human existence. Even confined to the local scale, a city's management of waste occurs in close proximity to settlements and supporting environmental services, often involves hazardous remnants of technological society's consumption, and can present significant risks to the economic, environmental and human health of the city itself.

Cape Town is the second most populous city in South Africa, with 3.5 million people. ${ }^{3}$ Although the metropolitan areas of Gauteng province are the economic hub of the country, Cape Town is a major economic centre. Finance and business services, manufacturing, and trade and tourism are the three most important sectors in the city. ${ }^{4}$ However, although there is a sizeable and active economy and some areas of the city have levels of affluence comparable to those of the developed world, the city also has many characteristics typical of developing nations. Unemployment is high and poverty is rife, with almost $40 \%$ of households at or near the poverty line. At least 400,000 people live in informal housing in townships, many with inadequate water and sanitation. ${ }^{5}$ These circumstances can pose a particular challenge to waste management. Governmental structures are strained by the pressing needs of the poor whilst consumption by wealthier segments of the population creates waste more characteristic of the developed world, but in the absence of sufficient resources to assure its safe handling. Among such wastes are technological products such as electronic goods which contain complex mixtures of substances, some of which are highly hazardous.

Cadmium is a toxic heavy metal that is widely applied in technological products, particularly in nickel-cadmium (NiCd) batteries. Although it occurs at low concentrations naturally, the risk of increased concentrations resulting from commercial applications has been widely recognized and restrictions on its use and disposal are common internationally. However, enforcement of the South African policies and regulations relevant to $\mathrm{NiCd}$ battery disposal is minimal, particularly with respect to the small quantities discarded by individual households and businesses. Taken together these can represent sizeable amounts. 
International experience has shown that large quantities of cadmium can arise in municipal solid waste (MSW) through the disposal of NiCd batteries. MSW is the non-industrial refuse collected from households and businesses by the municipal authority or private contractors, ${ }^{6}$ and may be disposed of to landfills that lack pollution protection mechanisms suitable for heavy metal disposal. Prior to this research the cadmium content of Cape Town's MSW was unknown, and the extent to which the city's cadmium metabolism could be expected to resemble that of a developed-world city was uncertain.

The overall objective of this research has been the characterization of NiCd battery use and disposal in Cape Town in terms of the amount of cadmium involved, and assessment of whether this contributes an environmentally significant quantity of cadmium to MSW in the city.

This dissertation reports on the application of substance flow analysis (SFA), a tool within the field of industrial ecology, to quantitatively investigate the use and disposal of $\mathrm{NiCd}$ batteries in Cape Town and the associated flows of cadmium. SFA is material-focussed and consistently applies the mass balance principle to all processes within a system, providing a thorough description of the system's material flows and avoiding the disregard of physical law implicit in many methods of economic analysis. The developing world context of the study was expected to give some insight into the challenges that industrial ecology methods such as SFA face in such settings. It further presented the possibility of transposing a qualitative understanding of cadmium metabolism to other developing-world cities.

Literature relevant to SFA methodology is reviewed in Chapter 2 (Sections 2.1-2.4), including important issues regarding the handling and quantification of uncertainty. From the basis of this review, the methodology used in the present work is developed in Chapter 3 (Section 3.2) and the SFA results comprise the whole of Chapter 4.

This dissertation also provides an assessment of the environmental significance of the cadmium flow to MSW identified by the SFA. The SFA results provide a quantitative description of the most important pathways for cadmium through the city"s economy and waste streams, but cannot provide direct guidance as to whether the amounts sent to landfill warrant concern. A methodology, based on information from the literature presented in Chapter 2 (Section 2.5), is developed in Chapter 3 (Section 3.3), to perform this assessment. It considers total cadmium release from landfills and the minimum potential contamination of agricultural soils that could result, cropland being the most relevant receptor against which to measure contamination potential with relevance to human health. Other sources of soil contamination are also taken into consideration. In the course of the methodological development and application, the relationship between solid waste management, wastewater treatment and cropland are explored. The results from the assessment are presented in Chapter 5.

Finally, Chapter 6 discusses the methodologies and findings, the future outlook for NiCd battery use and disposal, and some consideration of means by which the management of cadmium might be improved. The chapter closes with a summary of the most important conclusions and recommendations deriving from the work. 


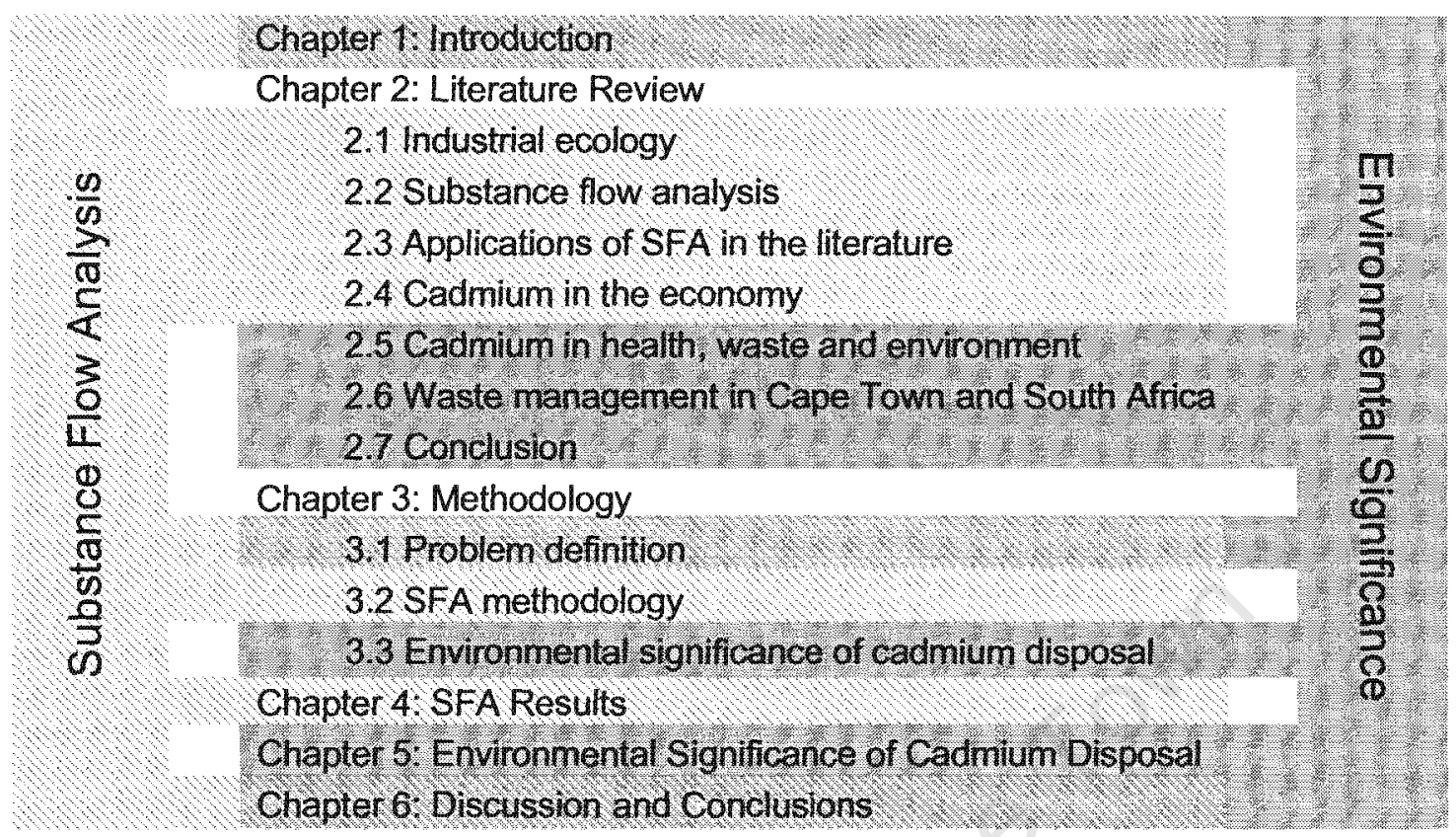

Figure 1: Outline of the thesis structure 


\section{CHAPTER 2: LITERATURE REVIEW}

\section{1}

\section{INDUSTRIAL ECOLOGY}

The field of industrial ecology is founded on a systems view of industrial and consumer activity that makes use of the so-called "biological analogy". Here an analogy is drawn between industrial systems and natural systems, with the intention that such a perspective will allow the highly efficient use of resources and minimal waste output observed in natural ecosystems to be designed into human industrial and consumer systems. ${ }^{7,8}$ A direct extension of this analogy is the central notion of industrial metabolism - that industrial transformations of materials can be studied as an interconnected system analogous to the systems of biochemical transformations that fall within the scope of conventional metabolism. The premises of industrial metabolism and their contrast to the perspectives of the time were laid out by Ayres and Kneese in $1969,{ }^{9}$ although it did not emerge as a distinctive field until the 1980s. They argued that the prevailing economic theories effectively violated the first law of thermodynamics by confusing services with materials. Hence they criticized the notion of 'final consumption of goods' as implying that such materials "somehow disappeared into the void". By not accounting for the original sources and final sinks of economically utilized materials, such economic thinking implied that environmental services are free and infinite, whereas they actually represent finite resources of increasing value.

An alternative to this paradigm of goods consumption is to consistently apply mass-balance principles throughout consideration of the production and consumption chain, and to consider the system with a focus on material flow as opposed to market (monetary) value. Such an approach assists the identification and quantification of actual and potential environmental emissions, and the proper description of the economic processes which utilize material inputs provided by the ecosphere.

Although still a young field, industrial ecology has developed considerably since its emergence as a distinct area of inquiry. Several techniques have arisen from the biological analogy, including:

- material flow analysis (MFA) which tracks the pathways of materials through the metabolism of social systems

- life-cycle analysis (LCA), which evaluates the total environmental effects of product usage from raw material extraction to ultimate fate

- design for environment, in which a life-cycle perspective is incorporated into product design processes

- industrial symbiosis, the study and development of ecosystem-like interrelationships of material and energy exchange between industrial entities so as to maximize efficiencies and minimize wastes. ${ }^{10}$

Industrial ecology is now an established field of academic study and research and, although its incorporation into policy-making and business decisions is still under development by its proponents, ${ }^{11}$ their successes can already be seen in, for example, business attention to LCAbased eco-labels, ${ }^{12}$ and the employment of permanent MFA practitioners by municipal authorities. $^{13}$ 


\title{
2.2.1
}

\author{
Material flow analysis
}

Understanding the flows of materials through society is crucial to the systems perspective of industrial ecology, so much so that it was placed centre-stage by White in his definition of industrial ecology as ${ }^{14}$

...the study of the flows of materials and energy in industrial and consumer activities, of the effects of these flows on the environment, and of the influences of economic, political, regulatory and social factors on the flow, use and transformation of resources.

The first law of thermodynamics forms the basis of the technique of material flow analysis. A system can be characterized as a flow diagram, termed a network of nodes by van der Voet, ${ }^{15}$ where economic processes of transformation and 'consumption' are interlinked by flows of a particular material. In order for mass and energy to be conserved, all inflows to a node must be balanced by equal outflows from and/or accumulations at the node. The mass-balancing principle is applied at every node within this structure to fill in missing data and identify hidden and diffuse emissions, providing a comprehensive and consistent picture of the flows of a material through society from its initial extraction as a unprocessed resource to eventual disposal. ${ }^{16,17}$ Such an understanding can provide a sound basis for rationalising resource use and minimizing adverse environmental effects.

\subsubsection{Substance flow analysis}

Substance flow analysis can be considered a special case of MFA in that the focus of study is a particular chemical or element, whereas MFA is broader in that it also encompasses bulk materials, for example wood. ${ }^{18}$ The methodology of SFA has been broadly outlined by van der Voet as being comprised of three steps: (1) defining the system; (2) quantifying the overview of stocks and flows; and (3) interpreting the results. ${ }^{19}$ Defining the system involves a description of system boundaries in terms of time (usually a year), geographical space, the substance of importance and its functions of relevance. In addition, the system may be divided into subsystems. She specified a division into economy (or anthroposphere), natural environment, and immobile stocks (the lithosphere). Hence in her framework there is no distinction between economy and anthroposphere, and only geological stocks are recognised as truly immobile.

Van der Voet also identified different approaches to the quantification stage. ${ }^{19}$ In order of their increasing data demands, these are : 
accounting / bookkeeping - treatment of the system as an accounting system, in which case stocks and flows are described by a combination of collected data and application of mass-balancing.

static modelling - description of the stocks and flows network as a linear system of equations, derived from the mass-balance principle and relationships between the stocks and flows (emission factors, for example). In combination with some accounting data, this allows the use of algebraic techniques to yield a mathematical description of the system at the time of study.

steady-state modelling - a different type of static modelling, where a linear system of equations is also used but changes of stocks are excluded. By taking input values as constants, this allows a view of system behaviour without the buffering effect of stock growth or decline: that is, the hypothetical equilibrium situation under current conditions. It does not provide a predictive model, but can be useful in considering the sustainability of a system's current state and for comparing different scenarios.

dynamic modelling - modelling of the system with the inclusion of time as a variable. This requires consideration of the residence times of substances in particular stocks, the retention times in environmental compartments, etc., and allows assessment of the future effects of management scenarios, since such dynamic models have quantitative predictive ability.

Kwonpongsagoon has described the methodology he used to model cadmium flows through Australia. ${ }^{20} \mathrm{He}$ specifically distinguished between 'traditional' SFA and 'mathematical' SFA. Traditional SFA is described as the development of a quantitative description of the system as a flow diagram using only data and mass-balance principles, whereas mathematical SFA aims to model the system as a set of equations, allowing manipulations that can provide greater insight. This distinction is equivalent to that between the bookkeeping and modelling approaches described above. Mathematical manipulations can include sensitivity analyses to identify areas for policy intervention, more thorough treatment of data uncertainty, and predictive capacity in the case of dynamic modelling. He went on to describe an 8-step procedure that he used to develop a static model: $:^{20}$

1) Choose substance, and identify timeframe and geographic system;

2) Collect data and information;

3) Identify related goods and processes;

4) Establish flow diagrams without data;

5) Emission estimation;

6) Spreadsheet calculation;

7) Establish flow diagrams with data;

8) Formulate an aggregate model.

This procedure gives greater detail than the overview given above, but is reliant on the availability of pre-assembled data. In this work, Kwonpongsagoon made use of secondary sources and did not undertake any primary data collection himself. This is presumably why some degree of data collection (step 2) was possible before considering related goods and processes (step 3). Similarly, an estimation of emissions was feasible before the construction of a quantitative flow diagram because a national database of reported emissions was available. The interesting feature of his method is the late stage at which he integrated the 
'system' and 'data'. This is evident in his execution of the above strategy, and clearly stated in a later paper, ${ }^{21}$ where the method is described as " $(1)$ system analysis, (2) mathematical model, (3) data acquisition and calibration of the model and (4) sensitivity analysis, simulations and uncertainty analysis."

Brunner and Rechberger have stressed that an SFA is not conducted in a linear fashion, but is an iterative process with each stage informing refinements of previous steps (Figure 2.1). ${ }^{22}$ They also pointed out that aligning geographical system boundaries with political or administrative areas can offer advantages because data is often compiled at these levels, increasing data availability, and because the findings of the study are more easily acted on if they apply to the area under a single administrative body.

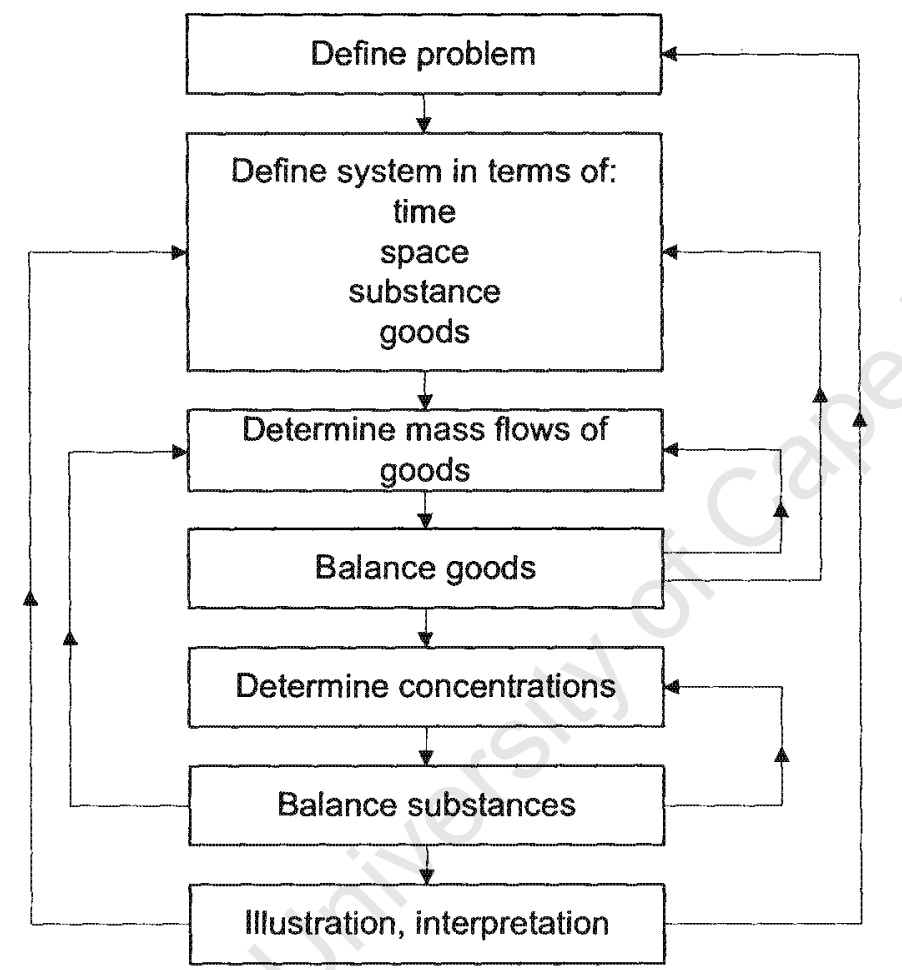

Figure 2.1: Methodological approach to SFA, adapted from [22].

\subsubsection{Indicators in SFA}

A important issue in the interpretation of an SFA is the representation of results in an accessible, meaningful and policy-relevant format, and van der Voet proposed that this is best achieved by deriving indicators from the results. ${ }^{19}$ Guinée et al. suggested several suitable indicators. These include: ${ }^{23}$

Risk ratio and transition period: The risk ratio is the ratio between the daily intake or environmental concentration and the acceptable daily intake or the relevant standard for environmental concentration, respectively. Hence values greater than 
unity indicate a human or environmental toxicity risk. The transition period is the time required for the risk ratio to increase to 1.

Total emissions: This is the total flow (in mass per year) of material from the economy to the environment, and is interpreted here to indicate environmental pressure. This interpretation must usually be made with caution, however. Although not addressed by Guinée et al., the 'pressure' is highly dependent on other factors, most obviously that of dilution.

Technical efficiency: This indicator is the percentage of inflow to an economic process that is converted to useful outflow to another economic process. Emissions and flows to landfill are therefore not included as 'useful' flows.

Functional and non-functional recycling rate: This is the percentage of outflow from a particular economic process that is recycled to an earlier stage in the economic flow of the substance. Functional recycling is a flow that intentionally includes the substance in question. Non-functional recycling is where the substance is present unintentionally, for example as a trace component in the functional recycling of another substance.

Relative accumulation in the economy: The total increase in the economic stocks in a given year expressed as a percentage of the total inflows into the economy in that year. This indicator could therefore be seen as a (net) percentage of inflows that are retained by the economy in a year.

\subsection{4}

\section{Data sources for SFA}

Data for SFA studies can be gathered from a wide variety of industry (e.g. associations, direct from companies and experts), government (e.g. environmental agencies, bureau of statistics, municipal records) and academic sources (e.g. journals). ${ }^{15,20,22,24,25}$ Direct measurement of flows and concentrations can also be undertaken, although this is usually very costly unless limited to a small scale. "Proxies" can often be used to fill data gaps, whereby available data for one quantity is used to estimate another quantity by an estimated relationship between the two. ${ }^{22}$

In their national-level SFA studies of cadmium, accessible and extensive official statistics provided Kwonpongsagoon ${ }^{20}$ and Hawkins et $a l^{26}$ with relatively direct routes by which to quantify the relevant flows. Data at the regional or city scale are often much scarcer and there is a need for additional data collection and resourceful use of that which is available. Data scarcity caused Timmermans and van Holderbeke to ignore societal stocks in their study of chromium in. Flanders, Belgium. ${ }^{25}$ Even after gathering additional data through questionnaire surveys, some of the values needed for quantifying flows could only be estimated by extrapolating from other regions or by adjusting national data. They achieved this by scaling such figures in proportion to either population or production quantities. ${ }^{25}$ Jonsson et al. also applied population scaling to adjust from regional to urban scale. ${ }^{27}$ Taking advantage of the absence of local production, Zumbuehl adjusted national import statistics according to regional GDP in order to estimate the flow of cathode ray tubes into Cape Town. ${ }^{28}$ Niza et al. also identified the dearth of data as a major difficulty in performing urban SFA, and incorporated the scaling of statistics available for other geographical scales into their model 
calculations of total material flow in Lisbon, Portugal. ${ }^{29}$ They used a variety of somewhat more sophisticated scaling factors based on, for example, retail and industrial activity, employment patterns and purchasing power of inhabitants, depending on the quantity in question.

\subsubsection{Uncertainty}

In SFA, as in other systems-based analysis tools for sustainability such as life-cycle assessment (LCA) or cost-benefit economic analysis, many important quantities must be evaluated on the basis of very limited data such as expert judgements or single data points. The best estimate often carries considerable uncertainty that itself can be difficult to evaluate. Although some researchers have included quantitative handling of uncertainty into their work, it has not yet been widely adopted in SFA. For example, since January 2007 the nine articles in the Journal of Industrial Ecology that carried the keyword "substance flow analysis", $24,30,31,32,33,34,35,36,37$ included only two with any estimation of uncertainty in the reported results. ${ }^{33,37}$ The LCA literature provides a richer source regarding the treatment of such uncertainty, and was consulted alongside SFA and other literature.

\subsubsection{Sources of Uncertainty}

Weidema and Wesnæs, proposed five 'data quality indicators', with which to describe the quality of any data set used in LCA. ${ }^{38}$ The first two are related specifically to the data itself and not its use in a particular context:

Reliability - An assessment of the methods of measurement, sources and verification used to determine a value for a quantity.

Completeness - An assessment of sample size and sample representivity underlying an estimated quantity.

The other measures assess the use of the data in the context of the study:

Temporal correlation - How closely the time of measurement corresponds to the period of interest.

Geographical correlation - How closely the regions of measurement and application correspond.

Further technological correlation - The extent to which the data relates to similar or different technologies to those under investigation, beyond those similarities and differences already reflected in geographical and temporal correlation.

Also in the field of LCA, a number of types of uncertainty have been distinguished by Huijbregts. ${ }^{39} \mathrm{He}$ identified six types of uncertainty (arising from inaccurate measurement, limited data, etc.) and variability (due to inherent variation in a parameter):

Parameter uncertainty - Uncertainty in the values of model parameters arising from imprecise measurement, limited data and use of data outside their context of strict validity.

Model uncertainty - Uncertainty in the results which arises from underlying assumptions (e.g. linearity of responses). These issues have limited effect on 
accounting-type SFA, as it does not attempt to model flows to the extent of future projections or environmental risk assessment.

Uncertainty due to choices - Numerous modelling choices are required in both LCA and SFA, which introduce the possibility of inaccurate modelling. In SFA this would include the selection of proxy variables, for instance.

Spatial variability - When data is not available for the specific region under study, it is often necessary to use available data from elsewhere.

Temporal variability - As for spatial variability, it is often not possible to obtain data for the specific time period under study.

Variability between sources and objects - A greater concern for LCA than SFA, this refers to variation in properties between different objects and processes of the same type (e.g. manufacturing processes for the same product). In the context of SFA, the overall flow of a large system is of interest rather than that attributable to a specified functional unit. Mean values are generally applied, which greatly reduces this form of variability.

Specifically within SFA, Hedbrant and Sörme have noted that uncertainty can arise from a limited amount of data, irrelevant factors influencing interview responses (e.g. the phrasing of a question), unrecognized lack of independence between data sources, use of data which is not strictly valid (e.g. proxy measures) and differences in definitions and classifications between sources. ${ }^{40}$

\subsubsection{Quantifying uncertainty}

It is important to recognise the possible sources of uncertainty in data collected for SFA, but it is also necessary to provide for this uncertainty to be quantified and propagated through calculations to yield a measure of the uncertainty it causes in the calculated results. Weidema and Wesnæs proposed that each data set could be assigned a score for each of their data quality indicators (see previous section), on the basis of a pedigree matrix which would standardize the assignment by giving generic scoring rules for each indicator. ${ }^{38}$ This method can systematize the assignment of semi-quantitative indicators. However, it does not allow for the applicability of a given data set to be considered when assigning its data quality scores. Two values of the same age, for instance, would get the same score for temporal correlation although their applicability to the period of study might vary considerably (annual production, for example, might not be as constant as water content). An approach to the combination of data quality indicators was presented, ${ }^{38}$ in which each indicator score is subjectively interpreted in terms of a coefficient of variation (CV) and these manipulated to provide a single $\mathrm{CV}$ for each data point. However, this procedure and the subsequent propagation of uncertainty suffers from a number of tacit assumptions which are not obviously true. For instance, it is not apparent that the different indicator categories or scores should be equally weighted, nor that they should allow a CV to properly represent them. Hence this approach would appear to provide some objectivity through the pedigree matrix, but this advantage is offset by the lack of rigor in the subsequent manipulations. Indeed, the need for a subjective quantification is not avoided, although it becomes more methodical through separate treatment of every source of uncertainty guided by the standardized scoring system. 
Another approach is to define each input as an interval between minimum and maximum bounds. ${ }^{41,42}$ Calculations then make use of the established rules of interval analysis which carry out parallel computations using the relevant bounds of each parameter in order to obtain a result as an interval - that is, a minimum and maximum estimate between which the true value is certain to fall. The initial choice of minimum and maximum values must often be made subjectively, but these values are easily reported and can be directly assessed by other parties - there is some transparency without the rigidity of pedigree matrices. Beyond the selection of intervals, the method is mathematically rigorous. However, it does suffer from the disadvantage that it gives no preference to any value within an interval, and treats the entire range of possibility equally. Very often some values of an estimated parameter are considered more likely than others and it is undesirable to lose this information, as imprecise it might be. ${ }^{43}$

Heijungs has argued ${ }^{44}$ that although mathematically complex, the propagation of error can be carried out analytically and is easily automated. His approach considers a result's sensitivity to error margins of inputs by computing the relevant partial derivatives of the result. Although it allows the assignment of different error margins to different inputs, all uncertainties must be symmetrical. The method also does not accommodate preferences for certain values within the error margin. Tan et al. argue that analytical propagation of probability becomes prohibitively difficult as model complexity increases. ${ }^{45}$

Some of the difficulties encountered with the above approaches can be overcome by treating uncertainty probabilistically. Instead of single numbers or intervals, input parameters can be described by probability distributions that reflect not only their estimated range of likely values but also relative likelihoods within these ranges. ${ }^{22,39}$ This provides a great deal of flexibility in the description of a parameter's uncertainty. The uncertainty is easily propagated through calculations by means of Monte Carlo simulation, ${ }^{22}$ which can accommodate any selection of different probability distributions (discrete or continuous) and large uncertainties in inputs without the need for complex analytical treatment. In Monte Carlo simulation a value is randomly selected from the distribution of each parameter and the results are calculated using this set of input values. This is repeated many times and the outputs are collated to yield a sample from the probability distribution of the result. In this manner it is possible to approximate the probability distribution of the output by randomly sampling from the input distributions, with the precision of the approximation increasing with more sampling iterations. Stratified sampling techniques such as Latin hypercube sampling can provide an alternative to simple random sampling that gives faster convergence to the true output distribution. ${ }^{39,46}$ The standard Latin hypercube method divides each input distribution into equiprobable intervals and then takes a random sample from each of these intervals, giving a more even representation of the distribution with less sampling effort. The Monte Carlo approach has been applied in SFA, ${ }^{21,47,48} \mathrm{LCA}^{49,50,51}$ and other fields, ${ }^{52}$ and has become integrated into several software platforms for $\mathrm{LCA}^{53}$

A variety of approaches have been taken to assign distributions to input parameters for Monte Carlo simulation. In his SFA of cadmium in Australia, Kwonpongsagoon assigned uniform distributions to all parameters because insufficient data was available with which to 
derive probability distributions. ${ }^{20}$ Presumably there was some imprecise information on the relative likelihood of values which was discarded in this process. It is interesting to note that this approach is not equivalent to that of interval analysis. Rather than producing uniform output distributions which could be interpreted like uncertainty intervals, outputs took on non-uniform distributions often resembling normal or log-normal shapes. ${ }^{20}$ This arises from the probabilistic interpretation of the uncertainty. The probability of all input parameters being identically equal to those extreme values which would maximize (or minimize) the output is exactly zero, as a result of the inputs being drawn from continuous probability density functions. By slight extension, the probability of all inputs lying very close to these values is small, because a much greater number of possible combinations of input values exists which would produce outputs of intermediate value. This effect would be present, albeit less conspicuously, in Monte Carlo simulation using any continuous input distributions, and reflects the assumed absence of consistently maximizing or minimizing systematic errors in the estimation of input parameters.

For an LCA of beverage delivery systems, Kennedy et al. proposed the assignment of a single, overall data quality score to each estimated input, based on expert opinion, and connected these to the parameters of beta distributions for use as inputs to Monte Carlo simulation of calculations. ${ }^{50}$ Their reasons for choosing the beta distribution were that: (a) suitable adjustment of its two parameters could produce a broad selection of distribution shapes; (b) no prior knowledge of the true distribution was required to use the beta distribution; (c) extreme values for each input could be set firmly with zero probability outside the specified range, preventing problems such as anomalous negative values; and (d) the beta distribution is widely accepted and applied in statistical practice. The flexibility of the beta distribution is appealing if only one family of distributions is to be used throughout a simulation, but even with little information about the true distribution it is unclear that the beta distribution should be universally favoured over other established distributions. Indeed, there is at least one circumstance where it would not be ideal: if there was a small probability that the estimated range of probable values was wrong. In this case its rigid limits on extreme input values could be a disadvantage.

A more flexible approach was taken by Miller et al., whereby the parameter distributions for the Monte Carlo calculation of agricultural nitrogen flows were selected by a variety of means depending on the available data and each justified separately. ${ }^{48}$ They made use of regression from sampling data to define normal distributions where possible, triangular distributions where an input was estimated on the basis of a likely range and most probable value, and several other distributions in other circumstances. Such an approach runs the risk of lacking transparency unless the rationale for selecting each distribution is clearly defended, but it is able to utilize the maximum amount of available information. The results of such a calculation can only be verified by careful consideration of each chosen distribution, but as much scrutiny would be needed to verify the applicability of a parameter's assigned distribution if it were assigned by default.

Whilst it provides a mathematically sound yet simple and flexible method of handling uncertainty, the applicability of Monte Carlo simulation has been the subject of some debate. A commonly raised concern is that without sufficient sampled data the distributions of input 
parameters are not adequately known ${ }^{21,41,45,40}$ and so the practice of assigning, rather than rigorously deriving or statistically inferring distributions is imprecise. This is clearly true, although other methods also incur imprecision as a cost of using non-sampled data, as discussed above. Any method applied to uncertainty of this nature will involve imprecise uncertainty estimates although some, like interval analysis, might discard some of the available information to give a more conservative (but still imprecise) measure.

Chevalier and le Teno argued that LCA data was often not suitably described by probability distributions because many parameters are not really exactly defined, ${ }^{41}$ such as production process parameters that vary from one operation to another. This is "variability between sources and objects' in the taxonomy of Huijbrechts ${ }^{39}$ described above, and is less relevant within an SFA context due to the use of mean values, which are exactly defined.

Another argument put forward by Choobineh and Behrens, in the context of economics, ${ }^{42}$ was that certain modelling situations involve unique and irreplicable circumstances and are thus fundamentally at odds with the axioms of probability as founded on the concept of repeated random experiments. Hence experts may be willing to estimate a 'probability' for a unique occurrence or quantity, but this would fall outside the axiomatic scope of probability theory. These authors suggest that the use of fuzzy intervals, an extension of interval analysis which uses fuzzy set theory to allow for preferences among values, provides a more suitable method for quantifying and propagating such uncertainty. This theory describes linguistic imprecision and subjective uncertainty on the basis of ambiguity rather than random variation. ${ }^{45}$ On the other hand, Morgan and Henrion point out that the objection of axiomatic inconsistency only holds within a frequentist interpretation of probability and that from a Bayesian viewpoint a probability distribution describes not just an inherent property of a statistical event but also the state of information about it. ${ }^{46}$ In principle, one of these viewpoints should be consistently adhered to throughout data analysis, but in practice it is found that in many circumstances the confidence intervals derived by classical (frequentist) statistical treatments correspond closely to those rigorously derived by Bayesian methods. ${ }^{46}$ Whilst it is strictly incorrect to view a confidence interval for a population mean as a probability judgement of the mean's value, the distinction between "a $95 \%$ confidence that the interval includes the mean" and it being " $95 \%$ probable that the mean falls within the interval" presents a knotty philosophical problem which will not be further addressed here. In any event, Morgan and Henrion claim that there is no basis for concluding that fuzzy intervals provide a better representation of non-frequentist uncertainty, ${ }^{46}$ and Tan et al. found that the two approaches applied to a biofuel LCA study produced comparable results. ${ }^{45}$

Morgan and Henrion suggest that the use of probabilistic uncertainty descriptions be limited to cases that pass the 'clarity test' proposed by Howard and Matheson ${ }^{54}$ - that hypothetically, given unlimited knowledge, it must be possible to state unambiguously whether or not a proposition is true. Any exactly defined value would pass the clarity test, but the variability of process characteristics considered by Chevalier and le Teno are examples of values that would not: ${ }^{41}$ the question "How much water is used to make product X?" does not have a single true answer if different production processes are practised. This test also excludes the probabilistic treatment of uncertainties that arise from modelling and scenario choices, as attempted by Huijbregts et al. In their LCA of house insulation options, Monte Carlo simulation was applied using discrete input distributions that defined alternative model 
choices. $^{49}$ In terms of the clarity test this would be inappropriate because all models are fundamentally approximate, and hence untrue. Even with perfect information it would only be possible to assess model structures as being 'better' or 'worse' but not 'true' or 'false'. On a more practical level, for most SFA studies this approach would be infeasible as different model structures would lead to entirely different data requirements, considerably extending the cost of the study. Furthermore, there is no clear procedure for devising alternative assumptions and no way of knowing whether all important possibilities have been included.

The SFA technique has been widely applied, especially in Europe. The majority of such studies have focussed on substances of dual economic and environmental importance, particularly toxic heavy metals and nutrients applied as fertilizer to agricultural soils. These include, among many others, mercury in the United States, ${ }^{55}$ chromium in Flanders, Belgium, ${ }^{25}$ phosphorus in China ${ }^{56}$ and nitrogen in Sweden. ${ }^{57}$ The technique has also been applied to other substances, for example dioxins in Denmark ${ }^{58}$; on widely varying scales, from lead in the $\mathrm{EU}^{59}$ to brominated flame retardants in a single recycling plant ${ }^{60}$; and with a resource-conservation rather than pollution perspective. ${ }^{61}$

\subsection{1}

\section{SFA of cadmium in other regions}

Cadmium has been the focus of many SFA studies in the past, but it must be noted that these were set in the developed world. Nevertheless, they can provide an indication of the likely pathways by which cadmium moves through other regions of the world and, used cautiously, suggest the relative importance of these pathways. Some support for the transposition of results has been provided by Lindqvist and von Malmborg, who compared SFA studies of three Swedish cities with substantially different economies: Stockholm, Linköping and Finspång. ${ }^{13}$ They found that the differences in cadmium accumulation within the economy and cadmium emissions were largely due to differences in waste management (Stockholm exports all its waste, whilst Linköping has a regional incinerator), and that if this was taken into account, the per capita accumulation of cadmium in the economy would likely be similar in all three cities. Of course, there is presumably an underlying similarity of Swedish society's lifestyle and affluence among these examples. It was found that, although industry handles large amounts of cadmium, both due to industrial nickel-cadmium batteries and, in Finspång, due to an alloying industry, only minimal emissions or wastes were generated by this sector. Hence industry in all three cities operated very efficiently with regard to cadmium, with an estimated recycling rate of over $99 \%$ for industrial batteries in Stockholm. It was also found that, in all three cities, the cadmium flow to 'waste' was dominated by the import of household NiCd batteries and their use in household and service sectors. In Stockholm a smaller contribution was also due to 'transport', in the form of cadmium alloys and plating in vehicle components. In their study the 'waste' sectors included recycling. In Linköping, the only city of the three that disposed of waste within its boundaries, approximately $50 \%$ of cadmium in the waste stream was recycled, all from NiCd batteries. 
Their results indicated that, once obvious local peculiarities had been taken into account, SFA results from one municipality could be qualitatively applicable to others, thereby easing the data scarcity that often hampers local studies.

Hawkins et al. have reported an SFA of cadmium in the U.S.A. for $2004,{ }^{26}$ summarized in the Sankey diagram of Figure 2.2 .

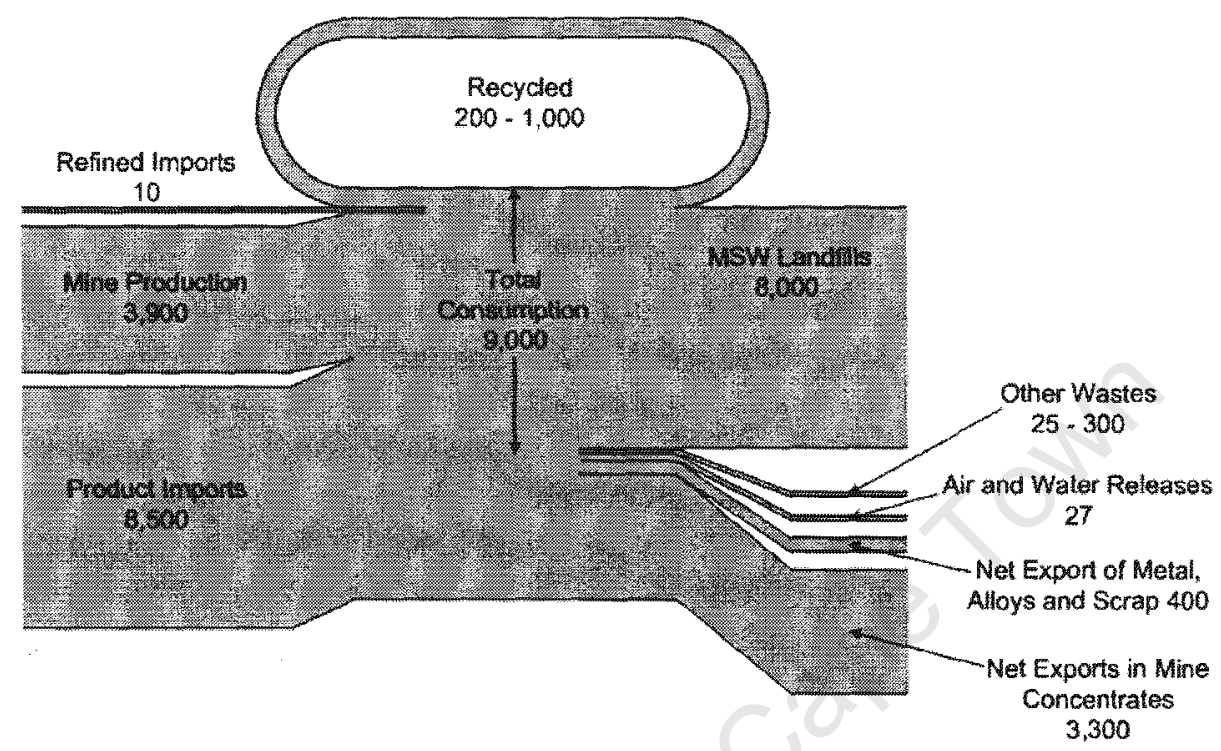

Figure 2.2: Functional cadmium in the U.S. economy for 2004-05 in tons, from [26].

The largest inflow, 'product imports', was comprised of cadmium in imported $\mathrm{NiCd}$ batteries. Of this, more than $83 \%$ was disposed of to municipal general waste landfills. The two other inflows resulted from the presence of cadmium as a minor component in zinc ore concentrate ('mine production'), most of which was exported after refining, and in lower concentrations in refined zinc that is imported ('refined imports'). ${ }^{*}$ Cadmium used in U.S. manufacturing was divided as follows:

$$
\begin{array}{ll}
78 \% & \text { NiCd batteries } \\
12 \% & \text { pigments } \\
8 \% & \text { coatings and platings } \\
1.5 \% & \text { plastics } \\
0.5 \% & \text { nonferrous alloys and other }
\end{array}
$$

Of the cadmium flow through products sold in the U.S., less than $20 \%$ was recycled. According to their model calculations, an increase in battery recycling would result in a significant increase in air releases, although it would reduce the cadmium flow to landfill. Ending cadmium incorporation into products was predicted to reduce all forms of emission, but the disposal of cadmium by-product from zinc production was not included in this projection.

\footnotetext{
* Zinc ores are by far the dominant source of primary cadmium world-wide, ${ }^{62}$ see Section 2.4 .
} 
Hawkins et al. also identified significant non-functional flows of cadmium in phosphates, fossil fuels and zinc compounds. Between 250 and 3200 tons of cadmium were applied to agricultural soils through phosphate fertilizers. Use of coal accounted for 100 to 1700 tons of cadmium, of which at least 2.6 tons were released to air, the remainder being present in solid combustion waste that was disposed of to landfill or used in construction. Cadmium present in petroleum amounted to 2 to 200 tons. Trace cadmium in zinc use was estimated at 300 tons. $55 \%$ of zinc was used for galvanizing. Zinc alloys and brass accounted for most of the rest, although zinc use in car tyres was identified as a potentially important emission source.

In Kwonpongsagoon's study of cadmium in Australia, ${ }^{20}$ he identified the major functional uses of cadmium as: NiCd batteries, both vented (large industrial) and sealed (small commercial); pigments for plastics; PVC stabilizers; and smaller contributions from plating, alloys and solders. NiCd batteries made up $90 \%$ of cadmium sent to landfill. Important nonfunctional flows included the use of phosphate fertilizers; sewage sludge; coal; gypsum; limestone, mostly used in cement production and construction but also in agriculture; tailings from copper mining and slag from beneficiation; and animal manures.

Some of the flows investigated by Kwonpongsagoon illustrate some subtle difficulties in defining the 'functions' that fall within the scope of study. For example, the major cadmium sources to air were estimated for $1998 / 99$ as: burning/wildfires $54 \%, \mathrm{Zn}-\mathrm{Pb}$ smelting and refining $14 \%$, dust raised from roads $14 \%$, electricity utilities $8 \%$. He did not address the relative relevance of these emissions to environmental or human health, however. The major concern regarding emissions of cadmium to the air is its subsequent deposition from the atmosphere to the soil or surface water. ${ }^{63}$ This mechanism will not allow wildfires to cause an increase in soil cadmium on a continental average, but clearly the release of fossil-fuel cadmium has this potential. Therefore it is somewhat uninformative, from an environmental perspective, to compare these "emission" sources. In a similar manner, the mining, beneficiation and trade of steel is examined. In absolute terms the amounts of cadmium mobilized by this subsystem appear significant. Closer examination, however, reveals that the cadmium concentration in the materials involved does not exceed $0.2 \mathrm{ppm}(\mathrm{m} / \mathrm{m})$. Since the background topsoil concentration is quoted as $0.1-1.0 \mu \mathrm{g} / \mathrm{g}$ (or ppm), the processes involved in steel production are not very relevant to cadmium accumulation. A concentration approach should probably be used with caution, however, since although cadmium concentrations in coal, for example, are low, the concentrations in the post-combustion products (especially the emitted flyash) are considerably higher.

Because patterns of cadmium use have been changing significantly as a result of environmental concern and technological progress, this section has focused only on more recent studies with particular points of relevance. It is nevertheless worth noting van der Voet's classic study of cadmium in the $\mathrm{EC},{ }^{15}$ and the remarkable parallel study of seven different metals in Stockholm ${ }^{64}$ which, although no longer trustworthy reflections of the current situation, have made other valuable contributions and are cited elsewhere in this work. 
Moll and colleagues found it useful to distinguish drivers of industrial metabolism at three levels to influence post-extraction material and energy flows. At the national level, policy and economic conditions influence production and supply of products and services; at the city level, infrastructure affects patterns of supply and consumption; and consumer choices are made at the household level. ${ }^{65}$ This implies that the examination of substance flows at the scale of single cities can provide unique insights that can contribute to decision making at a critical level. Lindqvist and Eklund pointed out that municipal government, through control of city infrastructure such as wastewater treatment plants and waste management facilities, often directly manages considerable flows and stocks of materials, including toxic metals. ${ }^{66}$ This was echoed by Lindqvist and von Malmborg, who noted that municipalities are also responsible for local policy and decision-making relating to spatial and environmental planning and industrial regulation, amongst others. SFA can provide supporting information which helps to identify relevant stocks, potential emission sources and important actors. ${ }^{13}$ It has been argued that the incorporation of industrial ecology, and specifically consideration of material flows, into systems of municipal environmental management is necessary for realising a transition to a more sustainable society, and that this could improve mutual understanding and cooperation between public and private players at the local level. ${ }^{67}$ In our increasingly urbanized world, cities form important foci for national and global material and energy flows. Characterizing substance flows within a city can therefore also contribute to a clearer understanding of resource depletion, material flow and stock growth at broader scales of relevance. ${ }^{29,64}$

\subsection{3}

\section{Previous studies in Cape Town}

Four studies have been identified that have applied industrial ecology methods to Cape Town or its surrounds. Van Beers and Graedel have investigated zinc and copper use in the city with a focus on quantifying in-use stocks as potential future resources. ${ }^{68,69}$ In both cases they proceeded by identifying the important recoverable uses and defining proxy indicators for which data was available, such as the extent of developed roads as a proxy for the zinc in streetlamp poles. This stock focus and the infrastructural use of these metals limits the relevance of their findings to the case of cadmium. However, they suggested that studies of material flows in Cape Town could provide important insights for other African cities for which less data is available. Next, a product-flow analysis for cathode-ray tubes by Zumbuehl focussed on the e-waste implications of their use in the city. ${ }^{28}$ Flows were estimated on the basis of adjusted national import statistics (see Section 2.2.4) because few manufacturers or distributors had been willing to provide data for the study. Finally, Nissing and von Blottnitz performed an MFA study of wood and paper in the city, drawing on data from a wide variety of sources. ${ }^{70}$ Although not recognised at the time, some fuel-wood flows they identified may be important for uncontrolled releases of the metals copper, chromium and arsenic through the burning of treated timber. 
Although cadmium minerals such as greenockite (CdS) are known, none are commercially exploited. Cadmium is produced exclusively as a by-product, principally from the processing of zinc sulphide minerals in which it occurs as an impurity. ${ }^{71}$ World refinery production since 1994 is shown in Figure 2.3.

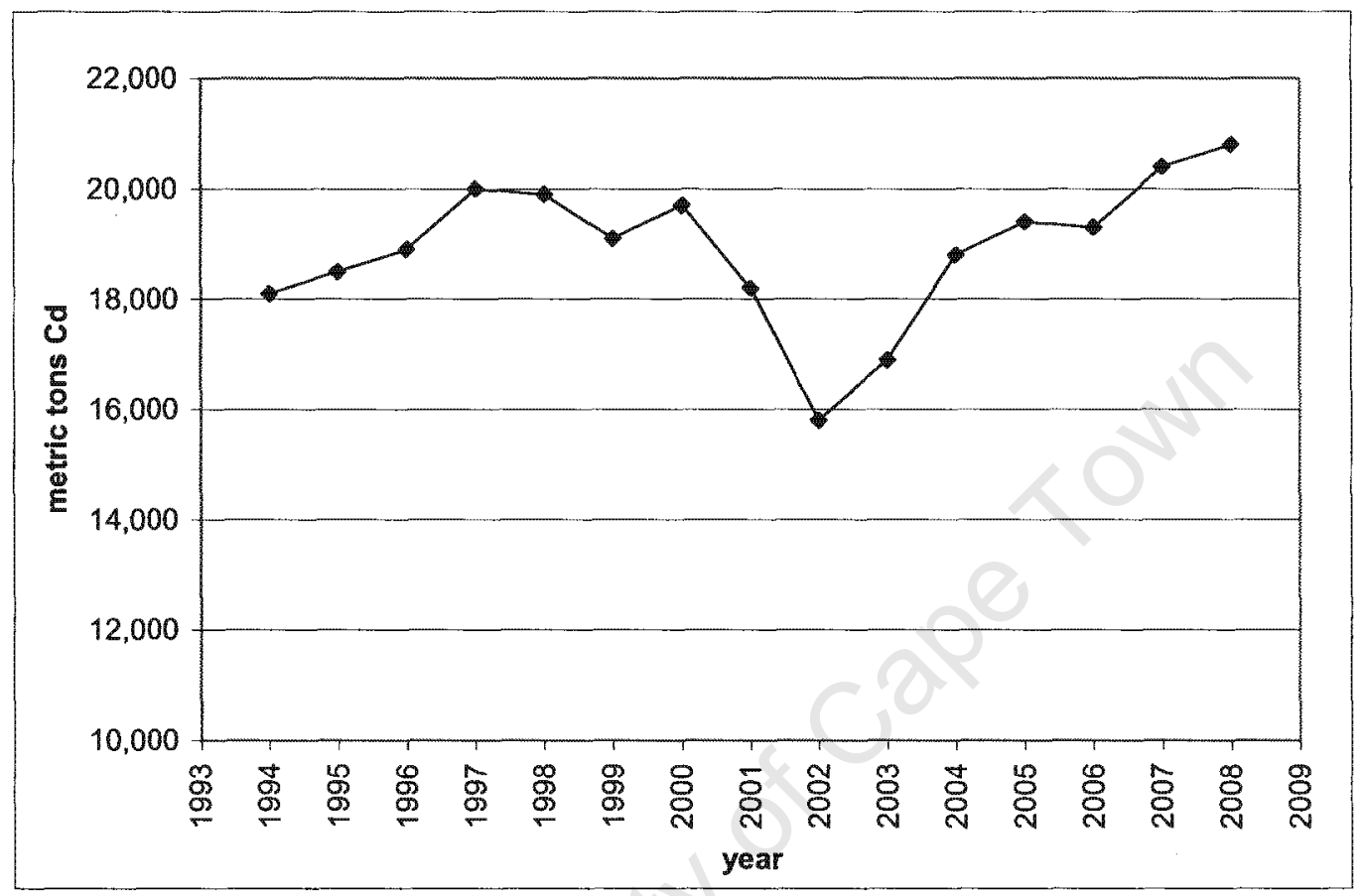

Figure 2.3: World refinery production of cadmium. Source: USGS [72]

Applications of cadmium are varied, but the last two decades have seen the share of cadmium use in nickel-cadmium (NiCd) batteries growing to dominate over all others. ${ }^{73}$ The US Geological Survey estimated that $83 \%$ of world cadmium consumption for 2007 went into the manufacture of $\mathrm{NiCd}$ cells, ${ }^{72}$ the basic components of batteries, which is in good agreement with the figures of the International Cadmium Association ${ }^{74}$ and the SFA results described in Section 2.3.1. A NiCd cell provides a voltage of $1.2 \mathrm{~V}$ on the basis of the reaction: $:^{75}$

$$
2 \mathrm{NiOOH}+\underset{\text { charged }}{\mathrm{Cd}}+2 \mathrm{H}_{2} \mathrm{O} \rightleftharpoons \frac{\mathrm{Ni}(\mathrm{OH})_{2}+\mathrm{Cd}(\mathrm{OH})_{2}}{\text { discharged }}
$$

$\mathrm{NiCd}$ cells come in two distinct types, which go by various names but will be referred to as small $^{*}$ and large ${ }^{\dagger}$ in this work. Small NiCd cells are manufactured in a range of sizes, including the familiar cylindrical consumer sizes (e.g. AA, C, D etc.). Larger vented NiCd cells are more akin to lead-acid motor vehicle batteries, being comprised of electrode plates

\footnotetext{
* Also referred to as consumer, portable or sealed cells.

${ }^{\dagger}$ Also referred to as industrial or vented cells.
} 
immersed in free-flowing liquid electrolyte, usually enclosed in a plastic casing. However, they differ in that large NiCd cells are usually fabricated individually and later connected to form a battery of the required voltage. The International Cadmium Association (ICdA) estimates that, on a cadmium mass basis, small cells make up $80 \%$ of $\mathrm{NiCd}$ consumption and large cells only $20 \%{ }^{74}$ This is supported by Kwonpongsagoon's estimate of small cells' share at $76 \%$ for Australia. ${ }^{20}$ The NiCd flows through household and service sectors in Stockholm reported by Lindqvist and von Malmborg are also in line with this breakdown. ${ }^{13}$

Small battery applications include: cordless power tools (estimated at $51 \%$ of worldwide use in 2002-2007), ${ }^{76}$ cordless telephones, portable audio-visual equipment, hand-held vacuum cleaners, other household appliances and toys, portable communication equipment, emergency lighting and medical equipment. ${ }^{20,73,74,76,77,78,79,80}$ Large cells are used for emergency and standby power backup, traction in electric vehicles such as forklifts (although they have also been used in electric cars in Europe ${ }^{73,74}$ ) and locomotive and aircraft starting power. $20,73,74,76,78$

Lesser uses of cadmium include CdS and CdSe pigments, stabilizers in plastics (PVC in particular), plating and coating for corrosion resistance, electronics applications and alloys and solders. ${ }^{20,71,72,73,74}$ An area for potential growth in the future is the use of $\mathrm{Cd}$ semiconductors such as CdTe in photovoltaic cells, ${ }^{74}$ although resource constraints could limit this to niche markets in solar power. $^{81}$

\section{CADMIUM IN HEALTH, WASTE AND} ENVIRONMENT

\subsubsection{Cadmium toxicity}

Although exposure to airborne cadmium can pose an immediate health risk to affected workers, acute toxicity through food and water is of limited concern to the general population because only a small fraction of ingested cadmium is absorbed. As a result, the single lethal oral dose is expected to be several hundred milligrams. ${ }^{71} \mathrm{~A}$ more general concern regards chronic exposure to cadmium pollution in the environment, usually through food grown in contaminated soil. ${ }^{82,83}$ Although only small amounts are absorbed, cadmium is retained for very long periods of time, with a half-life in humans of the order of decades. ${ }^{84}$ Small increases in cadmium intake can therefore have adverse effects in the long term. ${ }^{85}$ Additionally, its gradual transfer from the liver, where it is relatively innocuous, to the kidneys can cause the onset of severe health problems long after exposure has ceased. ${ }^{71}$ The major symptom of cadmium poisoning is irreversible kidney damage, which first disturbs protein metabolism but can ultimately disturb other kidney functions as well. There is some evidence of carcinogenicity in animals, ${ }^{71,84}$ but no causal link has been established for humans. $^{71}$ 


\subsubsection{Sanitary landfill practice}

Sanitary landfill practice was developed in response to the environmental and aesthetic problems encountered at waste dumps. Among these were bad odour, ground and surface water pollution, increased populations of problem fauna such as flies and rats and litter blown from the site. The two key principles of sanitary landfilling are that the waste be compacted, reducing the space it occupies, hindering access to animals and reducing its permeability to air and water; and that the deposited waste be covered with a layer of cover material at the end of every working day to keep out animals, bury the waste and keep in odours. ${ }^{86}$ Today large landfills are constructed with impermeable linings underneath the waste, to isolate it from the surrounding soil and prevent groundwater contamination. The main environmental hazards associated with landfills are gaseous emissions, especially of greenhouse gasses, and the emission of highly contaminated water from the waste (the leachate), which originates either from the waste itself or from rainwater percolating through it. $^{86,87}$

\subsubsection{Processes of landfill stabilization}

Landfilled waste undergoes a range of chemical, physical and biological processes of degradation, some taking place over long periods of time. These processes are referred to as the processes of landfill stabilization, and when the landfill mass has ceased to produce landfill gas it is deemed to be stabilized. This term is somewhat of a misnomer, however, as changes in the waste material will undoubtedly continue for long periods beyond this point. The processes occurring in a landfill are generally divided into five stages, detailed below. ${ }^{86}$

\section{Stage 1 - initial adjustment}

Immediately after placement of the waste, a short period of limited bacterial activity follows, during which sufficient moisture may build up and bacterial populations develop.

\section{Stage 2 - aerobic}

This stage usually lasts for only a few days, during which organic material in the waste undergoes aerobic degradation. Bacteria utilize the available oxygen as the terminal electron acceptor of their metabolism, and the atmosphere within the landfill is replaced by carbon dioxide produced as the final product of organic waste decomposition.

\section{Stage 3 - acidogenic}

Once the landfill interior has been depleted of oxygen, the organic material in the waste is degraded anaerobically. The hydrolysis and anaerobic degradation of high molecular-weight organic waste produces high concentrations of low molecular weight organic acids, resulting in a drop in $\mathrm{pH}$ in the landfill.

\section{Stage 4-methanogenic}

A population of methanogenic bacteria develops which utilize the organic acids as a food source, producing methane and carbon dioxide as products. After consuming the excess acid, a symbiotic relationship between acid-producing and methanogenic (acid-consuming) 
bacteria prevents further acid buildup. As a result, the $\mathrm{pH}$ rises again. The gas production prevents significant flow or diffusion of atmospheric oxygen into the landfill interior, so the internal atmosphere remains anaerobic. Under these conditions bacterial populations utilize other reducible material as terminal electron sinks, resulting in, among other reductive processes, the reduction of nitrogen salts to ammonia and sulfate to sulfide. Hence the redox potential of the landfill is lowered. This stage may continue for tens to hundreds of years.

\section{Stage 5-humic}

Eventually the rate of methanogenesis drops, although a significant amount of more stable (humic) organic material remains. Oxygen gradually reenters the landfill interior, and further oxidation of the remaining organic material can occur. The return of oxidative conditions will result in the reoxidation of sulfide to sulfate, as well as oxidation of some elemental metals to their hydrous oxides (iron in particular). Whether acid production from the oxidation of sulfide and the production of $\mathrm{CO}_{2}$ will lead to a drop in $\mathrm{pH}$ depends on the buffering ability of the landfill material at this stage. The processes of this final stage could occur very slowly, possibly taking as long as several thousands of years before the buffering capacity is exceeded, or all organic material is consumed. ${ }^{88}$

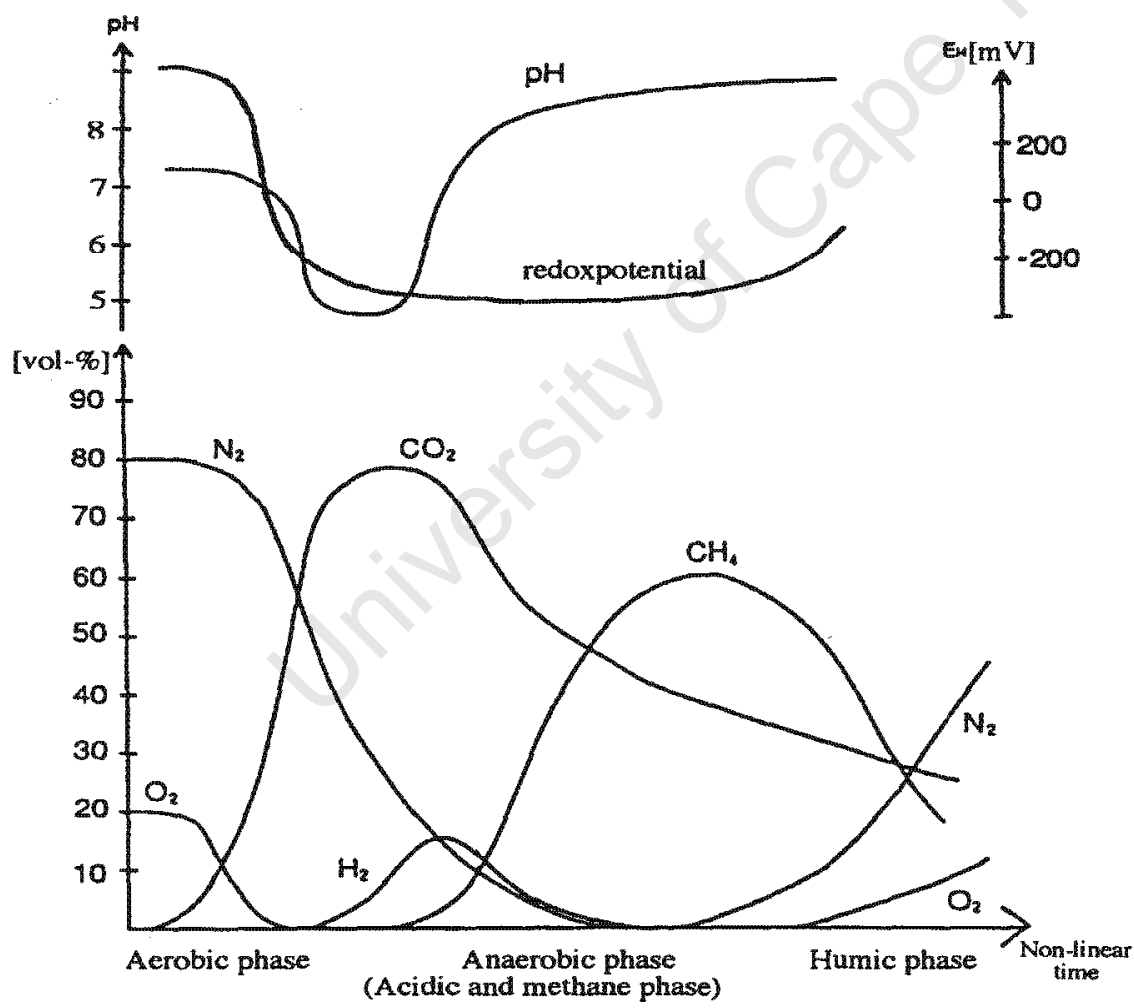

Figure 2.4: Approximate depiction of the characteristics of the chemical environment within a landfill mass, through the stages of its development. From [89]. 


\subsubsection{Mechanisms of heavy metal retention}

The retention of heavy metals by the landfill mass is thought to occur by several mechanisms. $\mathrm{Cd}^{2+}$ is readily precipitated from alkaline solutions. Cadmium (II) sulfide has low water solubility, and is believed to be an important form for metal retention in the waste mass. $\mathrm{CdCO}_{3}$ also has low solubility at high $\mathrm{pH}$, and may also contribute. ${ }^{90}$ Sulfide (as $\mathrm{H}_{2} \mathrm{~S}$ ) is formed during the methanogenic stage by microbial reduction of sulfate $\left(\mathrm{SO}_{4}{ }^{2-}\right)$ and sulfur compounds from degradable organic waste.

Erses and Onay demonstrated the precipitation of metals in two test reactors by the addition of metal solutions after the establishment of methanogenic conditions. ${ }^{91}$ They concluded that sulfide formation and precipitation played a major role in heavy metal attenuation, but that other mechanisms also contributed to the observed metal retention. Several metals were added as their sulfates, and so sulfur availability in their experiments was possibly higher than in a landfill environment.

Although sulfide precipitation might be an important contributor to heavy metal attenuation, precipitation of other metal sulfides will compete with that of cadmium. Iron, in particular, forms insoluble sulfides and is expected to be present in much larger amounts. Östman et al. sampled cores drilled from a Swedish landfill and concluded that the sulfur content was not enough to precipitate even half of all metals present. ${ }^{92}$ They observed correlations between organic matter and heavy metal content, and concluded that the organic material played a crucial role in binding metals. The role of organic matter in binding heavy metals is well established from a soil-science perspective, ${ }^{90,93}$ arising from the complexation and cationexchange character of many functional groups present in such material, particularly carboxyl, hydroxyl and phenolic groups. This ability varies with $\mathrm{pH}$ because protons can compete for the available binding sites.

Metal hydrous oxides are also potentially important adsorption materials for heavy metals. This, too, is an established soil-science principle, ${ }^{90}$ as well as a proposed explanation for the low heavy-metal leaching observed for MSW incinerator ash, ${ }^{34}$ which has a low organic content. It is likely that the large-scale formation of such oxides will not occur during the anaerobic stages, however, because of the suppressed oxidation of bulk metals and precipitation of cationic forms as sulfides.

With the possible exception of hydrous metal oxides, these attenuation processes account for the very low emissions of heavy metals usually observed from methanogenic landfills, generally amounting to a fraction of a percent of that present in the waste. ${ }^{95}$ This is because the methanogenic environment provides the reducing, slightly alkaline conditions that favour these mechanisms. However, increases in redox potential and lowering of $\mathrm{pH}$ could interfere. Sulfides, for example, are readily oxidized to yield acid, and sorption by hydrous metal oxides is hindered at lower $\mathrm{pH}$.

Although there is a considerable amount of evidence that heavy metals are largely retained by methanogenic waste, little research has considered their long-term stability in landfills. One of the first attempts was provided by Belevi and Baccini in $1989 .{ }^{96}$ Using data from a methanogenic landfill, they constructed a simple model that predicted an exponentially 
decreasing concentration of heavy metals in leachate over time. This model has a potentially fatal flaw, however, in that it assumes that methanogenic conditions persist indefinitely, In fact, as described above, conditions in the landfill are expected to change considerably over time. The onset of aerobic and possibly acidic conditions could remobilize the heavy metals, resulting in their emission at some time in the future. This is a process of the kind that Stigliani and Salomons have evocatively termed a 'chemical time bomb'. ${ }^{97}$ Bozkurt et al. $(1999,2000)$ have investigated this possibility by combining oxygen transport modelling with simple reaction schemes. ${ }^{88,89}$ The studies used very simple models of gaseous transport through the landfill body and considered only the oxidation of organic matter, assumed to be carbohydrates that undergo complete oxidation at rates similar to humic material from peat bogs, ${ }^{89}$ or only organic matter and the oxidation of iron compounds. ${ }^{88}$ In both cases they concluded that the redox and $\mathrm{pH}$ buffering capacity of the landfill should be sufficient to prevent the release of heavy metals for a period ranging from several centuries to many thousands of years. It should be noted, however, that these results are very sensitive to the waste composition and landfill management scenarios. Furthermore, whilst these models have made an important contribution to the theory of long-term landfill behaviour, too little research has been undertaken in this field to support reliable risk assessments, given the complexity of the landfill environment.

\subsubsection{Cadmium in agricultural soil}

Cadmium is one of the most bioavailable toxic heavy metals in soils, ${ }^{98}$ and the risk of cadmium exposure via crop plants is further enhanced by the relatively high levels that many plants can accumulate before growth inhibition is observed. ${ }^{82}$ This means that plant health cannot serve as an indicator of toxicity to humans or animals. Plant uptake of cadmium is affected by a great many factors including total soil cadmium content, plant species, soil $\mathrm{pH}$, cation exchange capacity (itself a function of mineralogy and organic material content ${ }^{83}$ ), redox conditions and the synergistic and antagonistic effects of other elements in the soil. ${ }^{82,85,98}$ Although the complexity of cadmium uptake processes and the variability of soil parameters makes prediction of human exposure extremely difficult, it is widely agreed that total soil content of cadmium is one of the most important determinants of its concentration in plant tissues. ${ }^{85,98,99}$

Various sources of cadmium soil contamination in agriculture have been documented internationally. The most commonly identified significant contributors are phosphate fertilizers, which carry cadmium originating as a trace element in phosphate rock deposits, the application of wastewater treatment sludges to agricultural land, and deposition of cadmium pollution from the atmosphere. ${ }^{63,83,85,100,101,102,103}$ Kloke et al. (1984) provided a cadmium balance for German agricultural soils ${ }^{101}$ which estimated that these three sources contributed $16-59 \mathrm{~g} \mathrm{Cd} / \mathrm{ha}$, with the total of other sources relatively insignificant at $\sim 1 \mathrm{~g}$ $\mathrm{Cd} / \mathrm{ha}$. In more recent years SFA studies have confirmed the importance of these sources. In their analysis of cadmium flows through the Östergötland region of Sweden, ${ }^{66}$ Lindqvist and Eklund (2002) identified sludge and phosphate fertilizers as the main cadmium contributors to agricultural soils. They pointed out that the potential for beneficial use of sludge in agriculture means that contamination of wastewater is not only an environmental and health 
risk, but also a question of efficient resource use. They also reported considerable atmospheric deposition of cadmium, but did not quantify the deposition to agricultural land specifically. However, their results implied a total annual addition of under $1 \mathrm{~g} \mathrm{Cd} / \mathrm{ha}$. These much lower results probably arose both from spatial variability and a decreasing trend in industrial air emissions and additions to agricultural soil over time, ${ }^{104}$ but to some extent also from the landfilling of most wastewater sludge in the study area. Van der Voet found that phosphate fertilizers and atmospheric deposition made the largest additions to European agricultural soil, ${ }^{15}$ but application of animal manures carried considerably more cadmium than wastewater treatment sludge. A similar conclusion was reached in Australia by Kwonpongsagoon (2006). ${ }^{20}$ Some of this cadmium may originate from mineral additives in animal feed, ${ }^{105}$ although in the Australian study ${ }^{20}$ the mean concentration in manure $(0.18 \mathrm{mg} / \mathrm{kg})$ implied by the published results was in the same range as that of the receiving soils.

\subsubsection{Cadmium in the air}

Atmospheric deposition of cadmium onto land, frequently identified as a significant contributor to contamination of agricultural soils, must of course originate from anthropogenic or natural emissions to the air. Corrected for non-concentrating redistributions (Section 2.3.1), Kwonpongsagoon's findings identify Australia's main sources of atmospheric cadmium as: $\mathrm{Zn}-\mathrm{Pb}$ smelter\&refinery, $52 \%$; electricity utility, $28 \%$; basic steel, $6 \% ; \mathrm{Zn}-\mathrm{Pb}$ mining, motor vehicles, oil refinery, each $3 \%{ }^{20}$ Metal emissions from vehicles generally deposit on soils close to the road, ${ }^{101,106}$ so agricultural soil would receive only a small proportion of total vehicle emissions. Hawkins et al. attributed $80 \%$ of air emissions in the US to the categories: cadmium coating and plating; primary $\mathrm{Zn}, \mathrm{Pb}$ and $\mathrm{Cd}$ smelting; chemicals; $\mathrm{Zn}$ and $\mathrm{Pb}$ mining; nonferrous metal recycling; other metal products; other mining. ${ }^{26}$ Van der Voet attributed the European emissions to ore refining industries, fossil fuel combustion, cadmium industry and incineration of municipal waste. ${ }^{15}$ Lindqvist and Eklund found that considerable deposition of cadmium can occur within a study area despite low levels of local emissions, due to atmospheric transport from more distant sources. ${ }^{66}$

\subsubsection{Cadmium in wastewater}

Municipal wastewater treatment is predominantly aimed at the removal of excess nutrients $(\mathrm{C}, \mathrm{N}, \mathrm{P})$ which could cause eutrophication and deoxygenation of receiving waters, and the reduction of pathogen loads. This involves primary treatment, the physical removal of suspended solids, usually followed by secondary treatment in which biological processing removes colloidal and dissolved matter, producing further solid material which is separated. The treatment produces semi-solid residues (sludge), and treated effluent water. ${ }^{107}$ Due to the use of a wide variety of materials in modern households and the discharge of industrial effluents into the same system, the wastewater received by wastewater treatment works (WWTWs) is often contaminated with heavy metals. These are concentrated in the sludge ${ }^{108}$ through both adsorption onto particles in primary treatment and biosorption during secondary treatment, ${ }^{109}$ to the extent that cadmium concentrations of sludges are usually orders of 
magnitude higher than that of treated effluent. ${ }^{108}$ However, since water generally comprises in excess of $99 \%$ of wastewater received by WWTWs, ${ }^{110}$ the mass distribution of metals between sludge and effluent is more equal than their respective metal concentrations. Karvelas et al. estimated that almost $50 \%$ of cadmium entering a Greek WWTW was released with effluent, and the other $50 \%$ was captured with sludge. ${ }^{108}$ The European cadmium flows given by van der Voet provide an estimate of $48 \%$, in close agreement with this. ${ }^{15}$ Kempton et al. have estimated that $40-70 \%$ of cadmium is removed with sludge, ${ }^{11}$ although as low as $30 \%$ has been reported. ${ }^{66}$

A diversity of sources can contribute to the cadmium load of wastewater. Lindqvist and Eklund attributed almost all cadmium in the wastewater of their studied region to emissions from in-use products which contain it, with a very small contribution from landfill leachate. ${ }^{66}$ Sörme and Lagerkvist came to the same conclusion, ${ }^{112}$ finding the greatest contributions in Stockholm were from car-wash businesses and household emissions. However, they were only able to identify the sources for $60 \%$ of the cadmium observed in wastewater. In contrast, Kwonpongsagoon noted that cadmium content of sludge in Australia was markedly higher in heavily industrialised areas, ${ }^{20}$ suggesting that production processes still make substantial contributions to wastewater in that country.

\section{6}

\section{WASTE MANAGEMENT IN CAPE TOWN AND SOUTH AFRICA}

In South Africa all landfill operations are required to obtain permits from the Department of Environmental Affairs. Each permit is issued with detailed specifications relating to the design, construction, operation and closure of the landfill site in question, with these requirements to a large extent determined by the landfill's classification. Classification is done on the basis of the size of the waste stream, the hazard level of the waste (rated 1-4, in decreasing order of hazard, and $\mathrm{G}$ for general waste), and the potential for leachate generation, on the basis of the average water balance at the site $(\mathrm{B}-$-, leachate generation not expected, and Bt, leachate expected). For medium and large landfills, the minimum requirements include that: ${ }^{113}$

- waste must be compacted

- waste must be covered daily

- an impermeable liner must be installed underneath the waste to prevent leachate from flowing into surrounding soil or groundwater

- $\quad$ surface and groundwater quality around the landfill must be monitored

- leachate quality must be tested at $\mathrm{B}+$ and hazardous landfills

- after closure, a final capping layer must be put in place to limit the exposure of the waste to water and air infiltration

- monitoring of groundwater must continue for up to 30 years after closure, depending on hydrological conditions at the site 
At present there are three landfill sites receiving MSW in Cape Town: ${ }^{114}$

Coastal Park: General waste landfill. An older inoperative section is unlined, ${ }^{115}$ but the newer section that is currently accepting waste has a liner and leachate collection system.

Vissershok H:h: Permitted hazardous site (ratings 3 and 4), which accepts a large amount of general waste as well.

Bellville: General waste landfill which is expected to close in the near future.

These existing landfills are running out of space and new landfill operations or alternative disposal options will be needed within the next decade. ${ }^{114}$ The City has been working toward the development of a new regional landfill which, due to technical, environmental and political considerations, is expected to be sited at least $40 \mathrm{~km}$ outside the city. ${ }^{116}$

Cape Town also has a privately operated hazardous landfill site (ratings 1-4), Vissershok $\mathrm{H}: \mathrm{H}$, adjoining the above-mentioned municipal site at Vissershok. In addition, there are a number of closed landfill sites in the city, among them Swartklip (Khayelitsha), Faure (Blue Downs) and Brackenfell which have ceased operations in the past ten years. ${ }^{117}$ Many of the closed landfills do not have proper liners or leachate collection systems. ${ }^{115,118}$ All Cape Town landfills are classified $\mathrm{B}+$, i.e. likely to be yielding leachate as a result of the natural climatic balance between rainfall and evaporation. ${ }^{115}$

Besides limited composting of garden waste and reuse of builders' rubble, all municipal waste disposal in Cape Town has historically gone to landfill with only medical waste being incinerated, ${ }^{117}$ and this remains the case today. ${ }^{114}$ At the end of the 1990 s no policies or official programs supported recycling in the city, although private recycling occurred particularly as a source of informal income among the unemployed. ${ }^{117}$ Since then the municipality has been shifting from a collection and disposal focus toward integrated waste management planning. This has the waste management hierarchy as its basis, which places top priority on waste reduction at source, followed by reuse and recycling, and views disposal as the option of last resort for material which cannot be eliminated by the preferred means. ${ }^{119}$ This approach has also been incorporated into national policy and legislation during this time. ${ }^{120,121}$ Within this framework the City and the waste management community have been exploring and implementing a range of waste diversion measures. Besides the environmental and resource benefits of such activities, they serve to extend the lifespan of existing landfills and will avoid some of the increased transport costs associated with a new landfill outside the city. ${ }^{116}$

Recycling and expansion of the use of garden waste and builders' rubble have featured strongly among the City's strategies for waste reduction. ${ }^{116}$ In the context of climate change concerns, the severe shortages of electricity experienced by South Africa in recent years and expectations that electricity prices in the country will continue to rise, energy-from-waste options have also entered the scene. Von Blottnitz et al. have provided preliminary assessments of energy recovery through waste incineration, anaerobic digestion, pyrolysis and gasification and found that there is potential to incorporate energy-from-waste operations into waste management in South Africa. ${ }^{122}$ Nissing and von Blottnitz found that there is substantial potential for energy recovery from wood products in the city's waste streams. ${ }^{70}$ Energy-from-waste possibilities are being explored by members of the City's solid waste management department. ${ }^{123,124}$ 
The main findings of this literature review can be summarized as follows:

Industrial ecology provides a framework for the characterisation of industrial production and consumption in terms of material and energy flows, avoiding the violations of the laws of matter and energy conservation implicit in conventional economic thinking. This can facilitate the transition to more sustainable modes of economic activity by properly accounting for material flows between anthroposphere and environment. Substance flow analysis (SFA) is an industrial ecology tool for the investigation of substance flows within a system through consistent application of the mass balance principle to all processes within it. SFA methodologies have been developed and widely applied to quantitatively describe and model socio-economic systems, and a range of indicators have been proposed which assist in interpreting the SFA results in environmentally relevant terms. Performing SFA on the scale of a city can provide valuable insights for actors who are able to directly enhance sustainability at the urban level. The economic and infrastructural importance of cities also means that knowledge of urban flows can improve understanding at the national and international levels.

SFA studies usually draw on a wide variety of data sources, some of which can introduce considerable uncertainty into the quantification. Often the uncertainty itself can only be estimated. It is important that this be acknowledged and its effects on the final calculated results be taken into consideration. There is still some debate as to which methods are most applicable or desirable for this purpose, but Monte Carlo simulation provides several advantages including flexibility, simplicity, and the containment of subjective judgement into the single step of assigning input distributions. It is also an established method which has previously been applied to uncertainty analysis in several different contexts including SFA.

Cadmium is a highly toxic heavy metal. Cadmium contamination of agricultural soil is of particular concern for human health, as the most common route of exposure is through food crops. Commonly identified sources of cadmium in agricultural soil are phosphate fertilizers, application of wastewater treatment sludges and atmospheric deposition. Emissions to the air originate from a variety of sources usually related to metal industries or fossil fuel combustion. Sources of cadmium in wastewater seem to vary from region to region, but it is agreed that wastewater treatment processes tend to concentrate the heavy metal in the sludge. Previous SFA studies in developed-world regions have identified the use of rechargeable nickel-cadmium batteries as the largest intentional use of cadmium and this to be the dominant source of cadmium in municipal solid waste (MSW). This agrees with international patterns of cadmium consumption.

In Cape Town all MSW is sent to landfill within the boundaries of the city. Although there is considerable evidence that cadmium is usually retained in methanogenic landfills, their postmethanogenic behaviour has been inadequately researched and mechanisms have been proposed by which cadmium could be released over the long term. Whilst early modelling 
suggests that the process of release could take hundreds to many thousands of years, these models are not sufficiently sophisticated to support confident predictions and the results are sensitive to waste composition and management practices. Existing landfills could therefore pose a risk in the future. Furthermore, Cape Town is currently rethinking its approaches to waste management and measures such as separation of recyclable materials and composting or anaerobic digestion of organic matter could become common in the near future. Such activities will result in substantial changes in waste composition and potentially alter the residual waste's ability to retain heavy metals such as cadmium.

The use of nickel-cadmium batteries in Cape Town presents the possibility that considerable quantities of cadmium are sent to landfill in the city, and this could risk future releases of cadmium into the environment. SFA is suited to quantifying material flows such as this, and the SFA methodology applied to the case of Cape Town and its waste streams is presented in the following chapter (Section 3.2). The results of the SFA, detailed in Chapter 4, provide quantification but not an assessment of potential environmental significance. This separate assessment requires consideration of the relationship between landfills and the environment, as well as comparison to other sources of cadmium contamination. The background information provided in this literature review is extended in the development of an assessment methodology in the following chapter (Section 3.3) and in the presentation of the calculations and results in Chapter 5. 


\section{CHAPTER 3: METHODOLOGY}

\subsection{PROBLEM DEFINITION}

International experience in developed-world regions suggests that municipal solid waste (MSW) in Cape Town could contain substantial amounts of cadmium from NiCd batteries. This cadmium might be sent to the city's landfills where its long-term retention cannot be confidently assured, and hence could pose a contamination risk in the future. Furthermore, current and foreseeable future changes in waste management practice could produce shorterterm risks of cadmium emissions from waste.

The central objectives of this thesis are therefore to provide quantitative knowledge of the cadmium involved, and to assess the environmental significance of this quantity of cadmium, so as to support appropriate decision-making.

As identified in the literature review, substance flow analysis (SFA) has been used to quantitatively assess flows of cadmium in several other settings. The first objective, to quantitatively describe flows of cadmium in Cape Town, is therefore approached by means of an SFA. This focusses on NiCd batteries to assess cadmium flows in the city, particularly those to MSW. The methodology for the SFA is presented in this chapter, and the results in Chapter 4.

The second aim of the thesis is to determine whether the amount of cadmium disposed is environmentally significant, and hence whether it justifies further research or precautionary action. Because future releases are of concern rather than present emissions, many of the commonly applied SFA indicators are not directly applicable. Environmental significance is therefore assessed in a more hypothetical manner. A methodology is presented in this chapter, and the calculations and results are given in a dedicated Chapter 5 .

\subsection{SFA METHODOLOGY}

\subsubsection{Methodological framework}

A methodological framework for SFA similar to that recommended by Brunner and Rechberger was followed in this work (Figure 2.1, Section 2.2.2) with the specification of 'goods' as nickel-cadmium batteries (Figure 3.1). ${ }^{22}$ 


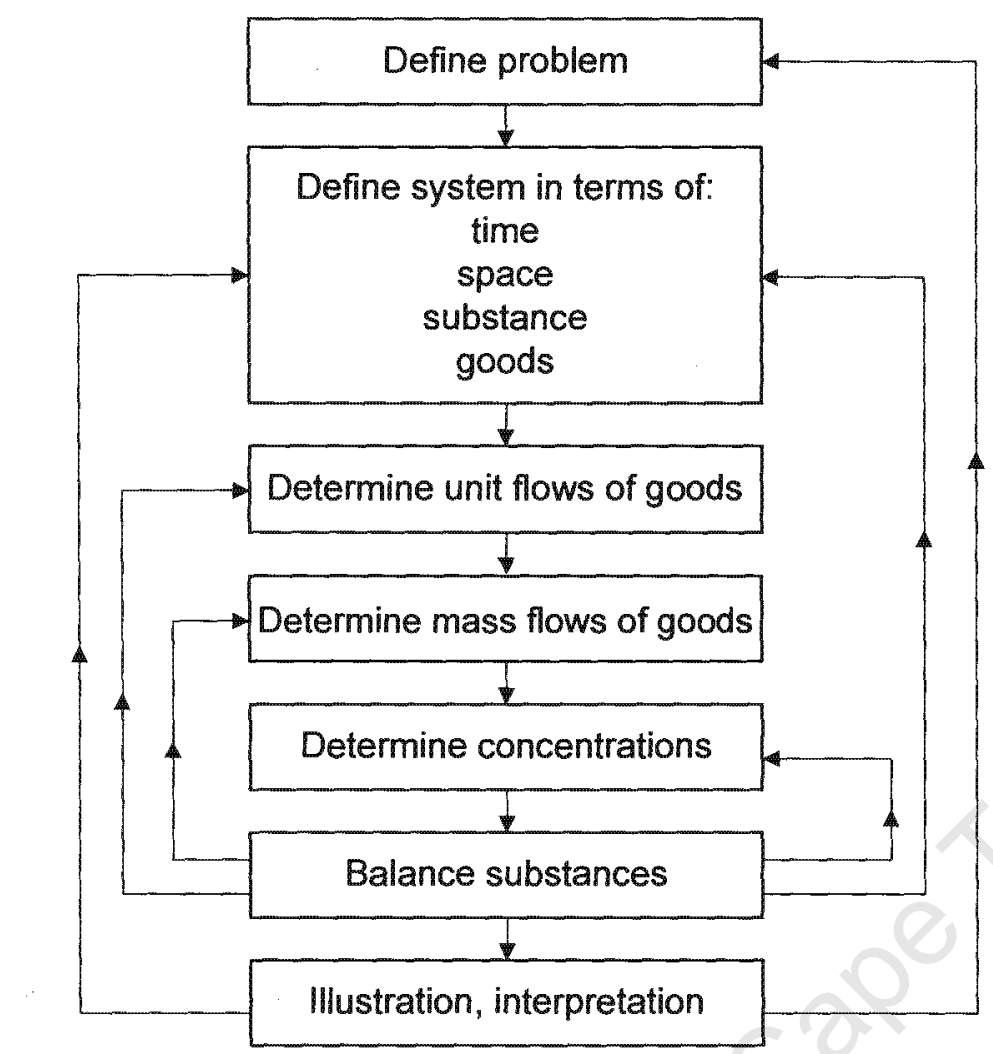

Figure 3.1: Methodological approach to SFA.

Data limitations precluded mathematical modelling of the system, as stocks and process characteristics could not be adequately determined. An 'accounting' approach was adopted as described by van der Voet, ${ }^{19}$ combined with an assumption of steady-state. Hence the flows to MSW were estimated by quantifying all other flows, assuming no stock changes and applying the mass balance principle. This provided a useful characterisation of the system as well as a quantification of the expected amount of cadmium disposal, notwithstanding the disposal delay involved. The boundaries of the system were defined spatially as the metropolitan municipal area of the City of Cape Town, except in the case of aviation NiCd battery use, and temporally by the year 2005. For aviation, the continual movement of aircraft prevented a clear geographical definition of the system, so a population-proportional share in national aviation flows was attributed to the city. This share of aviation batteries was considered to be within the system from their import into South Africa until the end of their useful lives, at which point the batteries were considered to be exported from the system unless their disposal took place within the geographical limits of Cape Town. The year of study was chosen to balance the greater data availability of the recent past with the lower commercial sensitivity of older data. Studying a full year provided advantages in terms of data availability as data is often reported on an annual basis, and offered a sufficiently long time frame to smooth out much of the variability that might be observed with shorter periods. 
Through the iterative approach depicted in Figure 3.1, the quantification method for each flow was developed during the course of the investigation, guided by the availability of data, growing understanding of the NiCd product systems and level of consistency among sources and values. The detailed discussion of each flow's quantification will be deferred to the results chapter. Here the quantification of flows will be discussed in general terms, and background to some specific methods used will be briefly presented.

\subsubsection{Overview}

In the first assessment, literature sources were reviewed to identify possible contributions to $\mathrm{NiCd}$ flows, and preliminary discussions with product manufacturers, distributors and waste management personnel allowed some to be eliminated. Those found to potentially involve significant amounts of cadmium were quantitatively investigated in detail. For large $\mathrm{NiCd}$ cells three categories were identified: aviation, electricity distribution, and other large battery applications. For small sealed NiCd cells the categories were: cordless power tools, other part-of-product NiCd cells (for example, electric toothbrushes or rechargeable flashlights), emergency lighting, and separate $\mathrm{NiCd}$ cell imports. Throughout the process, data were assessed for consistency and the uncertainty they introduced, often resulting in additional data collection or expert consultation.

\subsubsection{Detailed quantification}

Detailed quantification usually began with semi-structured interviews of experts in relevant fields, often industry professionals. Initial contact was made by telephone or email, a brief introduction of the project was provided and an interview requested. Interviews were conducted in person where possible, or telephonically at a pre-arranged time. Questions were prepared in advance and specific to each interview, but the dialogue was not restricted to these. Where company-specific data were requested, this was done toward the end of the interview after a rapport had been established with the interviewee and confidentiality had been explicitly assured. Notes were taken by hand during each interview and used to produce a permanent computer record on the same day. These interview records are provided in Appendix 1 .

In addition to interview data a wide range of other sources were used, including academic literature, company publications and websites, government releases and trade statistics. It was found that data on cadmium content were most readily available on a mass-percentage basis. The general strategy was therefore to determine the number and mass of NiCd cells used in a particular application and convert this to cadmium mass. However, there were additional steps that varied from one category to another, and in some cases total cell mass could be estimated without knowing the number of cells. 


\subsubsection{Scaling factors}

In several cases data for Cape Town were not available and either original data or calculated results for the national scale had to be adjusted to give estimates for the city. Scaling factors were developed and applied to each product group as required. In addition to the use of population and GDP share, two new scaling approaches were applied, one based on reported market trends worldwide and one on national survey statistics.

\section{Scaling of aviation battery flows}

Aviation battery use was scaled according to population, with a scaling factor of $0.07 .^{3}$ This was necessitated by aircraft movement, and represented an attribution of national flows to the Cape Town population rather than an actual estimation of flows in the geographical area of the city (Section 3.2.1).

\section{Power tool scaling factor}

Market research experience worldwide has found construction activity and motor vehicle numbers to be indicators of power tool demand, reflecting a trade-dominated market. ${ }^{125}$ The South African market follows this pattern of trade dominance. ${ }^{126}$ National power tool figures were therefore scaled to Cape Town using the geometric mean of Cape Town's share in total South African buildings completed in 2005, and share in total registered vehicles at the beginning of $20055^{5,127,128}$ This gave a scaling factor of 0.15 .

\section{AMPS scaling factor}

For part-of-product sales and separately imported small sealed cells, three survey questions from the South African All Media and Products Survey (AMPS) 2005 were selected as proxy measures. ${ }^{129}$ This survey canvassed 24,407 respondents across the country in 2005 , with 2519 of these in Cape Town. The chosen proxy measures were the population-adjusted proportions of total affirmative responses attributed to Cape Town:

- Ownership of a digital video camera (17\%)

- Small electrical appliance bought new in the last 12 months (14\%)

- Vacuum cleaner in household (19\%)

The geometric mean of these values provided a scaling factor of 0.165 .

\section{Scaling of non-aviation large cell flows}

In order to correctly interpret national import statistics, the estimated non-aviation use of large NiCd batteries in Cape Town had to be adjusted to a national value. This was achieved using Cape Town's $11 \%$ share in national GDP. ${ }^{4}$ These batteries are generally used in industrial and electrical distribution applications, both of which were expected to be correlated to economic activity.

Given the considerable uncertainty surrounding these methods of scaling, $95 \%$ confidence limits were constructed to allow for $+/-40 \%$ of the mean value. However, because population-scaling for aviation applications was attributional, this scaling factor was only assigned $\mathrm{a}+/-5 \%$ uncertainty. 


\subsubsection{Survey methodology for emergency lighting applications}

Building regulations in South Africa require the installation of emergency lighting under a range of common circumstances ${ }^{130,131}$. This lighting is required to operate independently of the electricity mains supply, and preliminary investigation revealed that $\mathrm{NiCd}$ batteries often provide the power source in these units. ${ }^{132}$ Due to the complexities of the construction and property management industries, it was decided that the most effective manner in which to determine the patterns of supply, installation, maintenance and disposal of these units would be to conduct a small survey of electrical contractors, as these tradesmen were expected to invariably play a role in some part of every lighting installation's life cycle. Such a survey also provided an opportunity to determine whether NiCd cells found any other significant applications in building electrical systems.

\section{Hypotheses}

As part of an exploration of these units' usage, the survey aimed to evaluate eight hypotheses relevant to the quantification of the associated cadmium flows. These were:

- All buildings can be assumed to comply with the regulations governing emergency lighting

- All emergency lighting can be assumed to be supplied by the use of batterybackup emergency lighting units.

- All these units run on nickel-cadmium cells.

- The units are supplied by a limited number of industry wholesalers.

- Cells used in the battery packs are only supplied with the unit. It can be assumed that no other significant battery flows enter the emergency lighting stock in the city (for example, through repair or battery retrofitting).

- Emergency lighting is the only significant application of NiCd batteries in building infrastructure

- Electrical contractors are major disposers of old units and their enclosed batteries.

- Essentially all spent batteries are disposed of with municipal waste.

\section{Survey structure}

Thirty electrical contracting firms were selected at random from the Yellow Pages telephone book and called. In the initial call it was explained that a study of battery use was being performed, they were asked whether their company does work involving equipment that uses battery backup, and asked whether this includes emergency lighting units. If the company did any work with such units, an interview was requested.

The questionnaire was designed with established survey practice in mind. ${ }^{133}$ As far as possible, the questions delayed the specific mention of $\mathrm{NiCd}$ batteries by the interviewer in order to avoid introducing any forms of bias to subsequent responses. Potentially sensitive questions regarding suppliers and disposal methods were placed toward the end, by which stage a rapport had been established with the respondent. Where appropriate, response options for multiple-choice questions were exhaustive. In the interview the respondent was presented with a page carrying six time choices which provided the response options for several of the questions: 


$\begin{array}{ll}\text { - } & \text { Never } \\ \text { - } & \text { once per year } \\ \text {-11 times per year } & 1-4 \text { times per month } \\ \text { - } \quad \text { twice per week } \\ \text { daily basis }\end{array}$

These order-of-magnitude choices aimed to provide for suitable comparison between frequencies of different activities (installation versus maintenance, for example) whilst being relatively robust with respect to potentially distorted perception of time. For five of the fourteen respondents the order was reversed to counteract possible ordering bias. All questions were asked verbally, and answers recorded on a response sheet by the interviewer. The survey questions and response sheets are included in Appendix 2. Question 13, which asked the frequency with which the contractor is responsible for disposal of old units, did not usually get the expected response. In most cases respondents gave circumstances or explanations rather than making a selection from the above list, such as "we always are", or "usually they are left with the client". Since these comments were actually seen to be more valuable to the study, they were recorded instead. Throughout the survey most respondents offered extra anecdotal information and relevant comments, which were also recorded. On the same day as each interview this record of jotted-down comments was assembled into a more comprehensive computer document so as to provide a robust record for future reference.

At the end of the interview the respondent was presented with a page carrying contact details should they have any further queries or comments, and an introduction to the research project. Usually a brief discussion of the project would follow. The fuller context of the survey was only introduced at this point to ensure no bias in responses. Their availability to provide further assistance was checked, an offer was made to provide them with the outcome of the survey and they were thanked for their assistance.

\section{Uncertainty}

\subsubsection{Sources of uncertainty}

It is helpful to condense the literature of Section 2.2.5 into a set of distinguishable types of uncertainty which can be expected in this study. Some of the terms given to these types are borrowed from the cited LCA literature, although they are given distinct meanings in the SFA context here:

Parameter uncertainty - uncertainty regarding the true value of a quantity caused by limited data availability. The degree of uncertainty may vary considerably, from values that can be statistically estimated through extensive sampling, through to single estimates from expert sources with uncertainty largely reflecting a subjective view of the source's knowledge and veracity. Here it may also be necessary to consider the possible effect of other factors, such as the interview circumstances, phrasing of the question and personal or political opinions of the respondent. ${ }^{40}$ 
Spatial variability - uncertainty arising from the use of a value in a geographical region other than its intended region of validity. Here two sub-types can be distinguished: the adaptation of a value to different scales (e.g. the application of a national value to a single city), and the application of a value to a different region (eg the application of one city's value in another city).

Temporal variability - uncertainty arising from the use of a value for a time period other than its intended period of validity (e.g. using values from previous years as an estimate for the year of interest).

Model uncertainty - the accuracy of the results often relies on assumptions made during formulation of the model. For instance, it might be assumed that the consumption of two products are correlated. If a modelled relationship is taken to be true, either by assumption or because it is well known, but it is only expected to hold approximately (as with the consumption example for some products), then the uncertainty of this approximation can be estimated and taken into account probabilistically. Uncertainty introduced by erroneous model structure, however, cannot be quantitatively accounted for. Any assumptions that might introduce such errors should ideally be avoided, or otherwise be explicitly acknowledged so that their plausibility and applicability may be evaluated.

Uncertain independence - Where two data sources are not independent, the apparent uncertainty will be lower than the true uncertainty. This can be avoided through careful consideration of references and sources.

\subsubsection{Quantifying uncertainty}

In Section 2.2.5 several approaches to handling uncertainty were described. For this work, Monte Carlo simulation was selected. The objections to its use - that input distributions are not well known and that some uncertainties are not necessarily probabilistic - did not outweigh its advantages over other methods. It was accepted that the use of non-sampled data (expert judgements or single data points, for example) must always involve some subjective judgement of uncertainty. For Monte Carlo simulation the assignment of input parameter distributions is the stage of subjective judgment, and imprecision introduced here is really an inevitable consequence of insufficiently sampled data rather than of the method itself. However imprecise, the assignment of input distributions allows full use of all available information provided that the distributions reflect no more confidence than the information allows. This approach contains all subjective judgement within the single process of distribution assignment, so that if proper explanation of this step is provided then the method will be transparent. The second concern is perhaps valid for certain circumstances, such as once-off future events, but probability has proven a good model for uncertainty of many unknown values of the past and present. In this research all quantities that were considered probabilistically were exactly defined but imprecisely known - they would have passed the clarity test (Section 2.2.5) - and although sampling schemes for some of these might be difficult to conceive, the concept of probability distributions as knowledge representations was applicable.

In order to maintain the advantage of flexibility, no standardized procedure was enforced upon the assignment of input distributions. However, in practice only three forms of distribution were applied - normal, log-normal and uniform (Figure 3.2). 


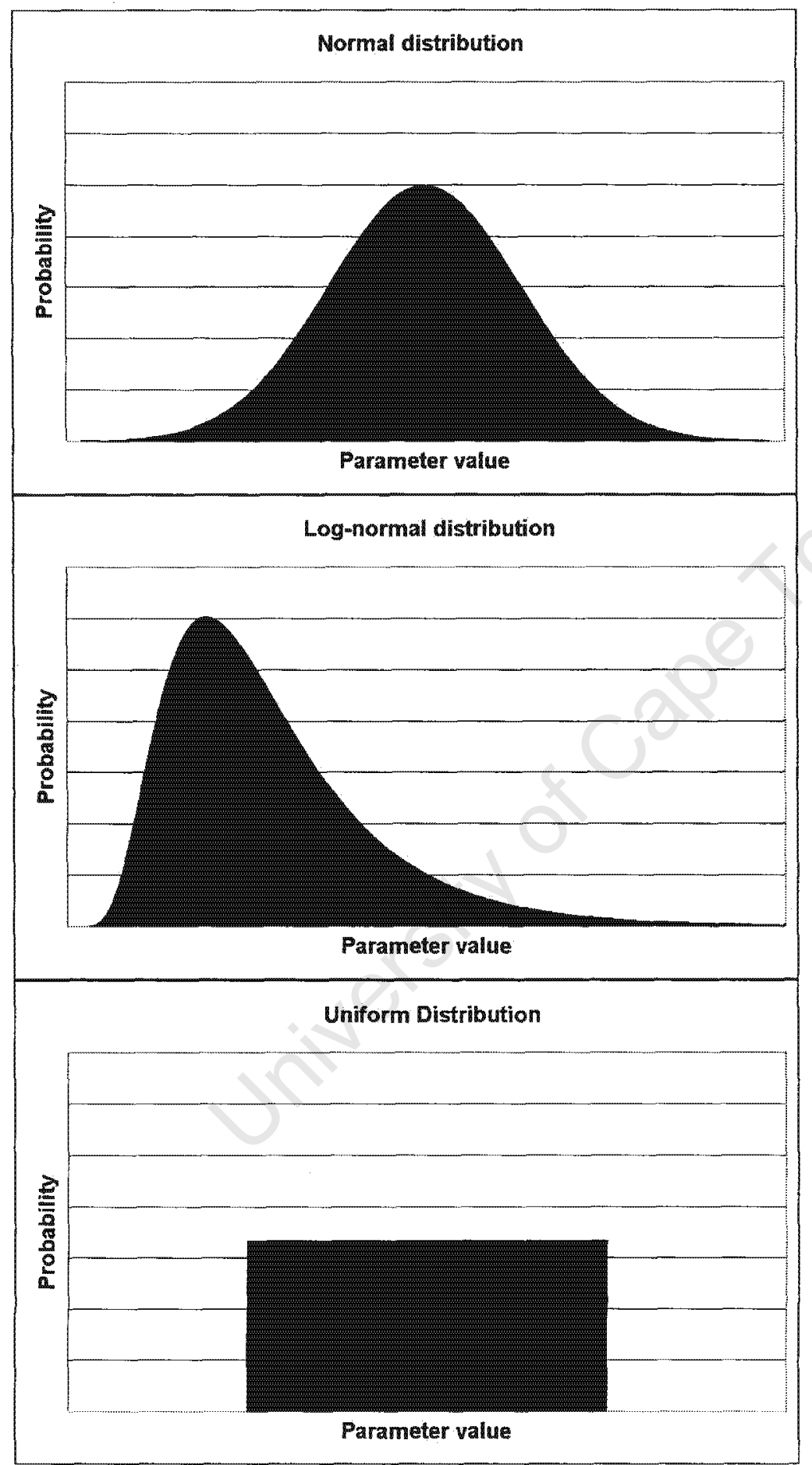

Figure 3.2: Three distribution types used to represent uncertainty in input parameters. 
In the majority of cases the input parameters were assigned normal distributions. The normal distribution was selected as it provided for a symmetrical spread of possible values with greatest probability near the midpoint of the distribution, in agreement with the perceived uncertainty of most parameters. Uniform distributions were used where there was an explicit lack of preference for any values within the range, and log-normal distributions in cases where positively skewed uncertainty was present, or to prevent anomalous negative values. The parameters of the distributions that determine their location and spread were estimated in various ways, and are more fully discussed with the relevant results in Chapter 4.

The Monte Carlo simulation model was built in Python 3.1, an open-source programming language with a range of statistical functions included in its standard libraries including random sampling capabilities for various distribution types based on the Mersenne Twister pseudo-random number generator. ${ }^{134}$ The model was built and run in Microsoft Windows XP Pro operating system, and its functionality was checked for agreement with random distributions calculated in Microsoft Excel using relatively small numbers of inputs and simple calculations. Simulations were carried out for 50,000 iterations. This was undoubtedly excessive, but the high computing speed achieved by the built-for-purpose simulation allowed this level of sampling with virtually no additional cost in computing time. For instance, the number of iterations, $m$, required to provide $95 \%$ confidence that the true percentile falls between $p-\Delta p$ and $p+\Delta p$, where $p$ is the percentile and $\Delta p$ is the confidence range in terms of percentiles, is given by ${ }^{46}$

$m=p(1-p)\left(\frac{1.96}{\Delta p}\right)^{2}$

Thus $95 \%$ confidence that the true percentile lies between the estimates for its two neighbouring percentiles $(\Delta p=0.01$ ) requires, for example, 1825 iterations for the 95 percentile $(p=0.95)$, and 9604 iterations for the median $(p=0.5)$. This is independent of the shape of the output distribution. ${ }^{46}$ After the simulation model had been constructed, it was found that the 2.5 and 97.5 percentiles, means and medians of 5 replicate simulation runs showed disagreement near $1 \%$ or lower. This extensive sampling also made more specialized sampling schemes unnecessary, and simple random sampling of the input distributions was used. The $2.5-97.5$ interpercentile range was used to characterize the uncertainty in the results, presented in the next chapter along with mean and median values. Appendix 3 provides a visual presentation of the main simulation outputs in the form of histograms.

\subsubsection{Uncertainty in predictions from regression}

In some cases $\mathrm{NiCd}$ cell masses were calculated from cell capacities using a least-squares linear regression line derived from manufacturer specifications (see Section 4.2.1). If the capacity was uncertain this could be incorporated into the mass estimate's uncertainty through Monte Carlo simulation. However, the prediction of mass from a linear regression model involves additional uncertainty arising from the imprecision of the model relationship, so that even when the capacity is known exactly (as in the case of electrical distribution, Section 4.3.2) the cell mass is not. Because the predicted masses were always applied to large 
numbers of cells, the relevant uncertainty was that of the mean mass, $\mathrm{E}(y)$. The confidence bounds for the mean mass based on a mass $\hat{y}$ predicted for a cell capacity $C$ are given by: ${ }^{135}$

$\hat{y} \pm t_{\alpha / 2} s_{\varepsilon} \sqrt{\frac{1}{n}+\frac{(C-\bar{x})^{2}}{S_{x x}}}$

where

$s_{\varepsilon}=\sqrt{\frac{\sum_{i}\left(y_{i}-\hat{y}\right)^{2}}{n-2}}$

and

$S_{x x}=\sum_{i}\left(x_{i}-\bar{x}\right)^{2}$

Here $t_{\alpha / 2}$ is the $t$-statistic based on $n-2$ degrees of freedom and significance level $\alpha$, with $n$ the regression sample size, $\left(x_{i}, y_{i}\right)$ are the points from which the regression model was derived, and $\bar{x}$ and $\bar{y}$ the corresponding mean capacity and mass values, respectively. For Monte Carlo simulation the probability distribution of the mean mass was approximated as normal, with a $95 \%$ confidence interval as calculated by Equation 3.1 defining two standard deviations from the mean. The degrees of freedom were 83 , at which the normal distribution closely approximates the $t$-distribution. Where cell capacity was uncertain (as for miscellaneous large cell applications, Section 4.3.3), a two-tiered sampling approach was applied which randomly selected a capacity value at each iteration, used this to calculate the parameters of the cell mass' probability distribution, and finally used these parameters to generate a random value from this distribution.

\subsubsection{Illustration and Interpretation}

The mean values of the SFA results from Monte Carlo simulation were used to construct the flow diagram given at the end of the Chapter 4 (Figure 4.6), and the 2.5-97.5 interpercentile ranges, means and median values for the key results are shown there in Table 4.37. The distributions of the Monte Carlo outputs are illustrated in Appendix 3. In addition to these flows, the functional recycling rate of cadmium in NiCd cells was calculated. Because the flows to landfill are not expected to be emitted to the environment in the immediate future, neither risk ratio nor transition period (Section 2.2.3) provide suitable indicators of the environmental significance if assessed under present conditions. An alternative assessment methodology was developed by which to assess its significance, as described in Section 3.3 and applied in Chapter 5. 


\section{ENVIRONMENTAL SIGNIFICANCE OF CADMIUM DISPOSAL}

The previous section described the substance flow accounting approach taken to estimate the cadmium flows in the city associated with NiCd batteries, including those to municipal solid waste. It was also necessary to ask whether or not the amounts of cadmium involved were "environmentally significant", in the sense of being sufficiently large to warrant concern and caution, or were in fact negligible from an environmental perspective. The amount of cadmium sent to landfill places a limit on the extent of possible impacts that this disposal could cause. It would be foolish to expend further effort researching or reducing these impacts if this limit was acceptably low. At present, cadmium sent to municipal landfills is not emitted into the environment to any appreciable extent, so evaluating most established indicators (Section 2.2.3) under present conditions would show only minor risks. However, this does not account for longer-term changes in the landfill environment or changes in waste management practice which might result in substantial cadmium release. Current understanding of landfill processes is not sufficiently advanced to provide reliable predictions of these effects. The assessment of environmental significance was therefore limited to determining whether there is a need to either avoid or to better quantify the risks of cadmium disposal with MSW.

\subsection{1}

\section{Assessment framework}

As has been noted in Section 2.5.2, landfills are not isolated from the environment but generate both gaseous and liquid releases. At properly managed sanitary landfills, the leachate is not released into the environment but rather collected and suitably treated. The majority of leachate from operating landfills in Cape Town is sent to wastewater treatment works (WWTWs) which also receive municipal sewerage and non-hazardous industrial wastewater. The treatment works produce sludge and final effluent. At present, the sludge is usually within the guideline metal limits for agricultural application, ${ }^{136,137}$ and is composted, pelletized or applied directly to agricultural land with excess material being stockpiled at some of the facilities. Final effluent, the treated water with some suspended sludge material, is generally released into the environment, although a small proportion is used for irrigation and some by industry ${ }^{*}$. This system is depicted in Figure 3.3.

\footnotetext{
* According to city data from 2005 , this amounted to $30.8 \mathrm{ML} /$ day, or just under $6 \%$ of the effluent production as calculated here. Most of this was utilized for irrigation, but golf courses rather than agriculture were the dominant users. ${ }^{138,139}$
} 


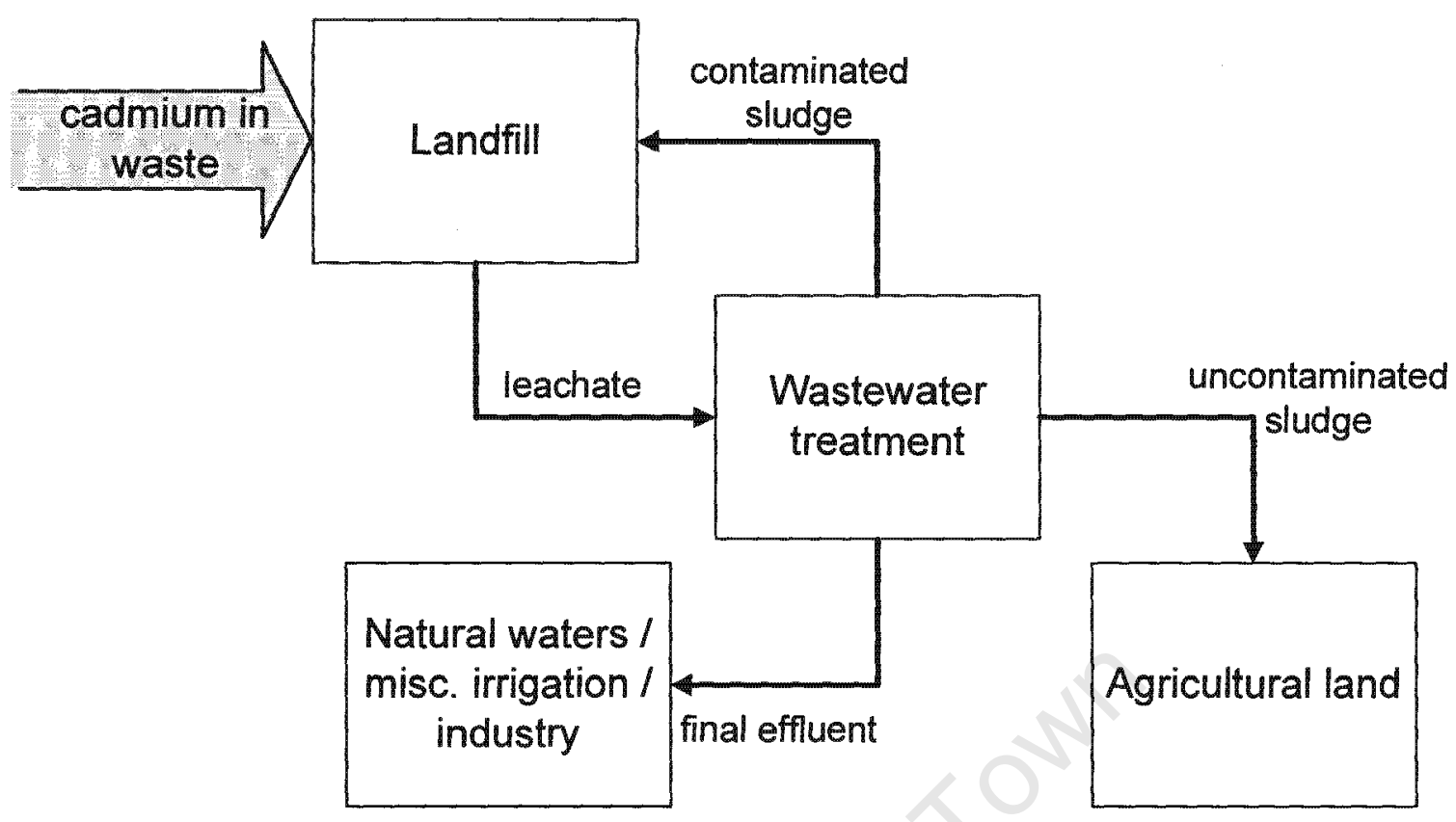

Figure 3.3: Interrelationship between landfill, wastewater and agricultural systems under current conditions.

At present there is no significant migration of cadmium from landfills to agricultural land or natural waters, but the connection to agriculture could lead to human exposure should landfill cadmium retention be compromised. Controls are currently in place to prevent this, but the possibility makes agricultural land an appropriate receptor against which to measure contamination potential, especially in light of the importance of food contamination as a pathway for human cadmium exposure (Section 2.5.1).

The assessment of environmental significance was undertaken by developing two "best worst-case" scenarios. Because the intention was an assessment of the total disposed cadmium and no reliable method is available to predict emissions, a steady state view was taken of the city's landfills in 2005 . This implied a hypothetical worst-case situation in which all NiCd-associated cadmium in MSW was immediately released in leachate and flowed to wastewater treatment. From this basis, best-case calculations were undertaken to calculate the minimum impacts such a release would have on agricultural soils. This approach was chosen in order to reach a most optimistic measure of environmental significance, so that an actionable result would not be weakened by uncertainties in the data. In the first scenario, all released cadmium was assumed to go to agricultural soil, providing the most direct measure of contamination potential. In the second scenario the cadmium was assumed to distribute between sludge and effluent releases in proportion to the 2005 distribution of background cadmium through the wastewater treatment system.

In both cases background flows and soil cadmium content were taken into account on the basis of 2005 estimates. Phosphate fertilizer use and wastewater treatment sludge were selected as most likely background sources on the basis of international experience (Section 2.5.3). Potential contamination from animal manure was considered, but found to be minor. It was omitted from the calculations because it was unclear to what extent the cadmium it 
carried was from anthropogenic sources, and able to increase average soil concentrations (see discussion of Kwonpongsagoon's work in Section 2.3.1).

Atmospheric deposition of cadmium onto agricultural soil was not considered because the major sources of atmospheric cadmium (Section 2.5.4) are largely absent from Cape Town. The city has a single secondary ferrous metal smelter which operates a modern electric-arc furnace, and a single oil refinery. The average air emission of cadmium for an oil refinery in Australia was only $21 \mathrm{~kg}$ in $1998 / 9,{ }^{20}$ only a part of which would have settled onto agricultural land. The single refinery in Cape Town was therefore considered a negligible source of cadmium to agricultural soil. No non-ferrous metal smelting, primary smelting or coal-fired electricity generation takes place in the city. Cape Town is faced by ocean on two sides and no heavy industries operate close to its landward edge, so deposition from other areas would also be negligible.

\subsubsection{Assessment indicators}

The assessment of the two scenarios described above was made on the basis of cadmium contamination per year, on a dry-weight ppm per hectare basis, and as transition periods required to reach $2 \mathrm{ppm}$. This is the limit for soils receiving wastewater treatment sludge given by official sludge-use guidelines. ${ }^{136}$ To the author's knowledge, this is the only regulated limit for cadmium content of agricultural soils in South Africa, and was taken to represent a safe upper limit for the cultivation of food crops.

Results from the assessment of environmental significance are presented in Chapter 5, building on the SFA results presented next in Chapter 4. 


\section{CHAPTER 4: SFA RESULTS}

\subsection{INTRODUCTION}

As described in Section 3.2, the quantification of relevant cadmium flows proceeded iteratively between information gathering, data collection, calculation and refinement. This chapter details the outcome of this process. Section 4.2 details the estimation of two general NiCd cell parameters, mass and cadmium content, which are applied in the subsequent quantifications. Thereafter, each subsection of Section 4.3 describes the data, calculation methods and results for a category of NiCd use. In each quantitative case, a table of parameters is provided showing the random variable inputs for Monte Carlo simulation of the flow in question. The simulation was constructed as a single model (see Appendix 4) and in some cases the results from one section were also inputs for another calculation. These are noted in the text but, being results, are not included in the input parameter tables for subsequent calculations. Results of the Monte Carlo simulation are provided as $2.5-97.5$ interpercentile ranges, means and median values, with all values rounded to two significant figures. This rounding approach was arbitrary, and the interpercentile ranges should be consulted to assess the uncertainty in the results. Finally, in Section 4.4 , key results are collated, the overall simulation results given and some of the immediate conclusions are discussed.

The Monte Carlo simulation was conducted for 50,000 iterations. Repeated simulation yielded results that varied in the order of $1 \%$ or less, which was negligible at this study's level of precision.

\subsubsection{Mean NiCd Cell Mass}

The mean mass of small sealed NiCd cells was estimated through a combination of literature values and direct sampling from two waste sources. The literature sources are summarized in Table 4.1.

Unfortunately the original sources for many of these values were unavailable, and no attempt had been made to adjust the mean mass values by sales volumes aside from making assumptions regarding the most common cell sizes. This risks distortion of the mean, exemplified in the mean value from Wilburn (2007), by cells which are available on the market but represent only a small proportion of sales. The Saft VRE range features some very high capacity (and hence high mass) cells for specialist applications (satellite use, for instance), which should certainly not receive equal weighting in the mean. In order to supplement this data, spent rechargeable cells collected at an e-waste recycling facility and a 


\begin{tabular}{|c|c|c|}
\hline Source & Description & Mean mass (g) \\
\hline Saft Batteries 2008 [140] & $\begin{array}{l}\text { low estimate: mean of AA cell } \\
\text { specs; high estimate: mean of } \\
\text { sub-C specs }\end{array}$ & $24-47$ \\
\hline $\begin{array}{l}\text { Sanyo Batteries } 2009 \\
\text { http://us.sanyo.com }\end{array}$ & $\begin{array}{l}\text { low estimate: mean of AA cell } \\
\text { specs; high estimate: mean of } \\
\text { sub-C specs }\end{array}$ & $24-48$ \\
\hline Wilburn 2007 [80] & $\begin{array}{l}\text { sealed consumer cells (Saft VRE } \\
\text { range) } \\
\text { power tool cells (Saft VRE-C) }\end{array}$ & $\begin{array}{c}19-150 \text { (average 60) } \\
43\end{array}$ \\
\hline Rydh and Svärd 2003 [79] & low: AA cell, high: sub-C cell & $25-45$ \\
\hline Rydh and Kariström 2002 [141] & $\begin{array}{l}\text { low: AA cell; high: sub-C cell (AA } \\
\text { and sub-C considered most } \\
\text { common sizes) }\end{array}$ & $22-50$ \\
\hline RIS International 2007 [77] & $\begin{array}{l}\text { AA } \\
C \\
C\end{array}$ & $\begin{array}{c}16.5 \\
54.5 \\
22 \\
75\end{array}$ \\
\hline
\end{tabular}

company involved in battery repacking in Cape Town were sampled. The sizes of all rechargeable cells were recorded (640 cells in total), and a selection of those marked as NiCd were weighed ( 54 cells). Cells from powertools were identifiable by pack shape, construction and use of sub-C cells, and were recorded separately. It was assumed that the weighed cells were representative of $\mathrm{NiCd}$ cells of that size, and that $\mathrm{NiCd}$ cells follow the same size distribution as all cells taken together. On this basis a weighted mean mass of NiCd cells was calculated using the measured masses and the size distribution in the entire sample. This provided a mean sub-C cell mass of $42 \mathrm{~g}$, and a non-powertool mean cell mass of $31 \mathrm{~g}$. The results supported the general assumptions of cell sizes seen in the literature, with $86 \%$ of all cells, and $72 \%$ of non-tool cells falling between AA and sub-C sizes. The complete data set is provided in Appendix 5. Despite the advantages of local sampling, these mean masses were not given absolute preference over the literature values and all sources were taken into account when selecting the parameter values given in Table 4.2. This was due to representivity concerns, particularly as the weight sample included a limited number of manufacturing brands, and that sampling from a battery repacking company fails to account for potentially different rates of repacking for different products. However, the results do support the selected parameter values.

The vast majority of powertool ${ }^{142}$ and emergency lighting ${ }^{143}$ applications use sub-C cells, so the mean sub-C cell mass was separately estimated and applied to these products. 


\begin{tabular}{|l|c|c|c|}
\hline Table 4.2: Mean cell masses for small NiCd cells & \\
\hline \multicolumn{1}{|c|}{ Parameter } & Mean Value & Uncertainty estimate & Distribution \\
\hline Sub-C mean mass $(\mathrm{g})$ & 43 & $+/-2$ standard deviations $\equiv 36-50$ & Normal \\
Non-powertool mean mass $(\mathrm{g})$ & 32 & $+/-2$ standard deviations $\equiv 21-43$ & Normal \\
\hline
\end{tabular}

*including non-powertool sub-C cells

In some cases the mass of large NiCd cells was available from expert knowledge or manufacturer specifications. In other cases, it was estimated from the capacity of the cells. According to electrochemical principles, the capacity of a $\mathrm{NiCd}$ cell is proportional to the mass of active electrode material it contains and, since this should be related at least approximately to the other materials, it was expected that a linear relationship would exist between capacity and cell mass. A selection of large NiCd cell specifications from four different manufacturers are displayed in Figure 4.1, showing the expected proportionality.

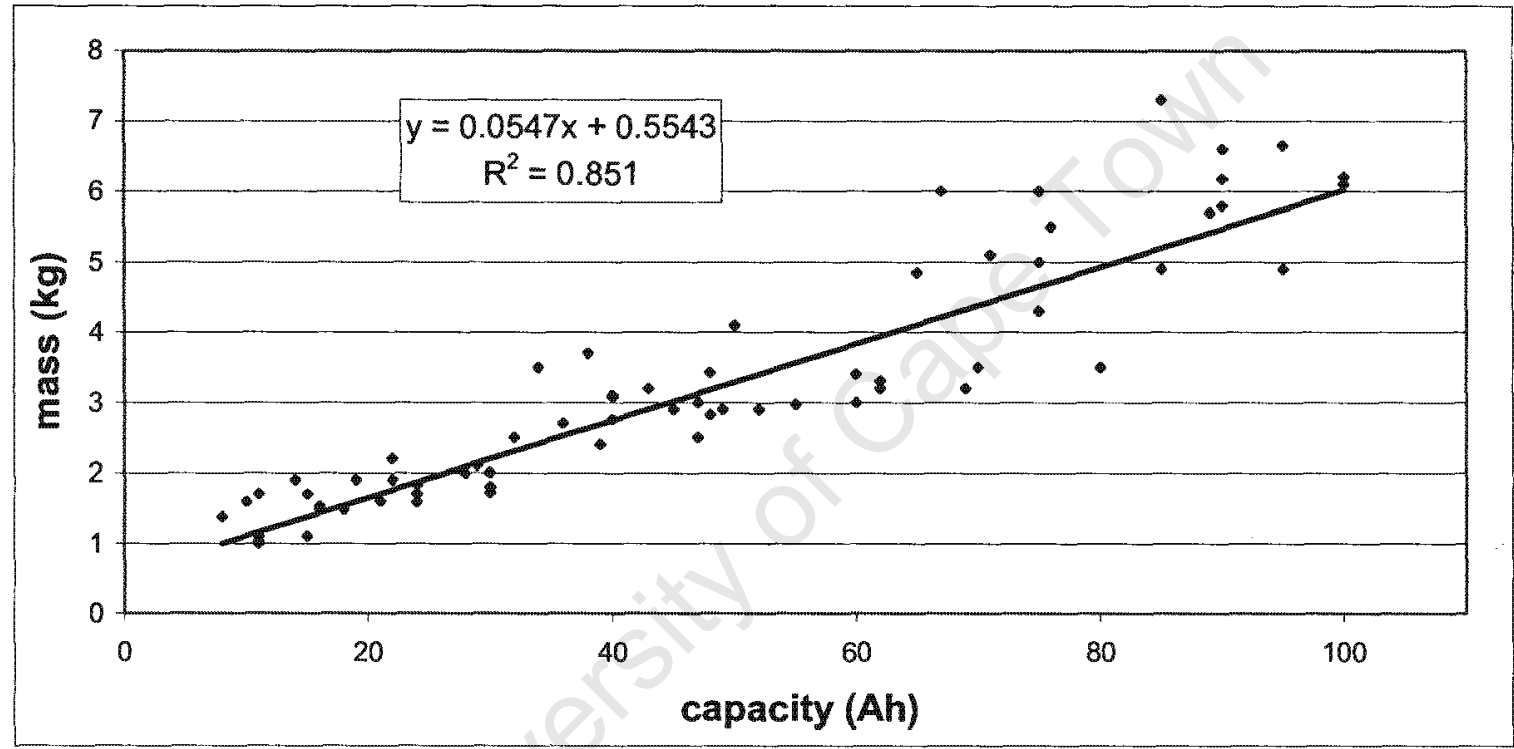

Figure 4.1: Relation between large NiCd cell capacity and mass. Sources: Alcad (www.alcad.com), Saft (www.saft.com), Emisa (www.emisa.es), GAZ (www.gaz-gmbh.com).

The least-squares relation was applied in cases where the mean capacity of large cells could be better estimated than their mass, with the associated uncertainty calculated as discussed in Section 3.2.3.3.

\subsubsection{Mean Cadmium Content}

Manufacturers do not generally publicize precise figures for the cadmium content of their cells, although broad ranges might be provided in product MSDS information. A number of literature values for the mean cadmium content of small sealed NiCd cells have been summarized in Table 4.3. Again, very few of the original data sources were available and their uncertainty was not often addressed. They were nevertheless in agreement with each other and with manufacturers' reported ranges. On the basis of these figures, the average cadmium content of consumer and part-of-product NiCd cells was taken to be $11-19 \%$ by weight. 


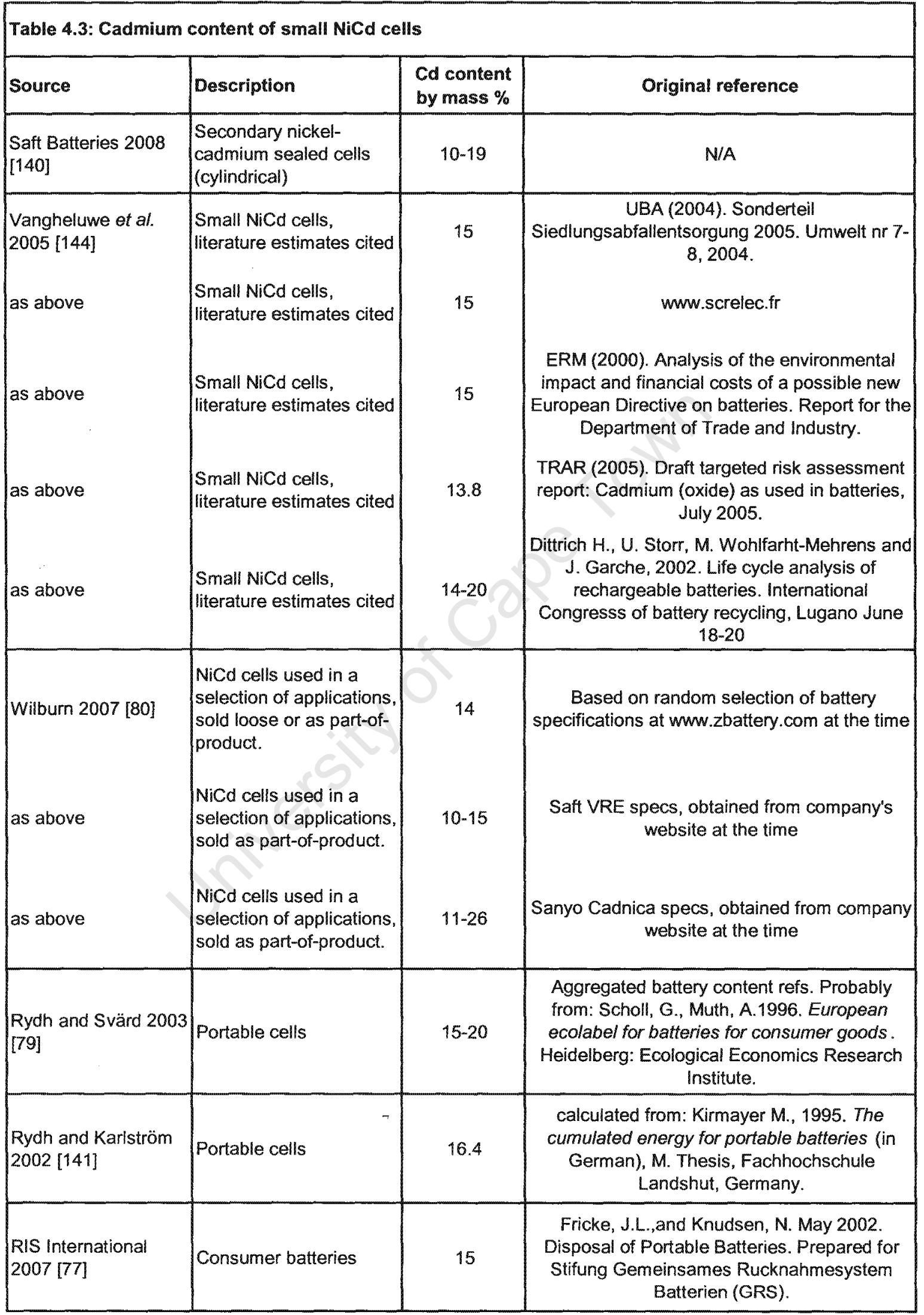


Large NiCd cells are generally held to contain a lower proportion of cadmium by mass (Table 4.4). Their average $\mathrm{Cd}$ content was estimated to be $5-12 \%$.

\begin{tabular}{|l|c|c|}
\hline Table 4.4: Cadmium content of large NiCd cells & \\
\hline Source & $\begin{array}{c}\text { Cd content by } \\
\text { mass } \%\end{array}$ & Original source \\
\hline Wilburn 2007 [80] & 8 & Manufacturer specifications \\
\hline Plachy 2003 [145] & 9 & not provided \\
\hline Saft Batteries 2008 [140] & $3-14$ & Maxima of Cd \% ranges from MSDS of various models \\
\hline HBL 2009 [146] & $3-10$ & MSDS for industrial battery range \\
\hline
\end{tabular}

The cadmium content parameters are summarized in Table 4.5 .

\begin{tabular}{|l|c|c|c|}
\hline \multicolumn{1}{|c|}{ Table 4.5: Mean cadmium content of NiCd cells } \\
\hline \multicolumn{1}{|c|}{ Parameter } & Mean Value & Uncertainty estimate & Distribution \\
\hline $\begin{array}{l}\text { Mean small cell Cd } \\
\text { mass percent }\end{array}$ & $15 \%$ & $+/-2$ standard deviations $\equiv 11-19 \%$ & Normal \\
$\begin{array}{l}\text { Mean large cell Cd } \\
\text { mass percent }\end{array}$ & $8.5 \%$ & $+/-2$ standard deviations $\equiv 5-12 \%$ & Normal \\
\hline
\end{tabular}

\subsection{DETAILED RESULTS}

\subsubsection{Aviation batteries}

Large $\mathrm{NiCd}$ batteries are used in aviation for starter power, although $\mathrm{Pb}$-acid batteries are also used for this purpose. All new aircraft are fitted with $\mathrm{NiCd}$ batteries in manufacture, ${ }^{147,148}$ but when these require replacement some owners prefer the cheaper $\mathrm{Pb}$ acid alternative. The prevalence of $\mathrm{NiCd}$ battery use varies with aircraft size, with two detailed industry estimates given, ${ }^{149,150}$ and other sources corroborating the general trend. ${ }^{147,151}$

\begin{tabular}{|c|c|c|}
\hline Table 4.6: Ratio of NiCd to Pb-acid battery use in aircraft \\
\hline Aircraft mass (tons) & \multicolumn{2}{|c|}{ NiCd : Pb-acid ratio } \\
\hline & Source $\mathrm{A}^{149}$ & Source $^{150}$ \\
$<5.7$ & $20: 80$ & $5: 95$ \\
$5.7-20$ & $60: 40$ to $50: 50$ & $80: 20$ \\
$>20$ & $\sim 100: 0$ & $\sim 100: 0$ \\
\hline
\end{tabular}


Aircraft batteries are of $24 \mathrm{~V}^{*}$ nominal voltage, ${ }^{147,148}$ and hence consist of 20 individual cells. ${ }^{150}$ Battery mass does not vary significantly with aircraft size, with the mean estimated to lie between 35 and $55 \mathrm{~kg}$. ${ }^{147,148,149,150}$ Mean battery lifetime was estimated to be $10-15$ years. ${ }^{147,148,149}$

Data from the Civil Aviation Authority (CAA), which maintains the South African aircraft registry, were used to estimate cadmium flows associated with these batteries for South Africa (Table 4.7).

\begin{tabular}{|l|r|r|r|r|r|r|}
\hline Table 4.7: Aircraft registration data for South Africa & \\
\hline \multicolumn{5}{|c|}{ No. } \\
\hline Aircraft mass (tons) & 1990 & 1991 & 1992 & 1993 & 1994 & 2005 \\
\hline$<5.7$ & 360 & 301 & 228 & 195 & 243 & 559 \\
$5.7-20$ & 3 & 4 & 11 & 6 & 10 & 25 \\
$>20$ & 1 & 2 & 2 & 4 & 4 & 36 \\
\hline
\end{tabular}

The inflow due to new aircraft was calculated on the basis of new aircraft registrations in 2005. The in- and outflows arising from old battery replacement were calculated using a simple aging model. The true lifetime distribution for aviation batteries was not known, but normal distributions have been found to adequately describe lifetimes of some appliances and vehicles, ${ }^{153}$ and were expected to provide sufficient accuracy. New registrations between 1990 and 1994 (inclusive) were assumed to have normally distributed lifetimes about a mean of 12.5 years, with 10 and 15 years both lying two standard deviations from this mean in line with most industry estimates. ${ }^{147,148,149}$ Although the CAA does not provide records predating 1990, years outside the 1990-1995 range would only have contributed a small number to the overall replacements of 2005 according to this model. For comparison, the years from 1995 onward would have made a relative contribution of under $3 \%$. The model also assumed that $\mathrm{NiCd}$ installations are only done to replace NiCd batteries - that is, that once an aircraft's original NiCd battery is replaced with a lead-acid battery it will not carry a NiCd battery again. Battery replacement predicted by this model was assigned a $5 \%$ relative standard deviation to provide $95 \%$ confidence bounds of $+/-10 \%$. The chemistry of replacement cells was assigned according to the distribution by weight class given in Table 4.8 , which uses the average of the proportions presented in Table $4.6^{\dagger}$. Due to the discrepancies between the two sets of expert estimates, each estimate was taken to be one standard deviation from the mean (either of the parameter distribution or underlying normal distribution) so that both estimates were comfortably within the range of uncertainty. The characteristics of large cells presented above were used to calculate the kilograms of cadmium associated with the total battery mass. Details of parameter distributions and uncertainty estimates are given in Table 4.9.

\begin{tabular}{|c|c|}
\hline Table 4.8: Average ratios used for NiCd to Pb-acid use in aircraft \\
\hline Aircraft mass (tons) & NiCd : Pb-acid ratio \\
\hline$<5.7$ & $12.5: 87.5$ \\
$5.7-20^{\dagger}$ & $65: 35$ \\
$>20$ & $-100: 0$ \\
\hline
\end{tabular}

\footnotetext{
* Two respondents stated this as $28 \mathrm{~V}$, which does not correspond to an integral number of $1.2 \mathrm{~V}$ cells. This was attributed to the fact that fully charged NiCd cells have an open-circuit voltage somewhat above $1.2 \mathrm{~V}$.

t The most divergent values were used for the 5.7-20 ton category, ie. 50:50 and 80:20.
} 


\begin{tabular}{|c|c|c|c|}
\hline Parameter & Mean Value & Uncertainty estimate & Distribution \\
\hline Battery lifetime (years) & 12.5 & $+/-2$ standard deviations $\equiv 10-15$ years & Normal \\
\hline NiCd use $\%,<5.7$ ton & 12.7 & $+/-1$ underlying standard deviation $\equiv 5-20 \%$ & Lognormal $^{s}$ \\
\hline NiCd use $\%, 5.7-20$ ton & 65 & $+/-1$ standard deviation $\equiv 50-80 \%$ & Normal \\
\hline NiCd use $\%,>20$ ton & 100 & 0 & Exact \\
\hline Battery mass (kg) & 45 & $+/-2$ standard deviations $\equiv 35-55 \mathrm{~kg}$ & Normal \\
\hline Battery replacements & $\begin{array}{l}\text { derived for each } \\
\text { weight class as } \\
\text { described above }\end{array}$ & $\mathrm{RSD}=5 \%$ & Normal \\
\hline $\begin{array}{l}\text { Mean large cell Cd } \\
\text { mass } \%\end{array}$ & 8.5 & $+/-2$ standard deviations $\equiv 5-12 \%$ & Normal \\
\hline Population scaling factor & 0.07 & $\mathrm{RSD}=2.5 \%$ & Normal \\
\hline
\end{tabular}

\# Used for derivation of battery replacement, but not an input parameter for Monte Carlo simulation

$\$$ A lognormal distribution was assigned to prevent negative percentage values.

There is a tendency for battery servicing, and hence replacement of faulty cells, to take place at the aviation hubs in Johannesburg and Pretoria. ${ }^{148,149,150,151}$ It is expected that few NiCd batteries would be taken out of service in Cape Town, since there is no battery workshop operating in the city. ${ }^{150}$ Given the mobility of aircraft, and that the CAA does not attribute a specific location to registered aircraft, the national figures for battery use derived above were scaled to Cape Town on a population basis, effectively attributing an equal responsibility for aviation cadmium flows to each South African resident. Because this scaling was merely attributional it was not subject to spatial variation. As such, the scaling factor was assigned a low level of uncertainty, which only reflected uncertainty in the underlying population data.

These calculations yielded the results presented in Table 4.10.

\begin{tabular}{|l|c|c|c|c|}
\hline \multicolumn{5}{|c|}{ Table 4.10: Cape Town-attributed cadmium flows arising from aviation batteries (kg Cd) } \\
\hline & 2.5 percentile & 97.5 percentile & mean & median \\
\hline Cadmium inflow & 99 & 260 & 180 & 170 \\
Cadmium outflow & 38 & 100 & 67 & 66 \\
\hline
\end{tabular}

One respondent stated that, in his experience, the usual practice for spent aviation batteries was to store them indefinitely in order to avoid the costs of disposal. ${ }^{148}$ This seemed plausible in the light of other responses ${ }^{149,151}$ which were unclear about disposal practices and mentioned ad-hoc uses being found for old batteries, which suggested that no defined disposal practices were in place and that they were generally remaining at workshops after removal. On the other hand, one company had a contractor to remove spent cells and provide certified disposal. ${ }^{150}$ Another respondent who specializes in aviation batteries also contracts a waste disposal firm, but reported that he seldom is asked to dispose of clients' spent batteries, ${ }^{147}$ although another respondent claimed that he sent these there. ${ }^{149}$ It appeared that no standard disposal practice for spent cells is established in the aviation industry and whilst some companies are ensuring safe disposal, others are opting for indefinite storage in order to avoid disposal costs. 
A major application of large NiCd cells is in electricity distribution substations, ${ }^{154,155,156,157}$ where NiCd batteries are used as back-up power for switching gear. This allows remote management of circuits when the substation is disconnected from the grid, for instance during a power outage or when a fault has been detected. ${ }^{156,158} \mathrm{NiCd}$ batteries are installed in the distribution system, whilst lead-acid battery banks are used in the high-voltage $(>11 \mathrm{kV})$ bulk supply systems. ${ }^{159,160}$ Hence only electrical distribution, and not the bulk supply system, contributes to cadmium flow in the city. Distribution is managed in the city by Eskom Distribution in some areas, and the City of Cape Town municipality in others.

The distribution system has two tiers of substations, the so-called 'step-down' substations ${ }^{160}$ which reduce bulk electricity supply voltage for smaller-scale distribution, and lower-voltage substations that further distribute this power and reduce its voltage to the end-user supply level. Different equipment standards apply to each. In the areas falling under Eskom Distribution, none of the step-down substation batteries were replaced in 2005, and $15-20$ batteries were replaced among the approximately 90 lower-voltage substations. The batteries were all $36 \mathrm{~V}$, with 32 Ah Saft Vantage cells. ${ }^{160}$ The 77 step-down substations in areas under municipal management saw installation of eight $110 \mathrm{~V}$ batteries to replace six $110 \mathrm{~V}$ batteries and two $30 \mathrm{~V}$ batteries in 2005 , all $29 \mathrm{Ah}^{159}$ The lower-voltage division oversees an estimated $900-1100$ lower-voltage substations. This division's records showed that 400 $29 \mathrm{Ah}$ cells and $18511 \mathrm{Ah}^{\mathrm{h}}$ cells ${ }^{161}$ were installed in 2005 , but it was not possible to determine how many were replacements and how many were installed in newly commissioned substations. It also seemed that an unusually small number of cells were installed by this division in 2005. The annual averages for 2005-8 were $125629 \mathrm{Ah}$ cells, and $65311 \mathrm{Ah}$ cells, with no apparent upward trend. As data was only available for these four years it was not possible to unambiguously identify 2005 as an outlier, and it was nevertheless accurate for the year under investigation. The average figures were, however, used when other values were calculated from the results (see Sections 4.3 .3 and 4.3 .8 below). The specifications of the batteries were determined by the City's standards, and therefore applied to all installations. However, batteries are purchased by tender, and hence makes and models varied and could not be readily determined from City records. ${ }^{159}$

The amount of cadmium associated with these installations was calculated as:

$$
\underset{\text { flow }}{\text { Cd mass }}=\left(\sum_{\substack{\text { battery } \\
\text { types }}}\left[\left(\begin{array}{l}
\text { batteries } \\
\text { replaced }
\end{array}\right)\left(\frac{\text { voltage }}{1.2 V / \text { cell }}\right)\left(\begin{array}{c}
\text { cell } \\
\text { mass }
\end{array}\right)\right]\right)\left(\begin{array}{c}
\text { Cd mass } \\
\text { proportion }
\end{array}\right)
$$

The mass of Eskom cells was obtained from manufacturer specifications ${ }^{140}$ as $2.50 \mathrm{~kg}$. The mass of cells replaced in municipal substations was estimated from their capacities, as described in Section 4.2.1.

Eskom has an arrangement with their battery suppliers to accept spent NiCd cells, which are then exported for certified recycling. ${ }^{160}$ They have a reputation for maintaining a $100 \%$ rate 
of return for recycling. ${ }^{156}$ Disposal of spent NiCd cells is not the responsibility of the City of Cape Town electricity department themselves. ${ }^{159}$ They are sent to the municipal stores department from which a private scrap company accepts them as a special service included in its collection of lead-acid battery scrap. ${ }^{162,163}$ Both lead-acid and NiCd batteries are sent to Fry's Metals in Johannesburg, a secondary lead smelter. Fry's does not officially accept NiCd batteries and cannot recycle them. They are instead disposed of as hazardous waste in Johannesburg. Certification of safe disposal has been supplied to the City, ${ }^{163}$ and at times Fry's imposes a disposal charge on the scrap dealer who acts as middle-man. ${ }^{162}$

The input parameters for the calculations are given in Table 4.11 and the results summarized in Table 4.12. Only the battery waste arising from the step-down section was included in the disposal figure for 2005 , as the number of waste cells from the lower-voltage side was uncertain. The "excess inflow" figure in Table 4.12 therefore includes additional cadmium exported to hazardous waste landfilling, and growth in the substation cadmium stock in Cape Town.

\begin{tabular}{|c|c|c|c|}
\hline Parameter & $\begin{array}{l}\text { Mean } \\
\text { Value }\end{array}$ & Uncertainty estimate & Distribution \\
\hline Eskom $36 \mathrm{~V}$ battery replacements & 17.5 & $+/-2$ standard deviations $\equiv 15-20$ & Normal \\
\hline Eskom cell mass $(\mathrm{kg})$ & 2.50 & 0 & Exact \\
\hline CoCT step-down $30 \mathrm{~V}$ batteries & & & \\
\hline replaced & 2 & 0 & Exact \\
\hline CoCT step-down $110 \mathrm{~V}$ batteries & & & \\
\hline replaced & 6 & 0 & Exact \\
\hline CoCT 29 Ah cell movements & 400 & 0 & Exact \\
\hline CoCT 11 Ah cell movements & 185 & 0 & Exact \\
\hline Ave CoCT 29 Ah movement 2005-8 & 1256 & 0 & Exact \\
\hline Ave CoCT 11 Ah movement 2005-8 & 653 & 0 & Exact \\
\hline 11 Ah cell mass $(\mathrm{kg})$ & 1.16 & standard deviation $=0.0953$ & Normal \\
\hline 29 Ah cell mass $(\mathrm{kg})$ & 2.14 & standard deviation $=0.0493$ & Normal \\
\hline Mean large cell Cd mass percent & $8.5 \%$ & $+/-2$ standard deviations $\equiv 5-12 \%$ & Normal \\
\hline
\end{tabular}

\begin{tabular}{|l|c|c|c|c|}
\hline Table 4.12: Electrical distribution cadmium flows in Cape Town (kg Cd) \\
\hline & 2.5 percentile & 97.5 percentile & mean & median \\
\hline Total inflow & 200 & 480 & 340 & 330 \\
Outflow to recycling & 65 & 160 & 110 & 110 \\
Outflow to hazardous waste & 61 & 160 & 110 & 110 \\
Excess inflow & 51 & 140 & 91 & 90 \\
\hline
\end{tabular}

*If the average lower-voltage CoCT flows for 2005-8 are used instead, the total inflow would be $310-790 \mathrm{~kg}$ (mean 540 )

\subsubsection{Miscellaneous large cell applications}

There are a range of other possible applications for large NiCd cells, although those described above are the most commonly identified by literature and industry sources. These include diesel generator starting for emergency situations and backup power for process control in industrial systems. ${ }^{156,164}$ The variety of circumstances involved precluded the 
identification of specific applications. On the other hand, the diversity of possible battery supply channels, ranging from major battery suppliers through to direct importation by users, prevented quantification on the supply side. These other uses were therefore estimated relative to NiCd use in the electrical distribution system. This was done on the basis of semiquantitative expert judgements from which the share of miscellaneous $\mathrm{NiCd}$ applications in total non-aviation (ie. total miscellaneous and substation) applications was assigned a uniform distribution on the range $[0.05,0.4]$. Table 4.13 summarizes these sources.

\begin{tabular}{|c|c|}
\hline Comment & Source \\
\hline $\begin{array}{l}\text { Substation use is "the target market" for large NiCd } \\
\text { sales }\end{array}$ & 155 \\
\hline $\begin{array}{l}\text { "most" large NiCd cells are for substation applications. } \\
5 \% \text { of sales for diesel starting }\end{array}$ & 154 \\
\hline $\begin{array}{l}\text { In terms of applications, electrical distribution is "the big } \\
\text { one", but there are others too }\end{array}$ & 156 \\
\hline $\begin{array}{l}\text { "The majority" of South African large NiCd sales are for } \\
\text { substation use }\end{array}$ & 164 \\
\hline
\end{tabular}

Three sources provided information regarding the capacities of large cells in general. One said that cells of under $10 \mathrm{Ah}$ were never seen ${ }^{154}$, and that his company only carried stock of cells of up to $55 \mathrm{Ah}$. Cells of higher capacity were specially ordered from foreign manufacturers, with those of $200 \mathrm{Ah}$ and above fabricated on an order-by-order basis. This source said that cells of over $100 \mathrm{Ah}$ were very rare. Another respondent said that most sales lay between 29-250 Ah, while his company, a local assembler of large NiCd cells in South Africa, only assembles cells in the 10-60 Ah range and imports all higher-capacity cells preassembled. ${ }^{156} \mathrm{~A}$ third industry expert said that the majority of large cells in South Africa fall between 10 and $30 \mathrm{Ah}^{164}$ Based on this information, the mean capacity of large cells was assigned a $95 \%$ confidence interval of 20-80 Ah. This reflected the possibility that some unidentified applications called for significantly higher capacities, though this was considered unlikely to shift the mean above $80 \mathrm{Ah}$. However, it was considered more likely that the mean would lie at the lower end of this range, so the parameter was assigned a lognormal distribution to reflect this asymmetry. The cadmium flow arising from these miscellaneous applications was then calculated as:

$$
{ }_{\text {flow }}^{C d}=E\left(\frac{P}{1-P}\right) M C / 100
$$

where $E$ is the size of the electrical distribution market for large NiCd cells (in units, calculated using the four-year average of lower-voltage substation use described in Section 4.3.2), $P$ is the proportion of the non-aviation large NiCd market made up of miscellaneous applications, $M$ is the mean mass of the cells used in these applications, calculated from the estimated mean capacity on the basis of the linear relation given in Section 4.2.1, and $C$ is the mean mass percent of cadmium in large $\mathrm{NiCd}$ cells. The parameters used in this calculation are summarized in Table 4.14, and the results in Table 4.15. 


\begin{tabular}{|c|c|c|c|}
\hline Parameter & $\begin{array}{l}\text { Mean } \\
\text { Value }\end{array}$ & Uncertainty estimate & Distribution \\
\hline $\begin{array}{l}\text { Misc. cell share of total non- } \\
\text { aviation market }\end{array}$ & 0.225 & range $=[0.05,0.4]$ & Uniform \\
\hline Misc. cell mean capacity (Ah) & 42 & $\begin{array}{c}+/-2 \text { standard deviations of underlying } \\
\text { normal distribution } \equiv 20-80 \mathrm{Ah}\end{array}$ & Lognormal \\
\hline Mean large cell Cd mass percent & $8.5 \%$ & $+/-2$ standard deviations $\equiv 5-12 \%$ & Normal \\
\hline
\end{tabular}

\begin{tabular}{|l|c|c|c|c|}
\hline \multicolumn{5}{|c|}{ Table 4.15: Miscellaneous large cell cadmium flow in Cape Town (kg Cd) } \\
\hline & 2.5 percentile & 97.5 percentile & mean & median \\
\hline Misc. large cell Cd inflow & 38 & 660 & 240 & 200 \\
\hline
\end{tabular}

\subsubsection{Cordless Power Tools}

Cordless power tools represent the largest application of NiCd cells globally. ${ }^{76}$ There is consensus amongst industry experts that in 2005 the vast majority of cordless power tools sold in South Africa were powered by NiCd batteries. ${ }^{165,166,167,168,169,170,171}$ These batteries consist of small NiCd cells, similar to consumer cells, which are connected in series and enclosed in a plastic casing with contacts to the tool circuit. Most power tools are sold with two batteries and a charger, ${ }^{166,167,170}$ allowing one battery to be charged whilst the other is in use.

The cadmium associated with power tool sales was calculated as:

$\begin{gathered}\text { power tool } \\ \text { Cd flow }\end{gathered}=\left(\begin{array}{c}\text { cordless power } \\ \text { tools sold }\end{array}\right) \times\left(\begin{array}{c}\text { mean batteries } \\ \text { per tool }\end{array}\right) \times\left(\begin{array}{c}\text { mean cells } \\ \text { per battery }\end{array}\right) \times\left(\begin{array}{c}\text { mean cell } \\ \text { mass }\end{array}\right) \times\left(\begin{array}{c}\text { mean } \text { Cd mass } \\ \text { proportion }\end{array}\right)$

As tool voltage is proportional to the number of cells in the battery and is readily available from manufacturer specifications, this can be used as an exact proxy measure:

$$
\begin{aligned}
& \text { mean cells } \\
& \text { per battery }
\end{aligned}=\frac{\text { tool voltage }}{1.2 \mathrm{~V}}
$$

Major distributors of power tools were approached in order to evaluate some of the variables in equation 4.1 and 4.2. They were usually willing to assist with general information, but only three companies supplied numerical sales estimates for 2005. Only one company provided figures disaggregated by tool type. This was insufficient for accurately determining power tool sales in Cape Town. 
The South African Power Tool Association (SAPTA) was also approached. The association coordinates a data-sharing agreement, through which their members provide sales data to an independent party which collates the data and calculates market share figures for them. In 2005 , only industrial-grade tool data was shared in this way, which was estimated ${ }^{170}$ by a SAPTA expert to account for $25 \%$ of SAPTA tool sales, by number. He also estimated that SAPTA member companies accounted for $50 \%$ of the total South African power tool market. The SAPTA sales figure was extracted directly from reported sales figures and hence of low uncertainty, so a narrow confidence interval was applied only to account for occasional reporting or rounding errors. The estimated percentages were considerably more uncertain and were therefore assigned much wider confidence intervals. These parameters are detailed in Table 4.17. The total South African tool sales for 2005 were then calculated as:

$$
\text { cordless tool sales }=\frac{\left(\begin{array}{c}
\text { SAPTA industrial } \\
\text { cordless tool sales }
\end{array}\right)}{\left(\begin{array}{c}
\text { proportion } \\
\text { industrial }
\end{array}\right)\left(\begin{array}{c}
\text { SAPTA } \\
\text { market share }
\end{array}\right)}
$$

Another estimate of the national power tool market in 2005 was obtained from South African import statistics in combination with market research data published by the Freedonia Group and interview data. ${ }^{126}$ The number of cordless tools sold, $N_{1}$, was estimated as

$$
N_{1}=U F
$$

Where $U$ is the total units imported (Table 4.16) and $F$ is the fraction of total tool imports that were cordless.

\begin{tabular}{|c|c|}
\hline Table 4.16: South African imports 2005 \\
\hline Classification & Net unit imports \\
\hline $\begin{array}{c}\text { HS847621 - Drills of all } \\
\text { kinds, for working in the } \\
\text { hand, with self-contained } \\
\text { elec. motor }\end{array}$ & 637,135 \\
\hline $\begin{array}{c}\text { HS846722 - Saws for } \\
\text { working in the hand, with self } \\
\text { contained elec. motor }\end{array}$ & 265,012 \\
\hline $\begin{array}{c}\text { HS846729 - Tools for } \\
\text { working in the hand, with self } \\
\text { contained elec. motor (excl. } \\
\text { drills \& saws) }\end{array}$ & 989,385 \\
\hline
\end{tabular}

Source: United Nations ComTrade database [172]

A lower bound for $F$ was estimated at $4.7 \%$ from the lowest estimate of its value from industry interviews. ${ }^{165,166,168,171}$ Interview data also suggested that an upper bound of $10 \%$ would be plausible. However, consideration of data from the Freedonia Group suggested that a higher figure could be possible. This data provided the estimated dollar-valued South African power tool market (at point of import, in 2007 dollars) for cordless and corded power 
tools in 1996, 2001 and 2006. Both series showed near-linear development, and so estimated figures for 2005 were obtained by linear interpolation. This provided a figure for national cordless sales value $V_{1}=N_{1} P_{1}$ and national corded sales value $V_{2}=N_{2} P_{2}$ (in 2005 dollars ${ }^{*}$ ), where $N$ is the number of units sold, $P$ their average prices and subscripts 1 and 2 indicate cordless and corded tools, respectively. There were then four equations available:

$N_{1} P_{1}=V_{1}$

$N_{2} P_{2}=V_{2}$

$N_{1}+N_{2}=U$

$N_{1}=U F$

Given these equations, a proposed probability distribution for $F$ implies a range of probable price ratios $P_{1} / P_{2}$, with these ratios inversely related to the value of $F$. Taking the estimated uncertainty of all contributing parameters into consideration (see Table 4.17), a maximum value of 0.10 for $F$ would imply that the mean price of cordless tools is at least $130 \%$ higher ( 2.5 percentile) than that of corded tools. This appeared too high on the basis of tool price comparisons and anecdotal industry data. ${ }^{171}$ Additionally, although cordless tools are always more expensive than their corded equivalents, a higher proportion of corded tool sales for top-end, expensive industrial tools skews the average prices somewhat toward a higher average price for corded tools. ${ }^{170}$ The upper limit was therefore extended to $15 \%$, with the lower limit from interviews retained, which provided for cordless tools to be from $50 \%$ higher ( 2.5 percentile) to $420 \%$ higher ( 97.5 percentile) in mean value. As neither end of this range was decisively preferred, $F$ was assigned a uniform distribution on $[0.047,0.15]$.

Although the majority of power tools are sold with two battery packs, a small number of tools are provided with only one. ${ }^{173}$ This proportion was known to be small, ${ }^{166,167,170,171}$ but its actual value was highly uncertain. This parameter was therefore assigned a uniform distribution of 1.8-2 packs per tool. This implied that at most $20 \%$ of tools are supplied with only one battery pack.

When asked which voltages were most common among cordless power tools in 2005 , respondents replied that $14.4 \mathrm{~V},{ }^{168} 12 \mathrm{~V},{ }^{171} 12 \mathrm{~V}$ and $14.4 \mathrm{~V},{ }^{174}$ and $12 \mathrm{~V}^{142}$ were most common, although tools of higher voltage formed part of the product mix. ${ }^{142,171,174}$ Listings in tools catalogues from the period ${ }^{173,175,176,177,178}$ concurred with this range, although some tools were listed with voltages outside of this range, in particular those of $18 \mathrm{~V}$ which were high-powered for the time. The mean power tool voltage was therefore assigned a normal distribution with a confidence interval of $12-16 \mathrm{~V}$, considering that the majority of power tools were expected to be either $12 \mathrm{~V}$ or $14.4 \mathrm{~V}$, with a smaller number at $18 \mathrm{~V}$ and an even smaller number outside this range. The most common tool voltages tend to increase over time $e^{168,171}$ as more powerful tools become available at lower prices. In 2008 sales included a large proportion of $18 \mathrm{~V}$ tools, ${ }^{166}$ whilst the majority of power tools sent for repacking were $12 \mathrm{~V},{ }^{142}$ implying that this was the dominant voltage some years earlier. This supports the view that the mean voltage in 2005 was unlikely to lie outside of the proposed range.

Virtually all power tool NiCd batteries are constructed with sub-C cells, ${ }^{142,179}$ so mean sub-C cell mass was used in the calculation of total cadmium flow.

\footnotetext{
"Conversion between 2007 and 2005 dollars was according to CPI, from www.measuringworth.com
} 
Spare power tool batteries are available from dealerships, but only a very small number are sold. ${ }^{165,166,168}$ Two reasons cited for the small spare battery trade were the high proportion of the tool price made up by the battery, ${ }^{165}$ which encourages the purchase of a complete replacement tool, and the possibility of repacking the battery ${ }^{168}$ (replacing the cells within the battery pack), which is cheaper than purchasing an original part.

Table 4.17 details the input parameters used to calculate the 2005 cadmium inflow from cordless power tools, using a Monte Carlo simulation of equations 4.1, 4.2, 4.3 and 4.4. Because two independent estimates of cordless tool sales were available, the calculations were followed through for each to yield two sets of Monte Carlo outputs. Neither estimate was preferred, so the two sets were combined and the pooled outputs taken to be the distribution of the result. The separate and pooled results of this simulation are shown in Table 4.18 and Figure 4.2.

Finally, the South African tool sales figures were scaled to a Cape Town estimate using the power tool scaling factor described in Section 3.2.2.

\begin{tabular}{|c|c|c|c|}
\hline Parameter & $\begin{array}{l}\text { Mean } \\
\text { Value }\end{array}$ & Uncertainty estimate & Distribution \\
\hline SAPTA industrial cordless sales & 22,000 & $\mathrm{RSD}=2.5 \%$ & Normal \\
\hline SAPTA proportion industrial to total & 0.25 & $\mathrm{RSD}=10 \%$ & Normal \\
\hline SAPTA market share & 0.50 & $\mathrm{RSD}=10 \%$ & Normal \\
\hline Total tool unit imports $(U)$ & $1,891,532$ & $\mathrm{RSD}=2.5 \%$ & Normal \\
\hline Dollar-valued cordless imports $\left(V_{1}\right)^{*}$ & $12,169,811$ & $\mathrm{RSD}=5 \%$ & Normal \\
\hline Dollar-valued corded imports $\left(V_{2}\right)^{*}$ & $45,943,396$ & $\mathrm{RSD}=5 \%$ & Normal \\
\hline Cordless unit proportion $(F)$ & 0.099 & range $=[0.047,0.15]$ & Uniform \\
\hline Battery packs per tool & 1.9 & range $=[1.8,2.0]$ & Uniform \\
\hline Mean tool voltage $(V)$ & 14 & $+/-2$ standard deviations $\equiv 12-16$ & Normal \\
\hline Sub-C mean mass $(g)$ & 43 & $+/-2$ standard deviations $\equiv 36-50$ & Normal \\
\hline Mean small cell Cd mass percent & 15 & $+/-2$ standard deviations $\equiv 11-19$ & Normal \\
\hline National-city tool scaling factor & 0.15 & RSD $=20 \%$ & Normal \\
\hline
\end{tabular}

*These values were used in the derivation of an upper bound for $F$, but were not parameters in the simulation.

\begin{tabular}{|l|c|c|c|c|}
\hline Table 4.18: Cadmium inflows to Cape Town in cordless power tools (kg Cd) \\
\hline & 2.5 percentile & $\mathbf{9 7 . 5 p e r c e n t i l e}$ & mean & median \\
\hline SAPTA-based estimate & 1,900 & 6,600 & 3,900 & 3,700 \\
Trade-based estimate & 1,500 & 7,800 & 4,000 & 3,800 \\
Pooled estimate & 1,700 & 7,300 & 3,900 & 3,700 \\
\hline
\end{tabular}




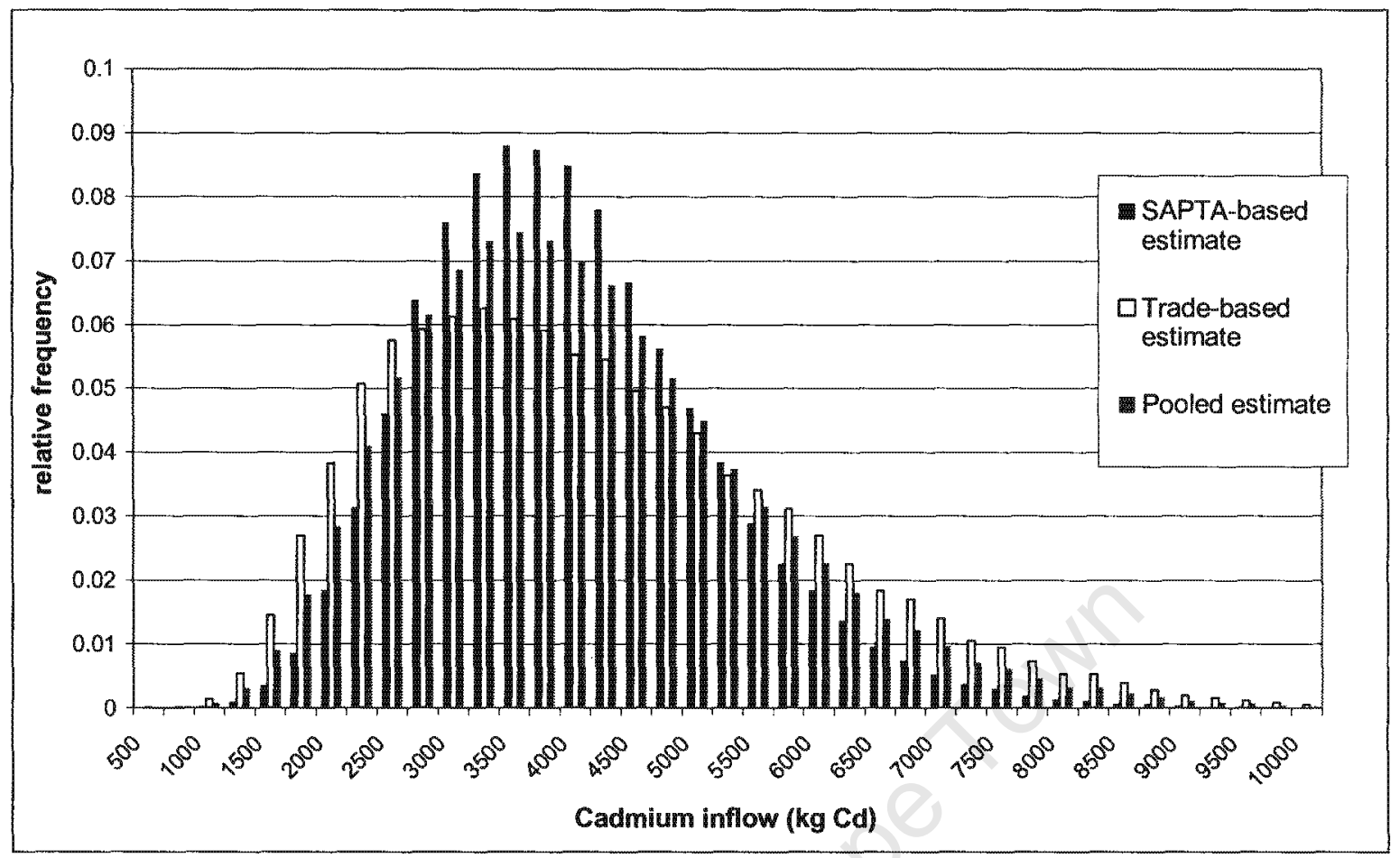

Figure 4.2: Estimated cadmium flow from cordless power tools.

\subsubsection{Part-of-product imports}

Nickel-cadmium cells are incorporated into a wide variety of consumer electronic products before shipping, and hence these cells are not specifically recorded in trade statistics. Two factors make this cadmium flow particularly difficult to estimate. Firstly, the variety of products involved would make a detailed quantification, as was performed for cordless power tools, prohibitively complex. On the other hand, aggregated trade statistics do not provide a suitable measure of their importation. For example, electric toothbrush sales are recorded in the South African trade statistics in the broad class 'electrical motor household appliances - other'. The problem of aggregation is somewhat less in other countries, such as the United States, where trade data is available at a more detailed level. An estimate was therefore made by interpreting South African import figures through comparison to those of the US.

Both US and South African trade figures are available in terms of the 6-digit harmonized system (HS) categories, ${ }^{172}$ which are internationally comparable. ${ }^{180}$ The United States International Trade Commission (USITC) provides more detailed data on US trade using an extension of the HS system to a 10-digit classification, the harmonized tariff schedule (HTS). ${ }^{181}$ Hence in the above example, the HS code 85.09 .80 signifies 'electrical motor household appliances - other', while in the HTS this is additionally subdivided into:
- $\quad 85.09 .80 .00 .40$
can openers
- $\quad 85.09 .80 .00 .45$
electric toothbrushes
- $\quad 85.09 .80 .00 .50$
evaporative humidifiers

etc. 
This allows much more specific quantification of product imports which might contain $\mathrm{NiCd}$ cells. The cadmium flows associated with US trade have been previously assessed using USITC figures by Wilburn. ${ }^{80}$ By compiling available data and consulting with experts at the US Geological Survey and the USITC, he identified the most important HTS categories covering NiCd products and estimated the proportion of these products carrying NiCd cells. With additional estimates of battery mass and cadmium content, he was able to estimate the inflows of cadmium into the US through part-of-product trade. His work was used as a basis for selecting relevant product categories and provided the proportions of those products carrying NiCd cells. Wilburn's calculations for cordless power tools were not taken into consideration, as the local quantification described in Section 4.3 .4 was considered to be more precise. In the US study, ${ }^{80}$ the battery mass and cadmium content was in most cases estimated by selecting a 'typical' battery type for each application. For the present work it was considered preferable to calculate a total number of NiCd cells across all non-powertool products, and then apply estimated overall average mass and cadmium content values. Since cell mass is variable even within product groups, inaccurate assessments of mean cell mass at the product level are more prone to error than the single task of assessing overall mean cell mass (where more of the variability would be averaged out), although the assessment of mean voltage must still be made for each product. Whilst more accurate for a calculation of total part-of-product cadmium imports, this approach does suffer the disadvantage of not providing cadmium import estimates at the individual product level.

Although it would clearly be inappropriate to assume proportionality between a particular product import and broad parameters such as GDP or population, it is much more reasonable to suggest that the proportion of goods from a six-digit HS category that fall within a particular ten-digit HTS category is approximately constant between countries. Hence the South African imports corresponding to the known US imports by HTS category were estimated as

SA imports $=\left(\frac{U S 10 \text { digit imports }}{U S 6 \text { digit imports }}\right)(S A 6$ digit imports $)$

The four largest HTS categories in terms of the associated import of NiCd cells to South Africa (as estimated by this method) are shown in Table 4.19 to clarify the extent of this assumption, and a complete listing of trade categories and import figures are provided in Appendix 6.

Equation (A) could be evaluated on at least three different bases: total import, net import or domestic import. Total import includes imports for re-export, and does not provide an accurate measure of trade inflows for consumption. Net imports do not include re-exports, but since product distributions in exports are in general likely to be much more countryspecific than for imports, the correction carries a risk of skewing the result. Therefore the use of domestic import figures was preferred in principle when evaluating Equation 4.5 to estimate imports for local consumption. This did still involve assumptions that:

- Local production (within the relevant HS classification) of either nation was not large enough to alter its product import distribution, or it produced a similar distribution of products for local sale. 
- Products imported into the countries' economic territory (ie pass through customs) were entirely destined for domestic consumption.

- Imports for consumption followed the same distribution of products within an HS code in both countries (as implied in Equation 4.5)

\begin{tabular}{|c|c|c|c|}
\hline HS Code & HS Category description & MTS Code & $\begin{array}{l}\text { HTS Category } \\
\text { Description }\end{array}$ \\
\hline 85.13 .10 & $\begin{array}{l}\text { Portable electric lamps designed to function by } \\
\text { their own source of energy (e.g., dry batteries, } \\
\text { accumulators, magnetos), other than lighting } \\
\text { equip. of } 85.12\end{array}$ & 85.13 .10 .40 .00 & $\begin{array}{l}\text { Portable electric lamps } \\
\text { with self-contained } \\
\text { energy source, except } \\
\text { flashlights }\end{array}$ \\
\hline 85.09 .80 & $\begin{array}{l}\text { Electro-mechanical domestic appliances, with } \\
\text { self-contained electric motor (excl. of } 8509.10 \text { - } \\
8509.40 \text { ) }\end{array}$ & 85.09 .80 .00 .45 & Electric toothbrushes \\
\hline 85.13 .10 & $\begin{array}{l}\text { Portable electric lamps designed to function by } \\
\text { their own source of energy (e.g., dry batteries, } \\
\text { accumulators, magnetos), other than lighting } \\
\text { equip. of } 85.12\end{array}$ & 85.13 .10 .20 .00 & Flashlights \\
\hline 85.17 .11 & Line telephone sets with cordless handsets & 85.17 .11 .00 .00 & $\begin{array}{l}\text { Line telephone sets with } \\
\text { cordless handsets }\end{array}$ \\
\hline
\end{tabular}

Unfortunately, South African trade figures were only available on a total trade basis. Consumer electronics manufacturing is, however, a very small industry in South Africa and it was therefore safe to assume that imports in these categories provided essentially all domestic consumption and exports. That is, within these product groups it was possible to equate net trade with imports for consumption in South Africa.

When equation A was evaluated using domestic imports for US data and net South African imports, the estimated South African imports for 2005 were as shown in Table 4.20. As parameters for further calculation, the values were assigned normal distributions with $95 \%$ confidence limits of $+/-50 \%$, reflecting the considerable uncertainty due to possible spatial variability. The estimated proportion of each product type that actually carried $\mathrm{NiCd}$ batteries in 2005 is given in Table 4.21 , taken from Wilburn, ${ }^{80}$ with an assumed uncertainty interval of $+/-10 \%$. This primarily reflected the assumed parameter uncertainty of the original estimates, as spatial variability of the battery chemistry distributions among imports was expected to be negligible.

\begin{tabular}{|l|r|r|c|}
\hline Table 4.20: Estimated product imports to South Africa \\
\hline Parameter : imports of & Mean Value & Uncertainty estimate & Distribution \\
\hline Cordless phones & 276,290 & RSD $=25 \%$ & Normal \\
Camcorders & 70,802 & RSD $=25 \%$ & Normal \\
Portable radios & 401,101 & RSD $=25 \%$ & Normal \\
Shavers & 489,828 & RSD $=25 \%$ & Normal \\
Electric toothbrushes & 864,207 & RSD $=25 \%$ & Normal \\
Portable vacuum cleaners & 60,552 & RSD $=25 \%$ & Normal \\
Flashlights & $3,103,329$ & RSD $=25 \%$ & Normal \\
Portable electric lamps & $1,339,819$ & RSD $=25 \%$ & Normal \\
\hline
\end{tabular}


Table 4.21: Proportion of products using NiCd batteries

\begin{tabular}{|l|c|c|c|}
\hline Product & NiCd proportion & Uncertainty estimate & Distribution \\
\hline Cordless phones & 0.40 & $\mathrm{RSD}=5 \%$ & Normal \\
Camcorders & 0.06 & $\mathrm{RSD}=5 \%$ & Normal \\
Portable radios & 0.06 & $\mathrm{RSD}=5 \%$ & Normal \\
Shavers & 0.22 & $\mathrm{RSD}=5 \%$ & Normal \\
Electric toothbrushes & 0.22 & $\mathrm{RSD}=5 \%$ & Normal \\
Portable vacuum cleaners & 0.22 & $\mathrm{RSD}=5 \%$ & Normal \\
Flashlights & 0.02 & $\mathrm{RSD}=5 \%$ & Normal \\
Portable electric lamps & 0.12 & $\mathrm{RSD}=5 \%$ & Normal \\
\hline
\end{tabular}

The average numbers of cells were estimated by compiling product specifications from a variety of sources, particularly internet-based spare battery dealers with online battery compatibility databases. In some cases no or very few examples of explicitly NiCd products could be found, partly because manufacturers of rechargeable products often do not publicize the battery chemistry used, and partly because some applications have seen NiCd cells phased out in the years since 2005. Where possible, NiMH-powered products were included to enlarge the sample, as these have very similar electrical characteristics and are directly substitutable for NiCd cells. The complete data set is provided in Appendix 7. Although statistical inference cannot be applied to the samples due to lack of knowledge of the population distributions, plausible confidence intervals could be assigned for the mean numbers of cells in each product group. It should be borne in mind that these represent the probable ranges for means taken across all such products imported into South Africa in 2005, and do not serve as a prediction of a randomly selected product's specifications. Where the range was drawn from a very small sample of products, or assumed in the case of portable radios, a uniform distribution was applied to the parameter. These parameter values are given in Table 4.22.

\begin{tabular}{|l|r|c|c|}
\hline Table 4.22: Mean number of cells per battery in imported products \\
\hline Parameter - mean cells in: & $\begin{array}{c}\text { Mean cells } \\
\text { (units) }\end{array}$ & Uncertainty estimate (units) & Distribution \\
\hline Cordless phones & 2.5 & $+/$ - 2 standard deviations $\equiv 2-3$ & Normal \\
Camcorders & 6.5 & range $=[5,8]$ & Uniform \\
Portable radios & 2.5 & range $=[1,4]$ & Uniform \\
Shavers & 2 & range $=[1,3]$ & Uniform \\
Electric toothbrushes & 2.5 & range $=[2,3]$ & Uniform \\
Portable vacuum cleaners & 7 & $+/-2$ standard deviations $\equiv 4-10$ & Normal \\
Flashlights & 4.5 & $+/-2$ standard deviations $\equiv 3-6$ & Normal \\
Portable electric lamps & 4.5 & $+1-2$ standard deviations $\equiv 3-6$ & Normal \\
\hline
\end{tabular}

With the estimated imports of product $i$ being $I_{i}, P_{i}$ the proportion of these products carrying NiCd batteries and $N_{i}$ the mean number of cells per product, and with $R$ the AMPS scaling factor described in Section 3.2.2, $M$ the mean non-power tool cell mass and $C$ the mean cadmium mass proportion of small cells, the estimated inflow of part-of-product cadmium to Cape Town in 2005 was

part-of-product $C d=\left(\sum_{i} I_{i} P_{i} N_{i}\right) R M C$ 
Other parameters are summarized in Table 4.23, and the results in Table 4.24.

\begin{tabular}{|l|r|r|c|}
\hline \multicolumn{1}{|c|}{ Table 4.23: Additional parameters for estimating part-of-product Cd flow } \\
\hline & Mean & Uncertainty estimate & Distribution \\
\hline Mean small cell Cd mass percent & 15 & $+/ 2$ standard deviations $\equiv 11-19$ & Normal \\
National-city AMPS scaling factor & 0.165 & $\mathrm{RSD}=20 \%$ & Normal \\
Non-powertool mean cell mass $(\mathrm{g})$ & 32 & $+1-2$ standard deviations $\equiv 21-43$ & Normal \\
\hline
\end{tabular}

\begin{tabular}{|l|c|c|c|c|}
\hline Table 4.24: Part-of-product cadmium inflows to Cape Town $(\mathrm{kg} \mathrm{Cd})$ \\
\hline & 2.5 percentile & 97.5 percentile & mean & median \\
\hline Part-of-product & 790 & 3,000 & 1,700 & 1,600 \\
\hline
\end{tabular}

\subsubsection{Battery Repacking}

Only three companies were identified as providing battery repacking services in $2005{ }^{142,165,168,174,182}$ One company, BatteryCell, provided its total NiCd cell import figures for a six-year period (35-37,000 cells) and estimated that these accounted for $85-90 \%$ of new cells, with the balance being sourced locally. ${ }^{174}$ The six-year average import was taken to be the best estimate of sales in 2005 as the company's imports were not necessarily equal to its sales in any given year, although an additional 10\% margin of error was included in the assigned distribution to account for the effect of temporal variation. Estimates were provided for the proportion of total NiCd repacking comprised of powertools (as several other instruments can also be repacked), and the proportion of repacking done for clients from outside the city limits. The mean sub-C cell mass was used for power, tool repacking, and the mean non-tool cell mass for the remainder.

International Power Products (IPP), another company providing battery repacking in 2005, did not provide figures of repacking quantities although values for the above proportions were estimated. ${ }^{142}$ However, the company collecting their battery waste provided an estimated annual mass of $\mathrm{NiCd}$ cells collected from them. ${ }^{157}$ As this was not estimated from recorded data nor specific to 2005 , a wide confidence interval was applied of $+1-20 \%$.

The third company, a division of UniRoss, was providing repacking services in Cape Town in 2005 but has since closed down. ${ }^{132,142,165}$ No data was available on the amount of repacking undertaken by this company. Its market share in Cape Town was assumed to fall within the range of $20-50 \%$, which corresponds to repacking half the average of the other two companies' volumes, to repacking twice their average volume. This was taken to be the likely range based on the frequency with which people in the power tool and related retail business mentioned them (Table 4.25). This market share estimate was assigned a uniform distribution due to the high level of uncertainty associated with it.

\begin{tabular}{|l|c|}
\hline Table 4.25: Frequency of mention of repacking firms \\
\hline BatteryCell & 5 \\
IPP & 1 \\
UniRoss & 2 \\
Other (not active in $2005^{182}$ ) & 2 \\
\hline
\end{tabular}


The parameter values for calculating cadmium flows are summarized in Table 4.26. Because repacking always involves removal of old cells, ${ }^{142}$ repacking done for customers outside of the city does not amount to a net cadmium flow. Rather, from a perspective of the city's cadmium metabolism, it simply converts new NiCd cells directly into cadmium waste. The associated in- and outflows are both represented by the item 'Exchange with outside city' in the results given in Table 4.26. 'Repacking for Cape Town' indicates the inflow for consumption within the city.

\begin{tabular}{|c|c|c|c|}
\hline Parameter & $\begin{array}{l}\text { Mean } \\
\text { Value } \\
\end{array}$ & Uncertainty estimate & Distribution \\
\hline BatteryCell cell imports in 2005 & 6,000 & $\mathrm{RSD}=11.4 \%$ & Normal \\
\hline $\begin{array}{l}\text { BatteryCell local cell purchase } \\
\text { proportion }\end{array}$ & 0.125 & $+/-2$ standard deviations $\equiv 0.10-0.15$ & Normal \\
\hline $\begin{array}{l}\text { BatteryCell power tool } \\
\text { proportion in repacking }\end{array}$ & 0.8 & $\mathrm{RSD}=5 \%$ & Normal \\
\hline $\begin{array}{l}\text { BatteryCell proportion out-of-city } \\
\text { business }\end{array}$ & 0.125 & $+/-2$ standard deviations $\equiv 0.10-0.15$ & Normal \\
\hline IPP NiCd mass repacked (kg) & 50 & $\mathrm{RSD}=10 \%$ & Normal \\
\hline $\begin{array}{l}\text { IPP power tool proportion in } \\
\text { repacking }\end{array}$ & 0.5 & $+/-2$ standard deviations $\equiv 0.40-0.60$ & Normal \\
\hline $\begin{array}{l}\text { IPP proportion out-of-city } \\
\text { business }\end{array}$ & 0.1 & $\mathrm{RSD}=5 \%$ & Normal \\
\hline $\begin{array}{l}\text { UniRoss repacking market } \\
\text { share in } 2005\end{array}$ & 0.35 & range $=[0.2,0.5]$ & Uniform \\
\hline Sub-C mean mass $(g)$ & 43 & $+/-2$ standard deviations $\equiv 36-50$ & Normal \\
\hline $\begin{array}{l}\text { Non-powertool mean cell mass }{ }^{*} \\
\text { (g) }\end{array}$ & 32 & $+/-2$ standard deviations $\equiv 21-43$ & Normal \\
\hline $\begin{array}{l}\text { Mean small cell Cd mass } \\
\text { percent }\end{array}$ & 15 & $+/-2$ standard deviations $\equiv 11-19$ & Normal \\
\hline
\end{tabular}

*including non-powertool sub-C cells

Table 4.27: Battery repacking cadmium flows in Cape Town (kg Cd)

\begin{tabular}{|l|c|c|c|c|}
\hline & $\mathbf{2 . 5}$ percentile & $\mathbf{9 7 . 5}$ percentile & mean & median \\
\hline Total inflow & 48 & 120 & 77 & 75 \\
Repacking for Cape Town & 42 & 100 & 68 & 66 \\
Exchange with outside city & 5.6 & 15 & 9.4 & 9.1 \\
Repacking waste to recycling & 5.2 & 10 & 7.5 & 7.4 \\
\hline
\end{tabular}

The battery waste from IPP was collected for recycling, the only confirmed small-cell recycling activity in Cape Town in 2005. Battery waste from BatteryCell was delivered to municipal facilities which were not equipped to properly dispose of it, and was believed to have been included in municipal waste streams. The waste management practices of UniRoss were unknown, but the company was not engaged in NiCd recycling at that time. ${ }^{132}$ 


\subsubsection{Emergency Lighting}

\subsubsection{Survey results}

\section{Response rate}

Nine of the contractors who were contacted did not do work with battery equipment or emergency lighting to any significant extent, three were unwilling to take part in the survey, and for four it did not prove possible to arrange an interview. Face-to-face interviews were carried out with 14 electrical contractors. The company sizes in the survey sample ranged from six employees to over 500 (median 32).

\section{Alternative power supplies}

The survey identified two other technologies used to power emergency lighting: UPS systems were mentioned by two respondents, and two mentioned the use of generators. One respondent said that if a building had a generator installed, lighting would usually be installed with connections to this instead of being supplied by battery.

\section{Retrofitting of battery backup}

In order to determine whether battery backup is ever retrofitted into pre-existing units, respondents were asked how frequently battery backup was installed on existing lighting systems. Excluding the installation of external UPS systems ( 1 respondent), only one respondent said that their company does this (1-11 times per year). Rechargeable alkaline batteries are used for this purpose.

\section{Supply of units}

Thirteen respondents (93\%) report purchasing the emergency lighting units fully assembled from suppliers, with battery packs and circuitry already enclosed. One of these thirteen said that, when under pressure for time, their company will occasionally purchase the components from the same supplier and assemble the unit themselves. Only one respondent said that they usually construct emergency lighting fittings themselves, although their reported frequencies of installation were quite low (< once per year or 1-11 times per year for all circumstances of installation - see below). They construct the units with rechargeable alkaline battery backup.

The suppliers for emergency lighting units listed by respondents are given in Figure 4.3. 


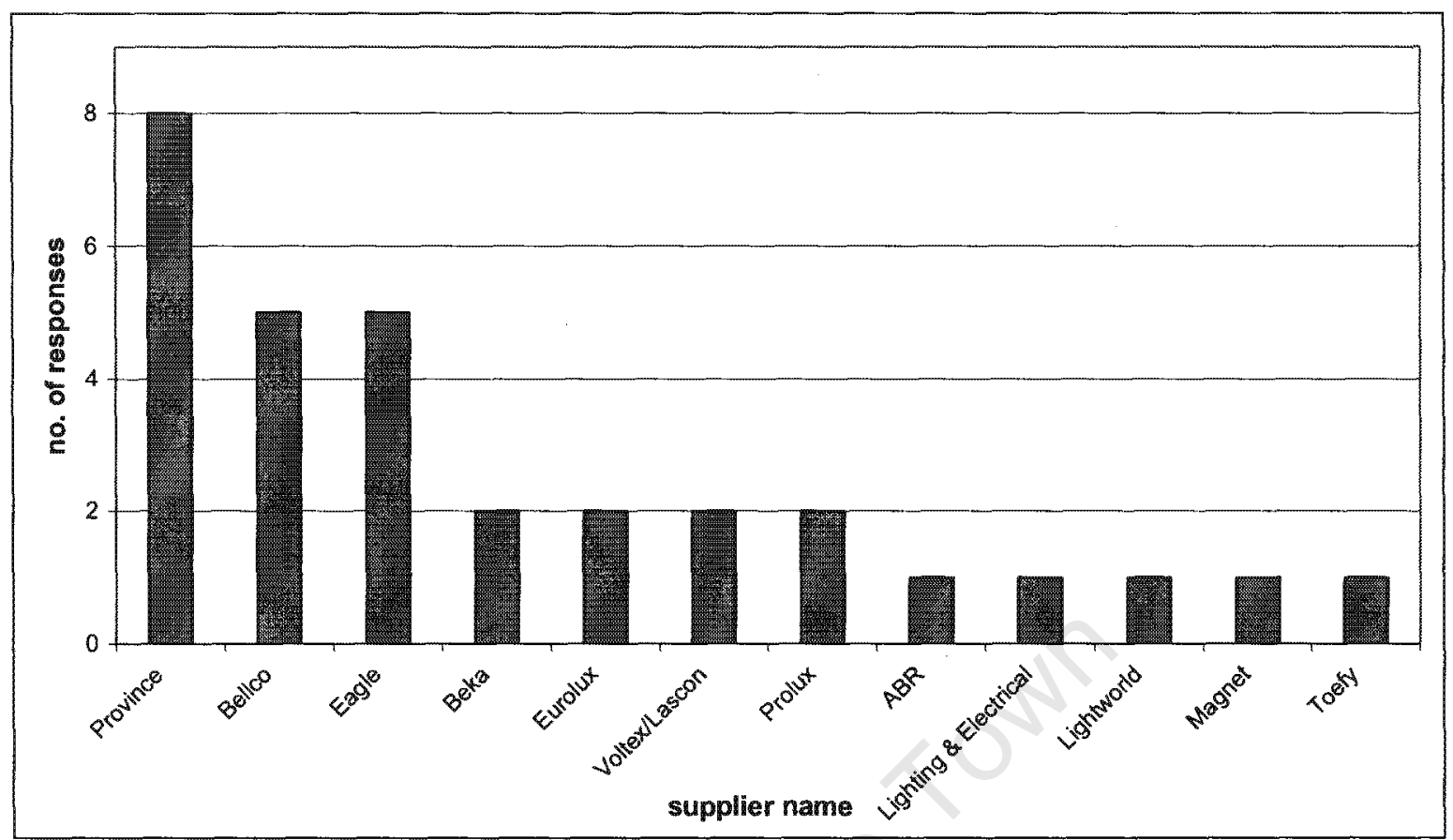

Figure 4.3: Frequency with which emergency lighting unit suppliers were mentioned

\section{Installation of units}

In order to gain an understanding of the circumstances under which emergency lighting units are installed, respondents were asked to select a frequency of installation under four circumstances:

- installation in newly constructed buildings

- first-time installation in existing buildings

- installation where all previously existing fittings were removed, (e.g. renovation)

- installation to replace broken units

The responses are summarized in Figure 4.4.

These responses showed that fitting of units in newly constructed buildings is dominant. Frequency of first-time installations is quite low, but did suggest that some buildings in the Cape Town area might not be compliant with the current fire regulations, hence requiring retrofitting at a later stage. 


\begin{tabular}{|c|c|c|c|c|}
\hline daily basis & 3 & 0 & D & 0 \\
\hline stwice per week & 0 & 0 & 1 & 1 \\
\hline $\begin{array}{l}\text { 1-4 times per } \\
\text { month }\end{array}$ & 3 & 1 & 2 & 0 \\
\hline 1-11 times per year & 5 & 4 & i & 4 \\
\hline$<$ once per year & 2 & 8 & 6 & 6 \\
\hline \multirow[t]{2}{*}{ never } & 1 & 1 & 1 & 3 \\
\hline & 总旁 & 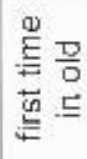 & $\begin{array}{l}\frac{\partial}{c} \\
\frac{c}{\mathrm{~d}} \\
\frac{\mathrm{d}}{0}\end{array}$ & $\begin{array}{l}8 \\
\frac{8}{8} \\
\frac{8}{0}\end{array}$ \\
\hline
\end{tabular}

Figure 4.4: Reperted rates of unit installation undet different circumstances.

It is also worth noting the relatively low reported frequencies for the replacement of broken units, which could imply any of the following:

- that they are discarded in the course of renovations before the end of their uselul lives

- that they are not tegularly tested or maintained and hence are not replaced even when broken

- they are installed during construction, but when they break down they are replaced with regular mains-only fittings (which are cheaper)

The issue of maintenance is discussed in the following section.

\section{Maintenance of units}

Several respondents mentioned 1-year guarantees or 1 -year maintenance agreements on all new work, during which any maltunctioning units would be repaired or replaced. Only three respondents said that they ever serviced or repaired emergency lighting units outside of the guarantee perion. "Two of them said this occurred when a client discovered that a unit was broken, and only one reported that repairs arose as part of a maintenance program. In all three cases the reported frequency was low (eonce per year or $1-11$ times per year), Only two of the three who reported non-guarantee repairs said that this ever involved replacing the cells in the units, and in both cases the battery packs were provided by the supplier of the lighting unit.

live respondents $(36 \%)$ specitically mentioned that these lighting units are poorly maintained by building management, with one respondent saying that their company prefers to use alternative emergency power supplies for this reason. It appeared that broken units or faulty batteries are scldom noticed until the power is cut and they are needed. 


\section{Disposal of old units}

Methods of disposal for the emergency lighting units, and in particular the enclosed batteries, were investigated. Initially it had been expected that a considerable proportion of end-of-life units would be handled by the electrical contractors who replaced them. However, as discussed above, the replacement of individual old units appears to happen surprisingly seldom. The surveyed contractors mentioned a range of disposal methods used when old units were removed. Most respondents gave a preferred or most common disposal method in conjunction with alternative disposal methods practised occasionally. The responses are summarized in Table 4.28 , with the column of practised methods carrying a tally of all mentions made of each practice.

\begin{tabular}{|l|c|c|}
\hline \multicolumn{3}{|c|}{ Table 4.28: Preferred and practised disposal methods } \\
\hline & preferred $^{2}$ & practised \\
\hline MSW collection & 1 & 3 \\
\hline municipal drop-off & 1 & 1 \\
\hline scrap metal dealer & 2 & 3 \\
\hline left with client & 6 & 6 \\
\hline returned to supplier & 2 & 3 \\
\hline waste contractor & 3 & 4 \\
\hline
\end{tabular}

*one respondent gave two equally preferred methods, hence the column adds to 15 responses.

Municipal waste drop-off facilities are not equipped or authorized to accept battery wastes, and any such material delivered to these sites will inevitably join the construction and municipal waste streams. ${ }^{183,184}$ It also seems likely that the batteries will end up in municipal waste when the responsibility for disposal falls to clients or scrap metal dealers, who are less likely to be aware of their hazardous nature. One respondent cited the high cost of proper disposal as the primary reason for leaving broken units with the client.

Three of the 14 respondents $(21 \%)$ reported safe disposal as a preferred method. Although returning to the supplier might be considered responsible disposal, the fact that the original manufacturer does not provide end-of-life take-back ${ }^{143}$ casts doubt on whether these units are in fact reaching safe treatment. Besides disposal to scrap dealers, which was only reported by the smaller companies, no correlation could be discerned between the company size or installation activity and the preferred disposal method (Table 4.29). The use of scrap dealers might arise from economic constraints specific for small companies, whereby the effort of saving and transporting scrap is seen as worth the small additional income.

\begin{tabular}{|c|c|c|c|c|}
\hline Table 4.29: Disposal preferences by company size \\
\hline \multirow{3}{*}{$\begin{array}{c}\text { Staff no. } \\
\text { (respondents) }\end{array}$} & Preferred waste disposal method (\% of respondents in size category) \\
\cline { 2 - 5 } & MSW/drop-off & scrap & client & $\begin{array}{c}\text { supplierl } \\
\text { contractor }\end{array}$ \\
\hline $0-30(7)$ & 14 & 29 & 29 & 43 \\
$31-60(4)$ & 0 & 0 & 75 & 25 \\
$>60(3)$ & 33 & 0 & 33 & 33 \\
\hline
\end{tabular}


Although several inappropriate disposal practices occur with regard to the units, this should be seen in the context of the volumes handled. The replacement of old units forms only a small fraction of the total numbers installed, and only under this circumstance might the electrical contractor remove the old unit. The number installed by electrical contractors is therefore far greater than the number they remove, and the balance must be accounted for by an increase in the stock in buildings and removal by other players, when a building is either renovated or demolished.

\subsubsection{Key survey conclusions}

\section{Evaluation of hypotheses}

All buildings can be assumed to comply with the regulations governing emergency lighting.

All emergency lighting can be assumed to be supplied by the use of battery-backup emergency lighting units.

It seems that a minority of large buildings in the city do not have emergency lighting installed. Also, UPS systems and generators are important alternatives for providing power to emergency lighting. It is clearly not possible to assume that all buildings comply with the regulated emergency lighting specifications, nor that they all do so by using battery-backup emergency lighting units.

\section{All these units run on nickel-cadmium cells.}

This cannot be assessed on the basis of this survey, as not all contractors were aware of the battery chemistry used in the units they installed. This was addressed by approaching the industry suppliers of these units, as discussed below.

The units are supplied by limited number of industry wholesalers.

Figure 1 above shows that certain suppliers are strongly preferred. Some of the most important suppliers were identified, although it was not certain that the survey had identified all major players.

Cells used in the battery packs are only supplied within a unit. It can be assumed that no other significant battery flows enter the emergency lighting stock in the city (for example, through repair or battery repacking of old units).

On the basis of this survey this assumption seemed justified with regard to NiCd batteries.

Emergency lighting is the only significant application of $\mathrm{NiCd}$ batteries in building infrastructure 
No other NiCd applications were identified by the survey respondents. On this basis it was concluded that battery-backup emergency lighting is the only major application of nickelcadmium batteries in the electrical systems of buildings.

\section{Electrical contractors are major disposers of old units and their enclosed batteries.}

Whist electrical contractors are conduits for a considerable number of batteries supplied to Cape Town, they handle few at the end-of-use stage. Although increased construction activity in recent years probably contributes to this, the evidence of poor maintenance suggested that the majority are removed by other parties, such as demolition companies. Furthermore, in many and possibly a majority of cases where an electrical contractor does remove an end-of-life unit another entity will take possession before disposal. Two were identified: the contractor's client (e.g. building management), and scrap metal dealerships.

\section{Essentially all spent batteries are disposed of with municipal waste.}

A sizeable proportion of units removed by electrical contractors are entering the municipal waste stream. However, a range of disposal methods are in use, and a considerable number of contractors practise safer disposal. Whilst it cannot be assumed that all batteries removed by contractors go to municipal solid waste, the volumes of waste batteries handled by contractors are very much smaller than the volumes they install in new units.

\section{Other conclusions}

Contractors almost always purchase emergency lighting units pre-assembled with batteries enclosed.

It is likely that the units, once installed, are poorly maintained and seldom checked.

\subsubsection{Follow-up on survey results}

\section{Investigation of supply chain}

All suppliers of battery-backup emergency lighting identified by the survey were contacted by telephone and asked what type of batteries were used in their units and, if NiCd, who supplied the units. The chemistries identified are detailed in Table 4.30. All suppliers providing NiCd-powered units reported that they purchased the battery and inverter components from a single company, and incorporated these into a variety of lighting units. This company was contacted, ${ }^{143}$ and provided an estimate of 400 units sold per month to Cape Town (amounting to 4800 per year). All units carry 5 sub-C cells. The company does not accept end-of-life units for disposal. Province Lighting (the most recognized supplier see Figure 4.3) - purchased 1191 units in $2005,{ }^{185}$ which is in general agreement with this figure.

Table 4.30: Batteries used in emergency lighting from identified suppliers

\begin{tabular}{|l|c|c|c|}
\hline Cell type: & NiCd & Pb acid & Not stocked \\
\hline Responses: & 6 & 4 & 2 \\
\hline
\end{tabular}


Two of the suppliers contacted did not stock emergency lighting. Presumably this arose from contractors referring to their default supplier from whom most fittings are purchased.

On the basis of the survey and subsequent investigation of the supply chain it was concluded that the single supplier was the only major source of $\mathrm{NiCd}$ batteries for emergency lighting in the city. The parameters used for calculation of the cadmium flows associated with emergency lighting are shown in Table 4.31, and the results summarized in Table 4.32.

\begin{tabular}{|l|r|c|c|}
\hline Table 4.31: Parameters for estimating emergency lighting Cd flow \\
\hline \multicolumn{1}{|c|}{ Parameter } & Mean & Uncertainty estimate & Distribution \\
\hline Battery back-up units sold & 4,800 & RSD $=5 \%$ & Normal \\
Cells per back-up unit & 5 & 0 & Exact \\
Sub-C mean mass (g) & 43 & $+/-2$ standard deviations $\equiv 36-50$ & Normal \\
Mean small cell Cd mass percent & 15 & $+/-2$ standard deviations $\equiv 11-19$ & Normal \\
\hline
\end{tabular}

\begin{tabular}{|l|c|c|c|c|}
\hline Table 4.32: Emergency lighting cadmium inflows to Cape Town (kg Cd) \\
\hline & 2.5 percentile & 97.5 percentile & mean & median \\
\hline Emergency lighting Cd inflow & 110 & 210 & 150 & 150 \\
\hline
\end{tabular}

\section{Investigation of disposal}

The poor levels of maintenance and low frequency of replacement implied that emergency lighting was installed in new buildings and removed during major renovations or demolition, but seldom under other circumstances. It was therefore concluded that the majority of end-oflife units were removed by demolition companies when stripping prior to major renovations or during building demolition. Six demolition firms were contacted, but none of the staff overseeing the scrapping of electrical systems were aware of emergency lighting or the batteries it contained. ${ }^{186}$ Electrical equipment removed during demolition operations was either sold second-hand (if functional) or sold as scrap metal. That which was not saleable was disposed of with municipal waste or demolition rubble. It is possible that some emergency lighting units were re-sold as normal lighting units on the second-hand market, with the battery back-up components unintentionally included. The probability of these reaching safe disposal channels would be even lower than those installed deliberately, as second-hand users would be unaware of their hazardous nature.

An anonymous telephone survey of seven scrap metal dealers in Cape Town revealed that none accepted or were involved in the recycling of $\mathrm{NiCd}$ cells. ${ }^{187}$ Consideration of the very small volumes of NiCd cells going to proper disposal (Section 4.3.9) suggested that any cells sent to scrap dealers with other scrap were ultimately disposed of with municipal waste. These considerations also make it very unlikely that old units left with clients are reaching proper disposal. 


\subsubsection{Separately Imported Small Cells}

In 2005 South Africa was a net importer of 5.3 million NiCd cells. ${ }^{172}$ This included both small consumer cells and large industrial cells, but trade statistics did not differentiate between these. South African imports of NiCd cells for aviation were estimated as described in Section 4.3.1. The use of large NiCd cells in electrical distribution and miscellaneous applications were estimated for Cape Town as detailed in the corresponding Sections 4.3.2 and 4.3.3. These estimates were converted to an estimate for South African use on the basis of regional GDP contribution, with a broad uncertainty interval to reflect the risk of spatial variability as described in Section 3.2.2. Here the four-year average of lower-voltage municipal battery installations was used, as this was considered a better measure by which to estimate national use (see Section 4.3.2). The importation of small cells into South Africa was then calculated by subtracting the estimated large cell imports from the total import figure. This calculation involved some error due to one company that assembles large NiCd cells inside South Africa. This company declined to provide their production figures. Imports of rechargeable battery components to South Africa are reported as a single aggregated figure which includes all component types and chemistries, so it was not possible to correct for this production. The estimated total usage of large NiCd cells was under $1 \%$ of imports on a unit basis, however, so disregarding domestic production of large cells was not a significant omission.

Small cell use was expected to correlate with the use of electrical and electronic appliances, so the national import figure was scaled to a Cape Town estimate using the AMPS scaling factor introduced in Section 3.2.2, and then corrected for small cell use in emergency lighting and battery repacking, both of which account for part of the NiCd cell imports. The parameters used in this calculation are summarized in Table 4.33 and the results presented in Table 4.34 .

\begin{tabular}{|l|r|r|c|}
\hline Table 4.33: Parameters for calculation of separately imported small-cell cadmium flows \\
\hline \multicolumn{1}{|c|}{ Parameter } & Mean Value & Uncertainty estimate & Distribution \\
\hline Net NiCd cell imports (total) & $5,334,358$ & RSD $=2.5 \%$ & Normal \\
GDP scaling factor & 0.11 & RSD $=20 \%$ & Normal \\
AMPS scaling factor & 0.165 & RSD $=20 \%$ & Normal \\
\hline
\end{tabular}

\begin{tabular}{|l|c|c|c|c|}
\hline Table 4.34: Separately imported small cell cadmium flows in Cape Town $(\mathrm{kg} \mathrm{Cd})$ \\
\hline & 2.5 percentile & 97.5 percentile & mean & median \\
\hline Small-cell imports & 1,900 & 6,700 & 4,000 & 3,900 \\
\hline
\end{tabular}

Many of these separately imported cells would have been sold for consumer use, but some may have been incorporated into products manufactured inside South Africa. As South Africa is not a major exporter of electronic goods, the re-export of NiCd cells as part-ofproduct goods would have been negligible. If sold to product manufacturers, their application is more likely to have been in products for the local market, as in the case of emergency lighting and battery repacking. 


\subsubsection{Disposal}

A variety of end-of-life flows have been described in the previous sections. The Vissershok $\mathrm{H}: \mathrm{H}$ hazardous waste landfill site is the only facility in Cape Town permitted to accept $\mathrm{NiCd}$ cells for disposal. The operating company was approached for information regarding disposal rates and estimated that one $210 \mathrm{~L}$ drum of mixed small-cell battery waste would have been disposed of in $2005 .^{188}$ The density of mixed batteries was approximately determined through displacement of water using a $17 \mathrm{~kg}$ sample from supermarket battery collection bins and an e-waste recycling facility. Not enough battery waste was available for extensive sampling, so a broad confidence interval was assigned to this value, corresponding to $+/-20 \%$ confidence limits. In $2005 \mathrm{NiCd}$ cells made up approximately $7 \%$ of the European battery market by weight, ${ }^{144}$ so a minimum mass proportion of $5 \% \mathrm{NiCd}$ was assumed for the mixed battery waste. It was conceivable that NiCd cells, due to their hazardous nature, could represent a considerably higher proportion in battery waste sent for hazardous waste disposal, so an upper limit of $50 \%$ was assumed. A uniform distribution was applied to reflect the uncertainty within this range. No large NiCd cells were disposed of at the facility. ${ }^{188}$ The parameters used to calculate the cadmium flow to hazardous disposal are summarized in Table 4.35. The results of this calculation are provided in Table 4.36, along with a collated summary of all end-of-life flows from the preceding sections.

\begin{tabular}{|l|r|r|c|}
\hline \multicolumn{1}{|c|}{ Table 4.35: Parameters for estimating Cd flow from NiCd disposal as hazardous waste } \\
\hline \multicolumn{1}{|c|}{ Parameter } & $\begin{array}{r}\text { Mean } \\
\text { Value }\end{array}$ & Uncertainty estimate & Distribution \\
\hline $\begin{array}{l}\text { Volume of batteries sent to hazardous } \\
\text { waste (L) }\end{array}$ & 210 & $\mathrm{RSD}=10 \%$ & Normal \\
$\begin{array}{l}\text { Mixed cell density (kg/L) } \\
\text { Mass proportion NiCd cells in battery } \\
\text { waste }\end{array}$ & 0.275 & range $=[0.05,0.50]$ & Normal \\
Mean small cell Cd mass percent (\%) & 15 & $+/$ - 2 standard deviations $\equiv 11-19$ & Normal \\
\hline
\end{tabular}

\begin{tabular}{|l|c|c|c|c|}
\hline \multicolumn{5}{|c|}{ Table 4.36: NiCd end-of-life cadmium flows in Cape Town (kg Cd) } \\
\hline $\begin{array}{l}\text { Small-cell hazardous } \\
\text { disposal in Cape Town }\end{array}$ & 2.5 percentile & 97.5 percentile & mean & median \\
$\begin{array}{l}\text { Small-cell export for } \\
\text { recycling }\end{array}$ & 5.6 & 25 & 12 & 12 \\
$\begin{array}{l}\text { Large cell export for } \\
\text { hazardous disposal }\end{array}$ & 61 & 16 & 7.5 & 7.4 \\
$\begin{array}{l}\text { Large cell export for } \\
\text { recycling }\end{array}$ & 65 & 160 & 110 & 110 \\
$\begin{array}{l}\text { Aviation export for storage/ } \\
\text { disposal }\end{array}$ & 38 & 100 & 67 & 66 \\
\hline
\end{tabular}

"excludes COCT lower-voltage substation replacements 
No facilities in South Africa recycle NiCd cells, and in fact only a few such facilities operate anywhere in the world. Waste management firms in Cape Town were contacted to determine whether they exported any NiCd cells for recycling, or sent any to hazardous waste disposal outside of Cape Town (as was found to be the case for some of those used in electrical distribution - see above). None reported either of these activities, and confirmed that any battery waste would be sent to the hazardous waste facility in Cape Town. ${ }^{189,190,191,192}$ Scrap metal dealers were also contacted to determine whether any scrap market was operating for end-of-life small NiCd cells. ${ }^{187}$ In order to avoid non-reporting of possible illegal shipments, the scrap dealers were contacted anonymously and asked whether they accepted NiCd cells for recycling. None reported accepting them.

One supplier of large NiCd cells offered a take-back service for their batteries in 2005, with the spent cells exported for recycling in Europe, ${ }^{156}$ but declined to offer figures for their exports. It is through this channel that Eskom cells were recycled, ${ }^{156,160}$ and it is feasible that some large cells from miscellaneous applications also followed this route.

Illegal dumping and littering was assumed to make no contribution to the city's NiCd flows. Municipal solid waste removal is provided in some form for over $95 \%$ of households in the city, ${ }^{3}$ which in conjunction with municipal street cleaning and clearance of illegal dumping implies that the vast majority of non-industrial waste generated in the city joins the MSW streams. Additionally, those areas with limited services are generally low-income areas, where widespread use of costly rechargeable products would not be expected.

Hoarding, the storage of end-of-life products for an extended period prior to disposal, has been documented with regard to electronic goods such as computer and television equipment, both internationally ${ }^{193}$ and in South Africa. ${ }^{194}$ However, experience with e-waste management suggests that small appliances that are easily discarded with household waste do not turn up in e-waste streams. ${ }^{95,196}$ This has been the experience with e-waste recycling in Cape Town, which has involved the establishment of several drop-off facilities in recent years. ${ }^{197}$ Given that a considerable volume of larger e-waste items has been collected but negligible numbers of small rechargeable consumer goods, it seems unlikely that end-of-life NiCd cells are being hoarded to a significant extent. This is supported by the experience of a recent drive to collect spent batteries at supermarkets, which got little response from the public and received predominantly non-rechargeable cells. ${ }^{132}$

It was concluded that the flows detailed in Table 4.36 were the only significant end-of-life flows of small NiCd cells other than disposal with municipal solid waste. The outflow of large cells from lower-voltage City of Cape Town substations was unknown, though this would have left the city for disposal as hazardous waste with other municipal batteries. The disposal methods for miscellaneous large cells also could not be determined. It is conceivable that some of these large cells were disposed of to $\mathrm{MSW},{ }^{154}$ but their large size and the fact that they are maintained and replaced by technically trained professionals makes this much less likely than for small cells. 


\subsubsection{Train starters}

No trains in Cape Town use batteries for start-up power. ${ }^{198}$ Diesel goods trains used lead-acid cells in the past, but these have been replaced with generator systems.

\subsubsection{UPS systems}

A brief telephonic survey of some of the larger UPS supply and installation companies in the city did not find any companies that worked with NiCd cells. Essentially all, if not all, UPS systems in the city run on lead-acid batteries. ${ }^{199}$

\subsubsection{Industrial vehicles}

A telephonic survey of several of the major distributors of forklifts and other industrial vehicles in Cape Town and South Africa, as well as traction battery suppliers, showed that all such vehicles operate on lead-acid battery power supply. ${ }^{200}$

\subsubsection{Cellular telephones}

Use of NiCd cells in cellular telephones was not expected to contribute significantly to cadmium flows, as most producers had substituted other battery chemistries into their product well before 2005. In addition, the largest part of the cellular telephone market in South Africa (as measured by the AMPS consumer surveys) developed after this substitution had occurred (Figure 4.5). As all cell phones in South Africa are imported, the battery mix was expected to follow the trends of international producers.

\subsubsection{Two-way radios}

Two-way radios, which in the past have often been NiCd powered, have also seen a phaseout in favour of other battery chemistries. Nickel metal-hydride batteries displaced NiCd several years before $2005,{ }^{203}$ and lithium-ion is now gaining market share. There is still some demand seen for repacking of batteries, ${ }^{132}$ however (Section 4.3.6). 


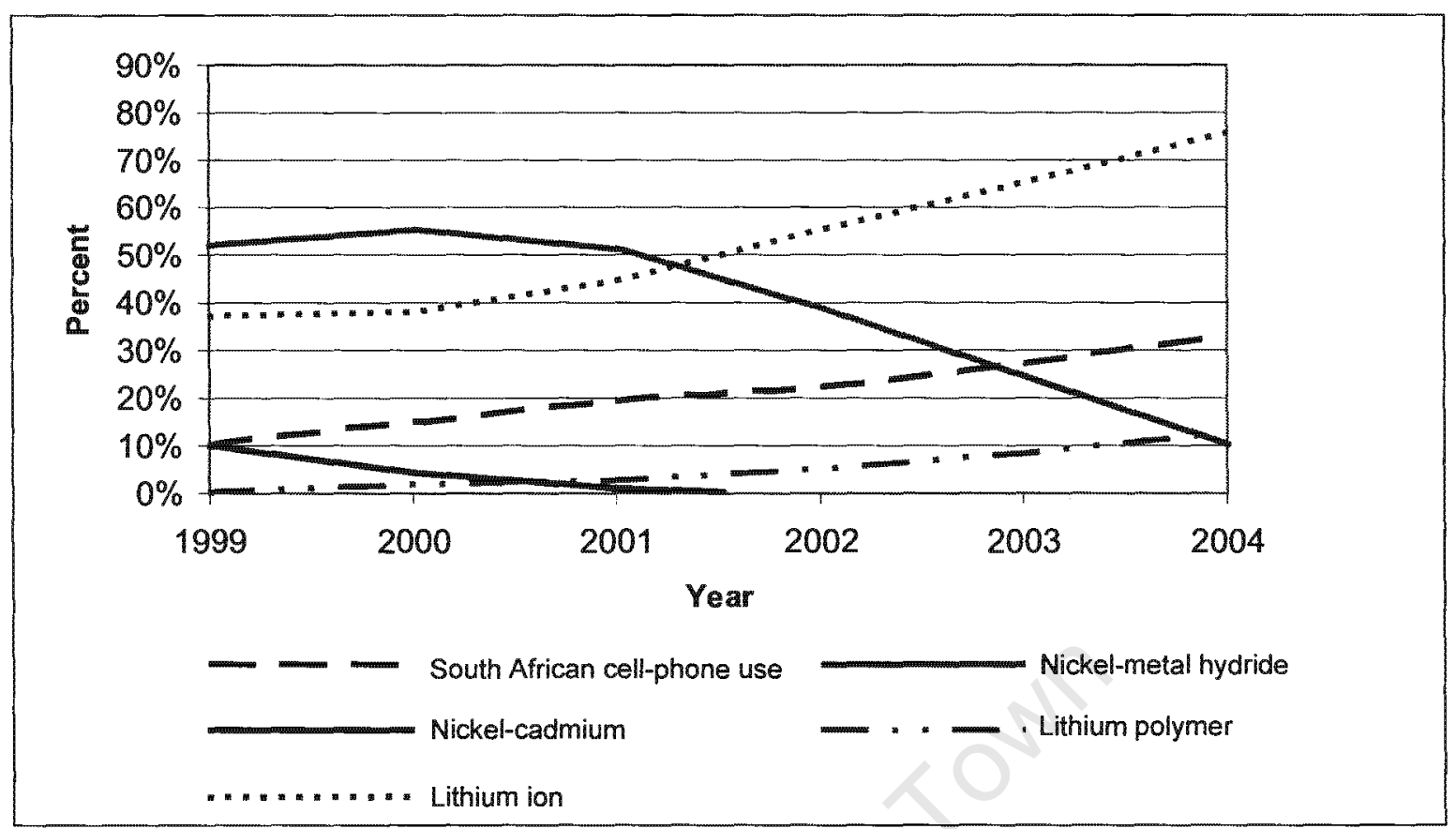

Figure 4.5: Worldwide cell-phone battery and South African use trends. Sources: [201], [202]. 
The results of the calculations detailed above were combined to provide totals for the cadmium flows through Cape Town. Where relevant, totals were calculated with each of the alternative power tool estimates (see Section 4.3.4) and the Monte Carlo simulation outputs pooled. In this way the output distributions of the two estimates were combined into a single distribution, with each receiving equal weighting. The mean-value results are depicted in Figure 4.6 and the results summarized in Table 4.37.

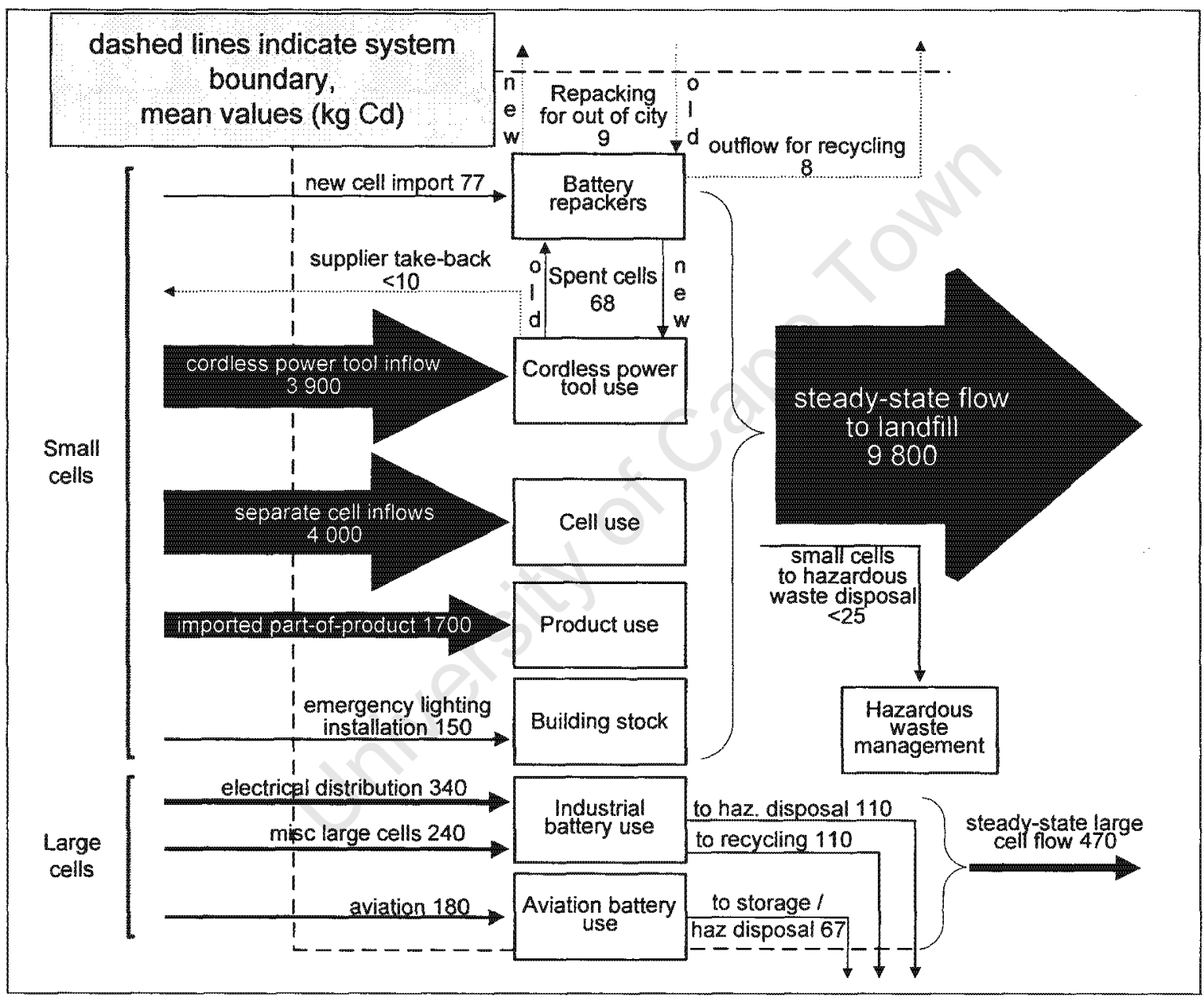

Figure 4.6: Summary of NiCd cadmium flows in Cape Town, 2005. 


\begin{tabular}{|c|c|c|c|c|}
\hline \multirow{2}{*}{ Table 4.37: Summary of results (kg Cd) } & & & & \\
\hline & $2.5 \%$ ile & $97.5 \%$ ile & mean & median \\
\hline Power tool inflow - pooled estimate & 1,700 & 7,300 & 3,900 & 3,700 \\
\hline Battery repacking new cell inflow & 48 & 120 & 77 & 75 \\
\hline Repacking external exchange & 5.6 & 15 & 9.4 & 9.1 \\
\hline Emergency lighting inflow & 110 & 210 & 150 & 150 \\
\hline Part-of-product inflow & 790 & 3,000 & 1,700 & 1,600 \\
\hline Separately imported small cell inflow & 1,900 & 6,700 & 4,000 & 3,900 \\
\hline SMALL CELLINFLOW & 5,600 & 15,000 & 9,800 & 9600 \\
\hline Aviation inflow & 99 & 260 & 180 & 170 \\
\hline Electricity distribution inflow & 200 & 480 & 340 & 330 \\
\hline Other large battery inflow & 38 & 660 & 240 & 200 \\
\hline LARGE CELL INFLOW* & 400 & 1,300 & 750 & 720 \\
\hline & & & & \\
\hline TOTAL INFLOW & 6,400 & 16,000 & 11,000 & 10,000 \\
\hline Repacking external exchange & 5.6 & 15 & 9.4 & 9.1 \\
\hline Battery repacking waste for recycling & 5.2 & 10 & 7.5 & 7.4 \\
\hline Small cell hazardous disposal & 2.6 & 25 & 12 & 12 \\
\hline SMALL CELL OUTFLOWS & 17 & 45 & 29 & 28 \\
\hline Aviation outflow to storage or disposal & 38 & 100 & 67 & 66 \\
\hline ESKOM to recycling & 65 & 160 & 110 & 110 \\
\hline CoCT to hazardous waste & 61 & 160 & 110 & 110 \\
\hline LARGE CELL OUTFLOW & 170 & 410 & 290 & 290 \\
\hline TOTAL OBSERVED OUTFLOWS & 200 & 440 & 320 & 320 \\
\hline STEADY STATE BALANCE: SMALL CELLS & 5,600 & 15,000 & 9,800 & 9600 \\
\hline & & & & \\
\hline STEADY-STAIE BALANCE: LARGE CELLS & 210 & 930 & 470 & 430 \\
\hline
\end{tabular}


Large cells contributed 3.4-14\% of total cadmium inflows in 2005, although this appeared to be unusually low due to the small number of installations in electricity distribution in that year. The average installations for $2005-8$ provided an average contribution of $5-17 \%$ (mean $10 \%$ ) by large cells.

The recycling rate for small NiCd cells was below $1 \%$, as was proper disposal as hazardous waste. For large cells this was calculated as $15 \%$ but this carries considerable uncertainty because the disposal practices for the 'other large cell' category could not be determined, and due to the unusually low number of large cells installed by the municipality in 2005 .

The steady-state balance of small cells in Table 4.37 gives the amount of observed inflowing cadmium that could not be accounted for in the observed end-of-life flows, and was taken as a measure of cadmium disposal to municipal waste. It should be noted that this steady-state assumption is almost certainly inaccurate if interpreted strictly with respect to the year of study, as a significant proportion of small-cell applications would have useful lives of more than a year - that is, this figure could include some growth of in-use stock. However, the very low activity of alternative disposal pathways and the prevalent practices in 2005 indicated that essentially all of this excess inflow would ultimately deport to municipal waste landfills in the city. In this sense, the steady-state balance for small cells can be seen as the commitment to future cadmium disposal that arose from consumption in 2005.

The steady-state balance for large cells cannot be interpreted unambiguously. Besides the inclusion of an unknown number of cells from municipal lower-voltage substation replacements which would have left the city for hazardous waste disposal, the very long life span of NiCd cells makes it conceivable that the balance arises predominantly from in-use stock growth. Indeed, a growth in aviation stock made a considerable contribution to the steady-state excess. On the other hand, indefinite storage was identified as one 'method' currently employed to avoid the costs of proper disposal, and the extent to which this reduces observed large cell outflows is uncertain. Hazardous waste disposal in other regions and export for recycling might also contribute. Finally, this study was unable to categorically rule out the possibility of large cell disposal with municipal waste. However, it was considered unlikely to occur routinely, if at all. 


\section{CHAPTER 5: ENVIRONMENTAL SIGNIFICANCE OF CADMIUM DISPOSAL}

\subsection{INTRODUCTION}

In the previous chapter, the NiCd battery flows of cadmium to MSW were estimated. It was also necessary to ask whether or not the amounts of cadmium involved were "environmentally significant", in the sense of being sufficiently large to warrant concern and caution, or were in fact negligible from an environmental perspective. The amount of cadmium sent to landfill places a limit on the extent of possible impacts that this disposal could cause. It would be foolish to expend further effort researching or reducing these impacts if this limit was acceptably low. The limited understanding of landfill degradation and soil-plant transfer processes in respect of heavy metals (Sections 2.5.2 and 2.5.3) renders a quantitative risk assessment infeasible, and this chapter will not attempt to present one. Rather, as described in Section 3.3, a hypothetical 'best worst-case' scenario is developed which determines the minimum likely contamination of agricultural soil that would result if landfills retained none of this cadmium, under the prevailing conditions of 2005 . This measures environmental significance as the potential of such a quantity of cadmium to cause environmental harm, irrespective of the probability of impacts. The connection between landfill and agricultural land is shown in Figure 5.1 (reproduced here from Figure 3.3 in Section 3.3). This indicates that if regulation were to fail, landfill cadmium could contaminate wastewater treatment sludges and thus agricultural soil.

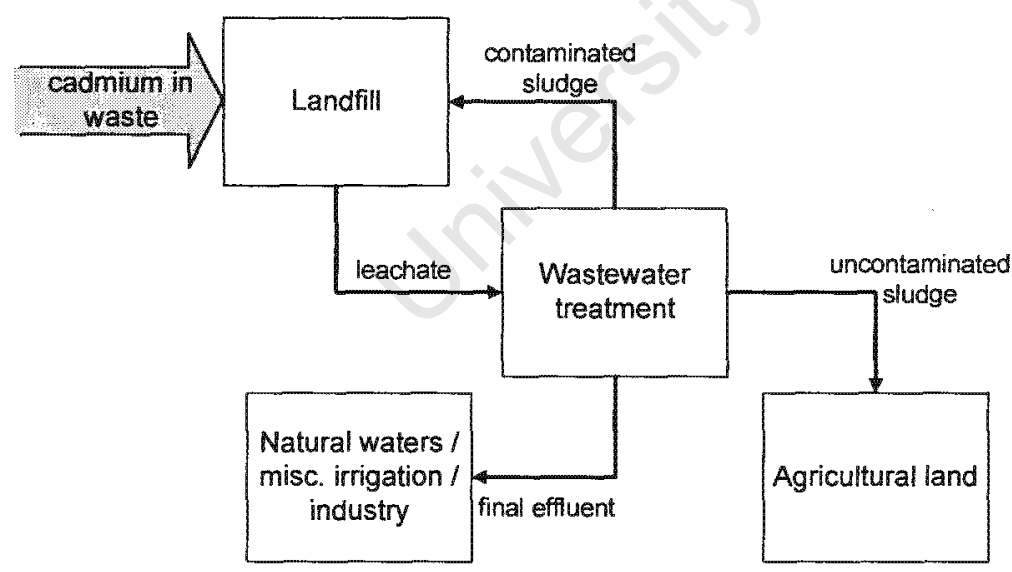

Figure 5.1: Interrelationship between landfill, wastewater and agricultural systems under current conditions.

Completing an assessment of soil contamination potential required estimates of the amount of agricultural land in Cape Town and its current cadmium status, considered in Section 5.2. Three other potential contributions to soil cadmium were identified: the cadmium present in phosphate fertilizers, the baseline flow of cadmium to agricultural land from wastewater treatment sludge and land application of animal manures. These are addressed in Sections 5.3 
to 5.5. Finally, the combined effect of these flows and the hypothetical landfill release is calculated in Section 5.6, on the basis of undiminished cadmium flow to land - the most straightforward scenario with which to judge the cadmium's 'significance' - and the cadmium flow with partitioning in the wastewater system - the more realistic calculation, but a more uncertain and opaque measure. Excepting the assumptions of zero landfill retention and, in the first scenario, the neglect of partitioning in the wastewater system, all these estimates are directed toward the minimum likely contamination. The results of the chapter's calculations are summarized in Section 5.7. CADMIUM IN SOILS

Two sources of analysis data were available from which to estimate the background concentration of cadmium in Cape Town's agricultural soils. One source was the municipal analysis of prospective receiving farmland before application of wastewater treatment sludge $^{138}$ (see Section 5.5), and another from research conducted in the Philippi agricultural area in the city. ${ }^{204,205}$ Together these amounted to 411 soil samples from agricultural properties within the city limits. The sources had used comparable sample preparation and analysis techniques. All samples were taken from active agricultural land between 2001 and 2008 , so they did not represent true background concentrations in the sense of 'natural' levels but rather a measurement of the current cadmium status of agricultural soil. The sampling sites are shown in Appendix 8. The data showed high variability and heavy positive tailing (Figure 5.2). Salient statistics are summarized in Table 5.1.

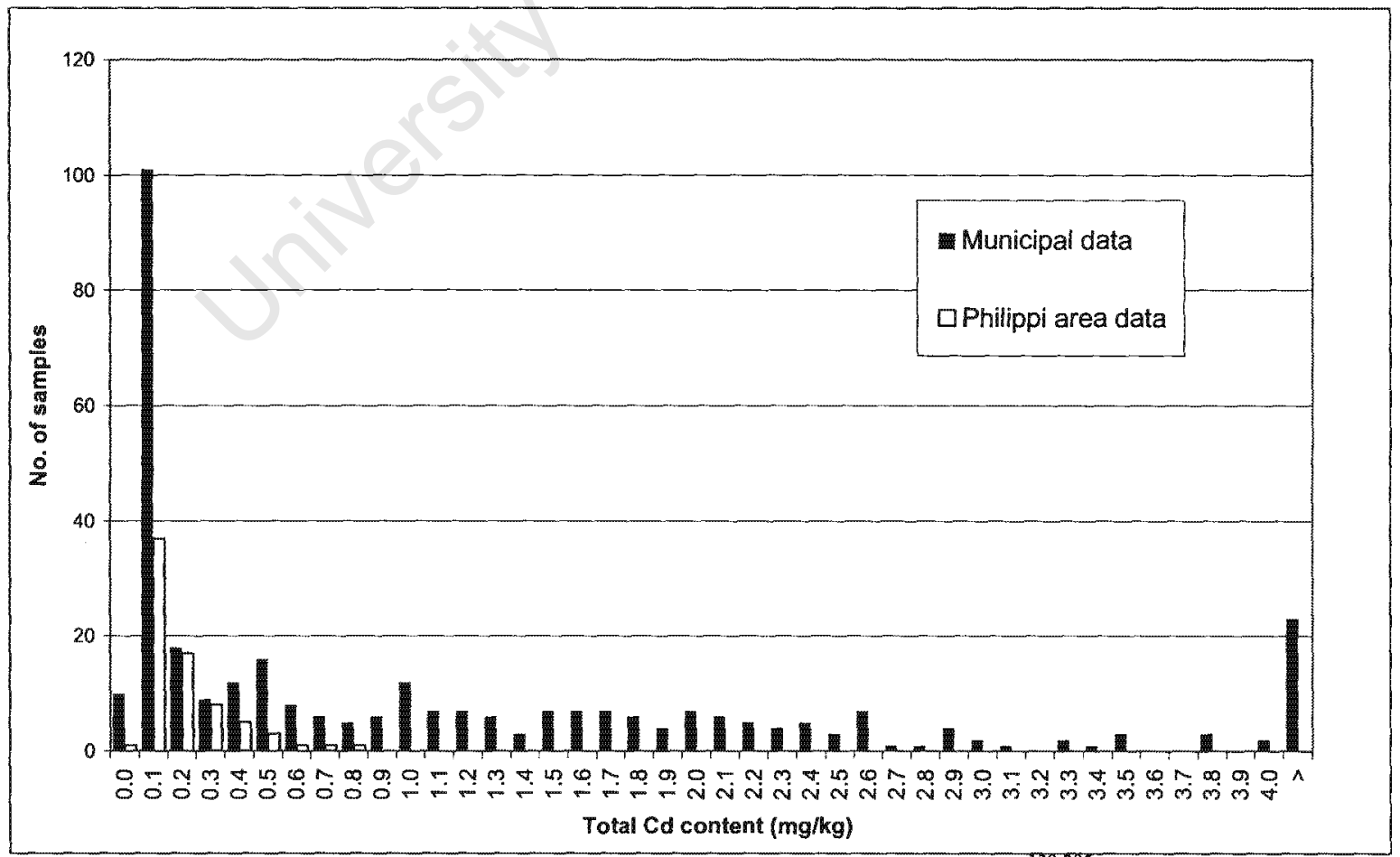

Figure 5.2: Cadmium concentrations in samples of agricultural soil in Cape Town. ${ }^{138,205}$ 


\begin{tabular}{|l|r|r|r|}
\hline Table 5.1: Sample statistics for agricultural soil Cd \\
\hline & \multicolumn{3}{|c|}{ Full data set } \\
\hline & Philippi & Municipal & Pooled \\
\hline Min (mg $/ \mathrm{kg})$ & 0.00 & 0.00 & 0.00 \\
Max (mg/kg) & 0.72 & 14.43 & 14.43 \\
Mean $(\mathrm{mg} / \mathrm{kg})$ & 0.14 & 1.22 & 1.03 \\
Standard deviation $(\mathrm{mg} / \mathrm{kg})$ & 0.16 & 1.75 & 1.64 \\
2.5 percentile $(\mathrm{mg} / \mathrm{kg})$ & 0.00 & 0.00 & 0.00 \\
Median $(\mathrm{mg} / \mathrm{kg})$ & 0.09 & 0.51 & 0.33 \\
97.5 percentile $(\mathrm{mg} / \mathrm{kg})$ & 0.53 & 5.80 & 5.43 \\
Sample size & 74 & 337 & 411 \\
Farms sampled & 68 & 24 & 92 \\
\hline
\end{tabular}

A lower initial cadmium content allows more cadmium to be added before a dangerous level is reached. As the objective was to examine the minimum potential effects of landfill cadmium release from a total soil contamination perspective, only a lower estimate of mean soil cadmium was required. The mean cadmium content of agricultural soil was therefore taken to be $0.1 \mathrm{mg} / \mathrm{kg}$.

Data for the crop area in Cape Town were available from a provincial census of commercial agriculture conducted in 2001/2, as given in Table 5.2. ${ }^{206}$

\begin{tabular}{|l|r|r|l|r|r|}
\hline Table 5.2: Cape Town crop area data & Area (ha) & $\%$ of total & Crop & Area (ha) & $\%$ of total \\
\hline Crop & 60 & $0.4 \%$ & Carrots & 548 & $3.6 \%$ \\
Maize for grain & 4057 & $27.0 \%$ & Sweet potato & 15 & $0.1 \%$ \\
Wheat & 19 & $0.1 \%$ & Green beans & 183 & $1.2 \%$ \\
Barley & 444 & $3.0 \%$ & Pumpkin & 117 & $0.8 \%$ \\
Other winter cereal & 876 & $5.8 \%$ & Other vegetables & 1386 & $9.2 \%$ \\
Other oil seed & 121 & $0.8 \%$ & Oranges & 170 & $1.1 \%$ \\
Lucerne & 25 & $0.2 \%$ & Other subtropical fruit & 120 & $0.8 \%$ \\
Teff & 668 & $4.4 \%$ & Apples & 90 & $0.6 \%$ \\
Other fodder & 38 & $0.3 \%$ & Pears & 495 & $3.3 \%$ \\
Other field crops & 489 & $3.3 \%$ & Peaches & 83 & $0.6 \%$ \\
Potatoes & 85 & $0.6 \%$ & Plums/prunes & 95 & $0.6 \%$ \\
Tomatoes & 194 & $1.3 \%$ & Table grapes & 220 & $1.5 \%$ \\
Cauliflower & 465 & $3.1 \%$ & Wine grapes & 3587 & $23.9 \%$ \\
Cabbage & 115 & $0.8 \%$ & Other decidous\&other & 5 & $0.0 \%$ \\
Onion & 38 & $0.3 \%$ & Other nuts\&tea & 220 & $1.5 \%$ \\
Beetroot & & \multicolumn{3}{|c|}{} \\
\hline
\end{tabular}

Although the census gathered income data for all tax-registered farming operations, it only achieved the response rates shown in Table 5.3 for crop area data, and reported the results unadjusted. It was not possible to correct for non-respondents, as the relations between crop type, farm size and income were unknown. 


\begin{tabular}{|c|c|c|}
\hline \multicolumn{3}{|c|}{ Table 5.3: Response rate for crop area data } \\
\hline Farm income & Total no. of farming units & Response rate (\%) \\
\hline$\geq R 4,000,000$ & 2,330 & $94.4 \%$ \\
$R 2,000,000-R 3,999,999$ & 3,041 & $69.5 \%$ \\
$R 1,000,000-R 1,999,999$ & 5,214 & $57.0 \%$ \\
$R 300,000-R 999,999$ & 11,805 & $51.6 \%$ \\
<R300,000 & 23,428 & $65.6 \%$ \\
\hline Total: & 45,818 & $62.7 \%$ \\
\hline
\end{tabular}

The response rates are higher for higher-income farming operations and it was expected that, for a given crop, crop area would be proportional to income on average. The response rates on a reported-area basis would therefore be somewhat higher than those of Table 5.3. Table 5.2 nevertheless underestimated the true areas, and was therefore at odds with the calculation of a minimum vulnerability for cadmium contamination*. However, other factors counteracted this effect. The actual land available for sludge application is smaller than the total crop area, because regulations restrict the application of sludge due to the risk of pathogen transmission. ${ }^{207}$ For instance, $23 \%$ of the crop area in Table 5.2 grows crops with edible parts that would come into contact with the soil, and hence would not be permitted to receive direct sludge application. Others which are eaten raw are also subject to sludge restrictions. Increased production of sludge-based compost and fertilizer pellets, which carry much lower restrictions, could avoid this limitation, but the major use of sludge in 2005 (as at present $^{139}$ ) was through direct application (see Table 5.11 in Section 5.5). The municipal soil analysis data showed two out of 24 farms $(8 \%)$ with average soil cadmium concentrations already in excess of the $2 \mathrm{ppm}$ regulated maximum for sludge use. Although this was not observed in the other data set, such existing contamination would further reduce the agricultural land available for sludge application. It was also assumed that changes in cultivated land area and crop distribution between the time of the census and 2005 could be ignored. Given the pressures of urban growth on Cape Town's peri-urban agriculture, it is very likely that the city's agricultural areas actually shrank over this period. Although a quantitative treatment was not possible, it was assumed that the effect of non-response was at least offset by these other factors, and hence that Table 5.2 provided maximum estimates for the agricultural land that was actually available for sludge application in any form.

\footnotetext{
* Dispersing a given amount of cadmium across a smaller area produces a larger increase in soil concentration. In the case of phosphate fertilizers (see Section 5.3), a larger agricultural area also gives rise to a greater total use of fertilizer, but this would increase in approximate proportion to the area under cultivation and hence the rate of contamination by fertilizers would be independent of the total area estimated here.
} 
The amount of cadmium applied to agricultural land in phosphate fertilizer was estimated from the amount of agricultural land, $L_{i}$, under each crop $i$ (see Table 5.2, in the previous section), the proportion of these crops cultivated using fertilizer, $P_{i}$, the amount usually applied, $A_{i}$, and the concentration of cadmium in the fertilizer, $C$. The annual addition to agricultural soil, $F$, was then calculated in $\mathrm{kg}$ as:

$$
F=\left(\sum_{i} L_{i} P_{i} A_{i}\right) C
$$

Fertilizer use and application rates were available for South Africa ${ }^{208}$ as shown in Table 5.4. Because the crop categories used for the classification of fertilizer use did not correlate exactly with those for crop area given in Table 5.2, the composite classification system detailed in Table 5.5 was used. This assigned each crop area classification to a composite category, and assigned a value for $P_{i} A_{i}$ to each composite category using the values available for fertilizer use.

\begin{tabular}{|l|c|c|}
\hline Table 5.4: Application of phosphate fertilizer to crops in South Africa \\
\hline Crop & Percent fertilized (\%) & Application rate $\left(\mathbf{k g ~}_{\mathbf{~}} \mathrm{O}_{5} / \mathbf{h a} \cdot \mathbf{y}\right)$ \\
\hline Maize & $95 \%$ & 30 \\
Wheat & $100 \%$ & 40 \\
Lucerne & $90 \%$ & 59 \\
Other pasture & $30 \%$ & 44 \\
Potatoes & $100 \%$ & 160 \\
Vegetables & $100 \%$ & 159 \\
Citrus & $100 \%$ & 35 \\
Subtropical fruits/nuts & $100 \%$ & 57 \\
Deciduous fruit & $100 \%$ & 159 \\
Vines & $100 \%$ & 36 \\
\hline
\end{tabular}

\footnotetext{
* This calculation assumes that Table 5.2 accurately portrays the crop distribution on the land available to sludge application. Given the various unquantified factors that affect the accuracy of this assumption (Section 5.2), especially the restrictions on direct sludge application for certain crops, it is worth noting that any error incurred will only effect the accuracy of the final result to the extent that fertilizer use rates on the land are different to those of the crops assumed to be growing there. Furthermore, it will be seen in subsequent sections that the contribution of fertilizer to soil cadmium contamination is very small, and hence does not affect the final assessment of disposed $\mathrm{NiCd}$ quantities.
} 


\begin{tabular}{|c|c|c|}
\hline Crop area classification & Composite category & $\begin{array}{l}P_{i} A_{i} \text { derived from original fertilizer } \\
\text { classification }\end{array}$ \\
\hline Maize for grain & Maize & Maize \\
\hline Wheat & Wheat & Wheat \\
\hline $\begin{array}{l}\text { Barley* } \\
\text { Other winter cereal* }\end{array}$ & Other cereal & Average $P_{i} A_{i}$ of maize and wheat \\
\hline Other oil seed" & Oil seed & Average $P_{i} A_{i}$ of sunflower and soybean \\
\hline Lucerne & Lucerne & Lucerne \\
\hline $\begin{array}{l}\text { Teff* } \\
\text { Other fodder } \\
\text { Other field crops* }\end{array}$ & Other pasture & Other pasture \\
\hline Potatoes & Potatoes & Potatoes \\
\hline $\begin{array}{l}\text { Tomatoes } \\
\text { Cauliflower } \\
\text { Cabbage } \\
\text { Onion } \\
\text { Beetroot } \\
\text { Carrots } \\
\text { Sweet potato } \\
\text { Green beans } \\
\text { Pumpkin } \\
\text { Other vegetables } \\
\end{array}$ & Vegetables & Vegetables \\
\hline Oranges & Citrus & Citrus \\
\hline $\begin{array}{l}\text { Other nuts and tea* } \\
\text { Other subtropical }\end{array}$ & Fruit / nuts & Subtropical fruits / nuts \\
\hline $\begin{array}{l}\text { Apples } \\
\text { Pears } \\
\text { Peaches } \\
\text { Plums/prunes } \\
\text { Other deciduous and other }\end{array}$ & Deciduous fruit & Deciduous fruit \\
\hline $\begin{array}{l}\text { Table grapes } \\
\text { Wine grapes }\end{array}$ & Vines & Vines \\
\hline
\end{tabular}

"These mismatched crop classes were not expected to make a significant difference to the outcome. Taken together they accounted for only $12 \%$ of agricultural land, and error would only be introduced to the extent that their actual fertilizer use was different to that of the crops from which $P_{i} A_{i}$ was derived.

Table 5.6 shows the cadmium and phosphorus compositions of phosphate fertilizers provided by a local supplier ${ }^{209}$ for two recent years:

\begin{tabular}{|l|r|r|r|r|}
\hline Table 5.6: Cd and P compositions of some phosphate fertilizers & \\
\hline & \multicolumn{2}{|c|}{ Cd (mg/kg) } & P (wt.\% as P) & $\begin{array}{r}\text { Mean Cd:P ratio } \\
\left(\times 10^{6}\right)\end{array}$ \\
\cline { 2 - 5 } & Year 1 & Year 2 & & 100.0 \\
Single superphosphate & 10 & 8 & $9 \%$ & 30.4 \\
Rock phosphate & 4.2 & 4.3 & $14 \%$ & 83.3 \\
Triple superphosphate & 18 & 12 & $18 \%$ & 10.5 \\
Monoammonium phosphate & 3.2 & 1.4 & $22 \%$ & \\
\hline
\end{tabular}

The cadmium content of phosphate fertilizer varies greatly, reflecting the variable concentrations in phosphate rock deposits and production processes. ${ }^{210}$ The values in Table 5.6 are typical for South Africa, ${ }^{209}$ however, and in the absence of volume-weighting 
factors a $10^{-5} \mathrm{Cd}: \mathrm{P}$ ratio was selected as a minimum estimate of mean cadmium content. Table 5.7 details all the values used to evaluate Equation 5.1.

\begin{tabular}{|l|r|r|}
\hline Table 5.7: Parameters for estimation of fertilizer Cd \\
\hline Crop category & $L_{i}$ (ha) & $P_{i} A_{i}(\mathrm{~kg}$ P/ha) \\
\hline Maize & 60 & 12 \\
Wheat & 4057 & 17 \\
Other cereal & 463 & 15 \\
Oil seed & 876 & 6 \\
Lucerne & 121 & 23 \\
Other pasture & 731 & 6 \\
Potatoes & 489 & 70 \\
Vegetables & 3146 & 69 \\
Citrus & 170 & 15 \\
Fruit/nuts & 340 & 25 \\
Deciduous fruit & 768 & 69 \\
Vines & 3807 & 16 \\
\hline Minimum fertilizer Cd:P ratio: & $10^{-5}$ \\
\hline
\end{tabular}

Using these values, Equation 5.1 gives $F$, the mass of cadmium added to Cape Town's agricultural soils through phosphate fertilizer use in 2005 , as $4.7 \mathrm{~kg} \mathrm{Cd}$.

\subsection{APPLICATION OF ANIMAL MANURES}

The manure data in Table 5.8 is provided by Kwonpongsagoon in his study of cadmium flows in Australia. ${ }^{20}$

\begin{tabular}{|l|r|r|r|}
\hline Table 5.8: Manure production and cadmium in Australia & \\
\hline Animal & Number & & \\
\hline Pig & $2,768,000$ & Annual manure (tons) & Annual Cd (tons) \\
Cattle & $20,825,000$ & $3,101,642$ & 0.56 \\
Veal calves & $6,026,000$ & $30,169,612$ & 2.6 \\
Chicken & $89,540,000$ & 336,229 & 1.47 \\
Sheep\&lambs & $117,491,000$ & $2,017,076$ & 1.48 \\
\hline
\end{tabular}

The agricultural census cited in Section 5.2 provided data on animal numbers in Cape Town, as given in Table 5.9. ${ }^{206}$

\begin{tabular}{|l|r|}
\hline Table 5.9: Agricultural animals in Cape Town \\
\hline Animal & Number \\
\hline Pig & 4,235 \\
Cattle & 8,482 \\
Chicken & 466,666 \\
Sheep\&lambs & 26,232 \\
\hline
\end{tabular}

Assuming the same cadmium excretion per animal as observed in Australia yields a total cadmium flow of $\sim 10 \mathrm{~kg}$ Cd per year. Whether or not this is included in the subsequent calculations makes little difference to the results of this chapter, even considering that calves were included with cattle in the animal numbers. However, it was omitted because the cadmium concentrations implied by Kwonpongsagoon's data were, with the exception of 
veal calves, all below $1 \mathrm{ppm}$ and hence within the range of natural soils. At this concentration it was unclear whether the cadmium arose from artificial feed additives or was naturally present in feed, and hence whether this flow had the potential to concentrate cadmium in soil.

\section{5 .1}

Sludge and Effluent Flows for 2006/7

Records from routine municipal testing provided ample data on cadmium concentrations in wastewater treatment sludges, but not all sludge volumes were available. As estimates for total sludge production were not available for 2005 , it was not possible to construct a material balance for this year. Instead, this was performed for the period July 2006 - June 2007 to give the distribution of sludge and water for each wastewater treatment works (WWTW), and this was then scaled to 2005 on the basis of inflow volumes. The following data were available for each wastewater treatment works in 2006/7: ${ }^{138}$

- total influent volume (ML)

- $\quad$ estimated total annual sludge production in dry mass (metric tons)

- $\quad$ estimated sludge solids content (wt. \%)

- $\quad$ sludge uses by volume $\left(\mathrm{m}^{3}\right)$, excluding stockpiling and loss with effluent

This is summarized in Figure 5.3 for a generic WWTW. Landfilling does not appear in this figure because no sludge was recorded as going to landfill in either time period.

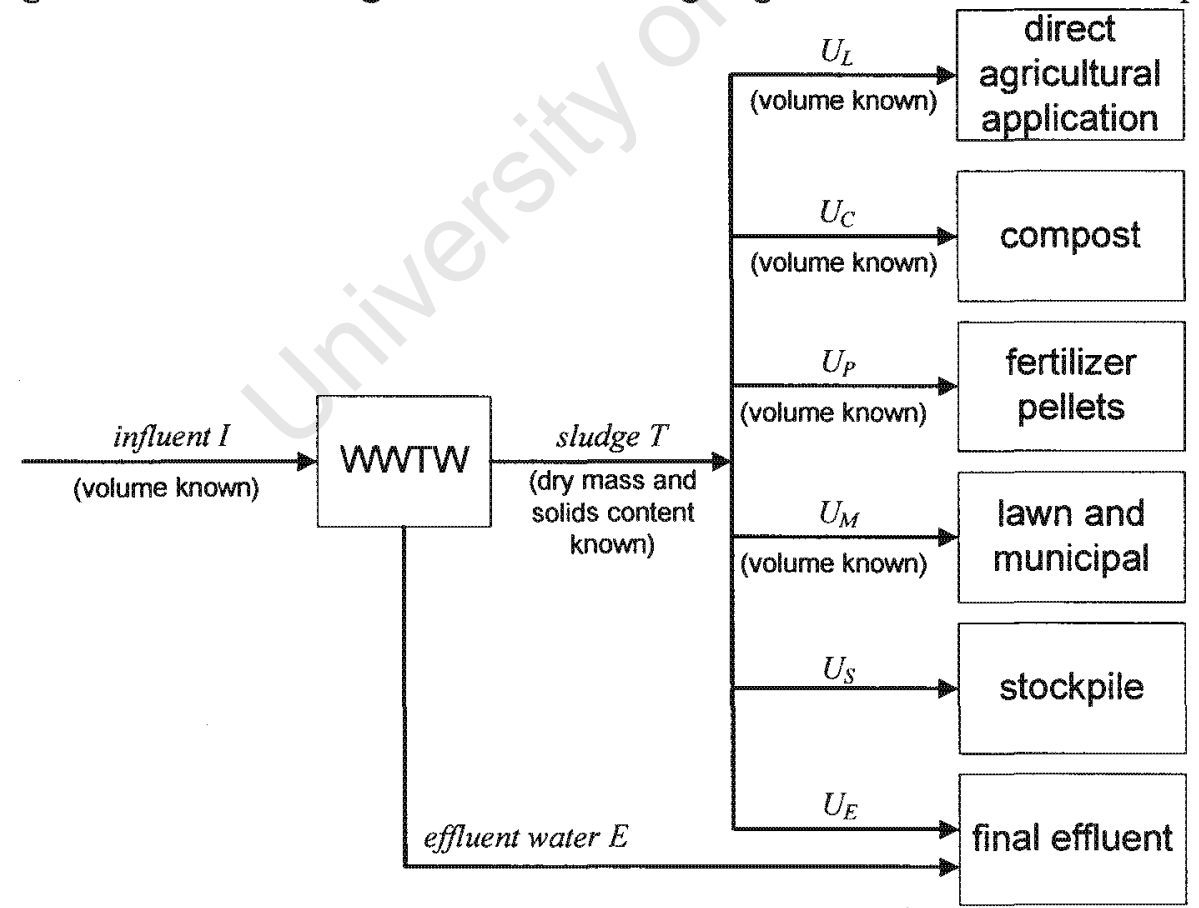

Figure 5.3: Conceptual material flow chart for a generic WWTW."

\footnotetext{
${ }^{*}$ Note that flows $U_{E}$ and $E$ are not actually separated at any stage, but are treated separately for the purpose of the material balance.
} 
In addition, the density of both influent and sludge is close to that of water $(1 \mathrm{~kg} / \mathrm{L})$ and on average final effluent contains approximately $17 \mathrm{mg} / \mathrm{L}$ of sludge, which was included in the sludge production estimates. ${ }^{139}$ All the variables in Figure 5.3 could therefore be expressed on a wet-mass basis, and related through the following set of equations:

$$
\begin{aligned}
& I=E+T \\
& U_{E}=\left(17 \times 10^{-6}\right) E \\
& \sum_{i} U_{i}=T
\end{aligned}
$$

Solving these equations with the 2006/7 data for each WWTW and summing these provided the city's sludge balance shown in Table 5.10.

\begin{tabular}{|l|r|r|}
\hline Table 5.10: Mass balance for all WWTWs in 2006/7 \\
\hline Flow & Wet mass (tons) & Dry mass (tons) \\
\hline Total influent & $206,017,857$ & 49,786 \\
Direct sludge land application & 118,680 & 20,033 \\
Sludge to compost & 36,667 & 6,891 \\
Fertilizer pellets & 4,329 & 4,156 \\
Sludge for lawn and municipal use & 6,024 & 2,410 \\
Stockpiled sludge & 38,030 & 12,797 \\
Sludge loss with final effluent & 14,356 & 3,499 \\
Final effluent water & $205,799,771$ & -0 \\
\hline
\end{tabular}

These figures exclude the $12,400 \mathrm{ML}$ of direct wastewater discharge from the city's three marine outfalls in the $2006 / 7$ period.

\subsubsection{Sludge, effluent and cadmium flows for 2005}

The mass flows calculated from equations $5.2-5.4$ for each WWTW were individually scaled to the period January - December 2005 according to the relative influent volumes at each works over the two twelve-month periods. The estimated city-wide wastewater balance for 2005 is given in Table 5.11, below. Monthly data for 2005 was available for the cadmium content of sludge and final effluent at each of the works, as well as for the three marine outfalls. Unfortunately these had minimum reporting limits, below which an accurate value was not always recorded ( $1 \mathrm{mg} / \mathrm{kg}$ for sludge and $1 \mu \mathrm{g} / \mathrm{L}$ for final effluent). In the case of sludge, these values were assumed to equal $1 \mathrm{mg} / \mathrm{kg}$. Since there were only six measurements in the data set which were below the reporting limit, and since most values were in excess of $2 \mathrm{mg} / \mathrm{kg}$, this was not expected to introduce a significant error. In the case of final effluent and outfall discharges, a large proportion of analysis results were recorded as $<1 \mu \mathrm{g} / \mathrm{L}$. Three

\footnotetext{
"This is the average across all city treatment works in 2008 , not flow weighted. A good effluent content is $10 \mathrm{mg} / \mathrm{L}$, and the government-regulated maximum limit is $25 \mathrm{mg} / \mathrm{L}^{139}$

The approximation $\left(1-17 \times 10^{-6}\right)^{-1} \approx 1$ is insignificant here.
} 
scenarios were therefore considered. In the first case it was assumed that no dissolved cadmium was present in effluent from WWTWs, and the only contributor to cadmium content was the $17 \mathrm{mg} / \mathrm{L}$ of suspended sludge. On this basis the mean cadmium content of sludge for each WWTW was used to calculate the cadmium released with its final effluent. For the coastal outfalls, for which sludge characteristics were unknown, a mean Cd content was calculated from analysis data for each outfall assuming all unrecorded values to be zero. In the second scenario the total final effluent concentrations of both WWTWs and outfalls was assumed to be $0.5 \mu \mathrm{g} / \mathrm{L}$, and in the third scenario this was set at $1.0 \mu \mathrm{g} / \mathrm{L}$.

\begin{tabular}{|l|r|r|}
\hline Table 5.11: Mass balance for all WWTWs in 2005 \\
\hline Flow & Wet mass (tons) & Dry mass (tons) \\
\hline Influent & $192,222,366$ & 46,989 \\
Direct sludge land application & 112,837 & 18,936 \\
Sludge to compost & 33,468 & 6,294 \\
Fertilizer pellets & 4,047 & 3,885 \\
Sludge for lawn and municipal use & 5,806 & 2,322 \\
Stockpiled sludge & 37,219 & 12,286 \\
Sludge loss with final effluent & 13,489 & 3,264 \\
Final effluent water & $192,015,501$ & -0 \\
\hline
\end{tabular}

The results of the sludge balance calculations, the cadmium analysis data for each WWTW and the above scenarios allowed the calculation of cadmium flow in sludge and a range of possible values for cadmium release with effluent. These results are given in Table 5.12.

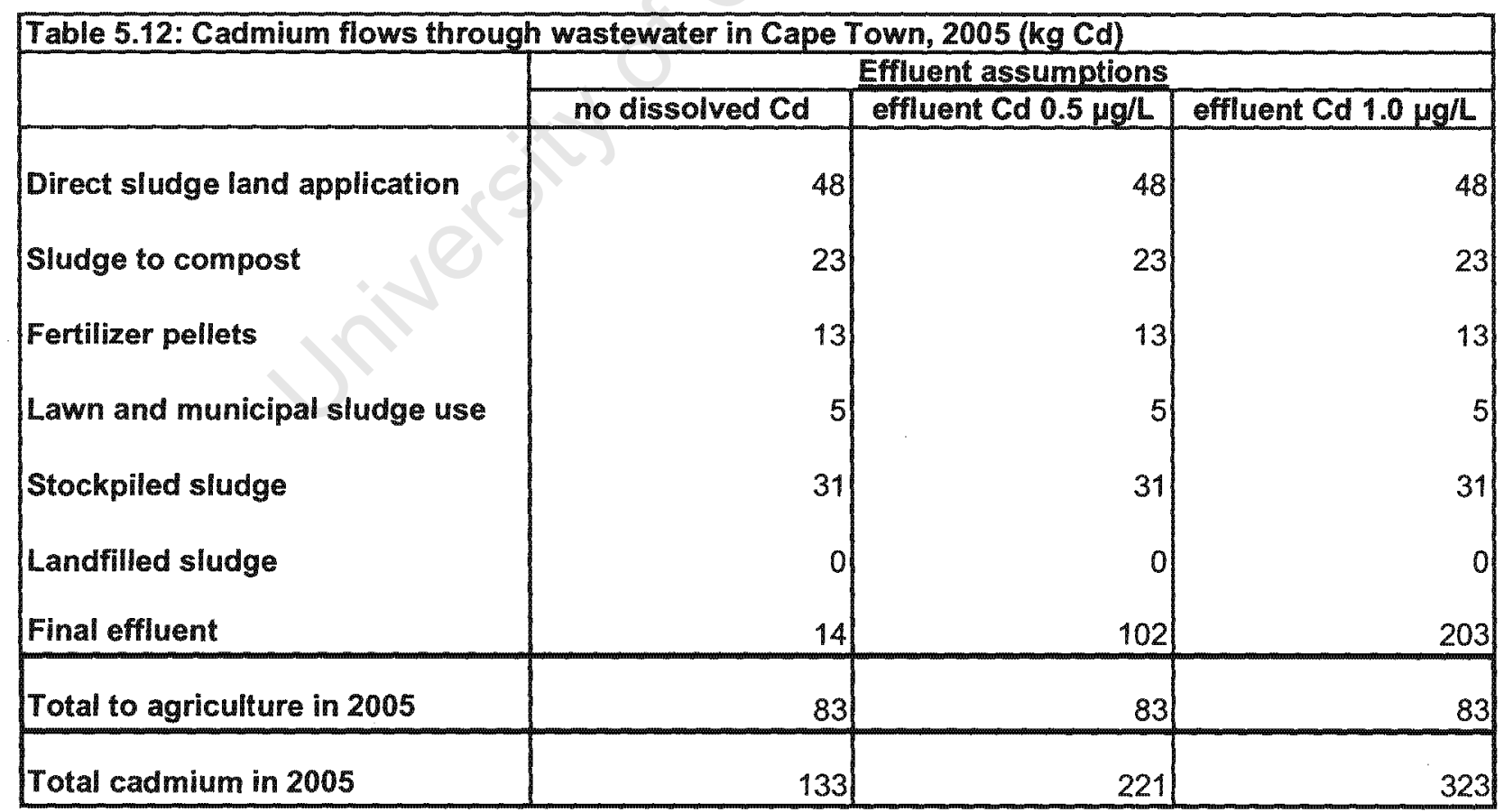

The calculated proportion of cadmium inflows released with final effluent varied between 11 and $63 \%$ depending on its assumed cadmium concentration. Clearly the manner in which cadmium distributes through the wastewater treatment system cannot be assessed on the basis 
of these data, although this does not affect the 2005 cadmium flow to agriculture through sludge. It is generally held (Section 2.5.5) that cadmium adsorbs strongly to organic solids and is concentrated in sludge during wastewater treatment. Note, however, that in all scenarios the concentration of cadmium in effluent was orders of magnitude lower than in sludge - the high proportion of effluent cadmium calculated in the high scenarios arose from the very large volumes of effluent produced by WWTWs.

The objectives of this chapter required a minimum estimate of the cadmium apportioned to agriculture, and hence a maximum realistic flow to final effluent. As literature and data suggested that the third scenario in Table 5.12 (effluent $\mathrm{Cd}$ at $1.0 \mu \mathrm{g} / \mathrm{L}$ ) was extreme, effluent concentration was taken to be $0.5 \mu \mathrm{g} / \mathrm{L}$ in the subsequent calculations. Landfill leachate made a negligible contribution to cadmium in wastewater. ${ }^{21,212}$ The 2005 results therefore provided a baseline without any double-counting when adding the hypothetical landfill release in the following section.

\subsection{RATE OF SOIL CONTAMINATION UNDER CONDITIONS OF ZERO LANDFILL RETENTION}

The previous chapter estimated the mass of cadmium sent to landfill in NiCd batteries in 2005 , which was designated $B$ (in $\mathrm{kg}$ ) and set at the minimum estimate of $5,600 \mathrm{~kg}$. The mass of cadmium applied to agricultural soils with phosphate fertilizer, $F$, was estimated in Section 5.3, as was the baseline amount applied with wastewater treatment sludge, $S$, in Section 5.5. Besides the total agricultural area, $L_{t o t}$, determined from the crop area data of Section 5.2 with

$$
L_{t o t}=\sum_{i} L_{i} \quad \text { (see Section } 5.2 \text { and 5.3) }
$$

the calculation of the rate of contamination required two further values: the soil density, $\rho$, and the depth of soil taken into account, $D$. $D$ was set at $0.30 \mathrm{~m}$, the depth to which wastewater treatment sludge is ploughed in during application. ${ }^{139}$ This is also a roughly typical depth to which the 'A' soil horizon extends (the "topsoil" depth) ${ }^{\dagger}$, characterized by considerable organic matter and accommodating the majority of soil biological activity, including most of crop root systems. ${ }^{213}$ Soil density is composition-dependent and highly variable. Mineral soil densities typically lie in the range $900-1900 \mathrm{~kg} / \mathrm{m}^{3}$. ${ }^{214}$ The presence of organic material reduces this considerably, however, with peaty soils reaching densities as $10 w^{214}$ as $300 \mathrm{~kg} / \mathrm{m}^{3}$. Because the interest was particularly on agricultural topsoil, which would contain substantial organic material, an upper limit of $1200 \mathrm{~kg} / \mathrm{m}^{3}$ was used here.

Two approaches were taken to assess the environmental significance of the cadmium flows quantified in Chapter 4, both founded on the hypothetical circumstance that all cadmium in

\footnotetext{
"Only 6 of the analysis results $(3.3 \%)$ were above $1 \mu \mathrm{g} / \mathrm{L} \mathrm{Cd}$, and only 2 were above $1.5 \mu \mathrm{g} / \mathrm{L} \mathrm{Cd}$.

The A horizon is also defined to include any evidence of cultivation, such as ploughing, where this has occurred. $^{213}$
} 
MSW was immediately leached from the landfill". The first scenario further assumed that all of this cadmium was applied to agricultural land with wastewater treatment sludge (in some form), allowing the cadmium release to be considered on the single basis of soil contamination. The second scenario took into account the partitioning of cadmium in the wastewater treatment system. This was somewhat more realistic, but suffered from highly uncertain distribution coefficients and, whilst still offering an estimate of agricultural contamination, also involved flows to natural waters and sludge stockpiles which would have environmental impacts of their own.

For the first scenario the hypothetical rate of soil contamination in 2005 was calculated as:

$$
R=\frac{B+S+F}{L_{t o t} D \rho}\left(\frac{1 h a}{10^{4} m^{2}}\right) \frac{\left(10^{6} \mathrm{ppm}\right)}{(1 \text { year })}
$$

which provided a value of $0.11 \mathrm{ppm} /$ year. Taking the background concentration of cadmium into account (Section 5.2), the transition period to the limit of $2 \mathrm{ppm} \mathrm{Cd}$ in agricultural soil was calculated as 18 years. This is the maximum amount of time taken under this scenario for all land available for sludge application to reach the regulated limit.

For the second scenario, a distribution coefficient $\varphi$ was calculated from the scenario of $0.5 \mu \mathrm{g} / \mathrm{L}$ effluent concentration given in Table 5.12. This was equal to the ratio of cadmium flow to agriculture, to the total cadmium in wastewater influent in $2005(0.378)$. The rate of soil contamination was then:

$$
R=\frac{B \varphi+S+F}{L_{t o t} D \rho}\left(\frac{1 h a}{10^{4} m^{2}}\right) \frac{\left(10^{6} \mathrm{ppm}\right)}{(1 \text { year })}
$$

This gave a value of $0.041 \mathrm{ppm} /$ year and a maximum transition period of 47 years. Analogous calculations were carried out for the other wastewater treatment flows under this scenario. The results of these and previous calculations are summarized in the following section.

\footnotetext{
* All leachate was taken to be transferred to wastewater treatment. In fact, one operating landfill in Cape Town has an on-site leachate treatment facility, but all its effluents are either sent to wastewater treatment ${ }^{215}$ or reintroduced to the landfill through irrigation for dust suppression. The wastewater treatment system is therefore the only receiver of cadmium lost from landfills.

${ }^{\dagger}$ A minor omission implicit in these equations is the possible reduction in fertilizer use as a result of sludge application. Given that only a small proportion of the city's agricultural land receives sludge in a year, and the very small cadmium contribution of fertilizer to total soil contamination, this was not significant.
} 
The calculations of this chapter yielded the conservative estimates summarized in Table 5.13, for two hypothetical scenarios. The key characteristics of these scenarios were:

- All cadmium disposed of with municipal waste is lost from the landfill in leachate, which is treated at a wastewater treatment plant.

- The first scenario assumed all cadmium released from landfills is applied to agricultural soil, in addition to the 2005 baseline flows to agriculture.

- The second scenario assumed that cadmium released from landfills is distributed among the outputs of the wastewater treatment system in proportion to the cadmium distribution of 2005.

- $\quad$ No sludge is diverted from agricultural use, despite high levels of cadmium contamination which would far exceed the limits specified by sludge-use guidelines. ${ }^{136}$

- The current agricultural soil limit for receiving applications of sludge, $2 \mathrm{ppm},{ }^{136}$ is considered the maximum acceptable cadmium concentration in agricultural soil.

\begin{tabular}{|lr|}
\hline Table 5.13: Summary of results - cadmium contamination of agricultural soil \\
\hline 2005 baseline flows & 4.7 \\
\hline Phosphate fertilizer application to agricultural soil ( $\mathrm{kg} \mathrm{Cd}$ ): & 83 \\
\hline Wastewater treatment sludge (all forms) to agricultural soil (kg Cd): & \\
\hline Zero landfill retention scenario: all Cd to agriculture & 5,700 \\
\hline Total cadmium to agricultural soil (kg Cd): & 0.11 \\
Rate of soil contamination (ppm/year): & 18 \\
Transition period to 2 ppm limit (years): & 830 \\
Average contamination rate (ha/year): & 2,200 \\
\hline Zero landfill retention scenario: cadmium partitioning in WWTWs & 0.041 \\
\hline Total cadmium to agricultural soil (kg Cd): & 47 \\
Rate of soil contamination (ppm/year): & 2,700 \\
Transition period to 2 ppm limit (years): & 810 \\
Cadmium to natural waters (kg Cd): & 320 \\
Cadmium to sludge stockpiles (kg Cd): & \\
Average contamination rate (ha/year): & \\
\hline
\end{tabular}

In the light of Table 5.13, it is clear that the disposal of NiCd batteries to MSW involves environmentally significant amounts of cadmium. Furthermore, these results were calculated with minimizing parameter values, and hence represent the minimum effects to be reasonably expected within the scenario conditions.

Whilst this chapter has provided a tool with which to assess the environmental significance of the cadmium flows in Chapter 4, it is important to bear in mind the severe limitations on the interpretation of Table 5.13. The greatest of these lie within the scenarios themselves. Most importantly, the assumption of zero landfill retention of cadmium is completely 
hypothetical, and was made solely for the purpose of this assessment. As discussed in Section 2.5.2, cadmium is generally retained in landfills during the methanogenic phases, although its long-term stability is uncertain. At present, landfill leachate in Cape Town does not contain significant amounts of cadmium. Also, the current management of the wastewater treatment system is such that leachates and sludges are regularly monitored. Major releases of cadmium would therefore be diverted before agricultural soil became excessively contaminated, in line with sludge use guidelines. ${ }^{136}$

Notwithstanding these limitations, this amount of cadmium clearly represents a potentially serious environmental hazard which deserves proper attention and due caution. 


\title{
CHAPTER 6: DISCUSSION AND CONCLUSIONS
}

\author{
6.1 \\ DISCUSSION OF RESULTS
}

\subsection{1}

NiCd Battery Flows of Cadmium in Cape Town

Chapter 4 presented the estimated cadmium flows in Cape Town resulting from the use of NiCd cells. Although these estimates have considerable margins of uncertainty, they nevertheless provide an overview of the city's cadmium metabolism and identify the important contributors. The total estimated disposal of cadmium to landfill at steady-state was 5,600-15,000 kg Cd (mean 9,800 kg). Despite the margins of uncertainty, it is clear that a considerable amount of this toxic metal was contained in the city's waste, but probably not sufficient to support viable local recycling even on a national level. 2005 was considered representative with respect to small cells, so these results would be reasonably accurate for any recent year.

The minor contributions to NiCd-associated cadmium flows by large cells agree with international experience, which has shown that large cells generally contribute about $20 \%$ to the total. Lindqvist and von Malmborg have reported the share of NiCd battery flows through households and service sectors (which would predominantly be small cells) in the cadmium metabolism of Stockholm as $72 \%$ of total inflows, ${ }^{13}$ which is substantially less than, but qualitatively similar to the 4-year average contribution of $-90 \%$ seen in Cape Town. They also reported that in Stockholm and two other Swedish cities these made the major contribution to cadmium in MSW. However, these cities achieved a significant recycling rate of $25 \%$ for these cells, whereas end-of-life practices in Cape Town are almost exclusively disposal-oriented for small cells. A comparison for large industrial $\mathrm{NiCd}$ cells shows that in both Cape Town and the three Swedish cities discussed by Lindqvist and von Malmborg the use and disposal of large cells is isolated from the general waste streams, but in Sweden this occurs through an almost complete recycling rate whereas in Cape Town a considerable amount goes to hazardous waste disposal. Kwonpongsagoon has reported the dominant contribution made by small cells in Australia, and a low recycling rate for these. ${ }^{20} \mathrm{He}$ reported a $76 \%$ contribution to $\mathrm{NiCd}$-associated cadmium flows arising from small cells. The smaller contribution by large cells in Cape Town can be partly explained by those industrial $\mathrm{NiCd}$ applications seen internationally which are completely lead-acid dominated in South Africa, including traction and UPS systems. This could be due to a greater price-sensitivity in the South African market: large NiCd cells are generally the more expensive option (as measured against lead-acid technology), whereas in many small-cell applications they are the cheaper alternative (relative to lithium-ion cells).

Per capita use of cadmium in NiCd cells in Cape Town was $\sim 3.3 \mathrm{~g} / \mathrm{ca}$. with small NiCd cells making the largest contribution, of $\sim 3.0 \mathrm{~g} / \mathrm{ca}$. This is not significantly higher than Kwonpongsagoon's 1998 Australian estimate of $3.1 \mathrm{~g} / \mathrm{ca}$, nor even his small cell estimate of 
$2.4 \mathrm{~g} / \mathrm{ca}^{20}$ However, per capita use is much lower than in Denmark in $1998,(8.5 \mathrm{~g} / \mathrm{ca})$, before the introduction of the European Battery Directive of $2006{ }^{17}$

The presence of some broad similarities between the NiCd metabolism of Cape Town and developed-world regions despite the differences in socio-economic environment suggests that there could be instances in which SFA results from other, better-researched economies could be applied to gain at least qualitative insight into material flows and environmental interactions in developing-world regions. This supports and extends the suggestion by Lindqvist and von Malmborg that individual municipalities might draw on SFA results from other municipalities if they lack the resources to undertake a detailed study of their specific region. ${ }^{13}$ The results from Cape Town might also be relevant to other developing-world cities. Of course, in the light of the differences also present, it would be necessary to clarify the factors influencing inter-regional parallels before such transposition of SFA results across world regions could be applied with any confidence.

\subsubsection{Environmental Significance of Landfilled Cadmium}

Chapter 5 presented an assessment of the environmental significance of the cadmium flows to municipal waste in terms of its likely minimum potential to contaminate farmland. The transition periods shown in Table 5.13 show that an annual release of this much cadmium could contaminate the agricultural areas of Cape Town to the current guideline limit of $2 \mathrm{ppm}$ in under two decades. Clearly an environmentally significant quantity of cadmium was contained in MSW in 2005.

These calculations served only as a framework by which to assess environmental significance in terms of contamination potential, and took no account of the likelihood of contamination. It is in fact unlikely that a landfill would display zero retention, and the present regime of wastewater treatment and farmland monitoring would prevent the realisation of the Chapter 5 scenarios. However, these caveats deserve closer inspection. Whilst a landfill is not expected to leach disposed cadmium immediately, there is great uncertainty surrounding long-term retention of heavy metals and possible mechanisms for metal release have been proposed (Section 2.5.2). Such releases would occur some time after the landfill is deemed to be 'stabilized', and hence post-closure monitoring might have ceased. Another consideration is that the short- to medium-term retention of heavy metals in landfills could vary with landfill practice. For instance, the diversion of organic material (for biogas digestion, for example) could significantly reduce metal adsorption sites and shorten the anaerobic phase, or landfill mining could cause a shift to oxidative conditions and produce a sudden release of previously immobilized cadmium. Any such changes to waste management practice should therefore be planned holistically, with consideration of the entire waste flow and an appreciation for the interaction of its various components.

It should also not be assumed that proper management of the system will necessarily continue indefinitely. Proper monitoring and compliance often depends on favourable political, organisational and economic conditions which may not persist over the entire lifetime of the risk. In South Africa several other municipalities have failed to maintain 
regulatory compliance at their wastewater treatment plants. ${ }^{216}$ Hence, although Chapter 5 used unrealistic future scenarios to conclude that the amounts of landfilled cadmium were significant, the assessment nevertheless involved real future risks.

The hypothetical release of landfilled cadmium considered in Chapter 5 would increase the cadmium concentration of wastewater and wastewater treatment sludge by several orders of magnitude. A suitable response, assuming proper controls were in place, would prove costly. Figure 5.1 showed that current practice would dispose of contaminated sludge to landfill, but this could close an accumulative loop rather than permanently isolating the cadmium, leading to ever higher costs. The loss of the valuable resource that sludge represents would be an additional cost. ${ }^{66}$ Avoiding this situation would require the installation of entirely separate leachate treatment systems, capable of efficiently isolating the released cadmium. This would also be an expensive option. The most effective and efficient method for prevention is to eliminate cadmium from the municipal waste stream before it is landfilled.

\section{2}

\section{METHODOLOGY DISCUSSION}

\subsection{1}

\section{SFA in a Developing-world City}

Although data gathering is a significant challenge in all SFA studies, this proved to be particularly true for this work. Some existing data sources were extremely valuable, particularly the wealth of data collected through environmental and process monitoring by the City of Cape Town which often spanned considerable timeframes in some detail. Publications by the national statistical bureau, Statistics South Africa, also proved useful, although those with local detail were usually published intermittently. Nonetheless, data for South Africa, and Cape Town in particular, were usually far less readily available, complete or detailed as those gathered by agencies in the developed world. Exceptions occurred when data were routinely generated in the course of operations, as for wastewater treatment monitoring, or when the gathering of data was specifically assigned as a function of a government body such as Statistics South Africa. The specific values required for an urban SFA are seldom directly available from such sources, however, because official statistics are usually gathered at a highly aggregated level, whilst routine environmental monitoring is emissions-focussed and not concerned with the up-stream economic origins of hazardous materials.

Industry associations have the capacity to facilitate research by providing an intermediary between individual companies and researchers, thereby making data available without exposing companies to the risk of releasing commercially sensitive data. ${ }^{17}$ Unfortunately industry associations in South Africa appear to be weak in comparison to their developedworld counterparts and gather little data, which are often incomplete or poorly maintained. Companies were generally unwilling to directly entrust commercial data to research, although helpful exceptions were encountered. Requests were seldom explicitly denied. It was more common for data to be promised but never provided, despite repeated follow-ups. The year of study was selected in the hope that such data would no longer be considered 
sensitive, but in retrospect it seemed that a more recent year would perhaps have posed no more difficulty. However, most industries were very willing to discuss technical and operational issues and few seemed to be particularly secretive toward or suspicious of research, even with regard to the environmental impacts of their products. This is not to suggest that all industries related to $\mathrm{NiCd}$ use are aware of and proactive toward the hazards of cadmium - on the contrary, some industry players were only marginally aware and generally unconcerned. It is preferable, however, for industries to be unconcerned but open to dialogue rather than to be fully aware but deliberately secretive.

Data gaps were overcome by adapting data from international sources and by gathering primary data from industry and municipal authorities, and personal contact with experts in various sectors of $\mathrm{NiCd}$ application was crucial to identifying relevant avenues of inquiry. It is doubtful whether this SFA study could have been completed within useful bounds of uncertainty on the basis of existing data sources alone.

In some respects the practice of SFA was somewhat simplified by the limited industrial and technological activity in Cape Town. Because production of NiCd cells does not occur in the city and manufacturing of electronic products is limited, the quantification of use could be greatly simplified by considering only imports and not local production or export. Specifying the system to correspond with the municipal area of the City of Cape Town further avoided many difficulties that might be encountered for other urban regions, because this metropolitan boundary incorporates the vast majority of urbanized space associated with the city, including virtually all of its "commuter shed". This administrative boundary could therefore be considered largely self-contained with respect to the products of interest, in the sense that essentially all products sold within the boundaries were expected to be used there. The aviation industry was the only exception in this regard.

\subsubsection{Spatial scaling of data}

The use of national-scale data was necessitated by a lack of data specific to the study area. This required the development of scaling factors for adjusting these values to the city level. Although the uncertainty this introduced was not likely to affect the conclusions of the study, it is of interest from a methodological point of view to consider the scaling factors more closely. The scaling factors derived for adjusting national data on power tool, separate cell and part-of-product flows to the urban scale differed from the population and GDP share of the city. Just as this scaling was necessitated by the lack of data on the urban scale, so it makes validation of their predictions difficult. South Africa has vast socio-economic disparities across regions and population groups, however, which could strongly distort relationships between consumption of technological products and population or economic activity. The power tool factor was based on market research and hence reflects established correlations that are expected to be more accurate than scaling by either population or GDP.

It is not possible to truly validate the assumed agreement between proportion of national NiCd use (separate or part-of-product) and the AMPS scaling factor (Section 3.2.2), but it is possible to test its underlying premise so as to decide whether it is preferable to the use of 
population or GDP. The premise was that the use of NiCd products would be more closely correlatad to use of other technological products. This would gain some support if it were shown to hold in other cisses, and to some extent AMP'S data can be used for this purpose. Unfortunately the comparison cannot be made at a smaller scale than provinces because the boundaries of the availatle data sources only align at this level, and thus some of the variability is hidden by the fact that all provinees contain more fariation than single municipalities (e.g. urban and rural, economically productive and umproductive, ete.). The observed variability would probably be greater if the comparison was made at the municipal scale, which could either strengthen or weaken the conclusions of the proviticial comparison. Nonetheless, the provincial picture is worth considering. and the conclusions arc probably transferable because sume provinees are quite ditferent, for example overwhelmingly urban and economically active (Gauteng) wersus very rural and genterally pour (Northern Cape). Figure 6.1 shows the proportions of affirmative responses to the four AMP's questions scen as being most 'technological', plotled with the provincial proportions of population and GDP,

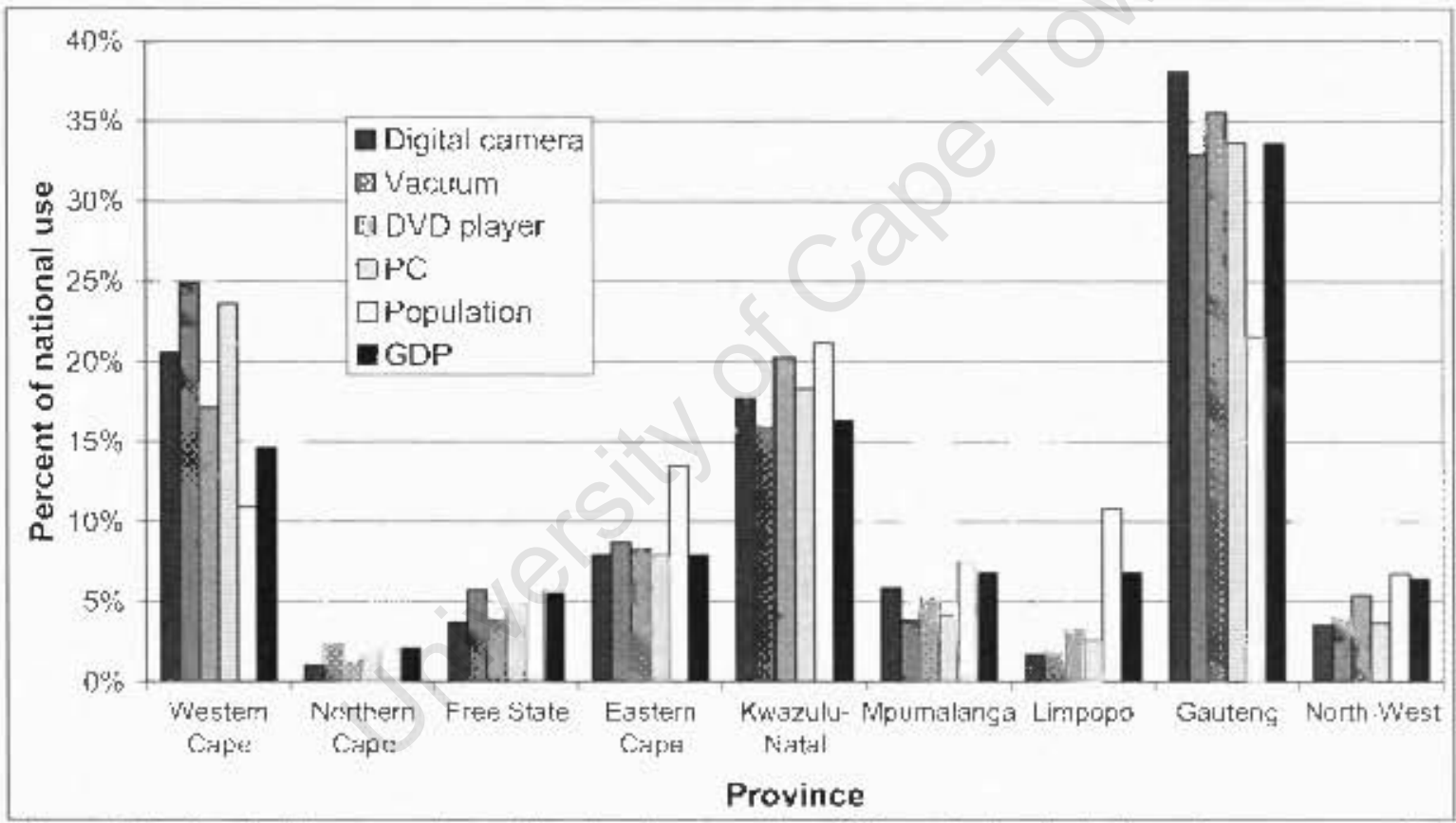

Figure 6.1: Provincial proportions of national ownerbhip of lour 'tochnological' products compared th proportion of national pousulation and GDP, Soures: $[3],[4],[129]$.

This does sugges that these technolngical products we more comrelated to each other than to GDP and especially to population, ant hence could serve as a belter proxy for another such product. Two of these products were incorporated into the AMPS scaling factor, but a third survey question - the purchase of a new stnall elcctrical appliance in the previous 12 months

\footnotetext{
* AMPS also carries data for telezisions and audio equipment, but the high propurtion of households owning these (72 and $60 \%$, respectively) produces a strong coriclation to population. In the absence of unequal ownership levels, as is the tase of troce suptisticaled tethoulogical priducts, population would generally be a goud proxy. By the same principle, vacuum clcanters might not be considered to be very "teclundogical" from a

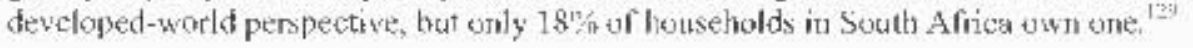


was also used. Resporses to this question were less correlated to the other two, and more closely to population, as shown ir Figure 6.2, but this question secmed at least as likely to reflect NiCd battery use as the other two.

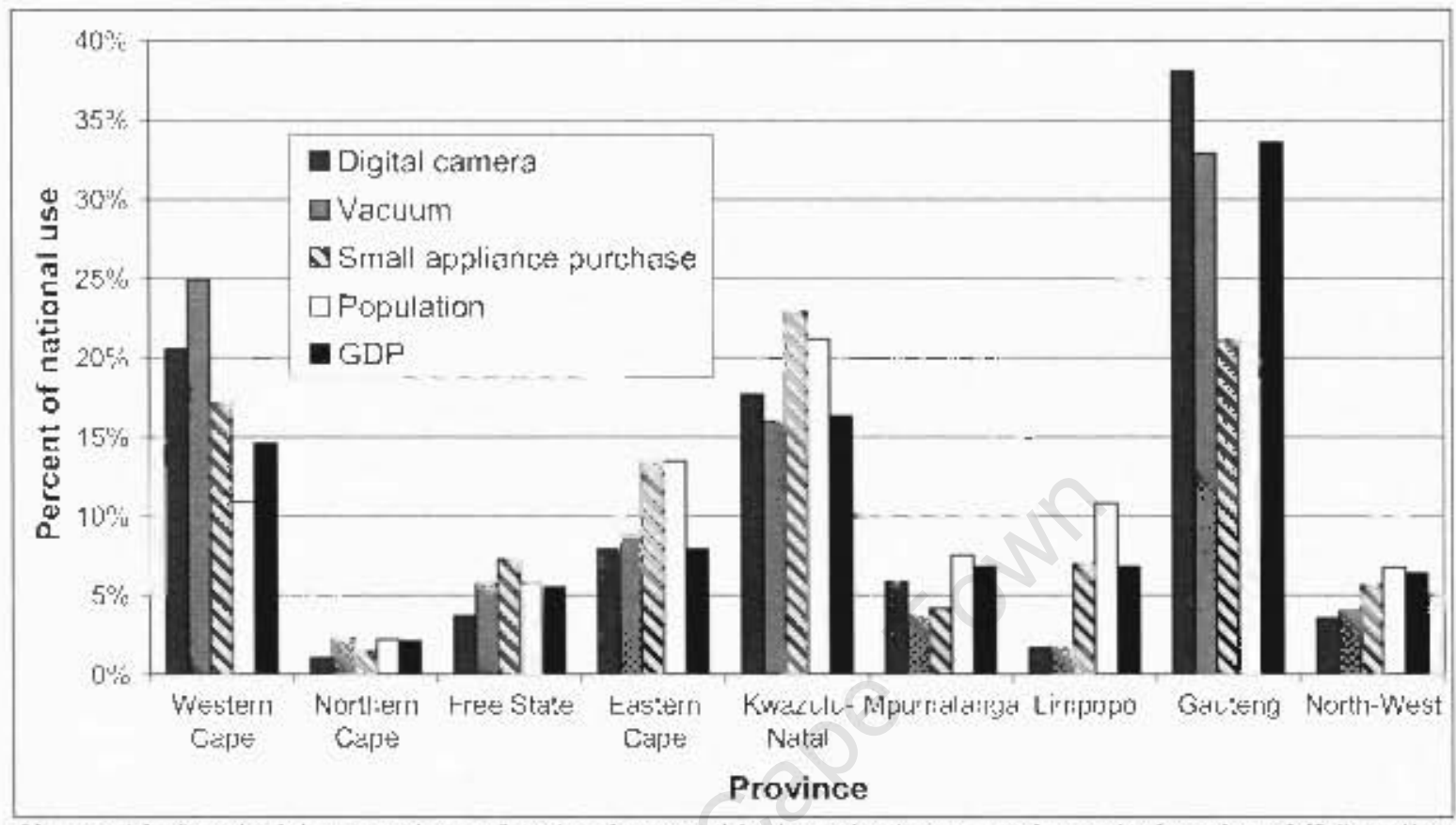

Figure 6.2: Provincial proportions of national onylership/purchasing as used to calculate the AMJS scaling factor, compared to proportion of national population and GDP. Sources: $[3],[4]:[129]$.

Recent purchases of small appliances appeared to move sonewhat separately from the other two proxies, but for the most part fell between these and the population proportion. Given the comelation seen in tigure 6.1 and the absence of scriously divergent behaviour by appliance purchases, the scaling factor used - the geometric mean of the three AMTS values in Figure 6.2 is likely to more closely track the use of NiCd cells than population or GDP. This approach avoided the prohibilive costs of performing a local quantification for cach of many NiCd applications, yet provided a much more plausible option than arbitrary adjustment using population or Gil)

\subsubsection{Method for Assessment of Environmental Significance}

The methodological approach taken in Chapter 5 provided for a preliminary assessnent of potential environmental risk with very low information requirements. This used hypothetical scenarios in which the "best worst-case" contamination of the receptor of greatest eoncern was assessed. The worst-ease aspect meant that this was a measure of the quantity of hazardous material involved rather than an assessnient of the likelihood of emission, and hence detailed knowledge of attenuation and transfer processes was not required. Ilowever. as the quanlity places an upper limit on the possible impact, this prelininary assessment would have avoided undertaking a comprehensive risk analysis for negligible amounts. On the other hand the best -ease aspect of the approach, by which only the minimum impacts of 
emission were considered, ensured that a conclusion confirming environmental significance could be made with confidence in spite of very uncertain data. In the case of NiCd battery disposal, this methodology served well. However, the approach would fail under circumstances in which the minimum impacts were found to be acceptable - such an outcome would provide no useful information, as impacts could be much greater than those considered under the best worst-case scenarios. This approach was also limited in that it determined that further precautionary research or action is required but could not conclude whether cadmium disposal would actually cause any of the postulated contamination. Unfortunately this is an indictment of the current state of knowledge, and at present only the precautionary principle can guide further actions.

\section{3}

\section{OUTLOOK AND RESPONSE}

The future for cadmium use in batteries is uncertain. In spite of growing concern and ever tighter restrictions on its use, particularly in Europe, world cadmium consumption has not shown a decline (Section 2.4). Production and consumption cut-backs in Europe have been offset by considerable growth elsewhere, particularly in NiCd production in the East. ${ }^{74}$ It cannot be assumed that NiCd use in Cape Town will follow that in Europe, given the economic, market and legislative differences between these regions. Lithium ion technology is a possible driver for $\mathrm{NiCd}$ elimination from power tools and some other applications. Although they remain considerably more expensive than the NiCd alternative, Li-ion batteries have a number of crucial advantages in power tool applications. How these advantages play out in the price-sensitive ${ }^{171,174}$ South African market, in conjunction with market and technology-related changes in battery cost, will significantly affect the future $\mathrm{NiCd}$ demand in the city. But even with lithium ion cell substitution in the power tool market, the import of cells or NiCd-containing products could continue or even grow. It should be noted that in many cases NiCd cells are considered to be the best available technology, most notably in emergency applications. Industrial batteries also have particular performance advantages, in terms of which $\mathrm{Pb}$-acid batteries are not equivalent.

The complexity of landfill chemistry and the limited understanding of long-term landfill behaviour make it impossible to guarantee the retention of cadmium, and even an expanded research effort into these areas might fail to quantify the risks with any confidence. Guided by the precautionary principle, the best course of action would be to eliminate the disposal of cadmium to MSW, given that its high toxicity makes even a substantially reduced amount a considerable risk. The waste management hierarchy (Section 2.6) urges reduction at source before considering reuse and recycling, but in the case of cadmium this neglects the fact that it is almost entirely produced as a by-product of zinc production. It is impossible to reduce cadmium extraction without reducing zinc consumption, and hence it seems likely that cadmium will continue to be present in some part of the global waste streams for some time to come. Reuse is not an option for NiCd cells either. Management options are restricted to recycling and disposal, although disposal could occur either before or after economic use. As a by-product, cadmium supply is highly inelastic, although sufficiently low prices can lead to closure of production facilities and the disposal of unrefined cadmium. ${ }^{74}$ This means that recycling could prove ineffective at reducing emissions, because the reduced demand for 
primary cadmium would increase its availability, possibly shifting the use of cadmium into other more diffuse, non-recyclable products. This has led to the suggestion that it is preferable to eliminate the use of cadmium in the economy and isolate it as a hazardous waste during the production of primary zinc. ${ }^{63}$ Given a choice between dispersed end-of-life emissions and hazardous waste disposal, the latter would appear a sensible option. A lifecycle perspective could point the other way, however. To the extent that primary zinc production will continue, cadmium will be available for refinement with insignificant additional extraction costs (economic and environmental). If a cadmium substitute would require dedicated extraction or more extensive processing, the environmental impacts of these activities should rightfully be weighed against the impacts of cadmium emissions. To rephrase this from a resource point of view, any by-product cadmium sent directly to hazardous waste disposal is a wasted resource. Depending on the additional costs of an effective collection system, the best option might be a single-use policy in which NiCd use is permitted or even encouraged but spent NiCd cells are disposed as hazardous waste rather than recycled.

Several arrangements for small-cell battery collection can be envisaged and some have been implemented with varying degrees of success. Municipal provision of drop-off points for household hazardous waste, whether permanent or only on an occasional basis, seldom achieve high participation rates. ${ }^{6,217}$ Extended producer responsibility (EPR) has been widely recommended ${ }^{218,219,220}$ and provision has been made in South African legislation for this to be implemented. ${ }^{221}$ With this approach, the producers and/or suppliers of a product are responsible for the costs of its safe end-of-life disposal or recycling. In its strictest form this requires that any shop selling a product must accept end-of-life returns without charge and return them to the original producer for recycling or safe disposal. Some of the advantages of EPR are that the costs of disposal (usually) become included in the price of the product, so that the user of the product pays for disposal when choosing a purchase, and that the producers have an incentive to make their product less hazardous or more recyclable so as to reduce the recycling or disposal costs. Although the toxicity of cadmium justifies the costs of a separate collection system, a system in which each producer separately collects and recycles or disposes of their products involves substantial duplication and is generally very inefficient. ${ }^{6}$ EPR legislation usually mandates or soon leads to the formation of cooperative arrangements, whereby a single collection body is established with industry funding. ${ }^{6,222}$ Depending on how producer contributions are calculated, this could give rise to an industrywide disposal 'commons', reducing the incentive to design better disposal or recycling characteristics into products.

The similar mechanisms of advanced recycling and advanced disposal fees (ARF, ADF) charge consumers for the end-of-life treatment of products at the time of purchase, with these payments financing a system for collection and recycling or safe disposal that accepts the end-of-life products at no additional charge. ${ }^{6}$

A significant weakness of simple EPR and ARF/ADF approaches is that even though the consumer does not have to make a monetary payment at the point of disposal there is still a disincentive toward returning the product to a collection point arising from the costs of time, effort and travel. This makes it difficult for such collection systems to achieve very high 
collection rates. From the consumer's point of view, such systems are identical to a recent battery collection program launched in South African supermarkets by a battery producer as a corporate responsibility initiative. This received a very weak response from the public in terms of quantities collected, ${ }^{132}$ although many factors might have contributed to this.

On the other hand, systems which charge a deposit at the time of sale, which is refunded when the end-of-life product is delivered to a collection point (usually any retailer), tend to achieve very high collection rates even with small deposits. In South Africa the recycling of lead-acid motor vehicle batteries uses a deposit system and has achieved recycling rates approaching $100 \% .{ }^{223}$ Collection of refillable soft drink bottles also operates by a deposit system in South Africa, and is perhaps more relevant to the NiCd case. Like small consumer batteries they have low residual value to the consumer and are very easily and conveniently disposed of with municipal waste. Nevertheless, a fairly small deposit has produced a return rate of over $95 \% .^{224}$

Large cells appear to offer relatively simple possibilities for safe cadmium use. Very high recycling rates have been achieved in other countries and in Cape Town the large-cell pathways already appear to be isolated from the MSW stream (although this partly involves indefinite storage of spent cells). Some of the necessary arrangements already exist in South Africa, with certain suppliers voluntarily implementing EPR and companies such as Eskom making conscientious use of these arrangements. The returned cells are exported for recycling to produce new batteries - a closed loop. ${ }^{155,156}$ However, in the absence of mandatory EPR these suppliers are at a price disadvantage to their competitors, whose lower prices do not include recycling commitments and therefore the batteries become hazardous waste or, more disturbingly, stockpiled by users to avoid disposal costs. It is quite possible that this situation could be remedied by introducing mandatory EPR under existing South African legislation. If cadmium use is preferred over direct disposal, whether on a closedloop or single-use basis, large cells could offer safe, controllable applications for the metal. There are also considerable possibilities for expanding this use, should other cadmium applications be deemed too risky. These include those applications seen internationally which are absent in South Africa (see Chapter 4) and areas for potential growth of the large-cell market worldwide, including electric vehicle batteries and storage of solar-generated electricity. ${ }^{74}$

It should be noted that most interventions to cadmium use and disposal cannot be effectively enacted only on the scale of a single city, but require extension of research, debate and action to smaller (household and business) and larger (national and even international) scales.

Aside from the current and future prospects for cadmium use and management of its disposal, the results presented here indicate that landfills in the city currently contain significant amounts of accumulated cadmium. These stocks will need to be considered when planning long-term management of these sites, or when considering such possibilities as landfill excavation for the purposes of landfill mining or reclamation. Excavation activities, in particular, carry the risk of rapidly returning the landfill material to an aerobic, oxidative state which could result in metal release (Section 2.5.2). 


\title{
6.4.1
}

\author{
Conclusions
}

The use of NiCd batteries in 2005 contributed $5,600-15,000 \mathrm{~kg} \mathrm{Cd}$ (mean 9,800 kg) to municipal solid waste in Cape Town, which was believed to be a representative annual steady-state flow. This was destined for disposal to landfills in the city. The largest contributions were from cordless power tools and small NiCd cells imported separately into South Africa, with a lesser contribution from the import of pre-assembled products containing NiCd cells. The recycling rate for the small NiCd cells used in these applications was below $1 \%$. The disposal of cadmium in such quantities has the potential to cause significant environmental harm, and is not necessarily safely contained by landfills in the long term. Furthermore, changes in waste management practice could inadvertently release this cadmium to the environment in the nearer-term.

Under present conditions, should landfills cease to retain the cadmium in municipal waste this would be transferred in leachate to wastewater treatment plants in the city. This would raise the cadmium load in wastewater treatment sludge by several orders of magnitude. Although monitoring and controls are currently in place to prevent contamination of agricultural land, the application of sludge to agricultural soils poses a potential pathway for contamination of food crops by cadmium in MSW. The best approach to ensuring that this cannot occur is to eliminate spent NiCd cells from MSW.

A methodology was presented for the assessment of environmental significance using very limited data, which assessed the "best worst-case" impact of the NiCd-associated cadmium on agricultural land. Although not a predictive tool, this methodology provided the unequivocal conclusion that the amounts of cadmium disposed of to MSW were of environmental concern.

Large NiCd cells contributed smaller but significant cadmium flows through the city's economy, amounting to $3.4-14 \%$ of total NiCd-associated cadmium flows, but were not believed to have contributed to municipal waste. However, it was found that some large cells were stored indefinitely at the end of their useful lives in order to avoid disposal costs.

Several similarities were observed between the NiCd metabolism of Cape Town and that of regions in the developed world. This suggested that it might be possible to gain qualitative insights into the metabolism of developing-world cities through knowledge of the more thoroughly studied developed world. The results from Cape Town might also give qualitative insight into the cadmium metabolism of other developing-world cities. There were important differences, too, and hence more research would be required to identify influential factors before this could be done with any confidence.

Performing SFA in a developing-world city involved significant data challenges, and relied heavily on primary data collection, although official records and literature were also very important sources. Industry associations were less well positioned as data repositories that 
their developed-world counterparts, whilst individual companies were usually unwilling to provide commercial data even confidentially and for years in the past. However, industry did provide willing and valuable sources for other information.

\subsubsection{Recommendations}

The City of Cape Town municipality oversees large flows of cadmium, particularly through the solid waste management system but also through their use as backup power supplies in the electricity distribution networks under the City's control. The City should consider the presence of spent NiCd cells in the MSW stream and ensure that waste management practices prevent dangerous emissions now and in the future. This is particularly relevant to the management of existing landfills which contain substantial accumulations of cadmium. In the context of alternative waste management practices currently being considered or implemented, these should include measures to eliminate improper NiCd disposal. If this is not done, new practices could risk inadvertently releasing the cadmium through, for example, reducing landfill retention capacity by removing organic material, or atmospheric emission from incineration.

The City of Cape Town could reduce the volumes of cadmium sent to hazardous waste disposal by including end-of-life recycling in tender requirements for the electricity distribution system. Some suppliers already offer suitable take-back arrangements.

The connection between landfills, wastewater treatment and agricultural soil presents a potential route for food contamination if cadmium retention by landfills were compromised. Current practices involve careful monitoring and controls at wastewater treatment plants which would prevent this. The City's organisational structures overseeing this must be robust and well maintained, especially if waste disposal practices enhance the risk of cadmium release. However, the most effective point of intervention would be to eliminate the disposal of cadmium to MSW.

Further investigation and debate is required to develop a sustainable policy toward the use of cadmium and particularly its use in NiCd cells. This should include the consideration of banning cadmium use in some (but not all) applications, extended producer responsibility aimed at safe disposal or recycling, and possible use of deposit systems to incentivise returns. A life-cycle perspective should be taken to ensure that the costs and effects of substitutes are also accounted for. To be effective, such policies will likely need to be formulated at the national level, and hence the debate must be undertaken nationally, as well as at the urban scale.

The possibilities should be explored for expanding the scope of routine environmental monitoring to include collection of relevant economic and societal data at the local level. This would facilitate future SFA studies, but would also inform environmental management with systemic information not often provided by emissions monitoring. 


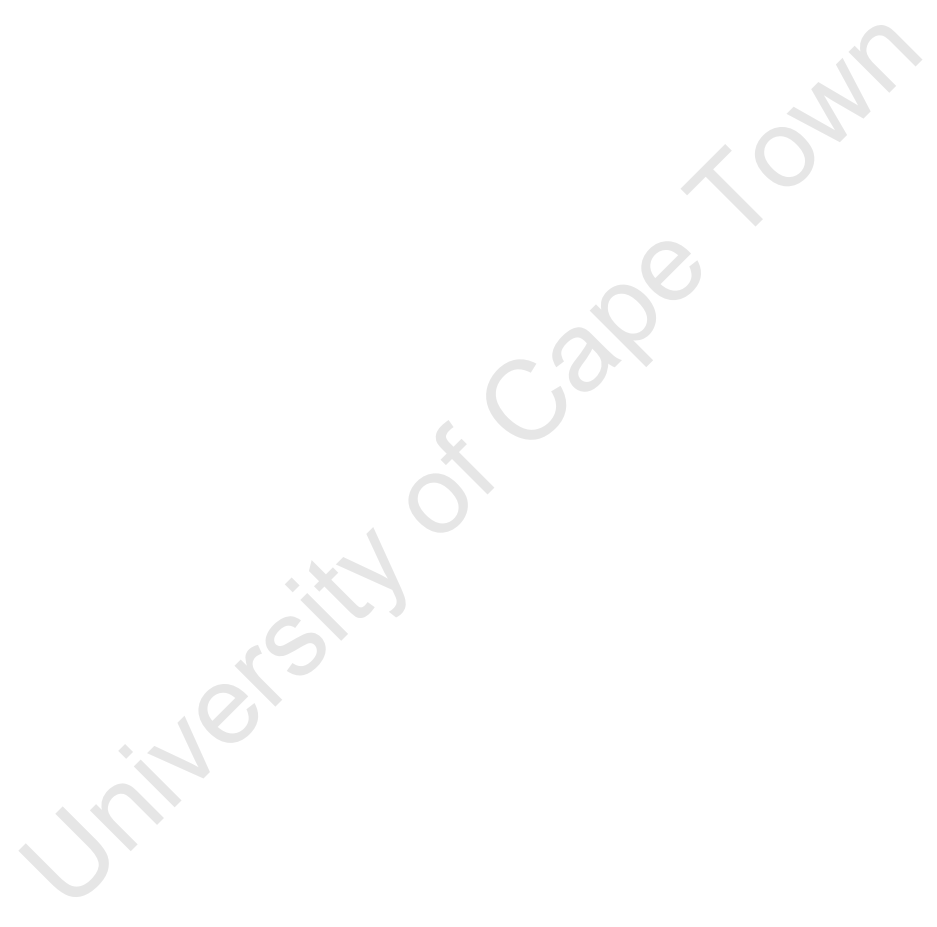




\section{REFERENCES}

1 Goodland, R. and Daly, H. 1996. Environmental sustainability: universal and non-negotiable. Ecological Applications 6(4):1002-1017.

2 Population Reference Bureau 2008. 2008 World Population Data Sheet. Available online: www.prb.org, accessed 22 October 2009.

3 Statistics South Africa 2008. Community Survey, 2007 - basic results: municipalities. Pretoria: Statistics South Africa, p. 92. Available online: www.statssa.gov.za, accessed 15 July 2008.

4 Provincial Government of the Western Cape (PGWC) 2009. Socio-economic profile: City of Cape Town 2006. Available online: www.capegateway.gov.za, accessed: 15 February 2009.

5 City of Cape Town (CoCT) 2006. State of Cape Town Report 2006: Development issues in Cape Town. Cape Town: City of Cape Town. p. 50.

6 Porter, R.C. 2002. The Economics of Waste. Washington: RFF Press.

7 Frosch, R.A. and Gallopoulos, N.E. 1989. Strategies for manufacturing. In: Managing the planet: readings from Scientific American magazine. New York: W.. Freeman and Co. pp.97-108.

8 Lifset, R. and Graedel, T.E. 2002. Industrial ecology: goals and definitions. In: $A$ Handbook of Industrial Ecology, edited by R.U. Ayres and L.W. Ayres. Northampton: Edward Elgar, pp. 3-15.

9 Ayres, R. U. and Kneese, A. V. 1969. Production, consumption and externalities. American Economic Review. 59(3): 282-297.

10 Harper, E.M. and Graedel, T.E. 2004. Industrial Ecology: A Teenager's Progress. Technology in Society 26: 433-445.

11 Cohen, M.J. and Howard, J. 2006. Success at its Price - The Institutionalization and Political Relevance of Industrial Ecology. Journal of Industrial Ecology 10(1-2): 79-88

12 Clift, R., Malcolm, R., Baumann, H., Connell, L. and Rice, G. 2005. Eco-labels and Electric Monks. Journal of Industrial Ecology 9(3) 4-7.

13 Lindquist, A. and von Malmborg, F. 2004. What Can We Learn from Local Substance Flow Analyses? The Review of Cadmium Flows in Swedish Municipalities. Journal of Cleaner Production 12:909-918. 
14 White, R. M. 1994. In: The Greening of Industrial Ecosystems, edited by B. R. Allenby and D. J. Richards. Washington: National Academy Press.

15 Van der Voet, E. 1996. Substance from cradle to grave: development of a methodology for the analysis of substance flows through the economy and environment of a region. $\mathrm{PhD}$ thesis, Leiden University, Leiden, Netherlands.

Bringezu, S. and Moriguchi, Y. 2002. Material flow analysis. In: A Handbook of Industrial Ecology, edited by Ayres, R.U. and Ayres, L. Northampton: Edward Elgar, pp. 79-90.

17 Hansen, E. and Lassen, C. 2003. Experience with the use of substance flow analysis in Denmark. Journal of Industrial Ecology 6 (3-4), 201-219.

18 Udo de Haes, H. A., van der Voet, E. and Kleijn, R. 1997. Substance flow analysis (SFA), an analytical tool for integrated chain management. In: Regional and National Material Flow Accounting: From Paradigm to Practice of Sustainability, Proceedings of the ConAccount Workshop, January 21-23, 1997, Leiden, Netherlands. Wuppertal: Wuppertal Institute for Climate, Environment and Energy. pp.32-42.

19 Van der Voet, E. 2002. Substance flow analysis methodology. In: A Handbook of Industrial Ecology., edited by R.U. Ayres and L.W. Ayres. Northampton: Edward Elgar, pp. 91-101.

20 Kwonpongsagoon, S. 2006. Integration of substance flow analysis, transport and fate of materials in the environment, and environmental risk assessment for provision of information for regional environmental management: cadmium as a case study in Australia. PhD thesis, University of New South Wales, Sydney, Australia.

21 Kwonpongsagoon, S., Peter Bader, H.-P. and Scheidegger, R. 2007. Modelling cadmium flows in Australia on the basis of a substance flow analysis. Clean Technologies and Environmental Policy 9(4): 313-323.

22 Brunner, P.H. and Rechberger, H. 2004. Practical Handbook of Material Flow Analysis. Boca Raton: CRC Press. pp.69-75.

Guinée, J.B., van den Bergh, J.C.J.M., Boelens, J., Fraanje, P.J., Huppes, $\quad$ G., Kandelaars, P.P.A.A.H., Lexmond, Th.M., Moolenaar, S.W., Olsthoorn, A.A., Udo de Haes, H.A., Verkuijlen, E. and van der Voet, E. 1999. Evaluation of risks of metal flows and accumulation in economy and environment. Ecological Economics 30(1): 47-65. 
24. Månsson, N., Bergbäck, B. and Sörme, L. 2008. Phasing out of Cadmium, Lead and Mercury - Effects on Urban Stocks and Flows. Journal of Industrial Ecology 13(1): 94-111.

25 Timmermans, V. and Van Holderbeke, M. 2004. Practical Experiences on Applying Substance Flows Analysis in Flanders: Bookkeeping and Static Modelling of Chromium. Journal of Cleaner Production 12: 935-945.

26 Hawkins, T.R., Matthews, H.S. and Hendrickson, C. 2006. Closing the Loop on Cadmium. International Journal of Life Cycle Assessment 11(1): 38-48.

27 Jonsson, A., Lindström, M. and Bergbäck, B. 2002. Phasing out cadmium and lead - Emissions and Sediment Loads in an Urban Area. The Science of the Total Environment 292: 91-100.

28 Zumbuehl, D. 2006. Mass Flow Assessment (MFA) and Assessment of Recycling Strategies for Cathode Ray Tubes (CRTs) for the Cape Metropolitan Area (CMA), South Africa. Masters thesis, Swiss Federal Institute of Technology, Zurich, Switzerland. Available online:

http://ewasteguide.info/Zumbuehl_2006_ETH-Empa, accessed September 2008.

29 Niza, S., Rosado, L. and Ferrão, P. 2009. Methodological advances in urban material flow accounting based on the Lisbon case study. Journal of Industrial Ecology 13(3): 384-405.

30 Villalba, G., Ayres, R.U. and Schroder, H. 2007. Accounting for Fluorine Production, Use and Loss. Journal of Industrial Ecology 11(1): 85-101.

31 Saikku, L., Antikainen, R. and Kauppi, P.E. 2007. Nitrogen and Phosphorus in the Finnish Energy System 1900-2003. Journal of Industrial Ecology 11(1): 103119.

32 Liu, Y., Villalba, G., Ayres, R.U. and Schroder, H. 2008. Global Phosphorus Flows and Environmental Impacts from a Consumption Perspective. Journal of Industrial Ecology 12(2): 229-247.

33 Kapur, A., Keoleian, G., Kendall, A. and Kesler, S.E. 2008. Dynamic Modelling of In-Use Cement Stocks in the United States. Journal of Industrial Ecology 12(4): 539-556.

34 Villalba, G., Liu, Y., Schroder, H. and Ayres, R.U. 2008. Global Phosphorus Flows in the Industrial Economy from a Production Perspective. Journal of Industrial Ecology 12(4): 557-569.

35 Harper, E. 2008. A Product Level Approach to Historical Material Flow Analysis Tungsten as a Case Study. Journal of Industrial Ecology 12(5/6): 768-784. 
36 Mao, J. and Graedel, T.E. 2009. Lead in In-Use Stock: A Dynamic Analusis. Journal of Industrial Ecology 13(1): 112-126.

37 Achternbosch, M., Kupsch, C., Sardemann, G. and Bräutigam, K.-R. 2009. Cadmium Flows Caused by Worldwide Production of Primary Zinc Metal. Journal of Industrial Ecology 13(3): 438-454.

38 Weidema, B.P., Wesnæs, M.S.1996. Data Quality Management for Life Cycle Inventories - an Example of Using Data Quality Indicators. Journal of Cleaner Production, 4(3-4): 167-174.

39 Huijbregts, M.A.J. 1998. Application of Uncertainty and Variability in LCA. Part I: A general framework for the analysis of uncertainty and variability in life cycle assessment. International Journal of Life Cycle Assessment, 3(5): 273-280.

40 Hedbrant, J. and Sörme, L. 2001. Data Vagueness and Uncertainty in Urban Heavy-Metal Data Collection. Water, Air and Soil Pollution: Focus 1: 43-53.

41 Chevalier, J.-L. and Le Téno, J.-F. 1996. Life Cycle Analysis with Ill-Defined Data and its Application to Building Products. International Journal of Life Cycle Assessment, 1(2): 90-96.

42 Choobineh, F. and Behrens, A. 1992. Use of Intervals and Possibility Distributions in Economic Analysis. Journal of the Operational Research Society, 43(9): 907-918.

43 Kmietowicz, Z.W. and Pearman, A.D. 1981. Decision Theory and Incomplete Knowledge. Hampshire: Gower. pp. 8-9.

44 Heijungs, R. 1996. Identification of Key Issues for Further Investigation in Improving the Reliability of Life-Cycle Assessments, Journal of Cleaner Production $4(3-4): 159-166$.

45 Tan, R.R., Culaba, A.B. and Purvis, M.R.I. 2002. Application of Possibility Theory in the Life-Cycle Inventory Assessment of Biofuels. International Journal of Energy Research 26: 737-735.

46 Morgan, M.G. and Henrion, M. 1990. Uncertainty - A Guide to Dealing with Uncertainty in Quantitative Risk and Policy Analysis. Cambridge: Cambridge University Press.

47 Bergsdal, H., Bohne, R.A. and Brattebø, H. 2007. Projection of construction and demolition waste in Norway. Journal of Industrial Ecology 11(3): 27 - 39. 
48 Miller, S.A., Landis, A.E. and Theis, T.L. 2006. Use of Monte Carlo Analysis to Characterize Nitrogen Fluxes in Agroecosystems. Environmental Science and Technology 40: 2324-2332, and supporting information available online: http://pubs.acs.org, accessed 13 October 2009.

49 Huijbregts, M.A.J., Gilijamse, W., Ragas, A.M.J. and Reijnders, L., Evaluating Uncertainty in Environmental Life-Cycle Assessment: A case study comparing two insulation options for a Dutch one-family dwelling. Environmental Science and Technology 2003 (37): $2600-2608$.

50 Kennedy, D.J., Montgomery, D.C. and Quay, B.H. 1996. Stochastic Environmental Life Cycle Assessment Modeling. International Journal of Life Cycle Assessment 1(4): 199-207.

51 Sonnemann, G.W., Schuhmacher, M. and Castells, F. Uncertainty Assessment by a Monte Carlo Simulation in a Life Cycle Inventory of Electricity Produced by a Waste Incinerator, Journal of Cleaner Production 11: 279-292.

52 Ellingham, I., Fawcett, W. 2006. New Generation Whole-Life Costing: Property and construction decision-making under uncertainty. London and New York: Taylor \& Francis. p. 26.

53 Lloyd, S.M. and Ries, R. 2007. Characterizing, Propagating and Analyzing Uncertainty in Life-Cycle Assessment - A Survey of Quantitative Approaches. Journal of Industrial Ecology 11(1): 161-179.

54 Howard, R.A. and Matheson, J.E. 1984. Readings in the principles and practice of decision analysis. Strategic Decision Systems: Menlo Park, California. Cited in: Morgan, M.G. and Henrion, M. 1990. Uncertainty - A Guide to Dealing with Uncertainty in Quantitative Risk and Policy Analysis. Cambridge: Cambridge University Press.

55 Alexis, C., Disch, S., Twaroski, C., Reindl, J. and Case, C.R. 2007. Substance flow analysis of mercury intentionally used in products in the United States. Journal of Industrial Ecology 11(3): 61-75.

56 Liu, Y., Chen, J., Mol, A.P.J. and Ayres, R.U. 2007. Comparative analysis of phosphorus use within national and local economies in China. Resources, conservation and recycling 51: 454-474.

57 Neset, T.-S. S., Bader, H.-P. and Scheidegger, R. 2006. Food consumption and nutrient flows: nitrogen in Sweden since the 1870s. Journal of Industrial Ecology, $10(4): 61-75$.

58 Hansen, E. 2000. Substance flow analysis for dioxins in Denmark. Copenhagen, Denmark: Danish Environmental Protection Agency. 
59 Tukker, A., Buist, H., van Oers, L. and van der Voet, E. 2006. Risks to health and environment of the use of lead in products in the EU. Resources, Conservation and Recycling 49: 89-109.

60 Morf, L.S., Tremp, J. Gloor, R., Huber, Y., Stengele, M. and Zennegg, M. 2005. Brominated flame retardants in waste electrical and electronic equipment: substance flows in a recycling plant. Environmental Science and Technology. 39(22): 8691-8699.

61 Xueyi, G. and Yu, S. 2008. Substance flow analysis of copper in China. Resources, Conservation and Recycling 52 (6): 874-882.

62 Borsari, M. 2005. Cadmium: Inorganic and Coordination Chemistry. In: Encyclopedia of Inorganic Chemistry, 2nd ed., vol. 2, edited by R.B. King. Chichester: John Wiley and Sons. pp.603-620.

63 van der Voet, E., van Egmond, L., Kleijn, R. and Huppes, G. 1994. Cadmium in the European Community: a Policy Oriented Analysis. Waste Management and Research, 12(6): 507-526.

64 Bergbäck, B., Johansson, K. and Mohlander, U. 2001. Urban Metal Flows - A Case Study of Stockholm. Water, Air and Soil Pollution: Focus 1: 3-24.

65 Moll, H.C., Noorman, K.J., Kok, R., Engström, R., Throne-Holst, H. and Clark, C. 2005. Pursuing More Sustainable Consumption by Analyzing Household Metabolism in European Countries and Cities. Journal of Industrial Ecology 9(1-2): 259-275.

66 Lindqvist, A. and Eklund, M. 2002. A Regional Cadmium Inventory: Interpretation and Management. Local Environment 7(3): 295-310.

67 Burström, F. and Korhonen, J. 2001. Municipalities and Industrial Ecology: Reconsidering Municipal Environmental Management. Sustainable Development $9: 36-46$.

68 van Beers, D. and Graedel, T.E. 2003. The Magnitude and Spatial Distribution of InUse Copper Stocks in Cape Town, South Africa. South African Joumal of Science 99: 61-69.

69 van Beers, D. and Graedel, T.E. 2004. The Magnitude and Spatial Distribution of InUse Zinc Stocks in Cape Town, South Africa. Ajeam-Ragee 9: 18-36. 
70 Nissing, C. and von Blottnitz, H. 2007. A Material Flow Analysis of Wood and Paper in Cape Town: Is There Potential to Redirect Flows in Formal and Informal Sectors to Foster Use as a Renewable Resource? International Journal of Environment and Sustainable Development 6(2): 147-155.

71 Schulte-Schrepping, K.-H. and Piscator, M. 2003. Cadmium and Cadmium Compounds. In Ullmann's Encyclopedia of Industrial Chemistry, $6^{\text {th }}$ ed. Weinheim, Germany: Wiley-VCH, vol.6, p.23.

72 Unites States Geological Survey (USGS) 1997-2009. Mineral Commodity Summaries. Available online: www.usgs.gov, accessed 1 April 2009.

73 Butterman, W.C. and Plachy, J. undated. Mineral Commodity Profiles - Cadmium. United States Geological Survey, Open-File Report 02-238. Available online: www.usgs.gov, accessed 19 June 2008.

74 Morrow, H. 2005. Cadmium markets and trends. International Cadmium Association, available online: www.cadmium.org., accessed 16 February 2009.

75 Salkind, A.J. and Klein, M. 1992. Batteries (Secondary Cells) In: Encyclopedia of Chemical Technology 4th ed., edited by J.I. Kroschwitz and M. Howe-Grant. New York: John Wiley and Sons. pp1032-1083.

76 Pillot, C. 2008. The rechargeable battery market, 2007-2015. Presented at Advanced Battery Technologies Conference, 1-3 July, 2008, Frankfurt, Germany. Available online:

www.avicenne.com/gb/batteries_and_power_supply_publications.htm

Accessed: 15 January 2009.

77 RIS International 2007. Canadian Consumer Battery Baseline Study. Report to Environment Canada, available online:

www.ec.gc.ca/nopp/docs/rpt/battery/en/c1.cfm, accessed 14 January 2009

Putois, F. 1995. Market for Nickel-Cadmium Batteries. Journal of Power Sources 57: 67-70.

79 Rydh, C. J. and Svärd, B. 2003. Impact on global metal flows arising from the use of portable rechargeable batteries. The Science of the Total Environment $302,167-184$.

80 Wilburn, D.R. 2007. Flow of Rechargeable Batteries in the United States, 1996 2005. Scientific Investigations Report 2007-5198. Reston, VA 20192: U.S. Geological Survey. 
81 Wadia, C., Alivisatos, A.P. and Kammen, D.M. 2009. Materials Availability Expands the Opportunity for Large-Scale Photovoltaics Deployment. Environmental Science and Technology 43: 2072-2077.

82 Asami, T. 1984. Pollution of Soils by Cadmium. In: Changing Metal Cycles and Human Health, edited by J.O. Nriagu. Berlin, Heidelberg, New York, Tokyo: Springer-Verlag. pp. 95-111.

83 van der Perk, M. 2006. Soil and Water Contamination. London: Taylor and Francis Group. p. 86, pp. 131-132.

84 World Health Organisation 1992. Environmental Health Criteria 134: Cadmium. Geneva, Switzerland: World Health Organisation. pp.20-23.

85 Alloway, B.J. 1995. Cadmium. In: Alloway, B.J. (ed.) Heavy Metals in Soils, 2nd ed, edited by B.J. Alloway. Glasgow: Blackie Academic and Professional. pp. $122-151$.

86 Vesilind, P.A., Worrell, W., Reinhart, D. 2002. Solid Waste Engineering. Pacific Grove, CA: Brooks/Cole. p. 18, p.158, pp. 120-121.

87. Bilitewski, B., Härdtle, G. and Marek, K. 1994. Waste Management. Berlin: Springer-Verlag. pp.259-302.

88 Bozkurt, S., Moreno, L. and Neretnieks, I. 2000. Long-term processes in waste deposits. The Science of the Total Environment 250: 101-121.

89 Bozkurt, S., Moreno, L. and Neretnieks, I. 1999. Long-term fate of organics in waste deposits and its effect on metal release. The Science of the Total Environment 228: 135-152.

90 Alloway, B.J. 1995. Soil processes and the behaviour of metals. In: Heavy Metals in Soils, edited by B.J. Alloway. London: Blackie Academic and Professional, pp. 11-25.

91 Erses, A.S. and Onay, T.T., 2003. In situ heavy metal attenuation in landfills under methanogenic conditions. Journal of Hazardous Materials B99: 159.

92 Östman, M., Whalberg, O., Ågren, S., and Mårtensson, A. 2006. Metal and organic matter contents in a combined household and industrial landfill. Waste Management 26: 29.

93 Alloway, B.J. and Ayres, D.C. 1997. Chemical Principles of Environmental Pollution, $2^{\text {nd }}$ ed. London: Blackie Academic and Professional. 
94 Øygard, J.K., Gjengedal, E., and Måge, A. 2005. Mass-balance estimation of heavy metals and selected anions at a landfill receiving MSWI bottom ash and mixed construction wastes. Journal of Hazardous Materials A123: 70-75.

95 Kjeldsen, P., Barlaz, M.A., Rooker, A.P., Baun, A., Ledin, A., Christensen, T.H. 2002. Present and long-term composition of MSW landfill leachate: a review. Critical Reviews in Environmental Science and Technology. 32(4): 297-336.

96 Belevi, H. and Baccini, P. 1989. Long-term behaviour of municipal solid waste in landfills. Waste Management and Research 7(1): 43-56.

97 Stigliani, W. and Salomons, W. 1993. Our father's toxic sins. New Scientist 140(1903): 38-42.

98 Logan, T.J., Goins, L.E. and Lindsay, B.J. 1997. Field Assessment of Trace Element Uptake by Six Vegetables from N-Viro Soil. Water Environment Research 69(1): 28-33.

99 Ismail, B.S., Farihah, K. and Khairiah, J. 2005. Bioaccumulation of Heavy Metals in Vegetables from Selected Agricultural Areas. Bulletin of Environmental Contamination and Toxicology 74(3): 320-327.

100 Senesi, G.S., Baldassarre, G., Senesi, N. and Radina, B. 1999. Trace Element Inputs into Soils by Anthropogenic Activities and Implications for Human Health. Chemosphere 39(2): 343-377.

101 Kloke, A., Sauerbeck, D.R. and Vetter, H. 1984. The Contamination of Plants and Soils with Heavy Metals and the Transport of Metals in Terrestrial Food Chains. In: Changing Metal Cycles and Human Health, edited by J.O. Nriagu. Berlin, Heidelberg, New York, Tokyo: Springer-Verlag. pp. 113-141.

102 Danish EPA 2007. Possible Control of EU Priority Substances in Danish Waters. Available online: www2.mst.dk, accessed April 2008.

103 Karlsson, S., Fredrikson, F. and Holmberg, J. 2005. Future Redistribution of Cadmium to Arable Swedish Soils. Journal of Industrial Ecology 8(4): 41-57.

104 Bergbäck, B., Anderberg, S. and Lohm, U. 1994. Accumulated Environmental Impact: The Case of Cadmium in Sweden. The Science of the Total Environment 145: $13-28$.

105 Guinée, J.B., and van der Voet, E. 2002. Risks of Metal Flows and Accumulation. In: A Handbook of Industrial Ecology, edited by R.U. Ayres and L.W. Ayres. Northampton: Edward Elgar, pp. 382-390. 
106 Turer, D.G. and Maynard, B. 2003. Heavy Metal Contamination in Highway Soils. Compatison of Corpus Christi, Texas and Cincinnati, Ohio Shows Organic Matter is Key to Mobility. Clean Technologies and Environmental Policy 4: 235245.

107 Kiely, G. 1997. Environmental Engineering. London: McGraw-Hill.

108 Karvelas, M., Katsoyiannis, A. and Samara C. 2003. Occurrence an Fate of Heavy Metals in the Wastewater Treatment Process. Chemosphere 53: 12011210.

109 Chipasa, K.B. 2003. Accumulation and Fate of Selected Heavy Metals in a Biological Wastewater Treatment System. Waste Management 23: 135-143.

110 Masters, G.M. and Ela, W.P. 2008. Introduction to Environmental Engineering. Upper Saddle River: Pearson. p. 316.

111 Kempton, S., Sterritt, R.M. and Lester, J.N. 1987. Heavy Metals Removal in Primary Sedimentation, I: The Influence of Metal Solubility. Science of the Total Environment 63: 231-246.

112 Sörme, L. and Lagerkvist, R. 2002. Sources of Heavy Metals in Urban Wastewater in Stockholm. The Science of the Total Environment 298: 131-145.

113 Department of Water Affairs and Forestry (DWAF), 1998. Waste management series: minimum requirements for waste disposal by landfill, 2 nd ed. Johannesburg: Department of Water Affairs and Forestry.

114 City of Cape Town 2008. State of Environment Report. Cape Town: City of Cape Town. pp. $46-48$.

115 Harraway, T.J. 1996. Chemical Characterisation of Landfill Leachate and its Potential Mobility Through the Cape Flats Sand. MSc Thesis, University of Cape Town, Cape Town, South Africa.

116 Hall, C.J., Haider, M. and Keraan, R. 2008. Impacts on Solid Waste Disposal Resulting from the Implementation of Intergrated Waste Management Policies and Plans: City of Cape Town. Proceedings of the 19th Waste Management Conference of the IWMSA (WasteCon 2008), Durban, South Africa, 6-10 October 2008.

117 Wright-Pierce Engineering 1999. Cape Metropolitan Council Integrated Solid Waste Management Feasibility Study Report. Draft document prepared for the Cape Metropolitan Council. Cape Town: Cape Metropolitan Council. 
118 Cape Metropolitan Council 2000. Background Information Document: Closure of Faure Landfill Site. Cape Town: Cape Metropolitan Council.

119 City of Cape Town 2006. City of Cape Town Integrated Waste Management (IWM) Policy. Cape Town: City of Cape Town.

120 Polokwane Declaration on Waste Management, First National Waste Summit, Polokwane, Northern Province, South Africa, 26-28 September 2001.

121 Department of Environmental Affairs and Tourism 2007. National Environmental Management: Waste Bill. Government Gazette, Republic of South Africa, B392007.

122 Von Blottnitz, H., Austin, G., Nissing, C., Schmalbein, N., Liphoto, L., Ncwadi, N. Gets, A. and Fedorsky, C. 2006. Burn, Gasify, Pyrolyse or Ferment? Making Sense of the Many Possibilities for Energy from Waste in South Africa. Proceedings of the 18th Waste Management Conference of the IWMSA (WasteCon 2006), Cape Town, South Africa, 5-8 September 2006.

123 Nontangana, M., 2008. Prospects of Anaerobic Digestion of Municipal Solid Waste in the City of Cape Town. Proceedings of the 19th Waste Management Conference of the IWMSA (WasteCon 2008), Durban, South Africa, 6-10 October 2008.

124 Novella, P. 2008. Waste to Energy - Is One Solution to South Africa's Energy Crisis to be Found in the Waste Being Disposed to Landfill? Proceedings of the 19th Waste Management Conference of the IWMSA (WasteCon 2008), Durban, South Africa, 6-10 October 2008.

125 Deneen M.A. and Gross, A.C. 2006. The global market for power tools. Business Economics, 41 (3): 66-73.

126 Freedonia Group, World Power Tools to 2011. Freedonia Group 2007, available online: www.freedoniagroup.com, accessed 20 February 2009.

127 Statistics South Africa (StasSA) 2007. Building statistics 2005. Available online: www.statssa.gov.za, accessed 25 October 2008.

128 Arrive Alive 2009. www.arrivealive.co.za, accessed: 16 February 2009.

129 South African Advertising Research Foundation (SAARF) 2005. All media and products survey 2005RA. Available online: www.saarf.co.za/, accessed 26 January 2009.

130 South African National Building Regulations and Building Standards Act, No. 103 of 1977. 
131 South African Bureau of Standards 1990. Code of Practice for the Application of the National Building Regulations. Standard SABS 0400-1990. Pretoria, South Africa: South African Bureau of Standards.

132 Michael Rogers, UniRoss Batteries. Personal telephonic communication, January 2009.

133 Brace, I. 2004. Questionnaire design. London: Kogan Page.

134 Python Software Foundation 2009. www.python.org, accessed 26 June 2009.

135 Ott, L. 1998. An introduction to Statistical Methods and Data Analysis, 3rd ed. Boston: PWS-Kent Publishing. pp.338-361.

136 Department of Water Affairs and Forestry 2006. Guidelines for the Utilisation and Disposal of Wastewater Sludge. Volume 2 of 5: Requirements for the Agricultural Use of Wastewater Sludge. Pretoria: Department of Water Affairs and Forestry.

137 Alcock, N. 2009. Appropriate technology for reuse of sludge emanating from South African cities. Masters programme research report, University of Cape Town, Cape Town, South Africa.

138 City of Cape Town, unpublished data. Provided by P. King, Operations Support, Wastewater Branch, July 2009.

139 Peter King, City of Cape Town Operations Support, Wastewater Branch. Personal and email communications, July 2008 and January 2009.

140 Saft batteries 2009. www.saftbatteries.com, accessed January 2009.

141 Rydh, C. J. and Karlström, M. 2002. Life cycle inventory of recycling portable nickel-cadmium batteries.Resources. Conservation and Recycling 2002 (34): 289-309.

142 Jane Smit, International Power Products (IPP). Personal communication, January 2009.

143 Dennis Pillay, Cosine Developments. Personal telephonic communication, January 2009.

144 Vangheluwe, M., Verdonck, F., Versonnen, B. 2005. Contribution of Spent Batteries to the Metal Flows of Municipal Solid Waste. Report prepared for Recharge aisbl. Gent, Belgium: Euras. 
145 Plachy, J. 2003. Cadmium recycling in the United States in 2000. Circular 1196-O. Reston, VA 20192: U.S. Geological Survey.

146 HBL 2009. MSDS for industrial storage battery. Available online: www.hbl.in Accessed 21 February 2009.

147 Ronnie Grobbelaar, Aviation Battery Services. Personal telephonic communication, January 2009.

148 Joshua Grobbelaar, National Aircraft Corporation. Personal telephonic communication, February 2009.

149 Brian Rothman, Cape Aero Services. Personal telephonic communication, January 2009.

150 Llewellyn von Beneke, Execujet. Personal telephonic communication, June 2009.

151 Johnny Knoetze, Aviation Business Centre. Personal telephonic communication, January 2008.

152 South African Aircraft Registry 2008. Available online: www.avdex.co.za/saregister, accessed: 30 May 2009.

153 Mueller, D.B., Cao, J., Kongar, E., Altonji, M., Weiner, P.-H. and Graedel, T.E. 2007. Service Lifetimes of Mineral End Uses. US Geological Survey Mineral Resources External Research Program. Reston, VA 20192: U.S. Geological Survey.

154 Clive Rutter, Silicon Engineering. Personal telephonic communication, June 2009.

155 Ronnie Kallan, Willard Batteries. Personal telephonic communication, January 2009.

156 Synclair Naidoo, Static Power. Personal telephonic communication, January and February 2009.

157 Dudley Bradford, Desco Recycling. Personal telephonic communication, January 2009.

158 Marius van der Westhuizen, City of Cape Town. Personal communication, February 2009.

159 Kevin Pattenden, City of Cape Town. Personal communication, February 2009. 
160 Leon Drotche, Eskom Distribution. Personal telephonic communication, February 2009.

161 John Graham, City of Cape Town. Personal telephonic communication, February 2009.

162 Salliem Jainodien, Lead and Solder Sales. Personal telephonic communication, February 2009.

163 Douglas van Harte, City of Cape Town, Stores Department. Personal telephonic communication, January 2009.

164 Mervyn Barry, previously of First National Battery. Personal telephonic and email communications, February 2009.

165 Werner Botha, Bosch, Cape Town Branch. Personal communication, September 2008.

166 Chad George and Tony Sanderson, Metabo Power Tools, Cape Town Branch. Personal communication, October 2008.

167 Craig Klumper, Matus Tools, Cape Town branch. Personal communication, October 2008.

168 Andrew Longman, Makita Tools, Cape Town branch. Personal communication, October 2008 .

169 Peter Mumford, Ryobi South Africa. Personal telephonic communication, November 2008.

170 Peter Schneider, South African Power Tool Association (SAPTA). Personal telephonic and email communications, February 2009.

171 Fred Dohne, DeWalt South Africa. Personal telephonic and email communications, February 2009.

172 UN Comtrade 2008. United Nations Commodity Trade Statistics Database. http://comtrade.un.org, accessed 16 November 2008.

173 Bosch 2007. Professional blue power tools for trade and industry - range 2007. Midrand, South Africa: Bosch Power Tools.

174 Errol Pierce, BatterySell. Personal communications, November 2008 and January 2009.

175 Metabo 2005/2006. Main catalogue 2005/2006. Nürtingen, Germany: Metabo. 
176 Makita 2004. Power tool catalogue. Aichi, Japan: Makita.

177 Makita 2003. Power tool catalogue. Aichi, Japan: Makita.

178 Hitachi 2005. Power tools 2005. Tokyo: Hitachi.

179 Personal observation at Makita, Metabo and Bosch tool maintenance workshops, Cape Town, September and October 2008.

180 World Customs Organization (WCO) 2009. www.wcoomd.org, accessed 12 January 2009.

181 United States International Trade Commission 2009. www.usitc.gov, accessed: 9 July 2009.

182 Julian van Ginkel, Batteries Unlimited. Personal communication, October 2008.

183 Warren Saunders, City of Cape Town Solid Waste. Personal communication, October 2008.

184 Lindsay Heckrath, Interwaste. Personal communication, November 2008.

185 Jade Little, Province Lighting. Personal communication, November 2008.

186 Philip Redelinghuys, Ross Demolition; Paul Rothey, Bradis Group Cape Town; Steven Harmsen, Skye Demolition and Earthworks; Wendley Jenniker, W.H.J. Transport and Demolition; Adri van Bevender, UNEL Excavation and Demolition; L.O.Rall. Personal telephonic communications, January 2009.

187 L. Faivelowitz; SA Metal Group; Atlantic Recycling; L.O. Rall; Scrap for Africa; Marko Metals; All Scrap. Personal communications by anonymous telephonic survey, February 2009.

188 Paul Craig, Vissershok Waste Management Facility. Personal communication, August 2008.

189 Nono Jikumlabo, Enviroserv. Personal telephonic communication, February 2009.

190 Natalie Dodd, Wasteman. Personal telephonic communication, February 2009.

191 Brian Ikin, WG Waste Removals. Personal telephonic communication, August 2009.

192 Este van Dyk, Waste Control. Email communication, September 2009. 
193 United States Environmental Protection Agency 2007. Fact sheet: Management of electronic waste in the United States. Available online:

http://www.epa.gov/epawaste/conserve/materials/ecycling/docs/fact7-08.pdf, accessed 09 December 2009.

194 Finlay, A. and Liechti, D. 2008. E-waste assessment South Africa. Report of the e-Waste Association of South Africa. Available online: www.e-waste.org.za, accessed 20 November 2008.

195 Kirstie McIntyre 2009. Paper presented at the 4th International Conference of Life Cycle Management, Cape Town September 6-9 2009.

196 Oguchi, M., Kameya, T., Yagi, S. and Urano, K. 2008. Product flow analysis of various consumer durables in Japan. Resources, Conservation and Recycling 52: $463-480$.

197 Gerry Newson, Cape Town e-waste materials recovery facility. Personal communication, February 2009.

198 Wayne Arendse, Transnet Rail Engineering. Personal telephonic communication, June 2008.

199 Cape UPS; UPS Technologies; Compu-power; UPS Warehouse Cape; AC Digital Energy. Personal telephonic communications, October 2008.

200 SA Forklift; Nichiyu; Toyota Forklift; Barloworld Handling (Hyster); Horizon Batteries; Willard Batteries. Personal telephonic communications, January 2009.

201 Pillot, C. 2008. The worldwide rechargeable battery market, 2003-2008..

Available online:

www.avicenne.com/gb/batteries_and power_supply_publications.htm, accessed 31 October 2008.

202 South African Advertising Research Foundation (SAARF), All media and products surveys 1999-2004. Available online: http:/www.saarf.co.za/, accessed 26 January 2009.

203 Peter Hobbs, Alcom Systems. Personal telephonic communication, January 2009.

204 Meerkotter, M. 2003. Heavy metals, and vegetable farming in Cape Town. MSc Thesis: University of the Western Cape, Cape Town, South Africa.

205 Meerkotter, M. Unpublished data provided in January 2009. 
206 Statistics South Africa. 2006. Census of Agriculture Provincial Statistics 2002 Western Cape. Available online: www.statssa.gov.za, accessed 26 May 2008.

207 Department of Water Affairs and Forestry 2006. Guidelines for the Utilisation and Disposal of Wastewater Sludge - Volume 2: Requirements for the agricultural use of wastewater sludge. Pretoria: Department of Water Affairs and Forestry.

208 Food and Agriculture Organisation of the United Nations, 2005. Fertilizer use by crop in South Africa. Rome: FAO. p.25.

209 T. Beyers, Nitrophoska. Personal telephonic communication, September 2009.

210 Van Kauwenbergh, S.J. 2002. Cadmium content of phosphate rocks and fertilizers. Proceedings of the IFA Technical Conference, Chennai, India, 24-27 September 2002. Available online: www.fertilizer.org/ifa, accessed 27 June 2008.

211 Craig Mitchell, Vissershok Waste Management Facility. Personal communication, August 2008.

212 Melanie Traut, City of Cape Town, Scientific Services. Personal communication, March and May 2008.

213 Schaetzl, R.J., and Anderson, S. 2005. Soils: Genesis and Geomorphology. Cambridge: Cambridge University Press

214 Chan, K.Y. 2002. Bulk Density. In: Encyclopedia of Soil Science, edited by R. Lal. New York: Marcel Dekker.

215 Hamied Mazeema, previously of City of Cape Town. Personal communication, June 2008.

216 Yeld, J. 2009. Few checks at sewerage plants. Cape Argus [Cape Town], 30 September, p. 8.

217 Margai, F.L. 1999. Promotional Strategies for the Prevention and Proper Disposal of Household Hazardous Wastes. Journal of Environmental Systems 27(2): 85-99.

218 Lindhqvist, T. and Lifset, R. 2003. Can We Take the Concept of Individual Producer Responsibility from Theory to Practice? Journal of Industrial Ecology $7(2): 3-6$.

219 Fishbein, B.K., Ehrenfeld, J.R. and Young, J.E. 2000. Extended Producer Responsibility: A Materials Policy for the 21st Century. Available online: www.informinc.org, accessed 23 October 2009.

220 Environment Canada, 2009. www.ec.gc.ca, accessed 23 October 2009. 
221 Department of Environmental Affairs and Tourism. 2007. National Environmental Management: Waste Bill. South African Government, B 39-2007.

222 Bernardes, A.M., Espinosa, D.C.R. and Tenório, J.A.S. 2003. Collection and Recycling of Portable Batteries: A Worldwide Overview Compared to the Brazilian Situation. Journal of Power Sources 124: 586-592.

223 Kevin Burger, South African Battery Manufacturers' Association. Email communication, June 2009.

224 Anton Liebenberg, Peninsula Beverage Company. Personal telephonic communication, June 2009. 


\section{APPENDIX 1: INTERVIEW NOTES}

\begin{tabular}{|c|l|c|}
\hline Ref no. & Name & Page \\
\hline 132 & Rogers, M. & A2, A4 \\
139 & King, P. & A5 \\
142 & Smit, J. & A8 \\
143 & Pillay, D. & A10 \\
147 & Grobbelaar, R. & A11 \\
148 & Grobbelaar, J. & A13 \\
149 & Rothman, B. & A14,A16 \\
150 & von Beneke, L. & A17 \\
151 & Knoetze, J. & A19 \\
154 & Rutter, C. & A20 \\
155 & Kallan, R. & A25 \\
156 & Naidoo, S. & A26 \\
157 & Bradford, D. & A29 \\
158 & van der Westhuizen, M. & A30 \\
159 & Pattenden, K. & A31,A32 \\
160 & Drotche, L. & A34 \\
161 & Graham, J. & A35 \\
162 & Jainodien, S. & A37 \\
165 & Botha, W. & A38 \\
166 & George, C. & A40 \\
167 & Klumper, C. & A42 \\
168 & Longman, A. & A43 \\
169 & Mumford, P. & A46 \\
170 & Schneider, P. & A47 \\
171 & Dohne, F. & A48,A49 \\
174 & Pierce, E. & A50 \\
182 & van Ginkel, J. & A54 \\
183 & Saunders, W. & A56 \\
184 & Heckrath, L. & A59 \\
198 & Arendse, W. & A61 \\
209 & Beyers, T. & A62 \\
211 & Mitchell, C. & A63 \\
212 & Traut, M. & A68 \\
215 & Mazema, H. & \\
& & \\
\hline
\end{tabular}




\title{
MICHAEL ROGERS
}

\author{
Uniross SA
}

$19 / 06 / 2008$

\section{Battery collection scheme}

Uniross initiated their battery collection scheme as a trial at Makro stores in Dec 2007, which he says was not well supported by the public, presumably because of a lack of education and broad visibility. The program is being extended to collection at all Pick and Pay stores probably by the end of June, although some might have started already.

The program will accept any old batteries, not just those from Uniross.

Cardboard shipping bins will be placed inside cardboard display bins for the collection. Once the inner bin is full, it will be removed from the display box, sealed, and transported to JHB by the arrangement of Uniross (who is contracting a courier company). The inner box is approx $400 \times 400 \times 300 \mathrm{~mm}$, the size limited by the willingness of PnP to unnecessarily sacrifice commercial space (I think the major factor), and by the weight of large amounts of batteries. In JHB the batteries will be sorted according to chemistries and shipped to France (the Uniross head office) for recycling when a $40 \mathrm{ft}$ container can be filled.

Pick ' $n$ ' Pay is apparently giving strong backing to the program.

No records are kept of where batteries originate, but when the boxes arrive in JHB it would be possible to tell where they came from based on the transport papers.

Batteries include $\mathrm{Li}$ ion, $\mathrm{NiMH}, \mathrm{NiCd}$ and alkaline. The alkaline batteries are not sufficiently hazardous or recoverable to justify recycling, but should be disposed of as hazardous waste. They are not sent to France.

He says that data on the chemistry breakdown of batteries collected from around the country should be available from them.

So far, the volumes of batteries collected have been very small, and in fact the direct returns from Uniross customers and from their production facilities form the larger portion of what passes through the recycling centre.

He says that the recycling scheme involves considerable cost, which Uniross is willing to sustain on the basis of corporate responsibility, given that their core business lies in this sector.

He does not know of any other battery recycling programs in operation at present.

\section{Production of NiCads}


Uniross specializes in the production of small or portable battery systems. They no longer produce any consumer NiCad batteries, but they do produce NiCads for specialist purposes. He says two such uses are for emergency lighting systems in large buildings, especially public buildings, and two-way radio systems.

Emergency lighting systems include power backups for some (eg one in three) flourescents in passages, emergency exit signs, and the like. These batteries remain permanently on charge and thereby generate quite a bit of heat. NiCads are robust enough to withstand the sustained raised temperature and still operate reliably. He says this is a fairly large market, partly due to regulations that require large buildings to demonstrate that emergency lighting has been installed at the time of construction. In SA, there is apparently no monitoring beyond this point, however, so maintenance of these systems is probably very slack. In Europe, the phase-out of cadmium has seen these replaced by nickel metal hydride systems which cost more and do not last as long. There there is apparently more sustained monitoring of emergency lighting installations.

\section{Possiblities for survey}

He seemed very positive about the possibilities for setting up a sampling scheme for my project, in order to quantify and characterize the recycled battery stream from Cape Town. He even seemed to intimate that the labour side of data collection could be carried out by their people, although I'm not $100 \%$ on this. At this stage the stream is extremely small, however, so such a survey would likely best wait until the program is managing larger traffic. 


\section{MICHAEL ROGERS}

\section{Uniross SA}

$13 / 01 / 2009$

He said that he wasn't sure whether the Cape Town office was still open in 2005, and it might have been involved in NiCd repacking at that stage. However, no figures would exist for how many were done, partly as a result of an overhaul of the accounting system, and neither he, nor anyone he could think of at UniRoss, would be in a position to hazard a guess at how many were going out. It doesn't sound like any figures are going to come out of UniRoss.

In 2005 UniRoss was not involved in $\mathrm{NiCd}$, or any other, battery recycling.

Some small quantities of batteries are coming out of Pick ' $n$ ' Pay boxes at present, but 'nothing to write home about' just yet. 


\section{PETER KING}

CoCT Operations Support Wastewater Branch

01/07/2008

\section{Sludge types and characteristics}

Primary sludge is just partly dewatered raw sewage and is classed type A.

[He provided me with electronic copies of sludge use guides which include most of this information, as well as limits on soil content, sludge content, application, and more (saved in data/peter king). Much of the below is probably detailed there. These are, I think, more recent versions of a document he showed me called Permissible Utilization and Disposal of Sewerage Sludge, a WRC/DoA/DWAF report (no. TT85/97).]

Sludge types have in the past been divided into four categories - A to D - on the basis of their health risk. A is essentially raw (I think partly dewatered) sewage. B is digested sludge. $\mathrm{C}$ and $\mathrm{D}$ are both low in bacterial hazard, but $\mathrm{D}$ is also low in metal content.

There is a new sludge rating system that ranks A as the best, and also considers bacteria, stability and metal content separately.

The sludges from works are approx $14 \%$ solid, and are applied to the amount of 56 tons/ha, which equates to 8 tons/ha dry weight. It apparently has a consistency similar to soft peanut butter.

\section{Sludge application}

The vast majority of sludge produced in Cape Town goes to agricultural land. The exceptions are those times that limits are exceeded on certain batches, or there is no more capacity for composting of primary sludge. Vissershok $H: h$ is apparently not permitted for accepting sludge.

Most of the sludge produced in Cape Town is type B, except for those works that do not have digesters. In these cases (Potsdam and Borcherds), the type A sludge is composted by a contractor, in combination with other organic material (greens, fruit waste, etc.). The full composting process takes place over 42 days, including 5 days at $70 \mathrm{deg}$. C. This effectively kills all nasties, and the product is classed as $\mathrm{D}$. This is often palletized and can be applied simultaneously with seed. He said this was the only source of class D sludge (although its actually solid) in Cape Town.

The dry form of class D can be applied to the soil with seed, actually planting the seed into holes with the pellets.

The class B sludge more widely produced in CT can only be applied to land that produces crops that will be cooked (no fresh produce) and must be well ploughed in before planting. Ploughing is done to a depth of $300 \mathrm{~mm}$. 
Cape Flats is apparently granulating their sludge.

Application of sludges to the Phillippi agricultural areas was stopped some 20 years ago because these areas were producing fresh produce (vegetables and such) and the risk for worm spreading was high.

Sludges are currently applied at a rate of 8 tons / ha (dry mass) but there is talk of upping this to 10 tons / ha.

\section{Regulation of sludge application}

Limits for metal content etc. are set, as are the permitted annual application of metals. [See the guidebooks he gave me.]

Soils are sampled and analyzed before every application (he provided me with the full dataset of analyses going back to, I think, 2002).

All sludges are applied to a particular section of a farm, and everything is recorded. Hence it is possible to know who received how much at any stage, and look at the sludge analyses as they left the works over that period.

Aside from the tables detailing all the production and application of sludges (which he gave me electronically), he also has large maps showing the locations of all fields to which sludges have been applied, and indicating their numbers on the system.

\section{Treated Effluent}

At present a lot of the works effluent is used for irrigation or other purposes. He printed out a table indicating current and potential effluent usages in Cape Town for each works. Golf courses are significant users, some agriculture, but also industrial use.

Atlantis has pretty good sunshine. Currently they only have one crop on these field because they are unirrigated, but he believes that an extended system of effluent supply might allow these farmers to have three yields a day.

\section{Atlantis}

The wastewater works in Atlantis sound extraordinary. It seems that Peter was intimately involved in the planning. (He put it that "at the time, my boss allowed me to put in two wastewater works..." Industrial and residential wastewater are piped and treated separately. This was designed into the town, a luxury that was made possible by the fact that the town was designed and built from the ground up. He feeld that the marginal cost of this was very small - effectively it just required a fairly short section to carry two pipes instead of one, and the cost of this was partly offset by the lower price of the narrower pipes required (as apposed to one big one). 
The effluent from the residential works is used for groundwater recharge (basically letting it soak into the ground from ponds) up-flow from the well points that supply the town (residential and industrial) with water, and the industrial effluent is used for groundwater recharge below the wellpoints. All the effluent is used in this way, so there is no direct discharge into the sea. The watershed for the groundwater aquifer that they draw from is kept free of building (although it includes a large area of shifting dunes in any case). Some water is currently piped in from Blouberg to supplement the wellpoints (as an aside, this was apparently designed to allow reverse flow too, if this were ever required). He does point out that the arrangement does involve indirect discharge to the sea, through the groundwater flow.

\section{Data}

\section{KEEP THE DETAILED CITY DATA HE IS SENDING CONFIDENTIAL}

Taken from the hardcopy guidelines he had, soil limits:

$\mathrm{Cd}$

$\mathrm{Hg}$

$\mathrm{Zn}$

$\mathrm{Pb}$
Max permissible (mg/kg) Max annual addn. (g/ha.25year) 2

0.5

3140

2000

46.5

6.6
707000

101000

The Visserhok farmlands have been under cultivation for a long time.

\section{Sludge vs fertilizer}

Use of sludge allows farmers to reduce their chemical fertilizer use to just a light application once a year. He points out that, in terms of the energy required for fertilizer production, this is a significant reduction of carbon footprint.

Mise

The Vissershok farmlands no longer receive sludges, apparently because the land is owned by one of the Wasteman / EnviroServe companies, and the other one has the sludge contract - although they run Vissershok H:H together, they are apparently not on very friendly terms.

\section{Contacts}

Speak to Nitrophosco (Malmesbury), who trade in fertilizers, to see if they have analytical data on Cd levels. 


\section{JANE SMIT}

International Power Products (IPP)

23/01/09

\section{IPP}

A substantial part of IPP's business is battery repacking, although they also do a lot of battery sales, as well as a range of other electronic items (diodes... she mentioned a lot of other bits I don't understand). They repack in all major chemistries: $\mathrm{NiCd}, \mathrm{NiMH}, \mathrm{Pb}-$ acid, Li-ion. She said that in terms of Li-ion the major demand comes from laptops, however, which they are trying to move away from. This is because the laptop batteries have circuits integrated with the battery pack, which often give problems with repacking. If the voltage on the batteries drops too low, the circuitry turns itself off, and even if batteries are replaced it is not properly registered as operational, so it doesn't work.

About $40-60 \%$ of their repacking business is power tool battery packs.

Most of their business is by word-of-mouth, although some power tool dealerships have started to pass business to them.

They have quite a wide drainage area for business. She mentioned a number of surrounding areas (Hermanus, etc. type) but even get business from as far afield as Windhoek. However, she said approx. $90 \%$ of their business is for use within Cape Town.

\section{NiCd applications}

Besides the powertool repacking side, she mentioned medical applications (though she said that the defibrillators usually use high-power $\mathrm{Pb}$-acid, of roughly $\mathrm{D}$-cell size), hobbyists, such as remote control applications in cars etc., and photography and video, where they see a range of uses, from camera batteries, battery belts worn by cameramen to power cameras for long periods, and portable lighting applications.

Among power tools, she says the common NiCd voltages seen are 9.6, 12,14.4 and $18 \mathrm{~V}$, although the majority are $12 \mathrm{~V}$. She mentioned seeing some Hilti industrial tools of $24 \mathrm{~V}$, but such tools are infrequent.

During discussion around getting figures for NiCd sales, she pointed out that the cells come in a large range of sizes. Power tools essentially always carry sub-C size cells, though.

\section{Battery disposal}


She said that their disposal numbers would be different to their sales volumes, because although repacking was 1:1 for disposal, a lot of people would bring in a single spent battery and ask them for ten identical replacements, or that sort of scenario.

She says they have been trying to get a hazardous waste disposal permit for some years, but are still waiting.

Spent batteries are collected on the premises and when they reach sufficient volumes are sent for recycling, although once a load was sent to Vissershok as haz waste. In 2005 all batteries would have gone to Desco recyclers (she mentioned having to separate $\mathrm{Pb}$-acid cells from the rest).

\section{Other players}

She mentioned BatteryCell, saying that it was in Kenilworth. She thought Errol had emigrated to Australia (as opposed to not quite emigrating to NZ), but she was aware that the company had been sold on. She said that they were quite focused on power tools [which agrees with my impressions of them].

UniRoss apparently closed its Cape Town branch at most 18 months ago. The battery repacker at IPP has been there just over a year, and she says that they were still operating when she started.

Meltzer apparently deals in batteries, but they don't do any "value-added" work, ie repacking.

\section{Follow up}

She said that she would have a look at past records to try to determine the figures for NiCd cells sold in 2005. I asked her specifically for, at the least, an estimated range of NiCd cell numbers sold in 2005, although I did say any more detail, or more accuracy, would be very valuable. 


\section{DENNIS PILLAY}

Cosine Developments

$27 / 01 / 2009$

\section{Emergency lighting backup units}

Cosine manufactures backup units for power backup in emergency lighting. The units comprise the battery pack, inverter, and associated circuitry.

They make two type of units. One has a cutoff to take the battery off charge when it is fully charged. The battery will slowly charge and eventually charging will kick back in. This cycling near the top of the battery's capacity is not good for it (reduces capacity), so electricians should turn off the mains every so often, let the emergency battery power kick in, and run the batteries down so they can recharge fully. The other type they manufacture is much more expensive. It has a self-testing system (with microchip) which automatically runs the light off battery power for 2 minutes a week, and 40 minutes a month. It also senses faults such as a broken bulb or faulty battery, and has a system of flashing LED and / or buzzer to alert people to the problem.

All the units they manufacture are used for emergency lighting.

They estimate a lifespan of 2 years for the battery packs, which is on the safe side.

Beyond this, it is possible that reduction of battery capacity will prevent it from operating the light for the required amount of time in an emergency.

Their packs are $2 \mathrm{Ah}$ and $4 \mathrm{Ah}$, all $6 \mathrm{~V}$ ( 5 cells), with $2 \mathrm{Ah}$ the most standard.

\section{Cape Town sales}

Cape Town sales make up 20-30\% of their overall sales. Their largest sales are to lighting manufacturers in Johannesburg.

Virtually all their sales in Cape Town go to just three companies:

Bellco - 100 packs per month

Province -200 packs per month

Lightlines -100 packs per month

These are estimated figures, as orders usually come through continually for 20 or so packs at a time.

\section{Spent battery returns}

They don't accept old batteries back, only faulty ones as part of customer service. He estimates perhaps 1 or 2 in every thousand are faulty when they arrive.

[Subsequently (17/02/09) called them again and they said they use sub-C NiCd cells in the units]. 


\section{RONNIE GROBBELAAR}

\section{Aviation Battery Services}

$23 / 01 / 2009$

\section{NiCd use}

He estimates around $60-70 \%$ of aircraft use $\mathrm{NiCd}$ batteries. Most small aircraft use $\mathrm{Pb}$ acid, but the manufacturers tend to prefer $\mathrm{NiCd}$, so all new aircraft come with $\mathrm{NiCd}$, and all large aircraft, including airlines, use $\mathrm{NiCd}$.

In many cases the batteries run an auxiliary power unit (APU), which produces pressure to start the motor. Some systems do operate a direct-start, though.

\section{Battery specs}

He reckons the average weight is some 90 -odd pounds, but also gave a range of 15-90 pounds.

They contain 20 cells.

He said some odd things about voltages. It sounds like what he meant is that the motors the batteries are running have design voltages below the nominal voltage of the battery (which makes sense), and range from 14-24V. He made it sound as if batteries also come in voltages below $28 \mathrm{~V}$, but that conflicts with the 20 -cell figure, and he also mentioned that some people install two $14 \mathrm{~V}$ batteries instead (ie $28 \mathrm{~V}$ ).

Capacities are in the range of $5 \mathrm{Ah}-50 \mathrm{Ah}$.

Battery lifetimes are over 10 years for $\mathrm{NiCds}$, whereas a $\mathrm{Pb}$-acid that lasts over 2 years is considered to be a good thing.

\section{Maintenance, repair}

He only does servicing.

He says that they should be serviced [I think this means the deep cycling] every 200 flying hours or 3 months, whichever comes first. One reason for this is self-discharging, he says.

The batteries come as separable cells, so a single cell can be replaced. The cells themselves are not repairable (cannot even be opened and resealed). Hence any faulty cells are replaced.

\section{Replacement, disposal}


He says people will usually order their own new batteries from overseas, and just bring it to him for checking. Although he does occasionally import new batteries for clients, this is not normally the case.

Customers do not usually bring him their old batteries when putting in a new one. It does happen, though, in which case he checks what is serviceable, returns all workable parts to the customer for spares / backup and disposes of the unserviceable parts. When cells are disposed of, they go into a hazardous waste storage area and are collected by Wastetech (he thinks).

He has no idea what the majority of people are doing with their old batteries.

Replacement batteries come primarily from US, France and Germany.

\section{Suppliers}

He said there are 4 or 5 brands, three of which are:

Saft

Varta

Marathon 


\section{JOSHUA GROBBELAAR}

National Aircraft Corporation

$25 / 02 / 2009$

\section{NiCd use on aircraft}

Large starter-power $\mathrm{NiCd}$ batteries of around $35-40 \mathrm{~kg}$ serve for engine starting. These are $24 \mathrm{~V}$ units.

The large batteries allow for individual cells to be replaced, and this isn't uncommon. $\mathrm{Pb}$ acid batteries don't allow this.

At each big service the cells are checked and their water levels are recorded. If a cell shows higher-than-normal 'water consumption rate' it gets replaced. He says that there is a tendency for batteries to get serviced, and hence replaced if necessary in JHB. This is because there are strict regulations governing the servicing of batteries, including the dedication of a special area for the purpose, separate charging from servicing area, ventilation, etc. He says that this makes running a battery workshop very expensive, so not many companies have one.

The chemistry used on an aircraft depends to some extent on the pilot's use of it. All new aircraft are equipped with $\mathrm{NiCd}$, but the $\mathrm{Pb}$-acid are much cheaper, even though they do not last as long. As a result a number of aircraft owners opt to replace $\mathrm{NiCd}$ with $\mathrm{Pb}$-acid when the original battery needs replacement.

He says that a well looked after NiCd should last up to 15 years.

\section{Disposal}

Due to the strict regulations about battery disposal, it is apparently extremely expensive. He says that as far as he has seen, the common practice is just not to dispose of them at all - just get a container and store them in it indefinitely. He could not tell me what disposal costs were, nor how many batteries they currently had in storage at their company - he says he hasn't worked on that side for some time.

\section{Future}

He said I was welcome to get in touch with him if I have any further queries. 


\section{BRIAN ROTHMAN}

Cape Aero Services

$22 / 01 / 2009$

\section{Aviation use of NiCds}

All airlines use NiCd batteries. Smaller charter-type executive aircraft (8-seater roughly) also do.

Among smaller aircraft a lot use $\mathrm{Pb}$-acid.

The are roughly 15000 resident aircraft in South Africa. He estimates that $30-40 \%$ of these use NiCd batteries.

All these batteries are $28 \mathrm{~V}$, and fairly standard. They differ in design and shape, but not much in overall size or weight. The typical case in $30 \mathrm{~cm} \times 30 \mathrm{~cm} \times 30 \mathrm{~cm}$, weighing 50 $\mathrm{kg}$.

Military aircraft also use NiCds. Denel supplies the airforce.

NiCd advantages: can handle higher load without breakdown

higher amp-draw is okay

sealed, so no spillage problems

at altitude and low pressure, no issues with water dissipation

NiCd disadvantages: thermal runaway can occur (total battery internal burnout)

manufacturers say they should be deep cycled every 30 days

Deep cycling is only done in JHB (by Aviation Batery Services), as it requires quite fancy equipment. It used to be done in Cape Town, but there wasn't enough demand to justify it. Because of the inconvenience and cost of taking out the battery and sending it to JHB, most people don't do this that often.

They cost R50-60 000. Their lifetime is "almost infinite", which he specified as "you can easily get ten years out of them". $\mathrm{Pb}$-acid, by contrast, only last 2-3 years.

Li batteries are now arriving on the market.

\section{Suppliers and competitors}

He said that they are supplied from all the usual aviation suppliers, mentioning Placo [can't find them in the phone book] and Comair.

He said there are quite a few companies in Cape Town working in their field, but only mentioned Aviation Business Centre. 


\section{Service and disposal}

He says that the deep cycling is really the only maintenance involved. When replacing old batteries, they send the old ones up to Aviation Battery Services. Pb-acid they dispose of in Cape Town [which I took to mean they sell them off to a lead-acid battery collector]. He says some people keep NiCd cells around the workshop and use them as power sources for misc. use, such as load testing.

\section{Leads}

Aviation Battery Services - Ronnie Grobbelaar 


\section{BRIAN ROTHMAN}

Cape Aero Services

16/02/2009

\section{Aviation use of $\mathrm{NiCds}$}

He says that the break down of $\mathrm{NiCd}$ use by aircraft size would run approximately along the lines of:
Aircraft mass
$\mathrm{NiCd}: \mathrm{Pb}$-acid ratio
$<5.7$
20:80
$5.7-20$
$60: 40$ to $50: 50$
$>20 \mathrm{t}$
almost 100:0

He says that virtually all military aircraft will run on NiCd (they can afford to spend tax money!).

Helicopters also use either NiCd or Pb-acid. He reckons the split is around 60:40. 


\section{LLEWELLYN VON BENEKE}

\section{Execujet}

$15 / 06 / 2009$

\section{Company}

Execujet provides a range of aviation services to private aircraft (and possibly commercial aircraft too - he seemed to know a lot about commercial practices too). This includes a range of technical services, including an electrical workshop with a battery shop providing a full range of battery services (cleaning, servicing, replacing, deep cycling...)

They are planning to open servicing facilities in Cape Town in the future.

\section{Battery characteristics}

All have 20 cells/battery $(1.2 \mathrm{~V}$ per cell $)$

Approx 40-43 kg mass

Mostly 40-44 Ah capacity

All the NiCd cells can be opened for topping up. He says that some of the lead acid batteries are sealed. These are often used when aircraft are used to go to places with limited technical facilities, e.g. operating in African countries, because they require very little maintenance.

NiCds are preferred because they are more robust, can withstand total discharge, and last longer.

NiCds often come into their workshop older than 10 years. He says he would estimate $\mathrm{NiCd}$ lifespan at $5-10$ years. $\mathrm{Pb}$ acid are around 2 years.

\section{Battery use}

He provided the following estimated proportions of $\mathrm{Pb}$ acid use:

Aircraft tons

$\mathrm{PbA} \%$

$<5.7$

95

$5.7-20$

$20 \%$

$>20$

$0 \%$

Battery servicing and replacement 
Cape Town does not have a proper battery shop. Cape Town's $\mathrm{Pb}$-acids are often serviced and otherwise dealt with there, but the aircraft will usually fly to Johannesburg for NiCd maintenance, or freight the battery up to them. He says that this usually means that batteries are replaced in Johannesburg.

They often replace single faulty cells, but manufacturers generally advise that if 4 or more cells in a battery are faulty, the entire battery should be replaced. They often are not able to get complete batteries from the suppliers, however, so they will usually replace all the cells in the battery, but not order a complete battery. 


\section{JOHNNY KNOETZE}

Aviation Business Centre

21/01/2009

0219340966

\section{The company}

The company was recently taken over by new people, so there is little knowledge about the business in the past, or records of past disposal etc.

They work on smaller aircraft, generally up to a maximum of 19 seaters in size.

\section{The batteries}

$\mathrm{NiCd}$ batteries are used on some aircraft, but $\mathrm{Pb}$-acid has been replacing them for several years now, with the new $\mathrm{Pb}$-acid batteries matching them for performance.

The batteries are $28 \mathrm{~V}$, and around four times the size of a car battery (and quite expensive - the $\mathrm{Pb}$-acid ones go for some $\mathrm{R} 12 \mathrm{~K}$ ).

The NiCd batteries are sent away for deep cycling once a year. This can be done in JHB.

Only three of the aircraft they maintain still use NiCd batteries, and when these reach the end of their lives they will be replaced with $\mathrm{Pb}$-acid.

He doesn't know what the battery mix looked like in 2005. He also doesn't know what happened to old NiCd batteries that were disposed of in the past. He has heard of people putting them to other uses, including even putting them in their cars.

\section{Follow-up}

He referred me to Cape Aero Services to speak to Mr. Ben Ferreira. They work on 3 airliners and do small aircraft maintenance. 


\section{CLIVE RUTTER}

Silicon Engineering

$29 / 06 / 2009$

\section{The company}

Silicon is a distributor for HBL NiCd cells from India.

NiCd sales only make up some $3-5 \%$ of their business, and they really only deal in them so as to provide a more complete range to their clients.

The do little business in Cape Town. They recently refused the tender conditions for CoCT NiCd contracts in electrical distribution, because of a "consequential damage clause" in the contract which would have made them liable for any damages arising from a battery failure in switchgear control.

\section{Battery technology}

$\mathrm{He}$ is not very enthusiastic about NiCd technology. They receive a lot of lip-service as being top-of-the-range technology, and some engineers insist on them largely as statusquo specs, not because they have carefully considered the advantages and costs. He has spoken with an engineer who specifically stated that he requires NiCds "because I only want the best" - and was not willing to consider the possibility of PbA substitution. This is to some extent a result of British influence in South African engineering circles. At a conference with an American audience, he says he found very few people who used large $\mathrm{NiCd}$ batteries in preference to $\mathrm{PbA}$. See also about the relative scale of $\mathrm{NiCds}$ in projects under "Sales" below.

His biggest objection to NiCd cells is cost - they are around twice the price of comparable $\mathrm{PbA}$. Maintenance is also a big concern ("vastly more maintenance") - the lower voltage per cell means a greater number of connections per total battery voltage that must be connected. They also need regular discharge, and must be boosted occasionally to regenerate total capacity. This causes gassing, which leads to KOH spills, and this is both corrosive and conductive, both problematic characteristics in an electrical setting.

$\mathrm{PbA}$, in comparison has been much more usable since the technologies introduced around 1975 (apparently in response to a threat from Bell to find an alternative energy source if the existing technologies were not improved. Pre-1975 PbA batteries were even more of a maintenance hassle than $\mathrm{NiCd}$, and maintenance was a major focus of the battery producers' improvement efforts). Now calcium or selenium alloys are used for the electrodes, which virtually eliminate gassing, allow the batteries to be left on constant flow charge, and only require topping up of the water every three years or so. 
He believes that the maintenance characteristics of $\mathrm{NiCd}$ cells arises from the fact that no chemical reaction occurs in them - unlike the formation of $\mathrm{PbSO}_{4}$ in $\mathrm{Pb}$-acid batteries. [He called on an analogy with the heating of a basin of water to below boiling for long periods, and that it would gradually cool to below 'capacity', but I didn't really follow his argument - I don't see how this chemical characteristic would necessarily lead to better or worse maintenance requirements]

The big advantage of NiCds is their life span, which he estimates as 20 years.

\section{NiCd industry history}

Varta (Germany), Swedish companies, Saft in France and Alcad in the UK all manufactured large NiCd cells in the past, but a declining battery market led to several amalgamations over time. Then, in 1995/6 the EU introduced strict regulations regarding safety in NiCd assembly plants, which essentially would have necessitated total overhauls of manufacturing facilities. In response, Varta stopped manufacturing them completely, Alcad stopped their UK operations and Saft stopped manufacturing pocket-plate systems. The Swedish facilities had already been operating under strict national laws for some time, however, so their plants were not as affected. Today Alcad/Saft manufactures all their NiCds in Sweden, although they have a battery recycling plant in France.

\section{Import / manufacture}

They import complete cells and assemble them here to batteries of the required voltage. The South African market is not large enough to justify the assembly of cells from imported plate groups.

He mentioned that Static Power (Saft/Alcad cells) assembles some cells from imported plate groups, and that this was actually a hangover from Apartheid trade incentives put in place to encourage local manufacturing independence. Since then, the import duties on completed cells have actually been reduced to less than than of plate groups, and hence they have found themselves in completely the wrong position with respect to the costs of manufacture and sale.

\section{Battery characteristics}

He says that, as a result of price particularly, sales of batteries over 100Ah capacity is very rare. They have sold a few $200 \mathrm{Ah}$ cells in the past, but in addition to price these must be custom built by the manufacturers and have very long waiting times. 10Ah is the smallest capacity seen. They only carry stock up to $55 \mathrm{Ah}$ capacity - anything higher must be specially shipped from suppliers.

\section{Sales and applications of NiCds}

Most of their NiCd sales are for electrical distribution use in "power protection". Where they are not sold to Eskom or local govt., they are nevertheless usually for this purpose, 
in facilities which are large enough to have their own substations which are their responsibility. This is the case for their use on mines.

He says that they do make some sales to diesel starting applications, which makes up around $5 \%$ of their NiCd sales.

Railways used to use them on railway locomotives, but this was some 30 years ago.

They can be applied in UPS systems, but he hasn't seen this done. Because of the additional price, he says that if a customer wanted this, he would "have to have a lot of ignorance and a similar amount of money".

Business in the NiCd battery industry has extreme troughs and peaks. He says that many years ago they saw an order of 20000 cells (perhaps $10 \mathrm{~kg}$ each) from the railways, but nothing since. Similarly, when Sasol 2 and 3 were under development, some 40000 cells were put in, but nothing since.

They are supplying around 3.5 tons of NiCd cells per year (total cell mass) for the electrical distribution system in Durban, which is almost entirely for expansion of the system.

Telecoms systems only use $\mathrm{Pb}$-acid batteries.

He suggests that the places to look for large NiCds in Cape Town are:

- the electrical distribution systems (CoCT and Eskom),

- Caltex refinery [or whatever it's called now]

- the Navy

He also mentioned supplying them to Sappi and Mondi plants, but not in Cape Town specifically.

They also do supply to the aviation industry.

One of the reasons for $\mathrm{NiCd}$ batteries being used in circumstances where $\mathrm{Pb}$-acid would be better and more cost effective, is that in most projects the batteries are a minor component of the cost and the personnel responsible for them are never senior, well paid or considered important. Hence several million will be spent on a substation development, but the batteries will only take a small part of that - perhaps R100 000. In addition, skilled people in the units responsible for batteries are usually quickly promoted to other areas, so that the people who make battery-related decisions are usually either unmotivated or inexperienced, and not under major pressure to reduce the status-quo budget. Hence battery decisions are not carefully and critically considered.

Disposal / recycling / take-back 
He suspects that the usual method for disposing of spent cells in industry is to leave them on the side of the pavement.

They do not accept take-backs from their customers. In the past, an arrangement had been negotiated with HBL to accept their spent cells for recycling in India, but when it was attempted to carry out such recycling, HBL backed down on this, citing an Indian antidumping law that prevented them from importing spent cells. Supposedly the intention of the law had been to prevent the dumping of spent NiCd cells from China.

Most of their supply goes into new developments rather than replacement, so disposal is not an issue.

When they have spent cells, they often use them in the test bay, to check that their charger systems are functioning properly.

When disposal is required, they contract with Enviroserv.

He says that at present they have several crates of cells which will need to be disposed of. He estimates proper disposal costs at around $\mathrm{R} 1 / \mathrm{kg}$.

Proper disposal involves draining the electrolyte, and setting the batteries in concretefilled drums, which are then buried at an "A1" disposal site.

Placing an advanced recycling fee on batteries - as he says Static Power does (Saft/Alcad distributors) - places an additional $10-15 \%$ cost onto the price.

Since the batteries have a 20 year life expectancy, the people making purchasing decisions now do not feel it necessary to take the eventual disposal of the cells into consideration, as they will not be responsible for this. Only major companies - he mentioned Sasol and Eskom - take this into consideration and insist on using battery suppliers who can assure them of safe end-of-life disposal through payment of an ARF.

He knows of a company in the US who is able to accept spent NiCd cells from South Africa for recycling, called Battery Solutions. He thinks they make a profit on materials recovered, but do not pay for shipping. Hence they have looked at it on the assumption that only shipping costs would have to be provided. He knows that Saft/Alcad in France are also able to accept them.

\section{Misc}

"Eskom stands for Easy, Slow and COMfortable", he says, referring to an extremely inefficient bureaucratic system - apparently they are still waiting for a tender from 2006 to be adjudicated. Some time back he employed a quantity surveyor for a few months, gave him an expense account and a car, and told him to find out where Eskom purchased their NiCd cells, how many they were buying, and how many they had. In the end, the summary of his results was - "I have no idea, and neither does anyone at Eskom". 


\section{Leads}

Battery Solutions in the US www.batteryrecycling.com

Christopher Sova is in charge

This is a company which might be able to accept South African spent NiCd cells, perhaps without charge - although they wouldn't pay shipping.

Caltex refinery - speak to the electrical engineer in charge (he can't recall his name)

Eskom (Brackenfell)

\section{Follow up}

He says that I am welcome to call for any more info in the future.

He would be interested to hear about the results of this research. 


\section{RONNIE KALLAN}

Willard Batteries JHB

22/01/2009

\section{Sales of NiCd}

Willard specializes in $\mathrm{Pb}$-acid batteries, primarily for the automotive market. They have only JUST started to sell NiCds, with only one order from Denel, which has not yet been delivered.

The target market is for substations.

They intend to be involved in battery service as well, with their people doing battery maintenance at the substations.

\section{Specs and applications}

He says that at present all substations have NiCd batteries. A typical $11 \mathrm{kVA}$ substation will have a $32 \mathrm{~V}$ battery, consisting of $1.2 \mathrm{~V} \mathrm{NiCd}$ cells. The specs for their cells are: width: $86 \mathrm{~mm}$, depth: $46 \mathrm{~mm}$, height: $229 \mathrm{~mm}$. Mass: $1.4 \mathrm{~kg}$.

They are vented cells - the electrolyte can be topped up. However, under normal operation this should not be necessary.

\section{Supplies and returns}

They import their cells from an Indian manufacturer - HBL.

They have a 'back-to-back' agreement with the HBL, that any battery they replace will be accepted back for recycling, and the recycling is certified. HBL does not require that the returned battery be from them, but it is a one-to-one arrangement, so Willard won't accept batteries from someone who does not buy a battery from them in exchange. Hence they plan to return an equal number of batteries to India for recycling as they sell.

Willard is committed to $100 \%$ recycling of hazardous components in its batteries.

\section{Leads}

He says that Static Power in JHB, 011397 5316, is a major supplier of substation NiCds at present. 


\section{SYNCLAIR NAIDOO}

Static Power (JHB)

$22 / 01 / 2009$

\section{The business}

Static Power is the agent for Alcad and Saft, and have been for 35 years.

They have an assembly plant in Johannesburg for 10-60Ah vented-cell NiCds. Plate groups are imported and the cells are assembled here.

They also import Alcad and Saft batteries up to $780 \mathrm{Ah}$.

Whilst they do sell directly to City of Cape Town, they also sell to other businesses without knowledge of where the batteries will end up. Hence it is not possible to say how much of their business is in Cape Town.

They are the sub-Saharan Africa assembly point for collection of Alcad and Saft batteries.

\section{Applications}

He says that there are many applications for the batteries. Including substations, emergency lighting and diesel starting.

"Sub-stations are the big one", where the batteries are used to power circuit breakers. If there is a power outage/fire/fault, it is necessary to flip switches or breakers to disconnect the power. However, since the power is out, it is necessary to provide another source of energy to do so, and this is done with a $\mathrm{DC}$ motor powered by NiCds.

As an example of a diesel starting application, he says that fire-pumps in all airports have generators equipped with $\mathrm{NiCd}$ batteries for starting power. This is because they need to start reliably without mains power, and $\mathrm{Pb}$-acid batteries suffer from several disadvantages. Firstly, their European design life of 3-5 years can be as much as halved by the higher temperatures in South Africa and secondly they have a tendency toward 'sudden death'. NiCds, on the other hand, have around a 15 year lifespan (depending on temperature and maintenance), have better temperature resistance, and can start a motor even if only operating on $40 \%$ capacity.

Another advantage of $\mathrm{NiCds}$ is that, because they do not produce significant hydrogen under normal operation, it is not necessary to provide a special battery room, as it is for $\mathrm{Pb}$-acid battery banks.

Although he knows of NiCds being used in the aviation industry, they do not supply this kind of cell. 


\section{The batteries}

He says that this varies widely depending on capacity etc...

They cost around $30 \%$ more than corresponding $\mathrm{Pb}$-acid batteries.

\section{Servicing}

They do service the batteries they sell. He says that they offer three levels of service:

1st line: clean and electrolyte top-up

2nd line: capacity testing

3rd line: discharge, drain, replace electrolyte, constant current charge and capacity testing

The plate groups are never replaced within an existing battery. If this is necessary, it is cheaper just to replace the battery.

\section{Take-back}

They are ISO-compliant, which places requirements on the proper handling and safe disposal of hazardous materials.

They include an advanced recycling fee in their prices, which makes their batteries around $20 \%$ or so more expensive than they would otherwise be.

They are the sub-Saharan Africa assembly point for collection of Alcad and Saft batteries. Hence they accept any Alcad or Saft batteries, but disposal of any other makes would be charged for.

Batteries collected from South Africa drained in JHB (Enviroserv disposes of the alkaline electrolyte waste) and the plate groups (along with plate groups from cells that were drained in other countries) are packed into crates and shipped to the Alcad/Saft recycling facility in Sweden.

Certificated of safe delivery and recycling are issued for all containers, and shipping is done with proper authorization.

Because they are the sub-Saharan collection point, they export more cadmium for recycling than they sell in NiCds in South Africa. He doesn't think that it would be possible to tell what their South African recycling rate is really, because it would be complicated by these international flows, and by the long life-times of the cells (up to 20 years) making it impossible to tell whether cells are still in use or have been disposed of in some other way.

Batteries supplied to Eskom have a $100 \%$ return rate. He says Eskom is extremely good about proper returns. 


\section{Data}

He said he did not have figures, and felt that the company was extremely unlikely to provide any such figures given their sensitivity. However, the general manager would be the person to ask for such data. Her name is Elsabe Swart. He said she is extremely busy, and I am unlikely to get hold of her on a land line.

\section{Other suppliers}

He says that there are several other importers of other NiCd battery makes, which sell for less than theirs (c. 20\%), because they do not include any fee for proper disposal. These are imported from China and India in particular.

They were approached by Emisa (www.emisa.es), a Spanish company, which wanted them to be their agent in South Africa for a product that was $30 \%$ cheaper than what they are supplying now. They decline the offer, though, because it turned out that Emisa was not equipped to provide proper recycling or disposal.

South African suppliers:

Silicon Engineering - Clive Rutter

Blue Ginger

AMPtron

In Cape Town: Onlab - Jaques (Kuilsriver) - sounds like dealers, but probably not importers.

\section{SYNCLAIR NAIDOO}

Static Power (JHB)

22/01/2009

He said that the batteries they deal in are in the range of $11 \mathrm{Ah}$ to $1540 \mathrm{Ah}$, but that most applications call for somewhere between $29 \mathrm{Ah}$, and, in some big applications $250 \mathrm{Ah}$. 


\section{DUDLEY BRADFORD}

Desco Recycling CPT collections

03/01/2009

He does not do battery collections, but will accept drop-offs. He has taken collections from Jane Smit at IPP, and he says IPP is really the only significant company from which they get batteries. He estimates that he gets about $50 \mathrm{~kg} /$ year of NiCd batteries from her.

The Cape Town branch is a collection operation for Desco in JHB. 


\title{
MARIUS VAN DER WESTHUIZEN
}

\author{
CoCT Electricity Department - Infrastructure Manager \\ $20 / 02 / 2009$
}

\section{$\mathrm{NiCd}$ use in substations}

He explained that the NiCds are used to provide switching power on circuits when the circuits power is down. Basically, the electrical distribution system has monitors along the way that monitor what's going in and out of each section. If the measurements don't tally, switches will be thrown on each end to cut the power to that section of the system and isolate it. Then the NiCd batteries within the section allow control of the circuits despite the lack of mains power, so that 'telemetry' or other remote management systems can still operate.

\section{Leads}

Mostly he referred my questions to other people. He didn't spell out any names, so spellings here might be wrong. He called Mr Manfred Coeste, and asked him to arrange for me to be given info / arrange meetings. He said that Mr Coeste would probably refer me to Kevin Pattenden [who called me shortly after, so he must have done], who works of the high-voltage end of the distribution. He is based in Wynberg, and apparently worked on the lower-voltage $(<\mathrm{kV})$ side before his current position.

He also said that, when in Wynberg I should go to speak with Roadwell Mpongo (pronounced Rodwell), who works on the $<11 \mathrm{kV}$ side of the system, I think in the same or similar type of position as Pattenden.

He also mentioned Dr Rencontra, who I think is electricity manager for the City (ie. his boss).

He suggested that is no luck was had asking about disposal practices from the electrical side, I should speak to Rastiem Keeraam, in Solid Waste.

\section{Follow up}

He stresses that he considers both the infrastructure and intellectual property to belong to the City, and that he would like to check anything using their data before publication. 


\section{KEVIN PATTENDEN}

CoCT Electricity Department - High Voltage distribution

20/02/2009

He started off by saying he was willing to help as long as they didn't get into trouble (with nervous laugh) through some kind of environmentalist research project. [?!]

\section{Substation use of batteries}

On his side, he says the high-voltage end has some 80 substations equipped with $\mathrm{NiCd}$ batteries. The older stations have a $30 \mathrm{~V}$ battery and a $60 \mathrm{~V}$ battery, whilst some of the newer stations have a $60 \mathrm{~V}$ battery and a $110 \mathrm{~V}$ battery. They are around 21 Ah batteries.

On the lower-voltage end, there are about 1000 substations around the city. The person to speak to there is John Graeme, who is currently drawing up tender specs for a considerable replacement of the batteries.

The batteries undergo six-weekly maintenance for which there is paperwork including some info. He says it should be possible to get the data I want, although it might take some work. He agreed to meet me the following Monday.

\section{Contacts}

John Graeme, CoCT 


\section{KEVIN PATTENDEN}

CoCT Electricity Department - High Voltage distribution

$24 / 02 / 2009$

\section{Use of NiCds in substations}

In his area, (North and South) there are 40 substations. All of these have 60V, 29 Ah intertripping batteries, and also a tripping battery, either $30 \mathrm{~V}$ (in older stations) or $110 \mathrm{~V}$ (in newer stations), both types $29 \mathrm{Ah}$. He estimates that about $70 \%$ of stations conform to the new standard (110V) and $30 \%$ are still on the old $(30 \mathrm{~V})$. There are also 5 stations with an additional $110 \mathrm{~V}$ backup battery.

He called a colleague in the East area, who provided the following figures: 35 substations with $110 \mathrm{~V}$ tripping, 2 substations with $30 \mathrm{~V}$ tripping, all with $60 \mathrm{~V}$ intertripping (all 29Ah).

Larger stations use $\mathrm{Pb}$-acid batteries.

He had a map that showed all the relevant substations in Cape Town. This showed 37 City substations and 9 Eskom substations in the East area.

There is no West area.

Note that this is only on the high-voltage side. The lower-voltage side has a plethora of substations with their own batteries, but these fall under the management of the depots themselves.

\section{Replacement of batteries}

He says that batteries are usually replaced as a whole-not individual cells.

In North and South areas, no batteries were replaced in or since 2005. Also, no substations were commissioned in this period.

In the East area, which has much older equipment, $6 \times 110 \mathrm{~V}$ batteries were changed in 2005 , and $2 \times 30 \mathrm{~V}$ batteries. All $29 \mathrm{Ah}$.

Note that this is only on the high-voltage side. The lower-voltage side has a plethora of substations with their own batteries, but these fall under the management of the depots themselves.

\section{Lifetimes}

He called Mervyn Barry, who estimated that battery lifetimes are 15-20 years, 20 years if well cared for. 
He also said that some substations are more than 20 years old, and their batteries are still in pretty good condition.

\section{Suppliers}

Whenever they buy new batteries it goes out to tender, so there's no telling who actually would supply them. He did mention Amptron, Alcad and Chloride as frequent suppliers, though.

\section{Disposal}

Old batteries are taken to the Electricity Stores (in Maitland, I think he said), where the reclamation department would arrange their disposal. He doesn't think there is an external contractor involved in disposal.

\section{Leads}

He said that a very knowledgeable person to speak to about batteries is Mervyn Barry, who used to work for First National Battery but now has his own company. He has "been in the business since they invented batteries". 


\section{LEON DROTCHE}

ESKOM Distribution, Western Cape

$23 / 02 / 2009$

\section{Eskom distribution network}

He says that the greatest part of Eskom's distribution infrastructure in Cape Town is in Khayelitsha and Elsies River.

\section{Battery use in substations}

In their smaller distribution substations ( $11 \mathrm{kV}$ in and out) and the final distribution substations they have $36 \mathrm{~V}, 32 \mathrm{Ah}$ batteries. The indoor ones are referred to as 'brickbuilt' substations.

In the step-down substations they often use $110 \mathrm{~V} \mathrm{NiCd}$ batteries of between 32-71 Ah.

For larger distribution stations and upstream in the bulk supply, they use $\mathrm{Pb}$-acid.

There are about 90 of the smaller stations and 5-10 of the larger step-downs which are using NiCd batteries.

Their new batteries are all Saft (Vantage cells), which are recombination cells - only need topping up every 5 years or so. Some of the older small substations (about $50 \%$ ) use EP batteries (also Saft, but sold as Chloride) which are old-style vented cells.

\section{Installation}

In 2005 , from 15 to a maximum of 20 small substations (36V) would have had their batteries replaced. None of the step-down stations would have been replaced.

\section{Lifetimes}

The manufacturers claim a 20 year life span. Typically they expect a 16-20 year lifetime.

\section{Disposal}

They have an agreement with Alkaline batteries [in Johannesburg, I think] to accept all spent batteries from them. These are then exported to Switzerland for recycling, with complete certification along the way. 


\section{JOHN GRAHAM}

CoCT Electricity Department -distribution

$20 / 02 / 2009$

0215144280

0842221385

He said that he would like to get authorization for sharing detail data, and seemed put at ease by hearing that I had spoken with Marius van der Westhuizen already. He also expressed interested in the project, and said he would like to see what came out of the research / read reports etc.

\section{Substations and their use of NiCds}

He oversees the systems that take the $11 \mathrm{kV}$ supply down to $380 \mathrm{~V}$ for end use and pass some $11 \mathrm{kV}$ lines on to mini-substations for step-down to users. He estimates that, on his side, there are around 1000, give or take a hundred or so, substations in Cape Town, each equipped with a $30 \mathrm{~V} \mathrm{NiCd}$ battery bank ( 25 cells) for protection switching. The older ones have $11 \mathrm{Ah}$ capacities, but they are being upgraded to $29 \mathrm{Ah}$. He estimates a proportion of $70 \% 11 \mathrm{Ah}$ to $30 \% 29 \mathrm{Ah}$. About ten years ago the $11 \mathrm{Ah}$ was the only standard. There is also a suggestion doing the rounds that they should upgrade to a $110 \mathrm{~V}$ system, but this isn't being done yet and he doubts that it will - the operational difficulties and costs of carrying out such a changeover are prohibitive.

Downstream of the substations he oversees there are no NiCd batteries (stated categorically).

They are trying to apply a 90-day maintenance cycle on the batteries, although he said that lack of capacity was not making this entirely possible as yet, although it is the aim.

He referred to Kevin Pattenden's substations as the 'step-down' stations, and confirmed that they are using some $110 \mathrm{~V}$ systems there.

\section{Supply and disposal}

He didn't specifically state that Alcad was their only brand CoCT uses, but he did say that they were the main manufacturer of tripping batteries, and he mentioned them repeatedly.

He said I should contact suppliers for technical specs (see below).

He said he is out of touch with the actual practices involve with the batteries. In the past, spent batteries were disposed of by a contracted hazardous waste disposal firm, and to the best of his knowledge this is still the case, but he does not know for sure. He says that the area management (there are three in Cape Town), or the individual area stations (four in each area) should have better knowledge of this. He says that, if sent to a haz waste 
contractor, the standard is to go to Vissershok, although the treatment of waste there can vary depending on its characteristics.

He says that, in general for electrical systems, an insistence on proper end-of-life handling is becoming the norm in the City's dealings.

\section{Data availability}

He says that data on the installation and disposal of the batteries must exist, but it is probably not feasible to access. He says that he would be able to supply me with total stock movement for new batteries, although it might not be possible to go back as far as 2005 or even 2006 . However, this would reflect the installation of new batteries under three different circumstances: 1) replacement of a spent battery as part of battery maintenance, 2) replacement of the whole piece of protection equipment, possibly because of electrical failure, and 3) commissioning of new installations. He does not think it would be possible to tell how many of each circumstance occurred.

The separate area management ( 3 in the city) or individual depots ( 4 in each area) would know about their waste disposal practices.

\section{Leads}

Suppliers:

Static Power [actually already spoken with them] - Derrick Greeves

Silicon Engineering - Christopher Hansen 


\section{SALLIEM JAINODIEN}

Lead and Solder Sales

$25 / 02 / 2009$

\section{Collection of CoCT NiCd batteries}

He confirmed that he does collect CoCT NiCd batteries. His business actually collects their lead waste, including old $\mathrm{Pb}$-acid batteries and lead cabling, etc. He does the collection for free, as a favour to the City, since their lead waste is of value.

\section{Disposal}

All the batteries ( $\mathrm{Pb}$ acid and $\mathrm{NiCd}$ ) get put onto the same pallets and sent up to Fry's Metals in Germiston. He says that they don't really accept NiCd, and have at least sometimes charged him for their disposal. They hand them over to a waste management company over there for hazardous waste disposal.

\section{General disposal}

He says that nobody in Cape Town, or anywhere else besides JHB, is licenced to 'break' batteries - ie to drain them for transport. He says that law stipulates they can only be exported dry, and some scrap dealers who want to export them therefore illegally drain them, often discarding the old electrolyte into the sewage system. He transports the batteries as they are collected (ie still filled with electrolyte) to Fry's, who are licenced to do this. 


\section{WERNER BOTHA}

Bosch

$30 / 09 / 2008$

\section{Battery Chemistries}

Bosch has been manufacturing cordless power tools with $\mathrm{NiMH}, \mathrm{NiCd}$ and $\mathrm{Li}$-ion batteries. NiCd batteries were used more in the past, but were replaced by NiMH due to serious memory problems. Li-ion are relatively new in the market.

Bosch was the first to introduce Li-ions in South Africa, with Makita introducing them recently. He says these are the only two firms supplying power tools with $\mathrm{Li}$-ion batteries at present [I suspect this to be untrue]. Bosch launched its first Li-ion batteries in the DIY range about 5 years ago, and moved into industrial applications a couple of years ago. Garden tools have been the most recent additions to the Li-ion powered range (including a lawmower!).

He estimates that only $1 \%$ of cordless power tools sold in 2005 were Li-ion batteries, the rest being $\mathrm{NiCad}$.

Li-ion batteries are much more expensive. He gave an example of one NiCad which sold for $\mathrm{R} 900$, the Li-ion equivalent going for $\mathrm{R} 3500$. They are smaller and lighter, though, and self-discharge very slowly (A NiCad battery loses $1 \%$ of its charge per day if not used, a Li-ion only $2 \%$ every 6 months).

As Bosch tools are manufactured in Germany, battery chemistry technology is going to follow the European movement, and so a phase-out of NiCads can be expected as this occurs in line with European legislation.

\section{Tool use}

The Western Cape is the largest seller of cordless power tools for Bosch. He believes this is due to higher consumer awareness here.

Their batteries are guaranteed for 1500 charges, but he says they can reasonably expect a lifetime of 4500 .

Lifetime for the battery and tool is very difficult to judge, as it relies heavily on the extent of use and how well the tool is cared for. The batteries are very temperature-sensitive (with NiCads losing their capacity rapidly if heated to over $40^{\circ} \mathrm{C}$ and Li-ion if over 50 ${ }^{\circ} \mathrm{C}$ ). He reckons a DIY tool which is well cared for and used infrequently could last a lifetime. As a judgement, the above battery charge lifetimes can be compared to his estimate of 500 screws to be drilled per charge (on a roughly 1.5-2 Ah battery). He also mentioned an estimated 30min / year DIY use of tools, although this does sound kind of low. Perhaps if it is meant as constant use it would be fair.

\section{Tool and battery sales and use}


Approximately $10 \%$ of tool sales in the Western Cape are cordless.

Bosch makes far more tool sales than battery sales. This is because much of the tool cost is actually the battery (approx $75 \%$ of the price in most cases) so people usually would just replace the tool. He says that most battery sales are actually for upgrades (people wanting a battery with high amp-hours).

All cells in Bosch products are manufactured by Samsung or Panasonic. These are exactly like consumer cells (ie cylindrical metal cells) but unmarked and wrapped in card. They are packed together into the battery pack for the tool.

A workshop technician mentioned that UniRoss is involved in battery repacking (which I now believe is simply removing the old cells and putting in new ones) but that the repacked batteries do not perform as well as the orginals.

Bosch is accepting old batteries for customers, both through its office and through authorized dealers. He wasn't sure what they did with them.

\section{Misc}

He mentioned that customers were generally well informed these days, and when considering purchasing a tool they educate themselves on the internet in advance. $\mathrm{He}$ believes this is due to frustration with poor service received at dealers. Apparently they regularly arrange training sessions for dealers to get to know the tools well, but the attendance is very poor.

They get SABS approval for all tools brought into the country, which he thought was required by law, although he said many cheap imports are done without it, and make a lot of sales before anyone challenges them on the lack of approval. Apparently this process is quite expensive and is completely independent of approval from any European or other standards body. It also only lasts 10 years, after which the process must be repeated.

\section{Follow up}

He said he would contact Johannesburg office to try to get figures for NiCad sales through tools and spares for 2005 and 1998.

I should also ask him if he could get figures for the number of returned batteries, and who to ask what happens to them.

SABS should be checked out to see how detailed there requirements are.

He gave me the Bosch Handbook for Trade and Industry, which apparently contains considerable information about tool and battery specifications and the like. (confidential) 


\section{CHAD GEORGE}

and

Tony Sanderson

Metabo

$01 / 10 / 2008$

\section{Batteries and Chemistries}

They have never sold NiMH powered cordless tools, although they have been in the Metabo range internationally. Li-ion batteries were launched last year, and $\mathrm{NiCd}$ were $100 \%$ dominant before then.

The home chargers are able to put a NiCad battery through 1000 charges, but the top of the range charger can push this to 3000 .

\section{Manufacture and sales}

Their cells are manufactured by Panasonic.

Battery packs are imported fully assembled.

The Metabo NiCad batteries range from $9.6 \mathrm{~V}$ to $18 \mathrm{~V}$, but no $14.4 \mathrm{~V}$ packs are sold in SA.

The $18 \mathrm{~V}$ drill is a big seller.

Tony Sanderson gave a very confident estimate that 1200 cordless tools (with two battery packs each) were sold in 2005 in Cape Town. He said that a precise value would be extremely difficult to extract from the records, but that he was sure this estimate was not far off the true value.

Neither of them were involved in the business in 1998, but said that the number of cordless tools sold at that time were very small.

Sales of spare batteries are very small.

Tony call Dietmar Bofner at their JHB offices to get this relieable data: cordless power tools make up $4.7 \%$ of their running total tool sales, and $3.99 \%$ of year-on-year sales. 


\section{Tool use}

Chad's guestimates were $2 \mathrm{~h} /$ month DIY use, but their target market is industrial were a full working day $(8 \mathrm{~h})$ is assumed.

\section{Import and return}

Sales of the tools in SA requires SABS approval by law. Tony scoffed at the approval process, however, and believes it regularly allows sub-standard equipment onto the market.

They do accept battery returns from customers or dealers, but the numbers are small, and include those returned for faults. These are returned to the manufacturing centre in Germany.

Tony said that no records were kept on how many were returned, in so far as he knew.

\section{Contacts / leads}

Tony listed a few competitors: Makita, Bosch, Ryobi, Stihl, Star.

Dietmar Bofner - JHB head office, in sales

\section{Follow up}

Chad said that he was going to try to find the documentation that would detail the number of cells in each battery. He also gave me an old battery pack to check out.

Dietmar Bofner might be able to give figures on the number of batteries that are returned to Germany each year. He also sounds like the guy with his fingers on the figures, so he might be good to ask further questions. 


\section{CRAIG KLUMPER}

Matus, sole Hitachi distributors in South Africa

$14 / 10 / 08$

\section{Hitachi use of NiCads}

Craig says all Hitachi cordless power tools run on NiCad batteries, but Li-ion batteries will be introduced in a new tool range soon.

All cordless tools come with 2 batteries.

They do not accept returns of used batteries.

He 'thumb-sucked' that the lifetime of a battery should run into several hundred charge cycles.

The 24V 2.0Ah battery is quite large and heavy (list price R3162 for the battery alone). A glance through their catalogues showed a typical range of voltages, from around $7 \mathrm{~V}$ through to $24 \mathrm{~V}$ and up. The $14.4 \mathrm{~V}$ and $18 \mathrm{~V}$ seemed common.

\section{Business}

Cordless tools are manufactured in several countries around the east, including Japan, China and Malaysia. He said that often certain components would be manufactured entirely at a particular factory, then all components shipped from the various places of manufacture to a single assembly plant, and finally shipped to the purchasing countries.

Their company sells strictly wholesale.

The entire of Hitachi (including all sectors, e.g. building machinery, etc) is held by a holding company: TAI-YO-BUSSAN, which can be reached on 0114684869.

\section{Follow up}

He agreed to try to get a count or estimate of the Hitachi battery movement in 2005 , or failing that to try to estimate the 2006 sales himself. Also for loose batteries.

He lent me his current catalogue for Hitachi. 


\section{ANDREW LONGMAN}

Makita

$01 / 10 / 2008$

\section{Battery chemistries}

Makita has been dealing in NiCad cordless tools for a very long time (first launched in their range in 1978 with a $7.2 \mathrm{~V}$ system). The progression has been from $\mathrm{NiCad}$ to $\mathrm{NiMH}$ (about 5-6 years ago) to Li-ion (launched June or July last year). $\mathrm{NiMH}$ promised extra battery life, but he says they were considerably more expensive without any real technical advantage. These products have been pretty wholly replaced by the new Li-ion technology. The NiCads have generally been strong sellers nevertheless, andsold well in spite of NiMH and still do well due to price differences.

In both 1998 and 2005 he says the NiCads would have been the dominant chemistry by sales.

He claims that Makita was the first to release a 'full range' of Li-ion tools [which I guess is not a contradiction of Bosch's claim to being the first Li-ion supplier in SA].

Nonetheless, he said he thought the other companies had entered the market to some extent due to Makita's commitment to the technology, which is at odds with the Bosch claim to have brought $\mathrm{Li}$-ion tools into the market as much as five years ago.

They had 11 NiCad-powered tools in their catalogue for both $2003 \& 2004$.

Interestingly, he said that he was sure far more NiCads had been sold in 2005 than in 1998 , as a result of the growth in the cordless market.

He estimates that, in line with European pressures, Li-ion will completely replace NiCad batteries within about 2-3 years.

Li-ion cells require very special charging, with temp. control and battery monitoring. He compared the battery charger communication with the cells as to the communication that occurs between parts of a computer.

\section{Battery manufacture, product structure and sales}

He estimates that $<10 \%$ of power tool sales are cordless.

Sanyo manufactures all their cells.

Battery packs are imported as a fully assembled unit, and are not opened in their service department for repair. See battery repacking below.

Price comparison: 


$\begin{array}{cll}\text { Li-ion } 18 \mathrm{~V} & \text { 3Ah } & \text { R1300 (incl) } \\ \text { NiCad } 18 \mathrm{~V} & 2 \mathrm{Ah} & \mathrm{R} 1094 \\ 14.4 \mathrm{~V} & & \text { R875 } \\ 12 \mathrm{~V} & & \text { R760 }\end{array}$

Tools and battery packs are manufactured in Japan.

The number of cells in a battery pack determines the voltage. The individual cells are all $1.2 \mathrm{~V}$, and the voltage is additive (ie a $12 \mathrm{~V}$ battery has $10 \times 12$ cells).

He did stress that different cells, both in terms of their Ah rating and the make, will have different make-ups and hence different amounts of cadmium.

The spare battery trade is very small, with only a couple of each model sold every year.

Some of the older cordless tools used 'pod' battery packs, the oval cylinders that I think I have come across in batteries brought in as e-waste.

Battery voltages sold in NiCad:

7.2

9.6

12 (huge seller in 1998)

14.4 (huge seller in 2005)

18

The $18 \mathrm{~V}$ range is losing ground to Li-ion in a big way. Today the big-selling voltages are a mix of 12 and 14.4 in NiCad.

\section{Lifetimes}

He says their batteries have an estimated 500-550 charge cycle lifetime.

Under industrial use, his guesstimate was that a battery would last for 1-2 years if properly maintained. Under DIY use it could last many years.

\section{Battery disposal and repacking}

They do accept battery take-back, but I got the impression that they do it very informally. The dealers might accept them, but more likely would just refer people to their offices. He says over the last $4-5$ years they have only received about 80 batteries in this manner.

He mentioned some key info: a cause for the low sales in replacement batteries are battery repackers. He said that the dealers will generally accept worn-out batteries and replace them not with new, original Makita batteries, but with repacked batteries. The old batterie packs are sent to outside companies that specialize in battery repacking. He mentioned a Cape Town company, The Battery Sell, and thought that there were probably be others operating. 


\section{Contacts}

Peter Schneider - Makita JHB, involved in marketing and might be able to provide catalogues or other insight into the product range in 1998.

The Battery Sell

Probably Errol is the person to speak to.

\section{Follow up}

He agreed to try to get figures for the sale of NiCads in 1998 and 2005 for me, as well as figures for returns and a figure for the proportion of cordless tools in sales. Ife requested that the info be treated with confidence, and I assured him that his comment would be sought before anything was made public. 


\section{PETER MUMFORD}

Ryobi

$10 / 11 / 2008$

Ryobi only brought in Li-ion battery systems in the last week and has never had NiMH battery packs. Everything has been NiCd exclusively in the past.

The most popular sellers in cordless power tools are screwdrivers and drills.

He says that, as distributors to dealers, they have no idea of the market share of different tool applications or user groups.

\section{Follow up}

He said he would try to get sales figures for Cape Town for 2005 . 


\section{PETER SCHNEIDER}

Makita (but also SAPTA)

$17 / 02 / 2009$

He looked at my figures in ToolSource_MeetingData.xls (under Schneider in Correspondence folder) and went on to explain...

\section{His previous data}

The data he sent me is from the official SAPTA data, so it is as accurate as their reporting procedures.

The SAPTA figures that he previously provided were for industrial tools only. These are much more expensive, per unit, than DIY tools.

SAPTA estimates that industrial tools make up $25 \%$ of total tool sales.

SAPTA estimates that its members account for $+/-70 \%$ of the industrial tool sales market.

SAPTA estimates that its members account fro $+/-50 \%$ of total tool sales in SA.

Industrial tools sales have fewer cordless than DIY sales.

Ryobi is not a SAPTA member, and is a major player in the SA market. SAPTA estimates they have $+/-40 \%$ of national tool market share.

\section{Misc}

As an example of the price distinction between industrial and DIY, an industrial drill will cost R1800, a DIY cordless one R399.

A breaker tool (for which no-one would sell a cordless) comes in at about R17000, and this would never be sold as a cordless version.

SAPTA represents 7 major power tool brands in SA. He says that within SAPTA, a small club of three brands: Bosch, Stihl and Black\&Decker, share their DIY sales figures, but nobody else gets to see them.

He says that some people in industrial settings try to save money and buy cheaper (nonindustrial tools) either when cash-strapped or because they are concerned about theft of tools, which is a major issue.

He says at present about $90 \%$ of cordless power tool sales are $\mathrm{NiCd}$. 


\section{FRED DOHNE}

\section{DeWalt SA \\ $17 / 02 / 09$}

He confirmed that the data he had sent me gives the number of cordless DeWalt tool sales in 2005 , and the DeWalt national market share corresponding to each category.

He said that in 2005 DeWalt was unique in offering an $18 \mathrm{~V}$ "solution" in South Africa, based on NiCd, which involved a single battery design which was interchangeable among about 20 different tools (most of which would be included in 'other' in the spreadsheet he sent). This allowed people to purchase just the tool body if they already owned a DeWalt $18 \mathrm{~V}$ cordless. At this stage it was a pretty unique approach, although he says that Makita have now started a similar thing. NiCd were almost completely dominant in the tool chemistries.

He says that Makita are big players in the Western Cape market, but in 2005 they were fairly weak on cordless tools and DeWalt probably had considerable share in the province in cordless.

He says that as of 2007 Europe has banned NiCd powertools, forcing everyone onto $\mathrm{NiMH}$ until 2010, when they will be required to operate on Li-ion. [I don't think this is correct].

He says that the SA market is highly price sensitive (and Li-ions are very expensive), and hence it is still worth bringing NiCds into the country, and will probably remain so for some time. He did not seem to think the demise of the NiCd in South Africa was as imminent as some industry players have said, although he did say that the Li-ions did have some great advantages, specifically weight.

He says that DeWalt was around 5 th or 6 th in the powertool market in 2005 , but in cordless tools they were the leaders.

He used to work for Metabo until 2004. He says at that stage their cordless tools were pretty useless, and he doesn't think they did well. 


\section{FRED DOHNE}

\section{DeWalt SA}

03/08/09

In 2005 their cordless range was totally $\mathrm{NiCd}$.

Drills and screwdrivers are dominant in terms of sales in cordless tools. He says $95 \%$ of cordless tools are drills and drivers.

In 2005 the $12 \mathrm{~V}$ systems were very popular. He calls it the 'American way': over time, everything must get bigger and more powerful. Hence today the average is higher. In 2005 he says they sold almost $100012 \mathrm{~V}$ drills, and $60018 \mathrm{~V}$ drills, for comparison.

They only accept old battery packs when faulty, no end-of-life take-back.

The category 'Drills without torque setting' in the DeWalt data he says are likely to be a very limited category across most major manufacturers. He says that it quite critical for a tool, and their low sales numbers are probably seen across the industry. A possible exception is some cheap Chinese imports.

Li-ion is usually much more expensive than $\mathrm{NiCd}$. For example, one drill example was R1000 for the NiCd drill and R3500 for the equivalent Li-ion drill.

Cordless over corded prices can be compared from this example of a high-end industrial drill: Corded: R2000, NiCd cordless: R3500, Li-ion cordless: R5000

From DeWalt data he looked up the percentage of cordless to total tool sales in 2005:

$$
\begin{array}{ll}
\text { in sales value terms: } & 5 \% \\
\text { in numbers: } & 5.7 \%
\end{array}
$$

Industrial and trade use is their major market ("99\%"), although he does expect that some DIY users would buy their tools. 


\section{ERROL PIERCE}

Previous owner of BatterySell (owner in 2005)

$18 / 11 / 2008$

\section{General batteries}

He described NiCds as 'the old work-horse of batteries', with the particular characteristics of fast charge rates and high discharge capability.

NiMH provide a higher power/weight ratio. They are by nature slow charge and slow discharge, however. He says their use in power tool applications relies on circuitry to compensate for this, but it still means that the cells are operated at their limits and this shortens their operating lifetimes considerably.

Although NiCd batteries are claimed to have a cycle life around 1500 cycles, he says that these are 'laboratory condition' values, and that in reality a well cared-for battery will last in the order of 700 cycles. Even in terms of the 'lab condition' cycle lives, a manual he showed me give all other battery chemistries with considerably shorter lives (even the Liions in the area of 1000 cycles). [This does contradict what he said about the long lifetimes of Li-ions later, but then I suppose in the real world they are less prone to damage by charging mis-use].

His pamphlet also gave the self-discharge rate for NiCads as $20 \%$ per month.

Li-ion batteries require circuits for short-circuit avoidance and careful charge control to prevent under or over charging.

Although he has done it and might go into it again in the future, he says that Li-ion repacking is a tricky business. It is quite time consuming and difficult. In addition, the explosive risks of $\mathrm{Li}$-ion cells pose problematic culpability dangers if anything in a repacking job is not $100 \%$ and someone or something gets injured. He says that when $\mathrm{Li}-$ ion cells explode / ignite nothing can stop them. Water and sand are ineffective.

The memory effect seen in NiCds is caused by large-size crystal growth, which lowers the actual Ah performance of the cell.

$\mathrm{NiCd}$ chargers are apparently often a problem for cells, and he used to ask to check chargers at the time of repacking so that the new cells did not get damaged by a faulty charger system.

Proper cell manufacture takes place in positive-pressure dust-free areas, as contamination of the separator plates reduces battery performance, including the Ah performance.

He says that cells from many manufacturers are tested after fabrication. They might be manufactured to be $2000 \mathrm{mAh}$, but fail the capacity test. If the pass the $1800 \mathrm{mAh}$ test (or 
lower) they are then sold as such. He says that all these cells are the same size, although they differ in mass. [Hence, a correspondence between the Ah rating of a cell and its cadmium content might not hold all the time, as the amount of cadmium would be equal to the fabrication requirements of a high Ah cell].

He said that mass seems to differ considerably with Ah rating, although the sizes are the same. [This suggested, in conjunction with the above, an avenue that might be worth explorin - that there might be a better correlation between cell mass and $\mathrm{Cd}$ content than between cell Ah rating and $\mathrm{Cd}$ content].

He has had experiences in the past of testing batteries and the component cells in power tools and finding that their Ah performance is way below what is claimed.

A battery will only operate at the Ah of its weakest cell.

Venting will occur in $\mathrm{NiCd}$ batteries when the cell is charged at a very high rate.

He says that the standard charge time for a NiCd cell is $1 \mathrm{hr}$, but with a charger circuit that monitors the charging progress, this can be taken down to $15 \mathrm{~min}$. The circuitry uses an algorithm to determine when to stop charging, based partly on the temperature of the batteries (which increases with charging, to a point of $45^{\circ} \mathrm{C}$ for cut-off at full charge), and also on detection of a $32 \mathrm{mV}$ drop in the cell potential that occurs at the point of full charge (the negative delta voltage). He says that chargers might stop just beyond the negative delta voltage, or deliberately overcharge slightly to ensure total capacity is reached.

The dimensions of cells differ from manufacturer to manufacturer, with tolerances of $1 \mathrm{~mm}$ in height and $1 / 2 \mathrm{~mm}$ in diameter. He says this can cause problems where tool manufacturers have designed the battery casing to tightly accommodate a particular cell brand.

Li-polymer so far has found a limited market in hobbyist applications, because they have outstanding power/ weight ratios. This is their major use at this stage.

\section{The business}

He sold the BatterySell operation to Michael Fulton some months back, but has retained the business as a dormant entity.

He used to repack $\mathrm{NiCd}$, NiMH and Li-ion batteries for a range of things, inclusing laptops. He says he would have been able to get into Li-ion powertools, since he knew the basics, but he has not done them. I got the impression that this was primarily because they last for a very long time, and so the lead time until they appeared on the repacking scene was still underway when he sold the business. 
Power tools were his main source of revenue (he estimated $80 \%$ ), and this business came largely through tool repair shops, although he also provided to walk-in business.

He says that his reputation for excellent cells and good work spread quite widely, and he got a fair amount of business from outside the city. Some of this included agricultural equipment from Pietermaritzburg and even tools sent down from JHB, but also some work from towns around Cape Town (Stellenbosch, Malmesbury, Picketburg... I got the impression that he got business from all over the place). He estimates that $10-15 \%$ of his business was from outside the city limits.

Beside importing the cells, he also at one stage imported the Nickel tabs for connecting them. He was importing $99.6 \%$ pure Nickel tabs which were wider than the usual ones (thin tabs can overheat when the battery is put under stressful discharge). He says these had to be order in considerable bulk, so he actually sold them at cost to IPP (see below).

\section{The batteries of BatterySell}

He imports Sanyo batteries, which he says are exceedingly high quality. He says they claim a $0.0 . .01 \%$ failure rate, and he has never had a Sanyo NiCd faulty cell. He does also purchase some from within South Africa, in particular in cases were a nondemanding user (eg home DIY) is more price-sensitive than performance-sensitive. These are imported by other companies. He says these will not be reflected in his import figures, which are the easiest way to determine his sales for a year.

Sanyo apparently does not usually sell these to anyone except original producers of equipment that use them, and it took him some time to establish the contact and arrange to be able to buy and import directly from Sanyo.

He encourages power tool users to have their batteries repacked with 2 Ah cells [I think these are actually $1900 \mathrm{mAh}$ below], which he says often gives better performance than the tools did when new (and hence makes for happy customers). He did also do repacking with tools in lower Ah ranges.

He guestimates that his 2005 import figures would look something like:

$\begin{array}{ll}1900 \mathrm{mAh} & 2000 \text { cells } \\ 1700 \mathrm{mAh} & 1200 \text { cells } \\ 1300 \mathrm{mAh} & \text { less than these }\end{array}$

He thinks that the purchases from inside South Africa probably run at around 10-15\% over and above this.

He said that $95 \%$ of his business had been in NiCd repacking.

Besides an $80 \%$ predominance of power tools for repacking, he also saw a lot of other equipment, including hospital defibrillators (which he says operate on battery power), fruit picking counters, dental close-lighting equipment and survey equipment. 
He says that in 2005 the average power tool voltage was $12-14 \mathrm{~V}$ (although they did go up to $36 \mathrm{~V}$, but not normally).

\section{Waste disposal}

He said that some years ago he took spent cells to a Hazardous Waste Disposal Unit in the Athlone municipal area where Scientific Services and the Wastewater Treatment are located. They then stopped accepting batteries there.

He found out that there was an e-waste disposal site on Rosmead Ave [this would be the Wynberg drop-off] and he took spent cells there from then on.

He has approached the City at times to determine the proper disposal methods (and in the process spoke with Susan Dittke, who I think might have steered him toward the Wynberg drop-off) but the City response after the closure of the Hazardous Unit was that it he would have to arrange safe disposal through a private firm. At that stage he was quoted a fee in the range of R1000 for a $210 \mathrm{~L}$ drum. He feels indignant that he should have to pay so much for the safe disposal, given that most other operators and households would simply throw them out with the garbage. He says that from a business point of view, he cannot afford this. If necessary, he would prefer to simply tell customers to take the old cells away with them, and they can then throw them away themselves.

\section{Leads}

International Power Products (IPP) - Jane Smith. Another company doing battery repacking.

He did not know anything about the type of "vented-cell" NiCds I have been wondering about, but he said that people in the film industry often use quite large battery packs to power cameras and the like. These apparently run on NiCds.

\section{Follow-up}

He says that he compiled a good amount of information around batteries and repacking as part of his battle with beaurocracy in his aborted move to New Zealand. This included a fairly comprehensive list of $\mathrm{NiCd}$ applications (he said several pages). He said he would arrange a copy of at least some of this material for me.

He said he would look at his import records for 2005 and give me an estimate of sales from them.

[Later provided on 20/01/2009: His direct imports over a 6-year period amounted to 35-37 000 cells, 1900Ah and 1700Ah. He reminded me that he purchases $10-15 \%$ of his cells from within SA, ie imported by someone else. These are not included in this figure.] 


\title{
JULIAN VAN GINKEL
}

\author{
Batteries Unlimited
}

$28 / 10 / 08$

\section{The business}

Batteries Unlimited is actually a barely separate sister company of an electrical company that works largely in repair of photographic lighting equipment and the like. He says that the battery side is quite small, and the battery repacking operation is a small portion of that.

He does not import any batteries himself, only distributes.

\section{NiCads and Battery repacking}

He says that laptop batteries are really difficult to repack, apparently because the sneaky laptop manufacturers include an IC and memory chip inside that monitors the state of the battery and can only be reset with proprietary software. Thus you can replace all the batteries with new ones, but the pack will still register as uncharged. Of course, only the authorized dealers/servicing agents have the software.

He confirmed: total voltage on a battery pack is the sum of cell voltages, but Ah rating is equal to the Ah ratings of each cell.

They get NiCad repacking work primarily from power tools, but also from digital safe locks and digital doors locks (as they have in hotels).

He says that a huge range of toys are running on rechargeable batteries, including a range of remote control toys etc.

He even had an electrical scooter in for repairs, that ran on $\mathrm{Pb}$-acid.

\section{Battery suppliers}

His choice of supplier varies depending on price and availability:

Meltzer - JHB based, importers

Singer Photographic - distributors for Energizer

Specialized Batteries - JHB

Duracell

Eveready (who definitely made NiCads in the past - I saw one there)

He says that supermarkets are increasingly selling NiCads.

\section{Rechargeable alkaline}


Rechargeable alkaline batteries are being manufactured by Grandcell. Apparently the whole point of having rechargeable alkaline batteries is that many electrical appliances (cameras, calculators, whatever) are designed to function of $1.5 \mathrm{~V}$ disposable alkaline cells. This means that running them on $1.2 \mathrm{~V} \mathrm{NiCd}$ or NiMH is not ideal. The $1.5 \mathrm{~V}$ alkaline rechargeables thus provide a rechargeable option that also delivers the right voltage.

\section{Figures for 2005}

Their battery operation only started at the end of 2005, so he didn't really do any repacking in that year.

\section{Waste disposal}

He delivers all spent batteries to Non-Ferrous Metals.

\section{Contacts}

Errol Pierce - Battery Sell 


\section{WARREN SAUNDERS}

\section{$17 / 10 / 2008$}

\section{Woodstock drop-off facility}

The drop-off accepts only three types of waste: clean builders rubble garden waste mixed waste (general industrial/residential, non-hazardous type eg old furniture, garage empty-outs, etc.)

The three accepted waste types are handled separately.

If electrical contractors disposal of their waste materials there, this is not permitted and is against the regulations for what may be accepted there.

"Clean builders rubble" refers strictly to bricks, mortar, etc. without any wood, rhinoboard or other material included. In this form it is saleable to aggregate and similar companies who can re-use it. Once other things are mixed into it, however, it is not usually worth sorting it, and it must be landfilled. Builders rubble that goes to landfill is often used for cover and construction on the site, eg roads for trucks over the landfill.

Garden refuse is chipped on site by one of three chippers provided by the company that is contracted to manage the site (Interwaste). The chippers are moved from site to site. The chipped waste goes to composting plants or to a fuel manufacturing firm.

No 'wet' waste, ie mixed household waste is accepted. This is because the regulations require that such waste must be covered at the end of the day, and hence it must go straight to landfill. The drop-off facility often has a hold-over of some days.

Waste is contained in skips which are removed periodically. Those destined for landfilling go to Vissershok.

\section{Use and records}

The drop-off facilities were originally envisaged to provide for residents in the surrounding communities. Initially this went as far as requiring people to produce rate bills to deliver waste. This started to change when gardening companies demanded use of the drop-offs, because they were disposing of resident's garden waste. He says that the system is now being quite thoroughly abused by building contractors as well, but, although they now serve commercial entities more than residents, turning people away tends to lead to illegal dumping. Apparently when people are turned away they quite often just drive down a nearby side-street and dump everything there. In fact, a fair amount of illegal dumping occurs right outside the drop-off gates when it is closed. 
Records are kept of each skip removed, and the type of waste it (is supposed to) contain. The records also confirm arrival of the skip at Vissershok.

Loads of less than 1.3ton bakkie loads are accepted free of charge. Larger loads are not accepted, but must go directly to landfills.

There are supervisors on site directing vehicles and checking that loads are what they claim to be. He did concede that it was very difficult to check each load, and people could sneak the wrong waste type in if they wanted to hide it.

He says that, judging by their expenditure on the site and removals, its usage has risen considerably in recent years.

\section{Scavenging}

He says that scavenging is proving a problem at the site, and a small informal community has become established just outside the gates. They recover any valuable items from vehicles before they reach the gates. He estimates there are about $20-30$ people doing this. He gave the example that if someone had an old washing machine on the back, they would ask him for it, take it off in the road outside, strip what they can get money for and dump the waste material.

He said the materials that were most recovered by these people are iron, whole bricks, usable items in builders rubble eg handbasins etc, and old furniture.

Once a vehicle has entered the site, the waste material is apparently the property of Interwaste, so I infer that they have some interest in trying to keep at least the iron in the waste mix.

The scavengers sound like quite a lawless bunch. There are 6 guards at the site, but they are armed only with batons, and apparently there are regularly cases of them being overwhelmed by large groups that want to get in. In addition, there have been instances of retribution upon guards that forcefully block illegal entry. The guards walk to the station after work, and they are sometimes attacked en route. Apparently four guards have been violently assaulted in the last year. The police are unwilling to get too involved. He says they once came to the small settlement, and someone actually doused their car in petrol with the intention of lighting it!

He says the problems with scavengers at the site is more a result of the area than the attraction of a drop-off, and that no other drop-offs in the City experience these problems.

\section{Coverage of drop-offs and site management}

There are currently 21 drop-off facilities in the City, but he says this is well below target. The ideal is to have one within $8 \mathrm{~km}$ of every residence, which is a goal that is intended, 
although often made difficult due to the high cost of land and the noise problems, especially of the chipper.

$\mathrm{He}$ is the person on the CoCT side in charge of the drop-off, but the site management is contracted out to Interwaste at present.

Only Hout Bay and Killarney drop-offs are currently providing recycling collection (plastic, paper etc.) although this is expected to be expanded with the new contract for management of the sites. This is currently out to tender, and the current contract expires in April 2009. The contract lasts three years. 


\section{LINDSAY HECKRATH}

Interwaste

$04 / 11 / 2008$

\section{Waste types accepted at drop-offs}

All drop-off is free

Wynberg collects:

garden waste

builders rubble

several types of plastic

glass

metal

ewaste

motor oil (Rose Foundation)

paper, I assume

Batteries are NOT supposed to be accepted, as they are classified as hazardous waste which should go to Vissershok H:H. The drop-off is not permitted for hazardous waste, and as a rule none of the waste from there goes to Vissershok.

Fluorescent tubes are also not accepted, but they will be accepted under the new contract which commences in April. This will include a safe crushing and storage facility.

\section{Waste volumes and fates}

On average the site accepts around 50000 vehicles a month.

1-11/2 containers of e-waste per month, which goes to the Maitland MRF (Gerry Newson and the eWASA program).

$2000-3000 \mathrm{~L}$ of used motor oil, which is removed by the Rose Foundation.

$12-15 \times 6 \mathrm{~m}^{3}$ bins of scrap metal, which goes to MRC Steel.

Greens are chipped on site. What is not sold from the site is transported to bulk buyers, e.g. compost producers. None of the garden waste goes to landfill.

Waste for landfilling goes to Coastal Park.

\section{Drop-off operation and records}

Records are kept of vehicles arriving and the general section of waste they have (greens, recycling, builders...) and records are kept of the material transported from the site. 
People are around on site to oversee drop-offs, so there is a degree of supervision with regard to what people are delivering and which bins it goes into. The people at the site are all aware of what the site does and does not accept, ie not batteries.

The drop-off sites are supposed to be for the use of residents in the surrounding areas, but in practice they accept business waste too, in a City-authorized attempt to avoid illegal dumping.

\section{Leads}

MRC Steel - Theresa

\section{Follow up}

He says he will get the total amounts of metals and e-waste from all drop-offs for me. 


\section{WAYNE ARENDSE}

Transnet Rail Engineering

$13 \& 17 / 06 / 2008$

\section{About Transnet Rail Engineering}

Where he works in Salt River, they refurbish old trains. The work on both the "Shosholoza mail trains" used on the Ct-JHB line and on Metrorail electric trains.

\section{Cadmium in trains}

Neither diesel nor electric trains use NiCad batteries. In fact, they don't use batteries at all. The diesel trains used to use lead-acid batteries, but have since switched over to generator systems.

He checked up for me whether Cd-plated parts were used to any significant degree, and answered that there were no Cd-plated parts that he knew of.

\section{Follow up}

He did invite me to take a walk-through of the facility, but I doubt it will yield anything of interest to the project. 


\section{TESMAN BEYERS}

\section{Nitrophoska}

$17 / 09 / 2009$

\section{The company}

Nitrophoska does not manufacture any fertilizers. They simply import, bag and distribute.

\section{Cd levels}

South African law limits the Cd content of fertilizers to under $100 \mathrm{ppm}$ (total weight).

He provided the following analysis results for their phosphate fertilizer products for two previous years:

Type

Single superphosphate

Rock phosphate

Triple superphosphate

Monoammonium phosphate "MAP33" - water

insoluble

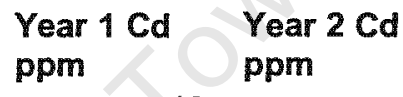

ppm ppm 10

4.2

18

3.2 wt. \% P (as

P)

8

4.3

12

1.4

He thinks these values are pretty typical for South Africa. They import from companies that adhere to EU and British standards, so very high levels are not seen in their products.

Cadmium content depends on the source of the phosphate rock from which it is manufactured, so it does vary. They import much of their stock, so their levels reflect something of the international imports to South Africa. 


\section{CRAIG MITCHELL}

\& Maree Cockcroft

Vissershok Waste Management Facility

$14 / 08 / 08$

\section{Vissershok Waste Management Facility}

The Vissershok $\mathrm{H}: \mathrm{H}$ actually runs as a separate company [but, if I recall from other sources, is wholly owned by Wasteman and Enviroserve, jointly]. Hence Wasteman and Enviroserve are considered clients, who liaise with waste generators separately.

When waste comes in that is a potential concern, a small laboratory is on the premises that can carry out preliminary analysis, but apparently if this turns up anything then samples will be sent out for extetnal analysis. Craig said that external analysis was often not really feasible because of the waiting time, and often waste could not be held for a month or more while waiting for results.

\section{Cadmium wastes at Vissershok $\mathbf{H}: \mathbb{H}$}

They said that no waste types that they receive in significant volumes contain cadmium as far as any analyses that they have done or had done. However, metal finishing sludges arrive in small quantities and hence are not analyzed. Only wastes arriving in volumes of many kilolitres are analyzed normally. Apparently sludge disposal is quite infrequent and usually relatively small quantities.

Batteries are disposed of by encapsulation, but the volumes are also low. Paul Craig was called in as the best person to estimate of the amounts, and he estimated that around one $210 \mathrm{~L}$ drum of batteries was disposed of per year. This would comprise a mixture of battery types, and the chemistries would not be recorded separately. He said that it would be possible to dig up records of the amounts that were disposed, but that it would be slogwork. He was willing, nevertheless. I said that I would get back to him if the exact volumes seemed relevant enough to justify the effort. Additionally it is likely that the volumes of batteries are recorded by the collectors (Wasteman and enviroserve).

Apparently no fly ash is disposed of at Vissershok as such. Craig said that general ash was mixed into flammables before disposal, but that this was not fly ash in particular. [It does, however, seem likely that this includes fly ash, since where else would it go, if it is indeed collected at the source?]

Craig mentioned sewage sludge, saying that this is disposed of there if it exceeds limits, does not have another purpose to fill, or in wet weather when the machinery cannot spread it onto wet fields.

Craig was not willing to give me samples of plating sludges without the disposer's permission, and said that Enviroserve and Wasteman, the collecting companies, were the 
ones who had relationships with the clients directly. Hence his suggestion was that a request to get samples of this material should be directed to the waste generators, possibly through these companies.

Apparently Glitterama only disposes of very small volumes of plating sludge, and hasn't done so in over a year or more.

Paul offered to provide me with a list of the major sludge disposers.

\section{Leachate}

All leachate is trucked to Athlone wastewater workds for treatment, with no treatment on site.

They do analyse the leachate, and apparently it is quite good. Craig seemed to think that access to their leachate data would not be problematic. Analysis data shows very low cadmium concentrations.

\section{Encapsulation}

Aside from the landfill, there is an encapsulation facility on the site. Waste for encapsulation is collected in drums, stored indoors until there are enough for encapsulation (this requires 64 drums) and then cast into concrete. The capsules stand in a lined area, and eventually they will be covered with soil and sealed in with an upper lining as well. Paul said that they will not stand out in the open for more than 10 years. Apparently phase 1 of the encapsulation area is almost full, and lining for the stage 2 is currently out for tender.

\section{Contacts}

Enviroserve: (021) 9518420

Richard de Niel might be a good person to speak to there.

Wasteman: (021) 3803000

Dave Baldwin: Environmental and Chemical Consultants

Maree described him as being the most knowledgeable waste expert in the country. 


\section{MELANI TRAUT}

Scientific Services, City of Cape Town

$28 / 03 / 2008$

\section{Leads and Suggested Sources}

Institute of Waste Management, a good central meeting point for the apparently quite small waste management community in Cape Town

Good journals for searching: Water Essay [or Assay], Water Research and Technology.

Scientific Service has a library that covers waste management issues quite thoroughly until around 2000 , beyond which it has not really been maintained.

Permitted pollutant levels are provided by a DWAF document entitled something like "General Authorization..."

Lindsey Strachan (pronounced 'Strawn') is Melani's counterpart in Durban. He established Durban's leachate treatment systems (the sequential batch reactor systems) which are now apparently more widespread there than in CT. Also involved in Durban's landfill gas utilization projects.

DWAF has offices in Bellville which can supply documents, incl. minimum requirements. The old minimum requirements are also apparently of value, since they do not change much from edition to edition.

SA Weather Bureau is a better source of reliable precipitation data than on-site weather gauges, etc.

Prof Maree in Civil Eng is involved in some way in landfilling in CT.

Margo Seine (spelling uncertain) is one of only two people in SA involved in landfill gas testing.

\section{Landfill sites}

Coastal Park has been going for over 20 years. It is a solely general waste landfill, and also the site on which the largest amount of research has been done. Surrounding groundwater is tested every 6 months.

Vissershok is essentially only a H:h site. It accepts a small amount of general waste, but this is co-disposed with ' $h$ ' hazardous waste. 
The Vissershok $\mathrm{H}: \mathrm{H}$ site is privately owned and operated, and charges substantially more for disposal than the municipal $\mathrm{H}: \mathrm{h}$ site. Surrounding groundwater is testing every 3 months.

Faure is a long-running general waste site, but she seemed to think the data was limited. I got the impression that testing has not been routine and management of the site has perhaps not been very well organised.

Tests cover COD, $\mathrm{NH}_{4}^{+}, \mathrm{NO}^{-}, \mathrm{pH}$, conductivity, metals (a wide range). Detection limit for $\mathrm{Cd}$ is $0.0005 \mathrm{mg} / \mathrm{L}$. Only very low levels of cadmium have been detected in groundwater or leachates.

She said that leachate samples collected by the Solid Waste people were sent for testing when leachate was produced at the landfills. General waste landfills do not produce as much leachate as the hazardous waste sites, because wet industrial sludges etc. contribute a great deal to leachate in the hazardous sites. Leachate passing through the treatment plant at Vissershok is apparently tested quite thoroughly in order to make sure the bacteria in the digesters will stay healthy. She laughed at the notion of a water-polishing reedbed being considered a 'wetland' of any sort, and did not seem to think that much lived in the reedbeds beyond the reeds themselves. She did not consider the accumulation of HMs in reedbeds a likely problem, and said that other organisms also need a clean environment to live.

Current test data also includes Faure, Bellville and Swartklip sites.

\section{General}

She made it clear that there was only a small community of people in Cape Town working on waste treatment and disposal issues, and suggested that getting into that community would be a good first step. She provided an invitation to a site visit and presentation convened by the Landfill Interest Group, a subsection of the Institute of Watse Management. 


\section{MELANI TRAUT}

Scientific Services, City of Cape Town

$29 / 05 / 2008$

\section{Suggested contacts}

Vissershok HH: Paul Craig (in the lab, probably closest to data and related info) and Craig Mitchell (the site manager)

Hamied Maze(e)ma no longer working with the city, but is working for the city on an external basis, from his own company.

(Prof?) Rod Ball, who she speaks very highly of in waste management, apparently a leader in the field.

\section{$\underline{\text { Data }}$}

Got copies of data for Coastal Park groundwater sampling about 2-3 years back (sampling done twice yearly), two analyses for Vissershok H:h leachate, and a groundwater analysis for Swartklip (now closed for about a year).

\section{Other}

The DWAF-to-DEAT jurisdiction transition has apparently taken place already, and seemingly with not much of a shake up of the existing systems. DWAF probably plays some role still, but licensing is now done through DEAT (some licenses have already been granted).

She would not comment on any goings-on in Vissershok $\mathrm{H}: \mathrm{H}$, because they are a completely separate operation. Mentioned that she had been called to testify against them in the past.

Using facilities, and particularly ICP, at Scientific Services does not seem a particularly unusual thing. She said it would be best organized through Peter Novella or similarly senior person in one of the City's departments, who could then authorize it through his department.

She mentioned that landfill stability is quite sensitive to what is put on top, especially w.r.t acidic wastes. 


\section{HAMIED MAZEMA}

Consultant to the City (ex-Wastewater \& Scientific Services)

$12 / 06 / 2008$

\section{Suggested Contacts}

The city did a study on Cd in wastewater at some time in the past. The study was done by Helien Freeze (who when he last knew was at PenTech), under the auspices of Jon Stow (who is now retired). Scientific Services may have a copy of this around. It was done within a 'Trade Wastes' section, or something like that.

Ismael Helday at Scientific Services is likely to be a good person to speak to about heavy metals in wastewater, as is Heidi Richards, who heads up the sewage lab.

Chantelle or Lorato, both with the Province, are good people to speak to about the waste information system (apparently acronymed as IPWIS). He seems sure that cadmium is a reportable substance.

\section{Heavy metals and wastewater treatment}

Cadmium is currently found in the wastewater streams, and is regularly monitored, partly because concentrations above $1 \mathrm{microg} / \mathrm{L}$ start to kill the bacteria. Final effluent release must also be below $1 \mathrm{microg} / \mathrm{L}$ (figures from calling Robert Passero at Scientific Services)

Sewage does not undergo special processing to remove heavy metals. They are largely separated with the sewage sludge.

HMs often found in wastewater are $\mathrm{Cr}$, both VI and III, Fe, $\mathrm{Mn}, \mathrm{Zn}$ and $\mathrm{Ni}$, with trace $\mathrm{Hg}$ and $\mathrm{Pb}$.

The ink industry was identified as a major Cd source to wastewater in around 1985-86, after which these releases were clamped down on.

A canal line does connect Athlone and Cape Flats wastewater works, which is used if Athlone is overwhelmed, although it could be used in the other direction he thinks. He does not know of any plans to stop treatment at Athlone, and in fact says that it has been recently extended to a current capacity of $200 \mathrm{ML} /$ day.

Analysis data should be available for all stages of wastewater treatment: raw sewage, processed sludge and treated effluent.

\section{Leachate and wastewater}


He considers it a possible that an accumulative loop might be in existence between wastewater works landfilling heavy metals with the sludge, which then leach out, only for the leachate to be passed back to the sewage works.

Vissershok effluent from leachate treatment is transported to a wastewater treatment works.

Bellville South leachate might go to the Bellville wastewater works, which are situated right next to the landfill.

\section{Info}

Electroplating of Cd does occur in CT on a small scale. Glitterama in Salt River is one place that does it. He has the feeling that much of the plating that is done is for the military.

The galvanizing process does involve a post-dip 'passivating' tank where Cd within the zinc coating might enter the wastewater stream.

A possible point of $\mathrm{Cd}$ release is through fumes released from the hot-dip tank of galvanizing plants. Apparently a lot of fumes and airborne particles are produced during the dipping, which might well liberate Cd to the atmosphere.

Wales apparently has quite a history of Cd poisoning associated with $\mathrm{Zn}$ mining and production. 


\title{
APPENDIX 2: SURVEY OF ELECTRICAL CONTRACTORS - RESPONDENTS AND MATERIALS
}

This appendix includes:

This page: the list of survey respondents

Page A71: the questionnaire, administered verbally with some responses recorded on the sheet

Page A76: the main response table, on which the majority of responses were recorded by the interviewer

\section{SURVEY RESPONDENTS:}

\author{
Adams Electrical \\ Alpha Electrical \\ Atlas Electrical \\ Brand Engineering \\ Electrogem \\ Goddards Electrical \\ JMB Electrical \\ John Farrell Electrical \\ KJH Electrical \\ L Thompson and Co. \\ MSJ Electrical \\ RA Electrical Engineering \\ Southern Star Electrical \\ WG Dixon
}




\section{ELECTRICAL CONTRACTORS SURVEY}

Date:

Sheet no.: A1

Company:

No. of employees:

Respondent:

Position:

Comments: 
This survey forms a part of a Master's research project I am doing at UCT. For a part of this I am looking into the use of certain rechargeable batteries for back-up power in Cape Town. If you would like me to explain or repeat any of the questions, please don't hesitate to ask.

FOR EACH ANSWER TO Q1-Q14 RECORD THE ANSWERS IN THE RESPONSE TABLE

Q1 What types of equipment does your company install which have a battery back-up power supply?

GET LIST. STRESS TYPE OF INSTALLATION IF ANSWER IS MORE DETAILED THAN THE FUNCTION. SPECIFICATION OF INDIVIDUAL MODELS NOT NECESSARY. IF ANSWER DOES NOT INCLUDE LIGHTING, PROMPT: Nothing like emergency lighting, or similar systems?

CONFIRM LIST AND PROMPT FOR COMPLETENESS: Is that everything?

Q2 What type of battery cell does this unit use?

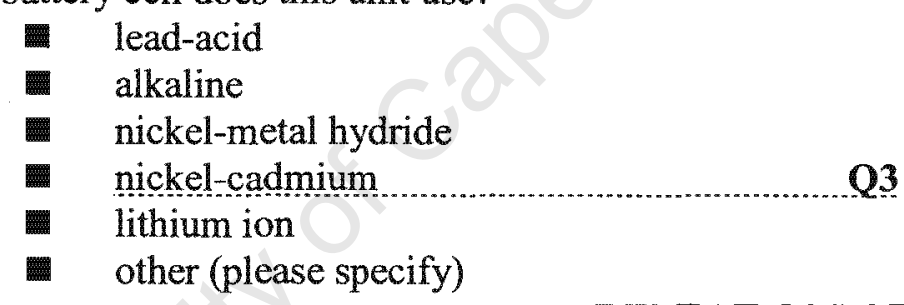

REPEAT Q2 FOR NEXT UNIT

Q3 Do you purchase the unit fully assembled with batteries included, or do you assemble it yourselves?

fully assembled
assembled in-house
as

Q4 Who is your supplier for this unit?

PRESENT TIME CARD TO THE RESPONDENT.

Please have a look at these time intervals. For the next few questions, please tell me which of the intervals applies best to X [FOR EACH UNIT LISTED IN Q1 FOR WHICH Q2=NCKEL-CADMIUM]

Q5 Using the card, how often do you install $\mathrm{X}$ in newly constructed buildings? 
Q6 How often do you install them in existing buildings where they were not previously installed?

Q7 How often do you install them to replace similar equipment that might still be working, for example during a renovation?

Q8 How often are they installed to replace a broken unit?

Q9 Are there other circumstances under which these units are installed? SPECIFY How often does this occur?

Q10 How often do you service or repair these units?

\begin{tabular}{l} 
NEVER \\
OTHERWISE \\
Q13 \\
\hline
\end{tabular}

\section{Q11 [NOT TO BE ASKED IF Q10=NEVER SERVICED]}

Would you say that they are usually serviced:

as part of a maintenance program

when a client has a broken unit

in both of these situations

another situation (please specify)

Q12 [NOT TO BE ASKED IF Q10=NEVER SERVICED]

Using the times on the card, how often does a service involve replacing the cells in these units?

Q13 [ALSO TO FOLLOW Q10 IF Q10=NEVER SERVICED]

How often is your company responsible for disposal of an old unit?

Q14 If it is possible to tell, would you say that over the last five years, the number of units being installed has:
increased
decreased
- stayed roughly the same
in is not possible to tell

REPEAT THE ABOVE Q2-14 FOR EACH OF THE EQUIPMENT TYPES

MENTIONED IN Q1 WHERE Q2=NICKEL-CADMIUM 
I would like to ask a few questions not specific to particular products. RECORD THE FOLLOWING RESPONSES ON THIS SHEET.

Q15 Using the card, how often do you install battery backup systems on pre-existing electrical systems?

$\square$ Never
$\square$ Less than once per year
$\square$ 1-11 times per year
$\square$ 1-4 times per month
$\square$ More than twice a week
$\square$ Every day

Q16 What battery chemistries are used in these installations?

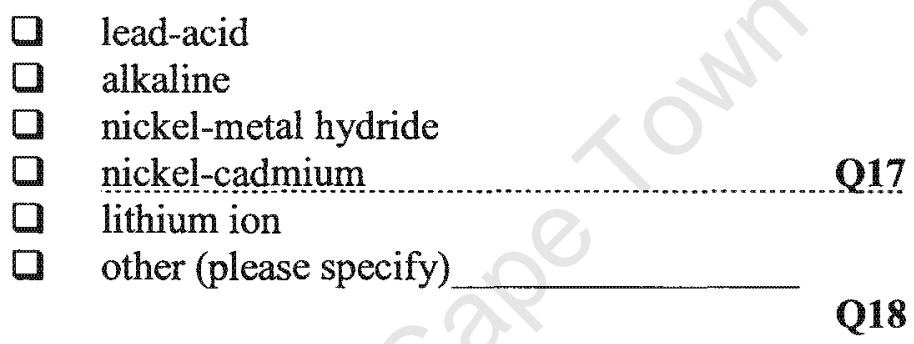

Q17 [ONLY TO BE ASKED IF Q16=NICAD OR Q12 NOT NEVER]

Who is your supplier for NiCad batteries?

Q18 [NOT TO BE ASKED IF Q12 AND Q13=NEVER]

How are old batteries or units disposed of?

IF BY WASTE DISPOSAL COMPANY:

Who is your waste disposal service provider?

COMPLETE THE FRONT PAGE, IF NOT ALREADY DONE 
Q19 Is there anything else you would like to mention or suggest regarding the use of battery backup systems?

Q20 Would you be available to answer further questions if these arise?

$$
\begin{aligned}
& \square \quad \text { Yes, willing to } \\
& \square \quad \text { No, not available }
\end{aligned}
$$

Q21 Would you like to be informed of the outcome of this survey and how it is applied to the research project?

$$
\begin{array}{ll}
\square & \text { Yes } \\
\square & \text { No }
\end{array}
$$

PRESENT THE RESPONDENT WITH THE BRIEF INTRODUCTION TO THE PROJECT, AND THANK THEM FOR THEIR HELP. 


\begin{tabular}{|c|c|c|c|c|c|c|}
\hline QI:LUT & Q2: type of cell & Q3: fully assembied? & Q4: unit supplier & Q5: hestall-new bidgs & $\begin{array}{l}\text { Q6: ingtalliold bidgs } \\
\text { (rir time) }\end{array}$ & $\begin{array}{l}\text { O7: instal-old bldgs } \\
\text { renou. }\end{array}$ \\
\hline & a lesd acid & I f fully assenbied & & 1. Never & I Never: & a Never \\
\hline & 0 alkaline & a. & & $a$ < ance per year & [C conce per year & [ c conce per year \\
\hline & a nickel-metal hydride & O assembled in-house & & a $1-11$ times per year & [a 1.11 Imes per year & a 1.11 tines per year \\
\hline & D nickel cadmilum...............93 & of & & morth & month & morith \\
\hline & D lithium ion & & & $a$ > twice per week & {$[$ s s wice per week } & D s twice per week \\
\hline & 0 other & & & D daly basis & O daily basis & a daily besis \\
\hline & nepieat Q2 & & & & & \\
\hline & (a lead acid & D fully assenbled. & & a Never & D Never & a Mever \\
\hline & D alkaline & a) & & $a$ < once per year & $a$ conce per year & a c once per year \\
\hline & I nickel-metal hydride & a assembled in-rouse & & a $1-11$ times per year & D $1-11$ únes per year & a $\quad 1-11$ ines per year \\
\hline & $\square$ nichel cadmium................ & {$[\quad \infty$} & & morth & month & month \\
\hline & a Ithium ion & & & $a$ > twice per wedk & $D$ > twice per week & a s twice per week \\
\hline & a othe & & & D daly basis & a daily besis & o daly basis \\
\hline & repeat Q2 & & & L & & \\
\hline & a lead acid & a fully assembled & & a Neve & (1. Rever & a. Never \\
\hline & a alkaline & 24 & & Q < once per year & a sonce per year & O sonce per year \\
\hline & [ nichei-metal hydride & a assembled in-house & & D 1.11 times per year & o 1.11 times per year & D 1.11 imes per year \\
\hline & a nichel cadritum............ 03 & Q5 & & inorth & month & month \\
\hline & 드 lithium ion & & & $a$ > twice per wek & {$[a$ > twice per week } & $a>$ twios per week \\
\hline & Q other & & & I daily basis & I daily basis & 0 daily besis \\
\hline & repert Q2 & & & & & \\
\hline & a lead acid & a fully assembled & & a Neva & a Rever & D Never \\
\hline & $\mathrm{a}$ alkdine & a4 & & $a$ < once per year & I < onoe per year & $a$ conce per year \\
\hline & I nickel-metal hydride & [ assembled in-house & & [ 1 -11 times per year & a $1-11$ times per year & O 1.11 times per year \\
\hline & {$[0$ nickel codinium...............93 } & $\begin{array}{ll}\mid & 05\end{array}$ & & morth & month & month \\
\hline & I thicm ion & 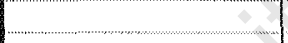 & & $a>$ twioe per week & a stwice per week & $\square$ > twioe per wrek \\
\hline & o othe & & & o daily basis & I daily basis & ㅁ. daily kasis \\
\hline & repeat Q2 & & & & & \\
\hline & 0 lead acid & D fully assembled & & I Never & 10. Never & ID Never a \\
\hline & $a$ alkdine & $=04$ & & D < once peryear & [ conce per year & a conce per year \\
\hline & I nickel-netal hudride & 0 assenbled in-bouse & & D 1.11 times per year & D t.11 bines per year & D 1.11 tines per year \\
\hline & a nickel cednium.............. & $\therefore \quad \infty$ & & morth & Inonth & month \\
\hline & 口, fithium ion & 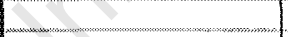 & & $\square>$ twice per week & $\square$ >twlce per week & o stwioe per week \\
\hline & a other & & & 0 daily basis & D. daily basis & 10 daily hasis \\
\hline & repeat 02 & 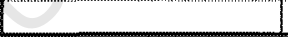 & & & & \\
\hline & Q lead acid & D tully assembled & & a Never & D Mever & D Never \\
\hline & 0 alkaine & a4) & & ㅁ < onoe per year & c conce per year & 0 conoe peryear \\
\hline & o nickel-metal hydride & a ssembled in-house & & D 1-11 tines per year & (c 1.11 imesper year & a 1.11 times per year \\
\hline & [ nichal cedmitm................., & $\quad 06$ & & morth - & monts & monts \\
\hline & a thium ion & & & $\sigma=$ twice per week & D. twice per week & $\square$ > twice per week \\
\hline & o other & & & D daly basis & 0 daily basis & 口 daily basis \\
\hline & repeat $Q 2$ & & & & & \\
\hline
\end{tabular}




\begin{tabular}{|c|c|c|c|c|c|c|}
\hline $\begin{array}{l}\text { Q8: install-old bldgs } \\
\text { replace broken }\end{array}$ & $\begin{array}{l}\text { Q9: install - other } \\
\text { circumstances }\end{array}$ & Q10: service or repsir & Q1 1: service reason & $\begin{array}{l}\text { Q12: service cell } \\
\text { replacement }\end{array}$ & $\begin{array}{l}\text { Q13: disposal of old } \\
\text { units. }\end{array}$ & $\begin{array}{l}\text { 014: 5-year unit } \\
\text { installiations }\end{array}$ \\
\hline O Never & & Io Never................ Q43 & D maintenance prog & D Never & I0 Never & 0 increased \\
\hline a conce per year & I Never & a conce per year & o broken & 0 sonceper year & D < onceper year & 0 decreased \\
\hline T 1.11 times per year & a < once per year & a $1-11$ times per year & 0 both of these & D 111 tines per year & I $1-11$ times per year & D stuved the same. \\
\hline month $\ldots \ldots \ldots \ldots \ldots \ldots$ & D $1-11$ times pa year & a 1.4 times per month & 0 other & month & month & a not possible to tell \\
\hline$q$ - twice per week & D 1-4 times per month & 0 > twice per week & & $0>$ twice per week & $\square>$ twice per week & \\
\hline$\square$ daily basis & $\begin{array}{l}a>\text { twice per week } \\
\square \text { daily basis }\end{array}$ & $\begin{array}{c}0 \text { daily basis } \\
\quad \text { otherwise Q11 }\end{array}$ & & a dally besis & a daily basis & \\
\hline a Never & & D Never.............013 & D maintenance prog & I Never & a Never & Q increased \\
\hline$\square$ ance per year: & (1. Never & [a \& once per year & $\square$ broken & a c conce per year & 10 \& once per year & $\square$ decreased \\
\hline a $1-11$ times per year & $\square$ sonce per year & [ $1-11$ tines per year & Doth of these & Q $1-11$ tines per year & I 1-11 times per year & o stayed the saine \\
\hline ninth & D. 1.11 tines per year & a 1.4 times per morth & $a$ other & morth & month & [1 not possible to tell \\
\hline$a$ s twice per weak & a $\quad 1-4$ tines per month & [ - s twice per week & & $a=$ twice per week & $q$ s twice per week & \\
\hline O daily basis & $\square$ s twice per meek & a daily basis & & $q$ dilly besis & ㅁ daily basis & \\
\hline & [a. daily basis & other wise Q11 & & & & \\
\hline a Never & & [D Never.............913 & I maintenanceprog & Q Never & a Never & 0 incressed. \\
\hline$q$ conce per year. & a Never & a s once per year & I broken & D e once per year & D c once per year & a decreased \\
\hline o 1 -11 times per year & $a$ s once per year & a $1-11$ times per year & a both of these & Q 1.11 times per year & ] 1 -11 times per year & a stayed the same \\
\hline month & o 1 -11 times per year & D $1-4$ tines per month & 0 other & month & month & a not possible to tell \\
\hline$a$ s twice per week & a 1.4 times per month & $a>$ twice per week & & $a$ s twlce per week & a $=$ twice per week & \\
\hline a dally basis & $\begin{array}{l}\text { a > twice per meek } \\
\text { a daily basis }\end{array}$ & $\begin{array}{c}\text { daily basis } \\
\text { oftherwize Q11 }\end{array}$ & & D daily besis & a daily basis & \\
\hline a Never & & N Never............013 & (1) meintenance prog & o Never & I Never. & a increased. \\
\hline$Q$ sonce per year & (c) Never & [ c once per year & O broken & a sonce per year & Q c conce per year & $\square$ decreased \\
\hline D 1.11 times per year & a conce per year & a 1.11 times per year & a both af these & a $1-11$ tines per year & o 1.11 tines per year & O stayed the same. \\
\hline morth & o 1.11 times per year & D 1.4 times per month & D other & month & month & Q not possible to tell \\
\hline D > twice per week & D. 1.4 times per month & a s twice per week & & $a>$ twice per week & $\sigma>$ twice per week & \\
\hline D daily basis & 0 >twice por week & O daily basis & (n... & 0 daily basis & a daily basis. & \\
\hline & D. deily basis & otherwise Q11 & & & & \\
\hline o Never & & a Never ........... 013 & a maintenance prog & a Never & a Never & 0 increased \\
\hline 0 sonce per year & D Never & 0 conce per year & 0 broken & D * once per year & $\square$ < once per year & $\square$ decreased \\
\hline D $1-11$ times per year & $a$ < once per year & D $1-11$ times per year & 0 both or these & E 1-11 times per year & D 1 -11 times per year & a stayed the sarne \\
\hline month & [ 1.11 times par year & D 1.4 times per morth & a other & month & morth & C not possible to tell \\
\hline$a>$ twice per week & II 14 times per month & a $>$ twice per week & & $D>$ twice per week & $\square$ > twice per week & \\
\hline a daily basis & $\theta$ s twice per week & o dally basis & & o dally basis & I daily basis & \\
\hline & D dsily basis & otherwise Q11 & & & & \\
\hline 口 Mever & & I Never.............013 & a mainenance prog & Q Never & D Never & C increased \\
\hline$q$ < once per year & I Never & E c once per year & $\square$ broken & {$[$ s once per year } & $\theta$ sonce per year & D decreased \\
\hline ㅁ $1-11$ bimes per year & $D$ sonce per year & o 1.11 times per year & D both of these & c $1-11$ times per year & D 1.11 imes per year & o stayed the same \\
\hline month & I 1 -11 times per year & C 1.4 times per month & D other & month & morth & ㅁ not possible to tell \\
\hline$\square$ > twice per week & ( 1.4 times per month & a s twotce per week & & a : twice per week & {$[\quad>$ twice per week } & \\
\hline$\square$ daily basis & $\square=$ twice per week & a deily basis & & $\sigma$ daily besis & $a$ daily basis & \\
\hline & D. daily basis & otherwise 011 & & & & \\
\hline
\end{tabular}




\section{APPENDIX 3: HISTOGRAMS OF MONTE CARLO OUTPUT DISTRIBUTIONS}

\section{Explanatory example:}

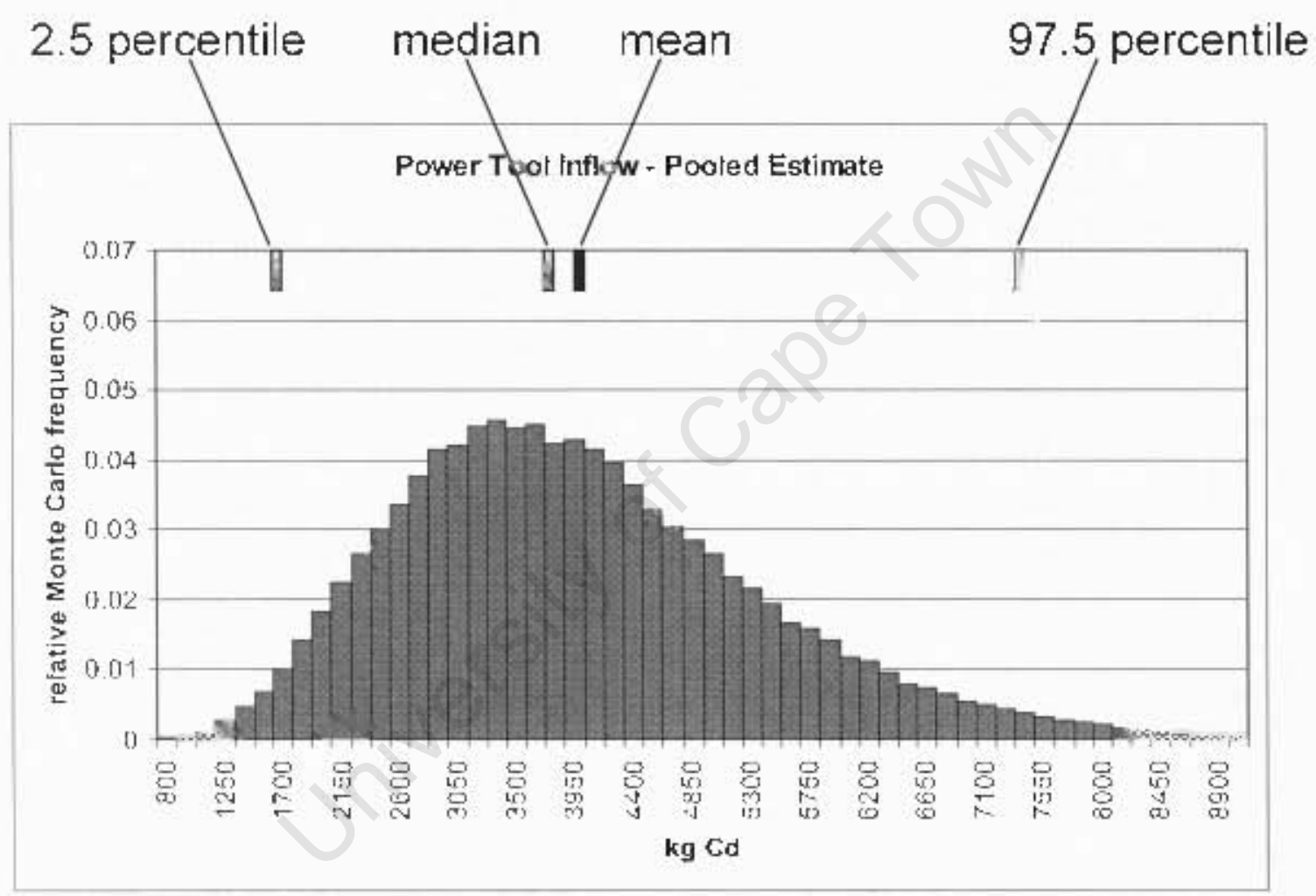



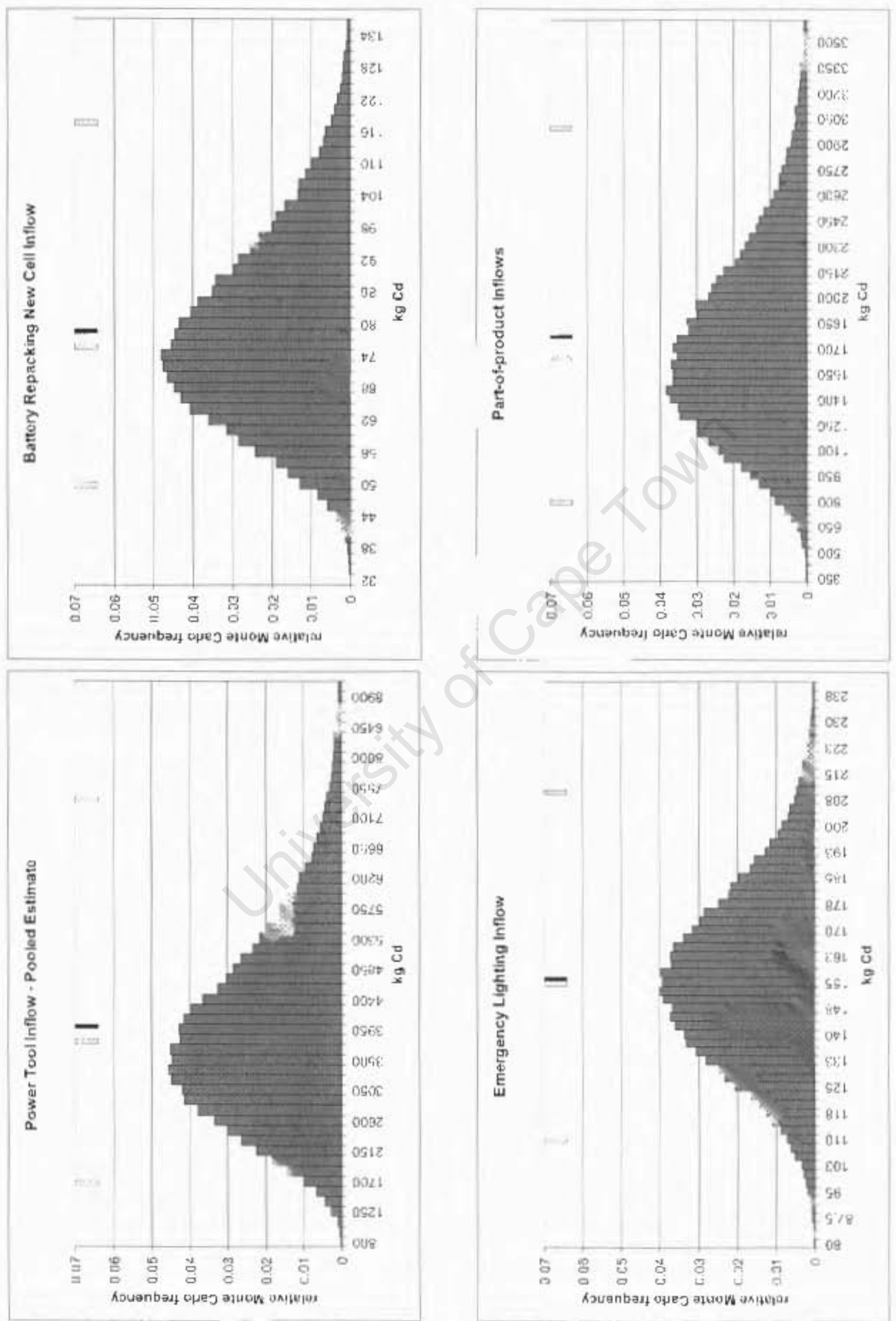

A 79 

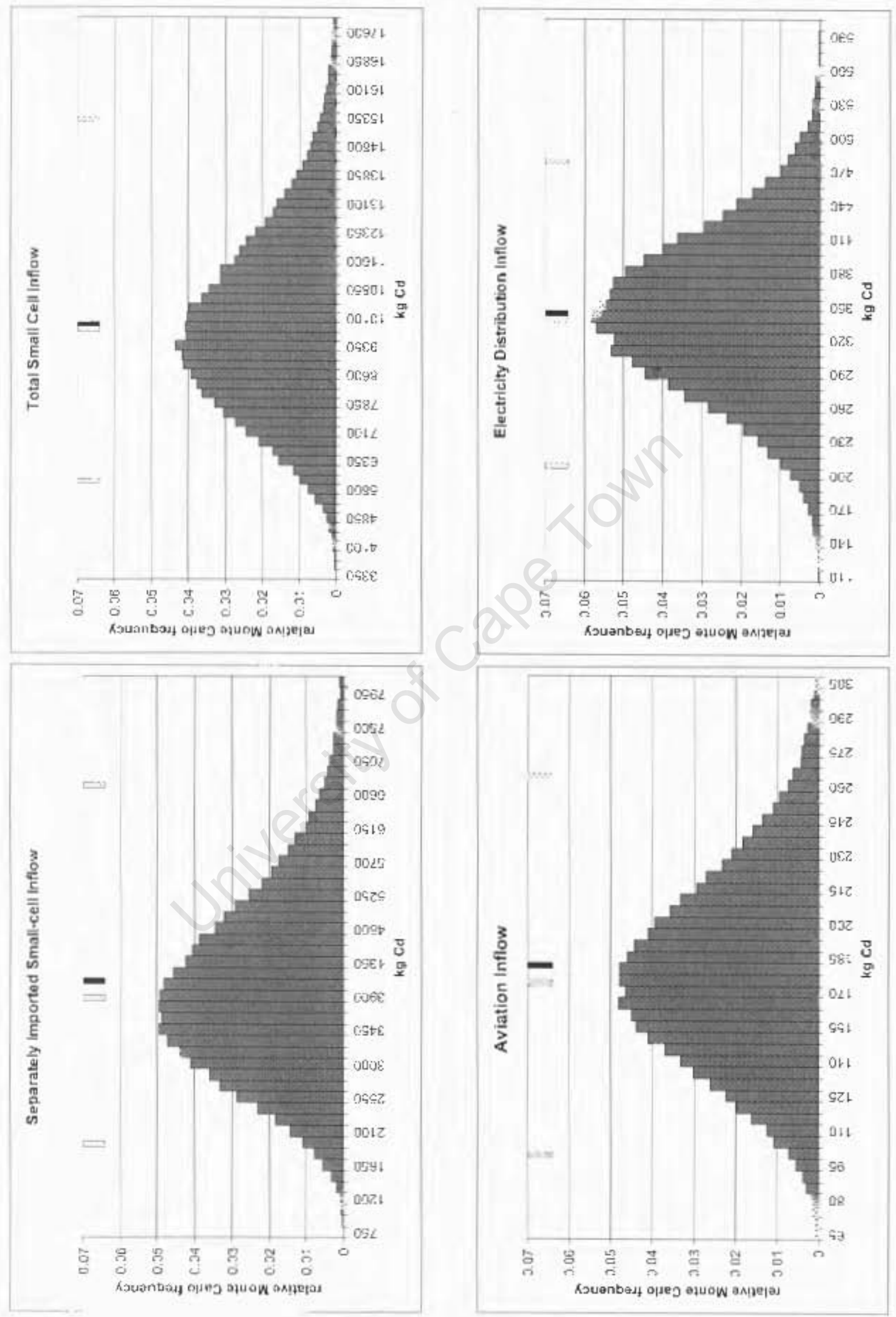

A 80 

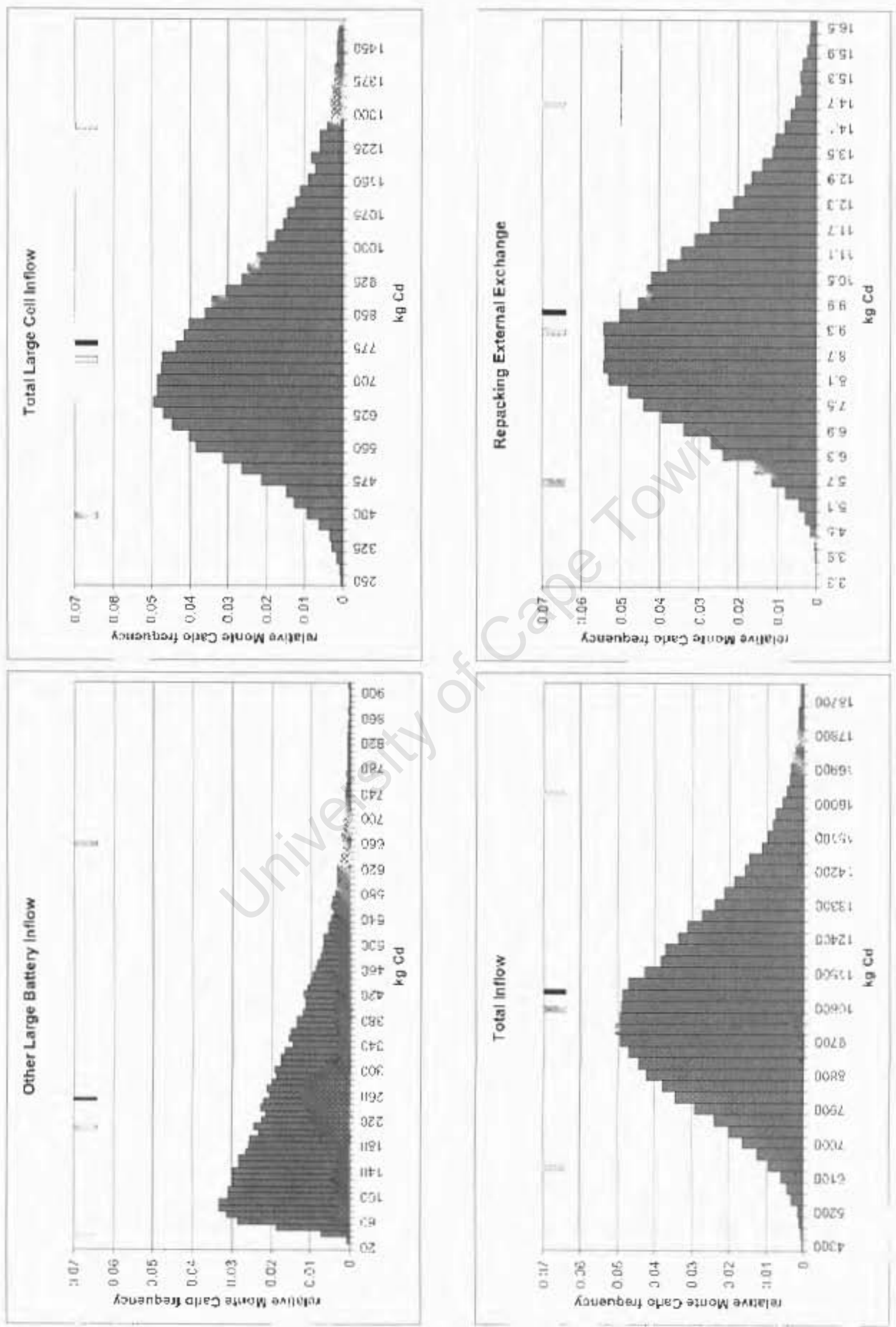

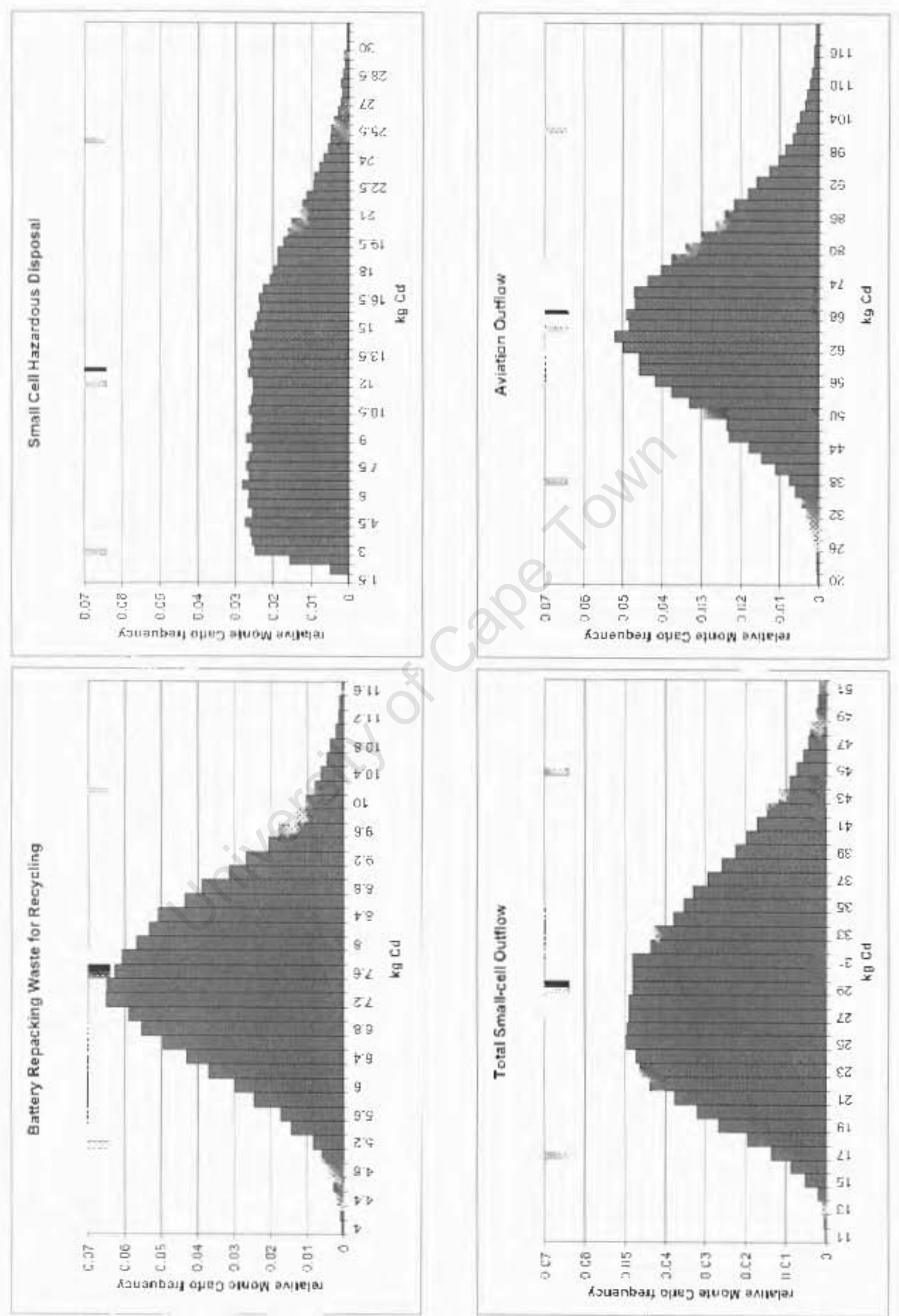

A 82 

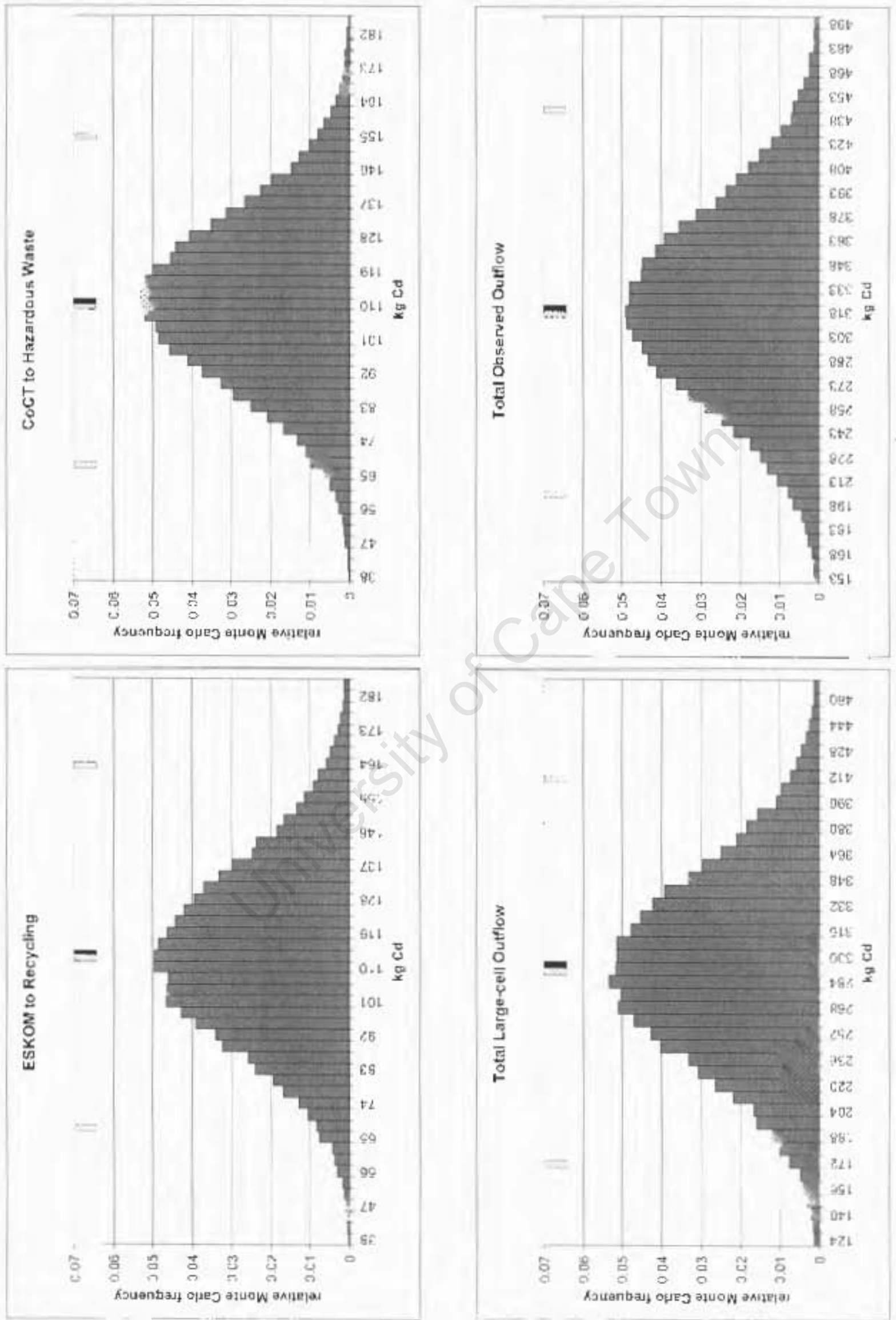

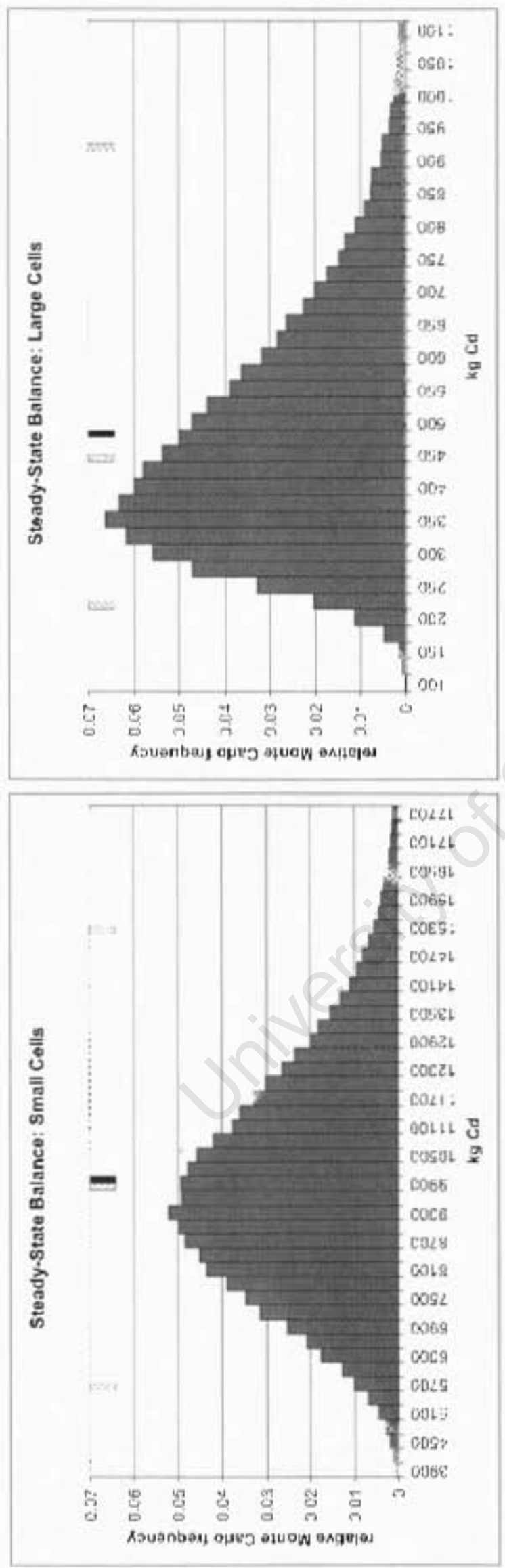


\title{
APPENDIX 4: PYTHON CODE FOR MONTE CARLO SIMULATION
}

\author{
import random \\ import math \\ results $=[]$
}

\# This creates a list which will hold

\# the lists of results

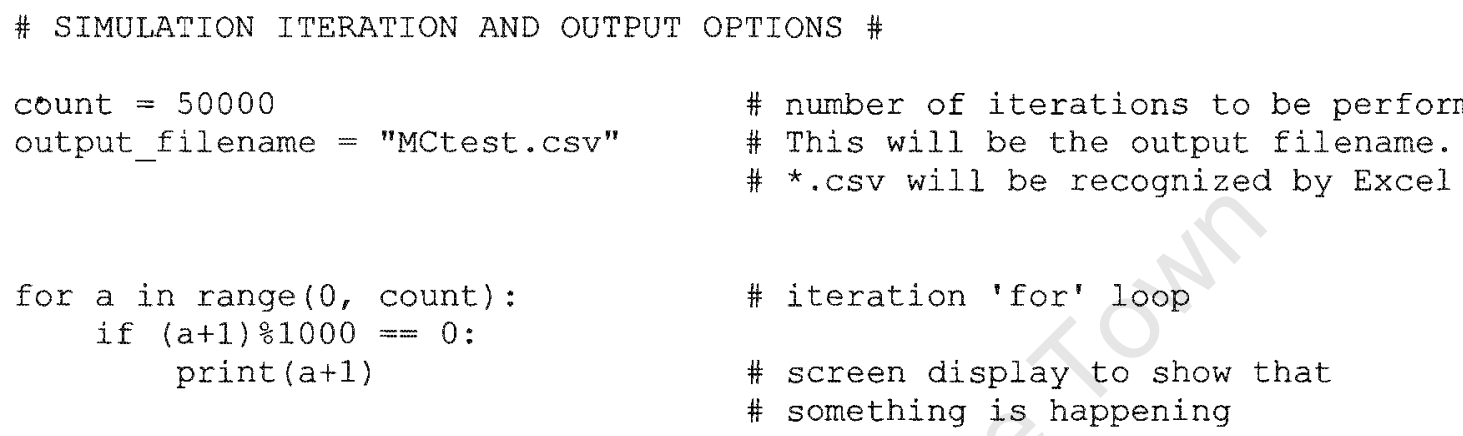

\# RANDOM VARIABLE PARAMETER. DEFINITIONS \#

* Scaling factors

PowerToolscaling $=$ random.normalvariate $(0.15,0.03)$

\# Power tool scaling factor

AMPScaling $=$ random.normalvariate $(0.165,0.033)$

\#AMPS scaling factor

Cordlessscaling $=$ random.normalvariate $(0.15,0.03)$

\# CT-SA power tool scaling factor

GDPScaling = random. normalvariate $(0.11,0.11 * 0.2)$

\# GDP scaling factor

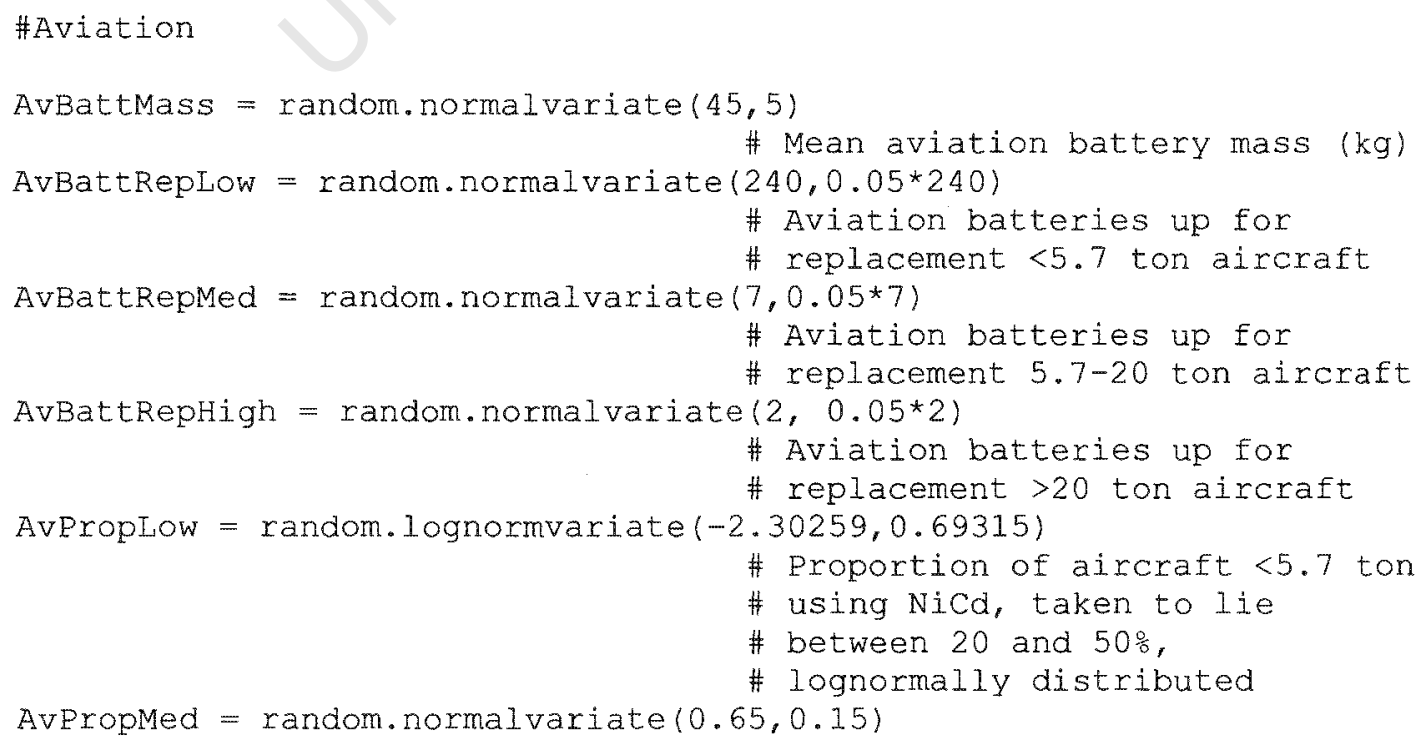




$$
\begin{aligned}
& \text { \# Proportion of aircraft } \\
& \text { \# 5.7-20 ton using NiCd }
\end{aligned}
$$

LargeCelicont $=$ random. normalvariate $(8.5,1.75)$

\# Cd content of vented cells

Popscaling $=$ random normalvariate $(0.07,0.025 * 0.07)$

\# Population scaling factor

\# Electrical distribution

Eskom $36 \mathrm{~V}=$ random.normalvariate $(17.5,1.25)$

\# No. of $36 \mathrm{~V}$ NiCd batteries

\# replaced by Eskom

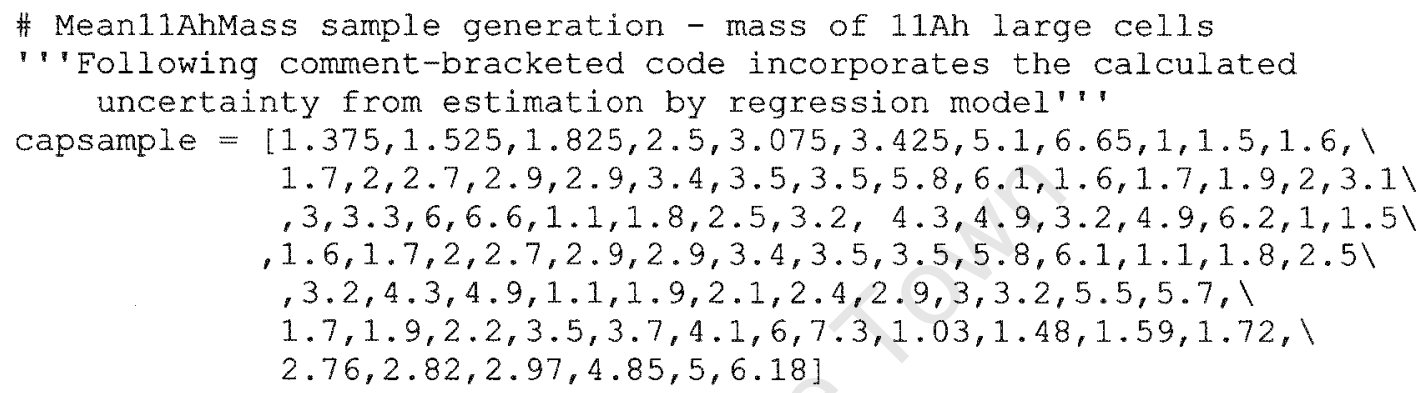




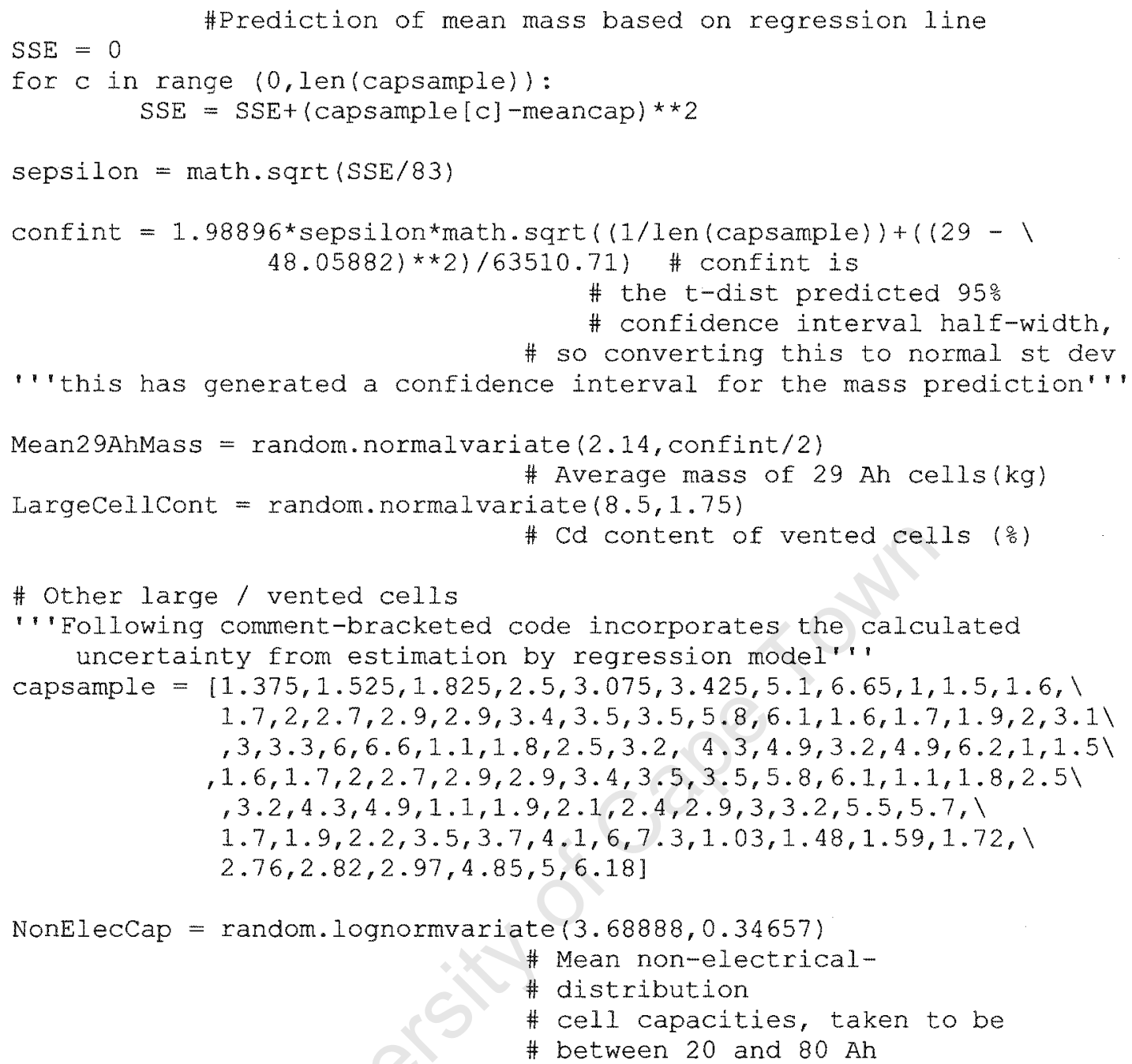


\# Generic small-cell parameters

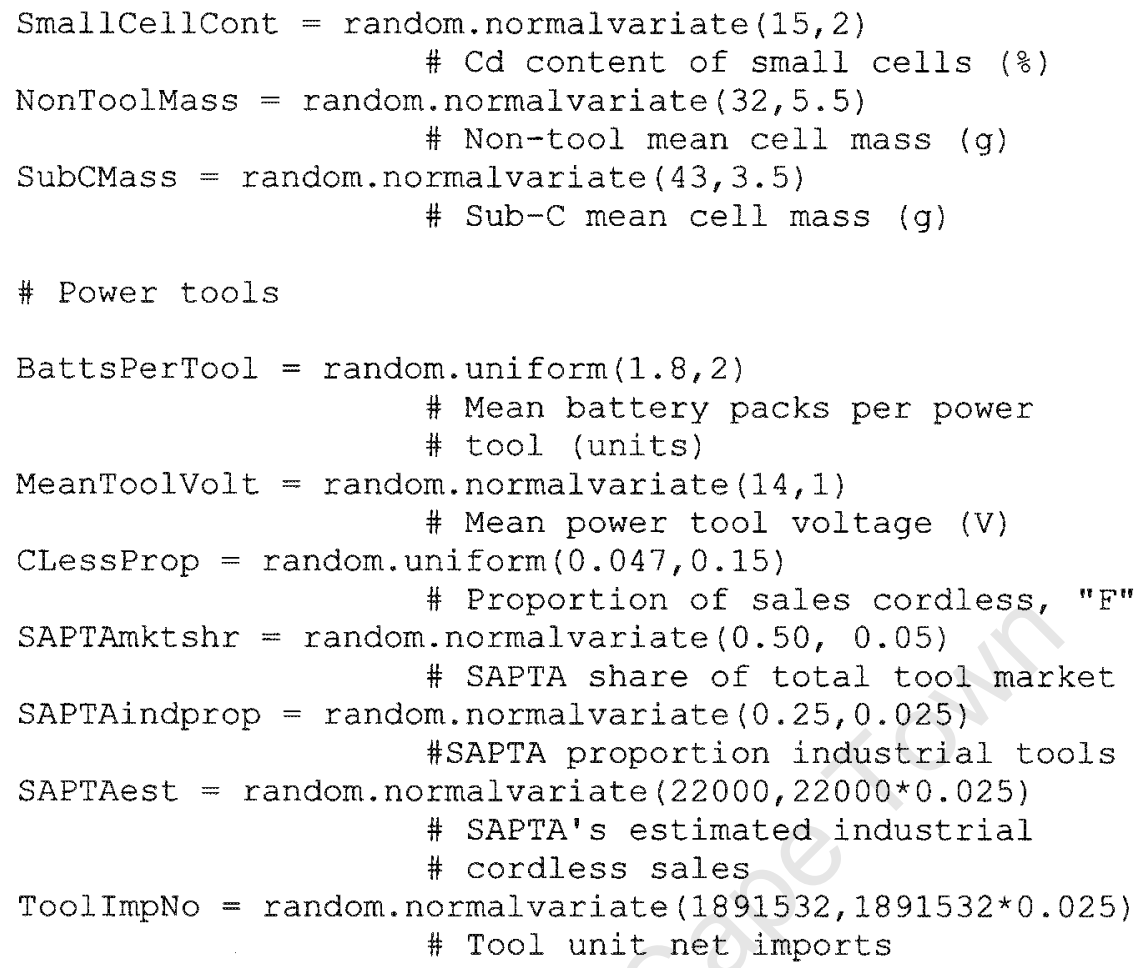

\# Part-of product: Import estimates from adaptation of Wilburn(2007) 


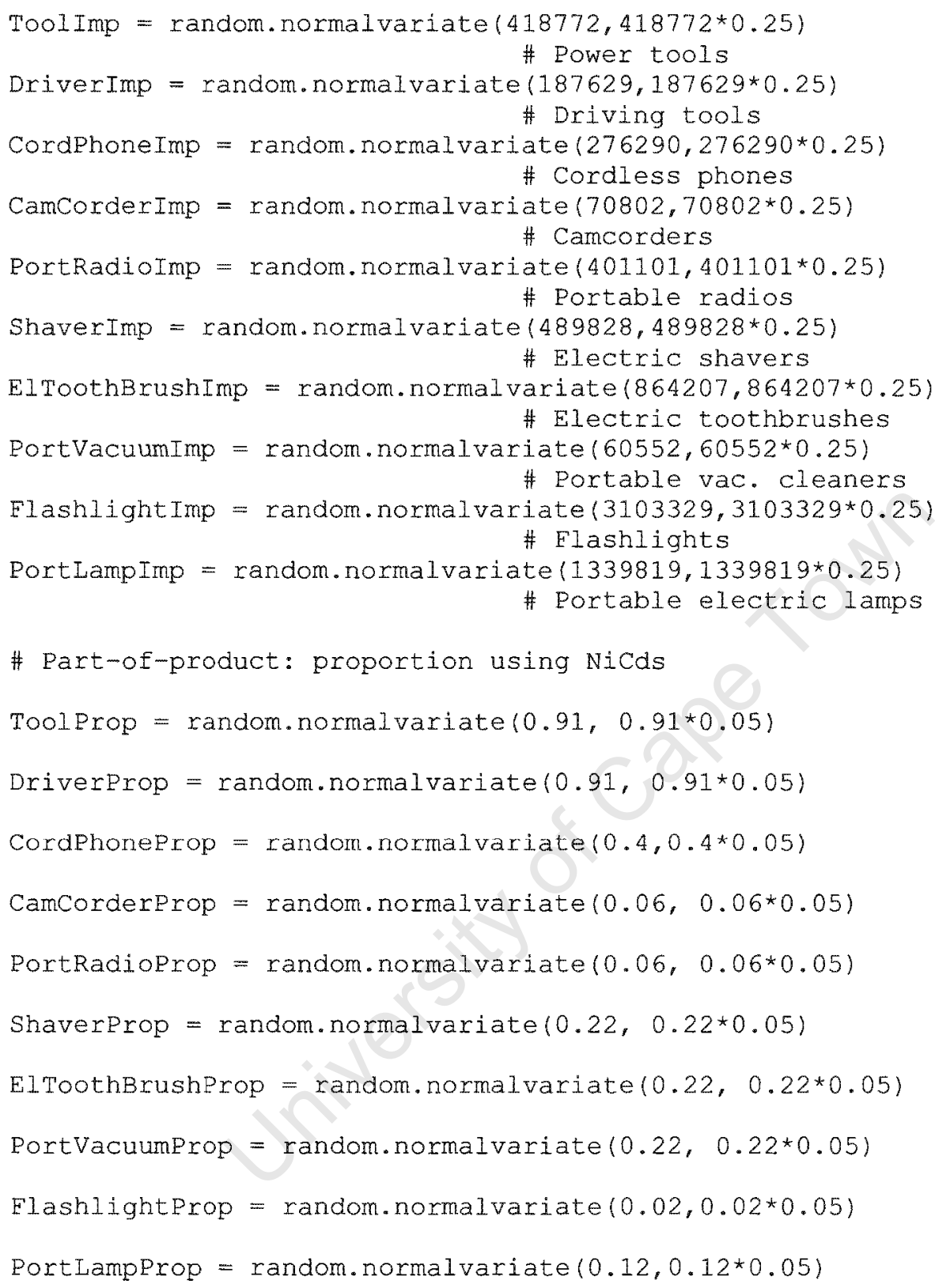




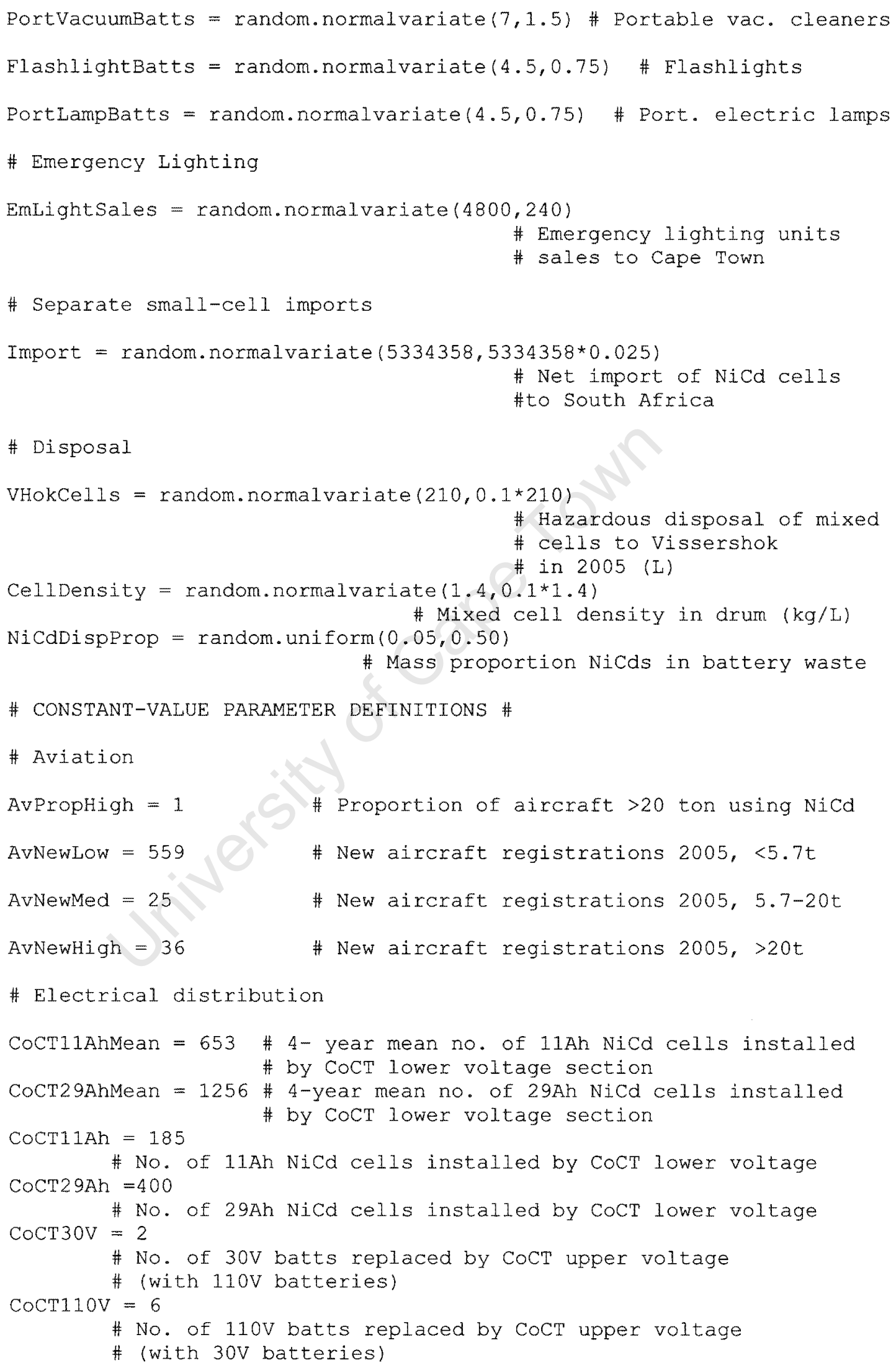




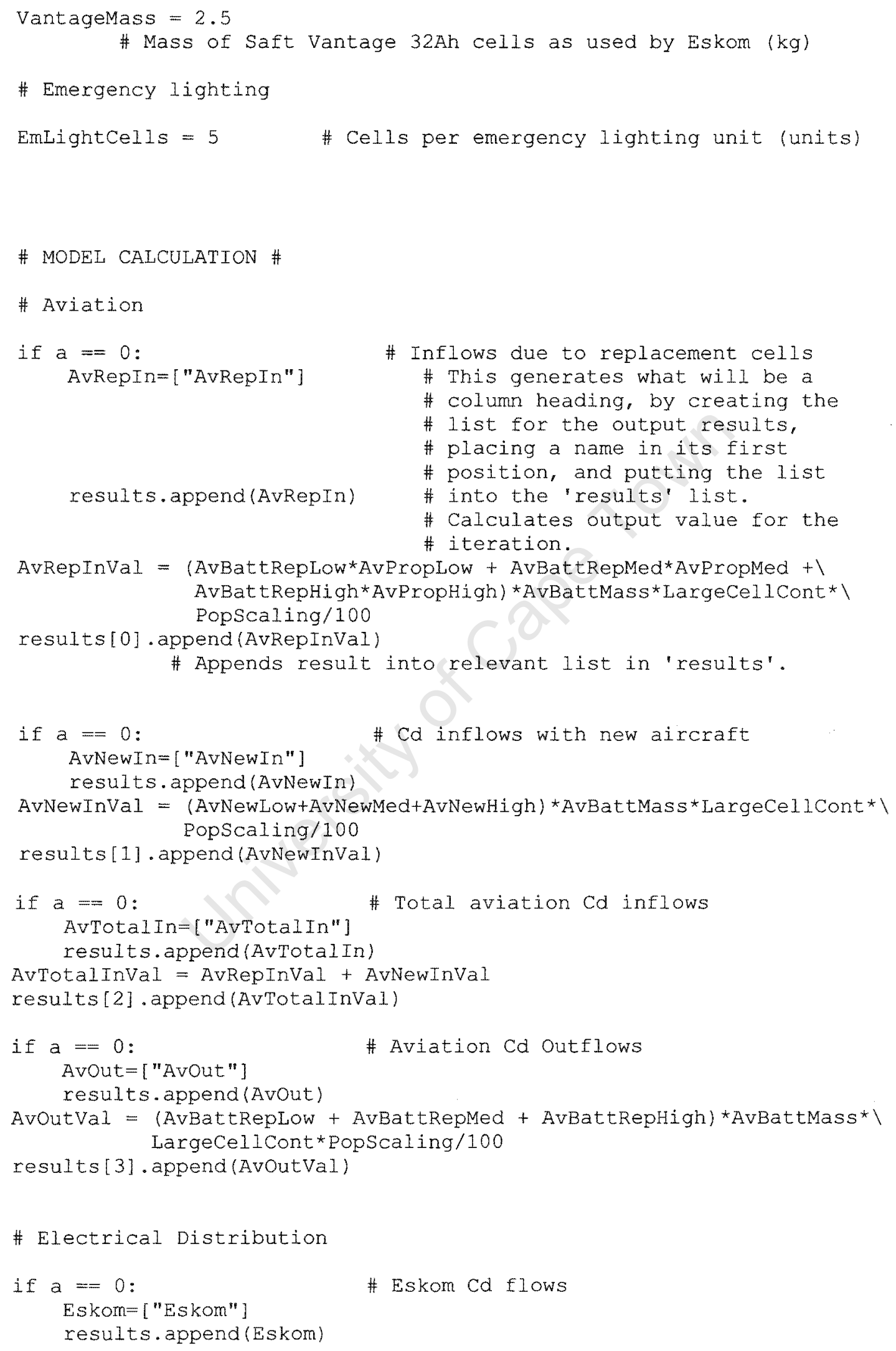




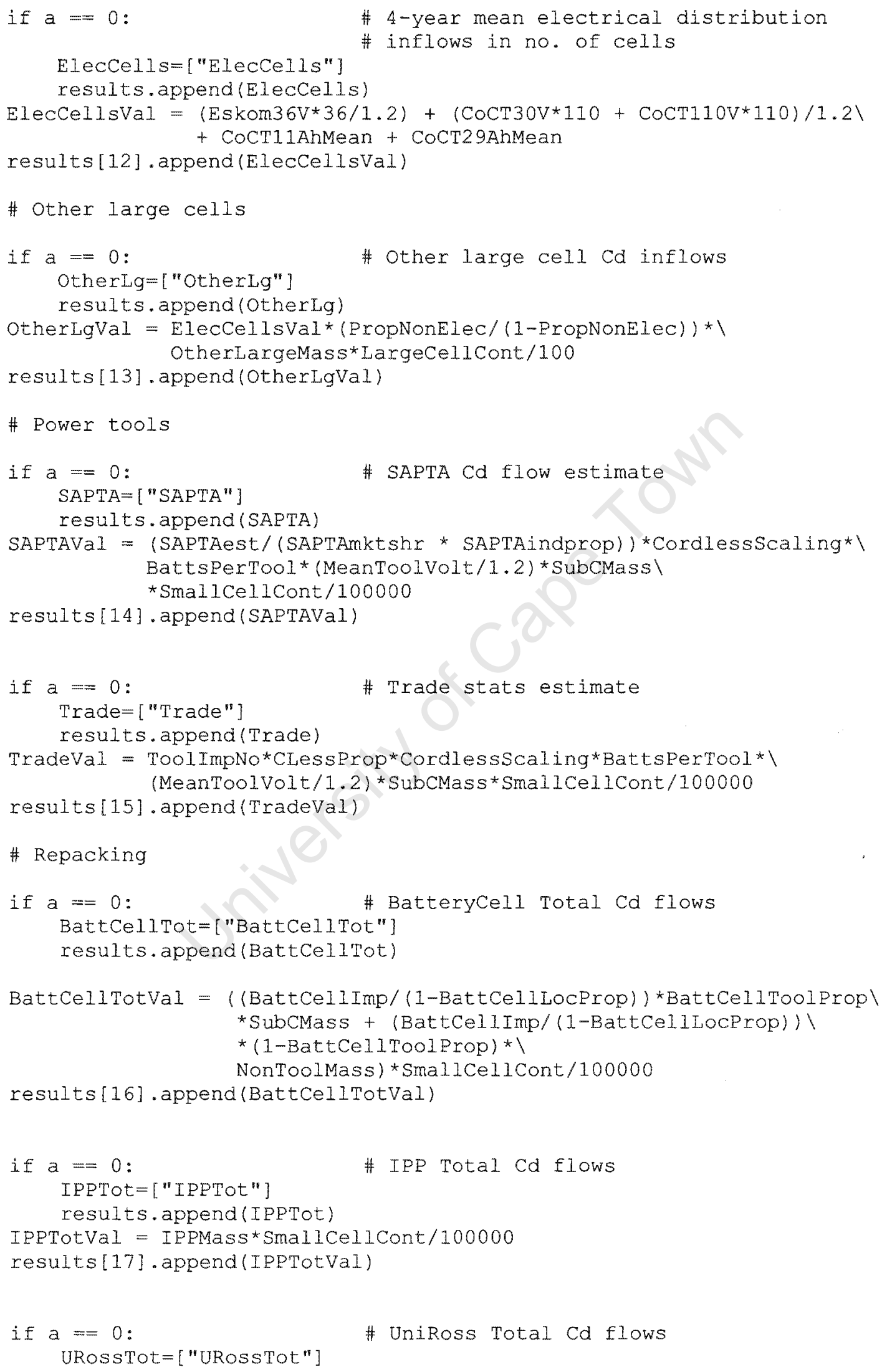


results.append (URossTot)

URossTotVal $=$ (BattCellTotVal+IPPTotVal)*URossMktShr $/(1$-URossMktShr $)$ results [18] . append(URossTotVaI)

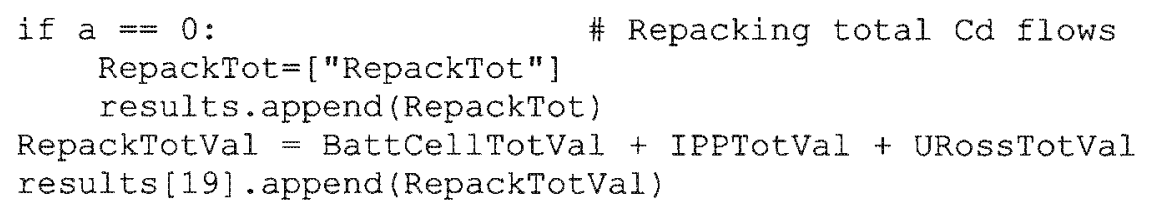




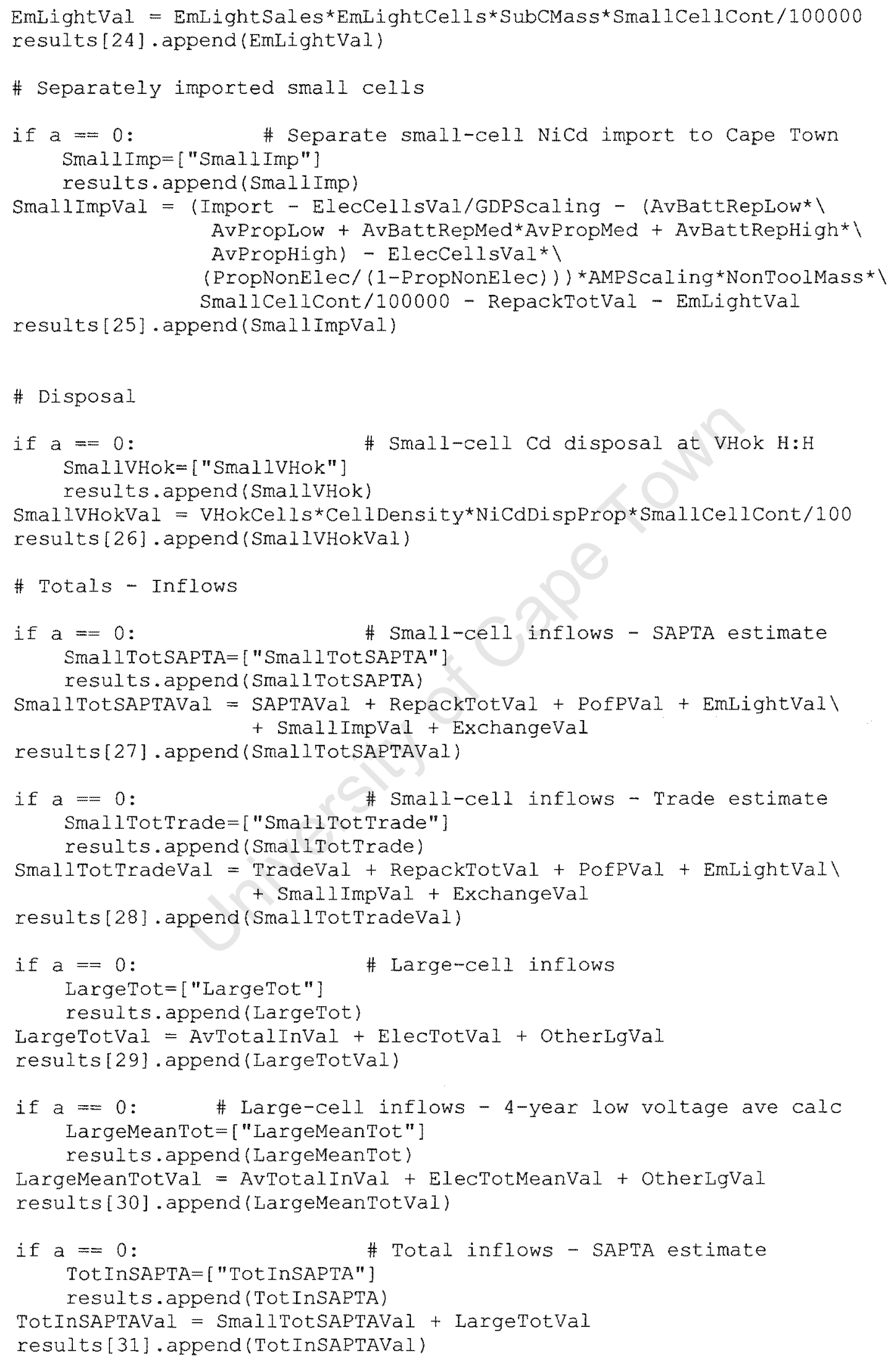




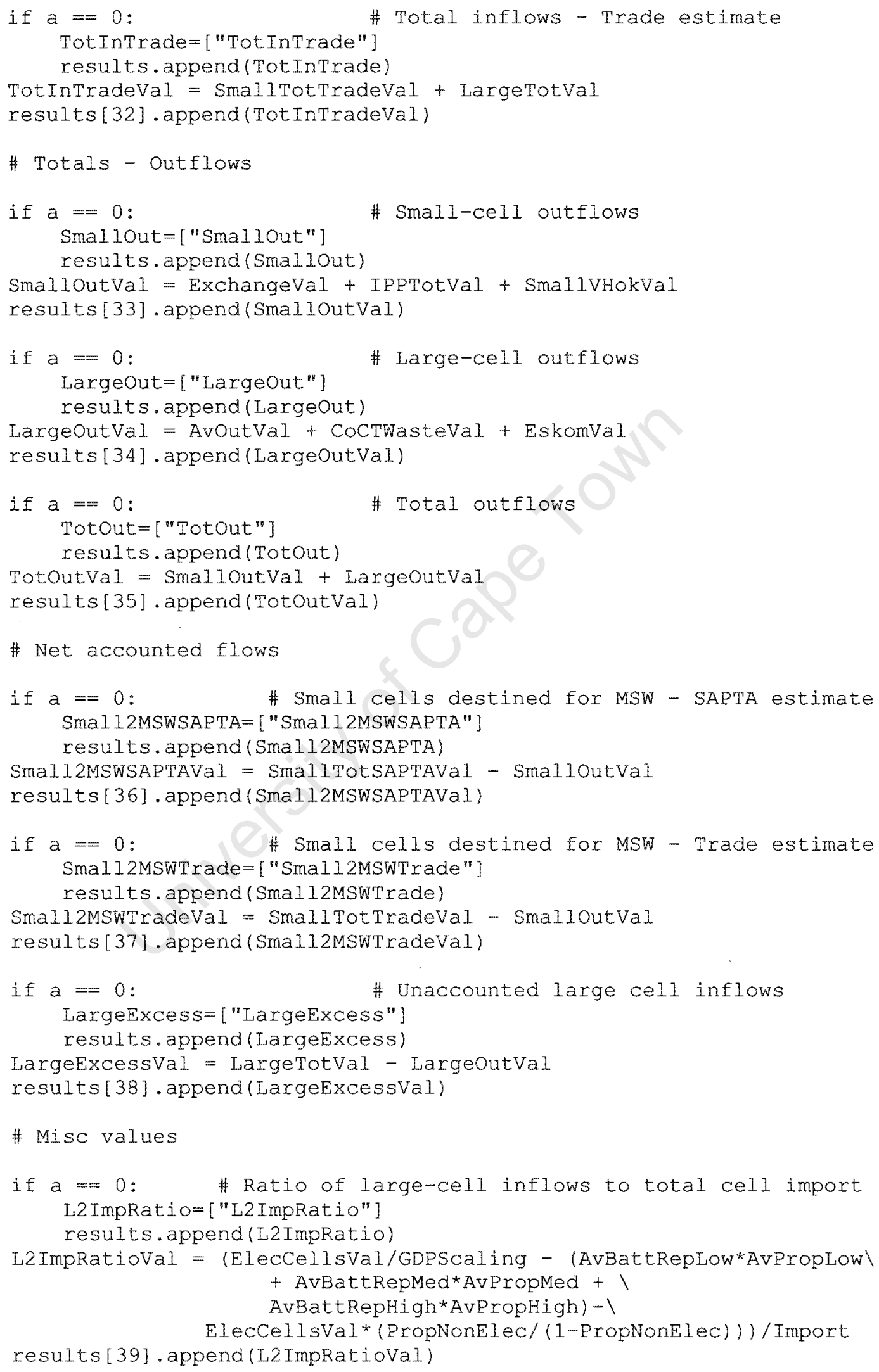


\# MODEL OUTPUT \#

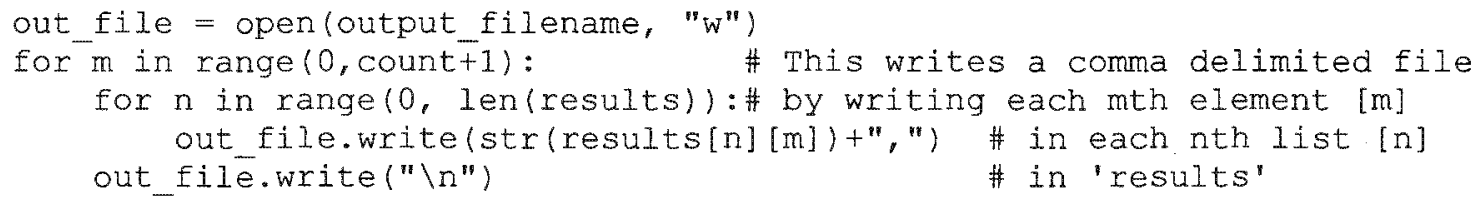

\#Python code filename: Finalcorrected.py 


\section{APPENDIX 5: BATTERY SAMPLING DATA}

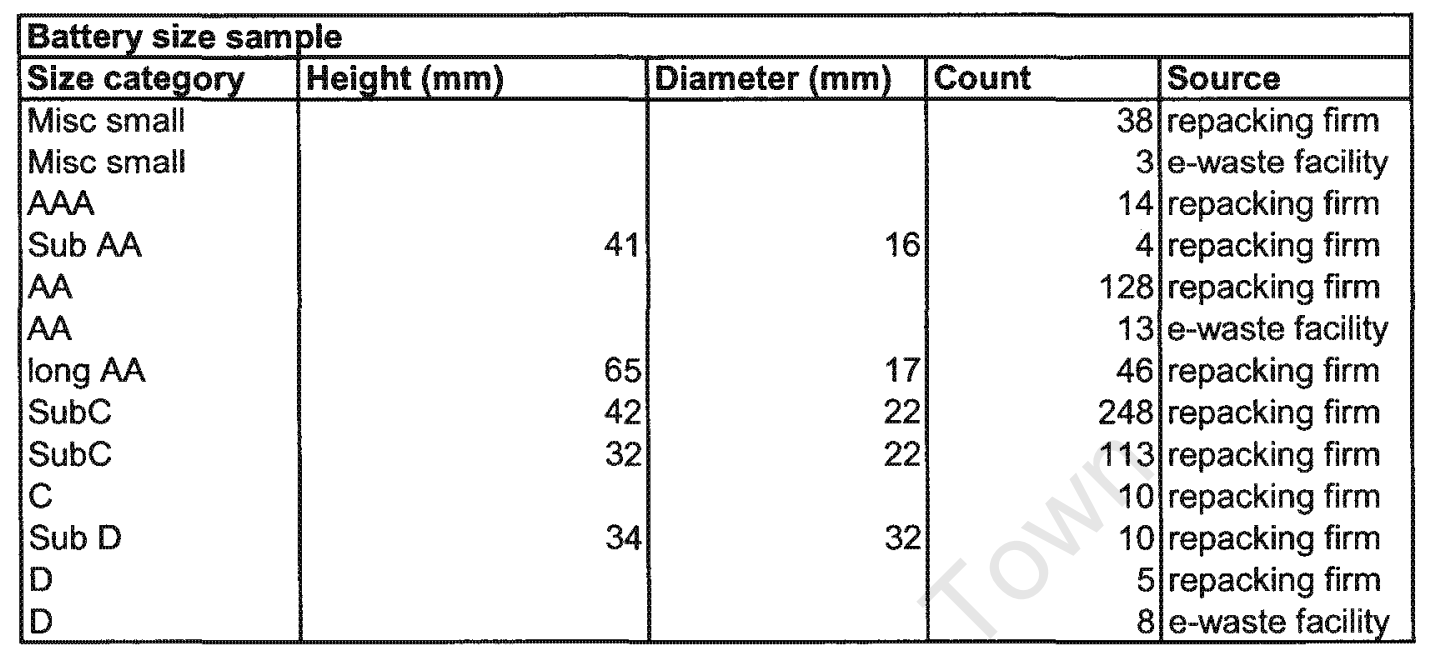




\begin{tabular}{|c|c|c|c|c|}
\hline \multicolumn{5}{|c|}{ NiCd battery mass sample } \\
\hline \multirow{2}{*}{$\begin{array}{l}\text { Size category } \\
\text { Misc small }\end{array}$} & Body height+tab $(\mathrm{mm})$ & Diameter (mm) & Mass (g) & Source \\
\hline & 8 & 25 & 13.35 & repacking firm \\
\hline & & & 13.36 & repacking firm \\
\hline \multirow{3}{*}{ Misc small } & & & 13.29 & repacking firm \\
\hline & 6 & 15.5 & 3.21 & e-waste facility \\
\hline & & & 3.62 & e-waste facility \\
\hline & & & 3.45 & e-waste facility \\
\hline Misc small & 26 & 17 & 18.19 & repacking firm \\
\hline & & & 18.00 & repacking firm \\
\hline & & & 18.15 & repacking firm \\
\hline Misc small & 25 & 22 & 26.53 & repacking firm \\
\hline & & & 26.26 & repacking firm \\
\hline AA & & & 23.95 & e-waste facility \\
\hline & & & $\begin{array}{l}18.54 \\
17.53\end{array}$ & e-waste facility \\
\hline AA & & & 21.22 & e-waste facility \\
\hline$A A$ & & & 19.65 & e-waste facility \\
\hline & & & $\begin{array}{l}20.48 \\
20.42\end{array}$ & $\begin{array}{l}\text { e-waste tacinty } \\
\text { e-waste facility }\end{array}$ \\
\hline & & & 19.94 & e-waste facility \\
\hline AA & & & 24.15 & e-waste facility \\
\hline & & & 24.35 & e-waste facility \\
\hline & & & $\begin{array}{l}24.12 \\
23.77\end{array}$ & $\begin{array}{l}\text { e-waste facility } \\
\text { e-waste facility }\end{array}$ \\
\hline AA & & & 19.36 & repacking firm \\
\hline & & & $\begin{array}{l}19.20 \\
19.18\end{array}$ & repackıng firm \\
\hline & & & 19.37 & repacking firm \\
\hline \multirow[t]{2}{*}{ AA } & & & 20.56 & repacking firm \\
\hline & & & $\begin{array}{l}20.50 \\
20.32\end{array}$ & $\begin{array}{l}\text { repacking firm } \\
\text { repacking firm }\end{array}$ \\
\hline & & & 20.53 & repacking firm \\
\hline \multirow[t]{3}{*}{ Subc } & 42 & 22 & 45.33 & repacking firm \\
\hline & & & $\begin{array}{l}44.63 \\
44.93\end{array}$ & repacking firm \\
\hline & & & 45.51 & repacking firm \\
\hline \multirow[t]{3}{*}{ Subc } & 42 & 22 & 44.69 & repacking firm \\
\hline & & & 44.81 & repacking firm \\
\hline & & & 44.99 & frepacking firm \\
\hline \multirow{6}{*}{$\begin{array}{l}\text { SubC } \\
\text { Sub D }\end{array}$} & 32 & 22 & 35.67 & repacking firm \\
\hline & 34 & 32 & 80.60 & repacking firm \\
\hline & & & 80.22 & repacking firm \\
\hline & & & 80.09 & repacking firm \\
\hline & & & 80.60 & repacking firm \\
\hline & & & 80.10 & repacking firm \\
\hline \multirow[t]{8}{*}{ D } & $56+4$ & 33) & 65.81 & e-waste facility \\
\hline & & & 65.98 & e-waste facility \\
\hline & & & 65.06 & e-waste facility \\
\hline & & & 66.99 & e-waste facility \\
\hline & & & 65.55 & e-waste facility \\
\hline & & & 66.47 & e-waste facility \\
\hline & & & 66.51 & e-waste facility \\
\hline & & & 66.33 & e-waste facility \\
\hline
\end{tabular}




\begin{tabular}{|c|c|c|c|c|c|c|c|}
\hline & \multicolumn{3}{|c|}{ US 10-DIGIT IMPORTS } & \multirow{2}{*}{$\begin{array}{c}\text { US 6-DIGIT IMPORTS } \\
\text { total units } \\
\end{array}$} & \multirow{2}{*}{\begin{tabular}{|c|} 
SA6-DIGIT NET IMPORTS \\
total units
\end{tabular}} & \multicolumn{2}{|c|}{ PROJECTED SA 10 -DIG IMPORTS } \\
\hline Descriptian & 6-digit code & units & $\begin{array}{c}\text { including } \\
\text { codes }\end{array}$ & & & units & $\begin{array}{c}\text { total units } \\
\text { product }\end{array}$ \\
\hline Cordless phones & 851714 & $50,968,683$ & 8517110000 & $50,968,683$ & 276,290 & 276,290 & 276,290 \\
\hline Portable radios & 852712 & $1,435,226$ & 8527120000 & $1,435,226$ & 401,101 & 401.801 & 401,101 \\
\hline $\begin{array}{l}\text { Portable vacuum } \\
\text { cleaners }\end{array}$ & 850910 & $7,137,480$ & 8509100020 & $42,617,834$ & 361.554 & 60,552 & 60,552 \\
\hline Flashlights & 851310 & $147,127,294$ & 8513102000 & $210,647,430$ & $4,443,148$ & $3,103,329$ & $3,103,329$ \\
\hline $\begin{array}{l}\text { Portable electric } \\
\text { lamps }\end{array}$ & 851310 & $63,520,136$ & 8513104000 & $210,647,430$ & $4,443,148$ & $1,339,819$ & $1,339,819$ \\
\hline
\end{tabular}




\section{APPENDIX 7: PART-OF-PRODUCT CELL COUNTS}

\begin{tabular}{|c|c|c|c|}
\hline \multirow{2}{*}{$\begin{array}{l}\text { Model } \\
\text { CORDLESS PHONES }\end{array}$} & No. of cells & Cell type & Source \\
\hline & & & \\
\hline Pacific Bell 800 & 3 & $\mathrm{NiCd}$ & muw.zbattery.com \\
\hline Sanyo CLTA 902 & 3 & $\mathrm{NiCd}$ & wuww.zbattery.com \\
\hline My Own Remote 650D & 3 & $\mathrm{NiCd}$ & www.zbattery.com \\
\hline Ikko KD10 & 3 & $\mathrm{NiCd}$ & www.zbattery.com \\
\hline Phillips Evalia 5600 & 3 & $\mathrm{NiCd}$ & www.zbattery.com \\
\hline Sharp CL510 & 3 & $\mathrm{NiCd}$ & www.zbattery.com \\
\hline Phillips CL8340 & 3 & $\mathrm{NiCd}$ & www.zbattery.com \\
\hline Pacer phone 8510 & 4 & $\mathrm{NiCd}$ & www.zbattery.com \\
\hline Carlton 7010 & 4 & $\mathrm{NiCd}$ & www.zbattery.com \\
\hline Pacific Bell 819 & 3 & $\mathrm{NiCd}$ & www.zbattery.com \\
\hline Microsoft MP900 & 3 & $\mathrm{NiCd}$ & www.zbattery.com \\
\hline A-Phone 1 & 3 & $\mathrm{NiCd}$ & unw.zbattery.com \\
\hline Pierre Cardin AMB9 & 3 & $\mathrm{NiCd}$ & www.zbattery.com \\
\hline Tel-Mate 19AG2 & 4 & $\mathrm{NiCd}$ & wmw.zbattery.com \\
\hline Audiosonic T120 & 3 & $\mathrm{NiCd}$ & www.zbattery.com \\
\hline Pager Phone 8513 & 4 & $\mathrm{NiCd}$ & www.zbattery.com \\
\hline Key Service 20864 & 3 & $\mathrm{NiCd}$ & www.zbattery.com \\
\hline Quasar 2100 & 3 & $\mathrm{NiCd}$ & www.zbattery.com \\
\hline Cidco CL991 & 3 & $\mathrm{NiCd}$ & wuw.zbattery.com \\
\hline Bell Phone 32001 & 3 & $\mathrm{NiCd}$ & www.zbattery.com \\
\hline UniSonic 6078 & 3 & $\mathrm{NiCd}$ & www.zbattery.com \\
\hline Sears 352 series & 4 & $\mathrm{NiCd}$ & www.zbattery.com \\
\hline Cybernet Phone & 3 & $\mathrm{NiCd}$ & www.zbattery.com \\
\hline Adara CD-03-FAO0-600 & 3 & $\mathrm{NiCd}$ & www.zbattery.com \\
\hline Hyostar CQ284 & 3 & $\mathrm{NiCd}$ & www.zbattery.com \\
\hline IBM 3445 & 3 & $\mathrm{NiCd}$ & www.zbattery.com \\
\hline Toshiba SX-2808 BK & 3 & $\mathrm{NiCd}$ & wuw.zbattery.com \\
\hline Sanyo TH1015M & 3 & $\mathrm{NiCd}$ & www.zbattery.com \\
\hline Panasonic KX-TC17 & 3 & NiCd & www.zbattery.com \\
\hline Spectra P210 & 4 & $\mathrm{NiCd}$ & www.zbattery.com \\
\hline Genesis CTI-8800 & 3 & $\mathrm{NiCd}$ & www.zbattery.com \\
\hline Electra 1000 & 4 & NiCd & www.zbattery.com \\
\hline Casio TC919 & 3 & $\mathrm{NiCd}$ & www.zbattery.com \\
\hline Go Phone GF-210 & 3 & $\mathrm{NiCd}$ & www.zbattery.com \\
\hline AT\&T 24116 & 4 & $\mathrm{NiCd}$ & www.zbattery.com \\
\hline CPT C7 & 3 & $\mathrm{NiCd}$ & www.zbattery.com \\
\hline Keytronics $9100 \mathrm{P}$ & 3 & $\mathrm{NiCd}$ & muw.zbattery.com \\
\hline Recoton T122 & 3 & $\mathrm{NiCd}$ & wuw.zbattery.com \\
\hline Key Phone KP 9100DX & 3 & $\mathrm{NiCd}$ & www.zbattery.com \\
\hline Panasonic KX-TG1311SA & 2 & $\mathrm{NiMH}$ & direct observation in-store \\
\hline Siemens Gigaset AL140 & 2 & $\mathrm{NiMH}$ & direct observation in-store \\
\hline Audioline CDL150 & 3 & NiCd & www.cellpacksolutions.com \\
\hline Audioline FF888 & 3 & NiCd & www.cellpacksolutions.com \\
\hline South Western Bell FF884 & 3 & $\mathrm{NiCd}$ & www.cellpacksolutions.com \\
\hline NTL D4001 & 2 & NiMH & www.cellpacksolutions.com \\
\hline
\end{tabular}




\begin{tabular}{|c|c|c|c|}
\hline Model & No. of cells & Cell type & Source \\
\hline \multicolumn{4}{|l|}{ CORDLESS PHONES CONT. } \\
\hline Samsung Cocoon & 3 & $\mathrm{NiCd}$ & www.cellpacksolutions.com \\
\hline Sagem Mistral 20-200 & 3 & NiMH & www.cellpacksolutions.com \\
\hline Diatron Geemarc Miami & 3 & $\mathrm{NiCd}$ & www.cellpacksolutions.com \\
\hline Panasonic FC225FA & 2 & NiMH & direct observation in-store \\
\hline Panasonic DECT & 2 & NiMH & direct observation in-store \\
\hline \multicolumn{4}{|l|}{ CAMCORDERS } \\
\hline Fujix M680 & 5 & $\mathrm{NIMH}$ & www.zbattery.com \\
\hline Polaroid PR-612H & 5 & NiMH & www.zbattery.com \\
\hline Duracell DR11 & 5 & NiMH & www.zbattery.com \\
\hline Pentax PVC-909A & 5 & NiMH & www.zbattery.com \\
\hline Ricoh NP-55 & 5 & $\mathrm{NiMH}$ & www.zbattery.com \\
\hline Realistic (radio Shack) 23-184 & 5 & $\mathrm{NiMH}$ & wuw.zbattery.com \\
\hline JBRO TP-55 & 5 & $\mathrm{NiMH}$ & www.zbattery.com \\
\hline Goldstar VS-C45 & 8 & $\mathrm{NiMH}$ & www.zbattery.com \\
\hline Fujix FF66 & 5 & $\mathrm{NIMH}$ & mww.zbattery.com \\
\hline Chinon C8-SC98 & 5 & NiMH & www.zbattery.com \\
\hline Toshiba SK-80 & 8 & NiMH & www.zbattery.com \\
\hline RCA PRO840 & 5 & NiMH & muw.zbattery.com \\
\hline Phillips 22AV5145 & 8 & NiMH & munw.zbattery.com \\
\hline Samsung VP-L359 & 5 & $\mathrm{NiMH}$ & www.zbattery.com \\
\hline JVC GR-AX201U & 5 & $\mathrm{NiMH}$ & www.zbattery.com \\
\hline Vart V221 & 3 & $\mathrm{NiMH}$ & wuw.zbattery.com \\
\hline Zenith VM-6300 & 8 & NiMH & wuw.zbattery.com \\
\hline Mustek Style DV3 & 4 & $\mathrm{NiMH}$ & muw.zbattery.com \\
\hline Nikon VN-9000 & 5 & $\mathrm{NiMH}$ & www.zbattery.com \\
\hline Polaroid PR-624-H & 5 & NiMH & www.zbattery.com \\
\hline Zenith VAC-690 & 8 & NiMH & wuw.zbattery.com \\
\hline Mustek DV 3032 & 4 & $\mathrm{NiMH}$ & wuw.zbattery.com \\
\hline Magnavox CVR-620 & 5 & NiMH & muw.zbattery.com \\
\hline Canon BP-726 & 5 & $\mathrm{NiMH}$ & uww.greenbatteries.com \\
\hline Victor BNV22 & 5 & $\mathrm{NiMH}$ & www.cellpacksolutions.com \\
\hline Pentax PVC905A & 5 & NiMH & www.cellpacksolutions.com \\
\hline Nordmende SV500 & 8 & $\mathrm{NiMH}$ & www.cellpacksolutions.com \\
\hline Orion VMC206 & 8 & $\mathrm{NiMH}$ & www.cellpacksolutions.com \\
\hline Kyocera BP1550 & 5 & NiMH & www.cellpacksolutions.com \\
\hline \multicolumn{4}{|l|}{ SHAVERS } \\
\hline Safeway Hair and Bear Trimmer & 1 & NiCd & direct observation in-store \\
\hline Panasonic ES 8168 & 3 & $\mathrm{NiMH}$ & direct observation in-store \\
\hline Braun Flex Integral 6520 & 2 & NiMH & unww.cellpacksolutions.com \\
\hline Phillips Philishave 805 & 2 & $\mathrm{NiMH}$ & uww.cellpacksolutions.com \\
\hline Phillips Philishave 890 & 2 & $\mathrm{NiMH}$ & www.cellpacksolutions.com \\
\hline \multicolumn{4}{|l|}{ ELECTRIC TOOTHBRUSHES } \\
\hline Interplak & 3 & $\mathrm{NiCd}$ & www. cellpacksolutions.com \\
\hline Krupps & 2 & $\mathrm{NiCd}$ & umw.cellpacksolutions.com \\
\hline \multicolumn{4}{|l|}{ PORTABLE VACUUM CL } \\
\hline Zuhai Kelitong KC11-72S & 6 & $\mathrm{NiCd}$ & kelitong.en.alibaba.com \\
\hline Yuyao Shengma eddrac SV510A & 6 & $\mathrm{NiCd}$ & mww.alibaba.com \\
\hline Zhongshan Face FVC-9605 & 6 & - & mun.alibaba.com \\
\hline Zhongshan Face FVC-9605 & 8 & - & wuw.alibaba.com \\
\hline Zhongshan Face FVC-9605 & 12 & - & www.alibaba.com \\
\hline
\end{tabular}




\begin{tabular}{|c|c|c|c|}
\hline \multirow{2}{*}{$\begin{array}{l}\text { Model } \\
\text { PORTABLE VAC. CLEANERS CONT. }\end{array}$} & No. of cells & Cell type & Source \\
\hline & & & \\
\hline AEG AG406 Rapido Handvac & 6 & $\mathrm{NiMH}$ & www.kalahari.net \\
\hline AEG AG1412 Lilliput Hand Vac & 3 & NiMH & www.kalahari.net \\
\hline AEG Electrolux hand vacuum & 3 & $\mathrm{NiMH}$ & direct observation \\
\hline Shine Leader Industrial Ltd & 4 & - & www.tradeeasy.com \\
\hline Shine Leader Industrial Ltd & 6 & - & www.tradeeasy.com \\
\hline Superb Technology Limited & 2 & $\mathrm{NiCd}$ & mww.tradeeasy.com \\
\hline Superb Technology Limited & 3 & $\mathrm{NiCd}$ & www.tradeeasy.com \\
\hline Superb Technology Limited & 4 & $\mathrm{NiCd}$ & www.tradeeasy.com \\
\hline Black \& Decker Dust Buster & 2 & $\mathrm{NiMH}$ & direct observation in-store \\
\hline Black \& Decker Dust Buster & 4 & $\mathrm{NiMH}$ & direct observation in-store \\
\hline Black \& Decker Dust Buster & 6 & $\mathrm{NiMH}$ & direct observation in-store \\
\hline Black \& Decker Dust Buster & 8 & $\mathrm{NiMH}$ & direct observation in-store \\
\hline Black and Decker Pivot Dustbuster & 10 & $\mathrm{NiMH}$ & direct observation in-store \\
\hline Black and Decker Pivot Dustbuster & 12 & $\mathrm{NiMH}$ & direct observation in-store \\
\hline Dirt Devil BRUM stick vacuum & 8 & NiCd & www.dirtdevil.com \\
\hline Dirt Devil Extreme Power Wet/Dry & 12 & NiCd & wuw.dirtdevil.com \\
\hline Dirt Devil Broom Vac & 8 & NiCd & www.dirtdevil.com \\
\hline Dirt Devil Scorpion cordless hand vac & 5 & $\mathrm{NiCd}$ & www.dirtdevil.com \\
\hline Dirt Devil Detailer cordless hand vac & 3 & NiCd & www.dirtdevil.com \\
\hline $\begin{array}{l}\text { Dirt Devil Breeze cordless hand vac } \\
\text { FLASHLIGHTS }\end{array}$ & 4 & $\mathrm{NiCd}$ & www.dirtdevil.com \\
\hline Maglite battery pack ARXX075 & 5 & $\mathrm{NiCd}$ & www.zbattery.com \\
\hline Maglite Mag Charger Rechargeable Flas & 5 & $\mathrm{NiCd}$ & mww.wikio.com/shopping \\
\hline Streamlight Polystinger & 3 & $\mathrm{NiCd}$ & www.streamlight.com \\
\hline Streamlight SL-20X & 5 & NiCd & www.streamlight.com \\
\hline Streamlight SL-20XP & 5 & $\mathrm{NiCd}$ & www.streamlight.com \\
\hline Streamlight Survivor Zone1 & 3 & $\mathrm{NiCd}$ & www.streamlight.com \\
\hline Streamlight Stinger LED & 3 & $\mathrm{NiCd}$ & www.streamlight.com \\
\hline Pelican Big Ed Rechargeable 3750 & 4 & $\mathrm{NiCd}$ & www.pelican.com \\
\hline Pelican 8060 Rechargeable LED & 4 & $\mathrm{NiMH}$ & www.brightguy.com \\
\hline Dorcy $5 \mathrm{MM}$ LED rechargeable lantern & 2 & $\mathrm{NiCd}$ & mww.dorcy.com \\
\hline Pelican M9 7050 rechargeable & 3 & $\mathrm{NiCd}$ & uww.pelican.com \\
\hline Pelican StealthLite 2450 & 4 & $\mathrm{NiMH}$ & mww.pelican.com \\
\hline Pelican 3660 Little Ed & 4 & $\mathrm{NiMH}$ & www.pelican.com \\
\hline Pelican 6050 M13 & 7 & $\mathrm{NiCd}$ & www.pelican.com \\
\hline RA Responder class 1 & 4 & NiCd & www.brightguy.com \\
\hline Responder 3C & 3 & $\mathrm{NiCd}$ & www.brightguy.com \\
\hline AquaSun eLED Rechargeable & 8 & $\mathrm{NiCd}$ & www.uwkinetics.com \\
\hline PORTABLE LAMPS & & & \\
\hline Dorcy Dynamo Lantern & 3 & $\mathrm{NiMH}$ & www.dorcy.com \\
\hline
\end{tabular}




\section{APPENDIX 8: MAP OF SOIL SAMPLING SITES}

This map shows the locations of soil sampling sites which provided the background data for Chapter 5, Vote that cach sampling site shown refers to a particular farm, not necessarily a single sample - scveral soil samples were taken at many of the sites.

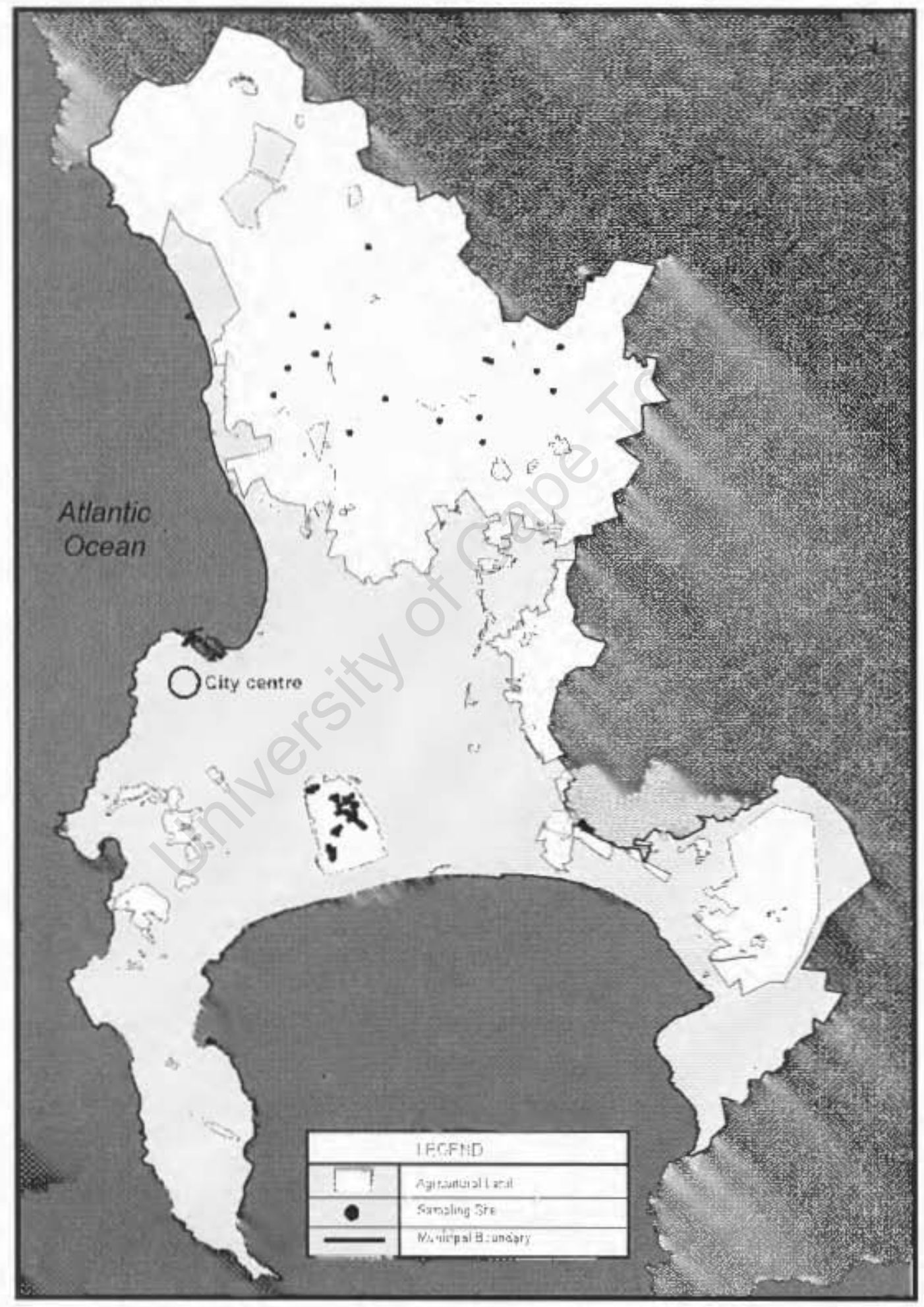

